\begin{abstract}
Universidade de São Paulo
Instituto de Astronomia, Geofísica e Ciências Atmosféricas Departamento de Ciências Atmosféricas
\end{abstract}

Modelagem hidrológica da Bacia do Rio Pirajuçara
com TOPMODEL, Telemetria e Radar Meteorológico

Kleber Lopes da Rocha Filho

\author{
Dissertação de Mestrado \\ Orientador: Prof. Dr. Augusto José Pereira Filho
}

SÃO PAULO, 2010 
Kleber Lopes da Rocha Filho

\section{Modelagem hidrológica da Bacia do Rio Pirajuçara com TOPMODEL, telemetria e radar meteorológico}

Dissertação desenvolvida como partes dos requisitos para obtenção do Título de Mestre em Ciências junto ao Departamento de Ciências Atmosféricas do Instituto de Astronomia, Geofísica e Ciências Atmosféricas da Universidade de São Paulo.

Área de Concentração: Meteorologia

Orientador: Prof. Dr. Augusto Pereira Filho

SÃO PAULO, 2010 


\section{DEDICATÓRIA}

A Regina Harumi, minha amada esposa, companheira, incentivadora e revisora de meu trabalho, sem a qual nada disto teria acontecido e

a minha futura filha Catarina Mie. 


\section{AGRADECIMENTOS}

Ao meu orientador, professor Augusto José Pereira Filho, pela confiança em mim depositada e oportunidade do desenvolvimento do trabalho. Também pela amizade e conselhos tão importantes para meu desenvolvimento como aluno e profissional.

Aos meus pais, Kleber e Telma e minha irmã Karina, pois durante toda a minha vida sempre incentivaram e mostraram a importância do conhecimento, com todo 0 suporte necessário. Sem eles nada disto teria acontecido.

A minha segunda família, Edson, Inês e Taeny, pela convivência sempre prazerosa e pela compreensão de ausências durante o desenvolvimento deste trabalho.

A Fundação Centro Tecnológico de Hidráulica, pela oportunidade do desenvolvimento deste trabalho, além dos dados cedidos.

Aos companheiros de trabalho do SAISP, Cristiane Andrioli, Ivan Martinez, Douglas Maria, Paulo Rogério, Alfredo Pisani, Leonardo Koshimura, Diego Caldas, Afonso Reis e todos da equipe de campo e Radar, pela convivência no dia a dia que de certa forma contribuíram para este trabalho.

Ao Eng. Flávio Conde, coordenador do SAISP e amigo, pela compreensão de algumas ausências e períodos de mais dificuldade durante o trabalho.

Aos amigos, vizinhos e acima de tudo irmãos, Carlos Gonçalves e Cristiane Andrioli, por todos os momentos tão importantes e felizes que contribuíram para "recarregar as baterias".

Aos amigos Bruno Biazeto e Eder Vendrasco, por dicas em códigos no início do trabalho.

Ao Eng. Aluísio Canholi por ceder a curva-chave utilizada neste trabalho.

Aos companheiros da Katarse, que considero como irmãos, Tersio Greguol, Mario Amore e Micael Amore, pelos anos de convivência que só trazem boas recordações, pela oportunidade dada a mim de participar desta família e pela compreensão de minha ausência. 


\section{RESUMO}

A Bacia do Alto Tiete abriga cerca de $50 \%$ dos habitantes do Estado de São Paulo e é afetada freqüentemente por eventos de inundações. Uma das principais fontes de problemas é a alta impermeabilização devida à ocupação da superfície nas últimas décadas. Um dos seus tributários secundários, a bacia do Rio Pirajuçara se insere neste contexto e sofre com problemas da mesma natureza. A modelagem hidrológica permite uma análise do escoamento superficial nestes ambientes e é útil na previsão de vazões por meio de redes telemétricas e sensoriamento remoto. Entretanto, redes telemétricas apresentam problemas de representatividade espacial e exposição, radares meteorológicos, apesar da maior resolução espaçotemporal das estimativas de precipitação, possuem várias fontes de erros e incertezas. A principal delas se refere à relação ZR. Deste modo, a integração dessas medições e estimativas pode minimizar erros de ambas. $O$ objetivo deste estudo é analisar aspectos hidrológicos da Bacia do Rio Pirajuçara por meio do modelo TOPMODEL com medições de vazão e precipitação disponíveis para 18 eventos monitorados entre outubro de 2008 a outubro de 2009. O modelo TOPMODEL foi calibrado com dez eventos e verificado com os demais. A calibração foi realizada com os dados da telemetria da Bacia do Alto Tietê, radar meteorológico de São Paulo e a combinação de ambos por meio da análise objetiva estatística. Os resultados da calibração indicam que o melhor desempenho foi obtido com radar meteorológico, com número de $\mathrm{NASH}$ de 0,51 , menor erro quadrático médio e menor viés médio absoluto. A verificação também indicou o mesmo resultado com número de NASH de 0,69. As simulações indicam que apesar da utilização da precipitação média, o modelo TOPMODEL simulou adequadamente cerca de $75 \%$ das vazões de alerta. $O$ trabalho evidencia as limitações da telemetria e seus impactos na integração com os dados do radar. 


\section{ABSTRACT}

The Alto Tiete watershed is home for about $50 \%$ of the inhabitants of São Paulo State and is affected by recurrent flashfloods. One major source of difficulties is the high rate of soil impermeabilization caused by dense surface occupation in the last decades. One of its secondary tributaries, the Pirajussara watershed suffers with similar problems. Hydrological modeling allows the analysis of runoff and other variables in these basins. It also useful for streamflow forecast based on telemetric networks and remote sensing measurements. However, surface networks lack spatial representativity and exposure is a also a issue, weather radars, in spite of their much higher spatial and temporal resolution rainfall estimation, are affect by several sources of errors and uncertainties; the most significant one being the ZR relationship. Thus, the integration of these measurements and estimates can minimize errors of both. The goal of the present work is to analyze the surface hydrology of the Pirajussara watershed based on the TOPMODEL, streamflow and rainfall measurements available for eighteen events between October 2008 and October 2009. The TOPMODEL was calibrated with ten events and verified with the remaining events. The calibration was performed with the Alto Tiete telemetric measurements of streamflow and rainfall only, the São Paulo weather radar (SPWR) only and a combination of both through the statistical analysis scheme. Calibration results show a better performance for the SPWR with a NASH number of 0.51 , least SME and mean bias. On the other hand, the verification also indicated better results for the SPWR with a NASH number of 0.69 . The simulations indicate that in spite of the use of the mean rainfall over the watershed, the TOPMODEL performed adequately for $75 \%$ of the streamflow alerts. It is also evident the limitation of the available network and its impacts on the integration to the SPWR rainfall data. 


\section{SUMÁRIO}

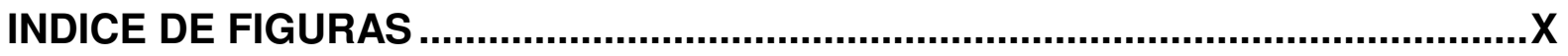

INDICE DE TABELAS …........................................................................... XVII

1. INTRODUÇÃO

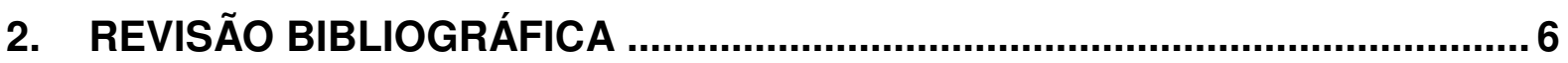

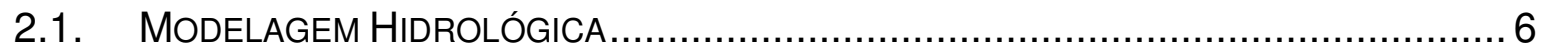

2.1.1. Classificação de Modelos Hidrológicos ............................................... 6

2.1.2. Discretização espacial de bacias hidrográficas ...................................... 8

2.1.3. Calibração de modelos hidrológicos ................................................... 10

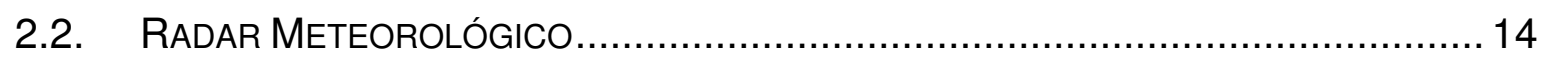

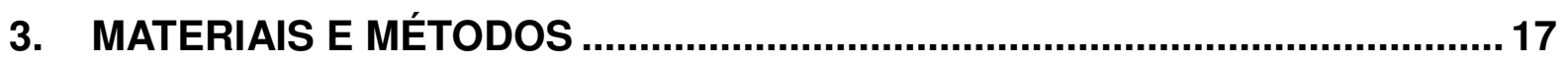

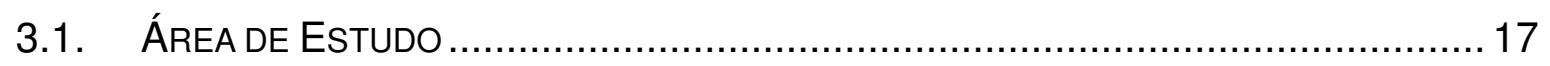

3.1.1. Características físicas da bacia do Rio Pirajuçara ................................ 17

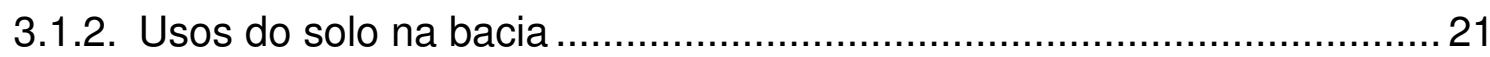

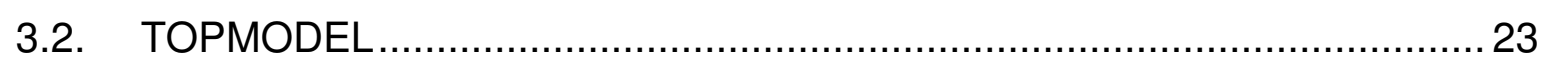

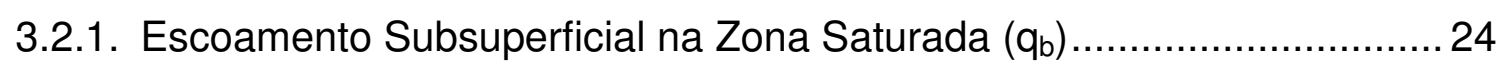

3.2.2. Escoamento Subsuperficial na Zona não saturada $\left(q_{v}\right)$......................... 29

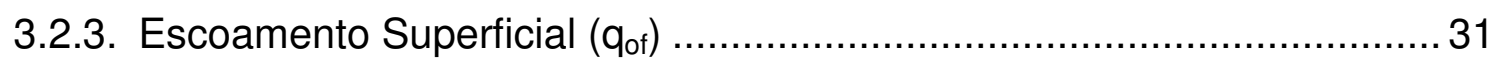

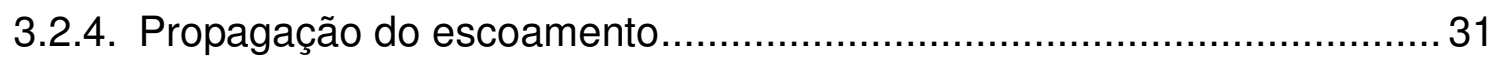

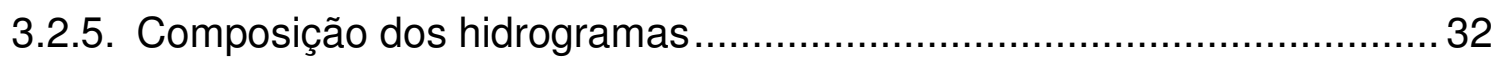

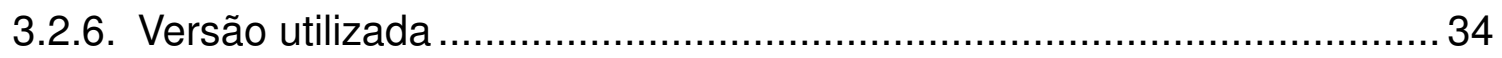

3.2.7. Índice de Similaridade Hidrológico da bacia do Rio Pirajuçara ............... 35

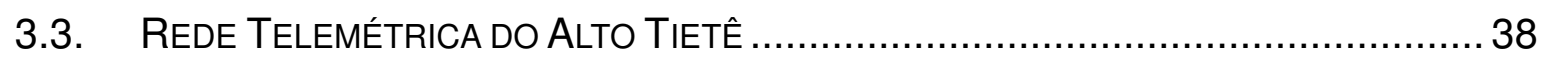

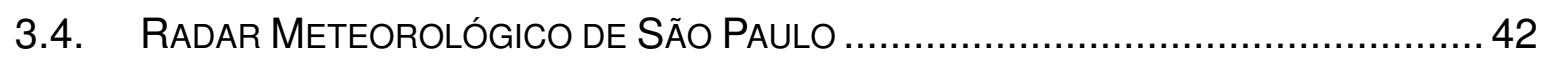

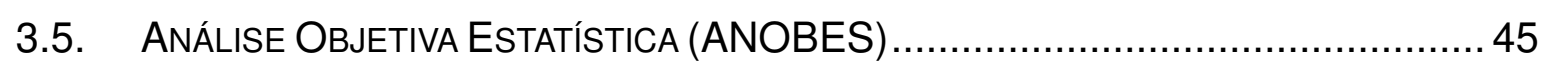

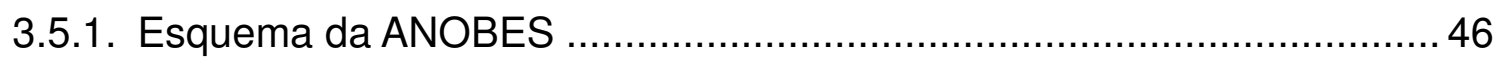

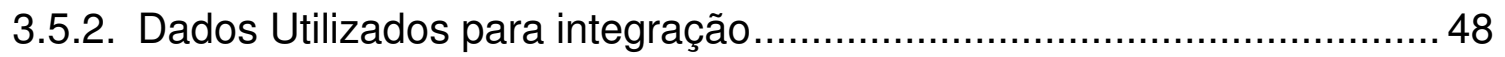

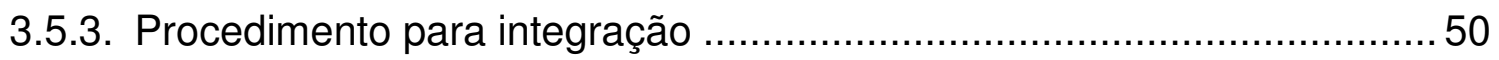

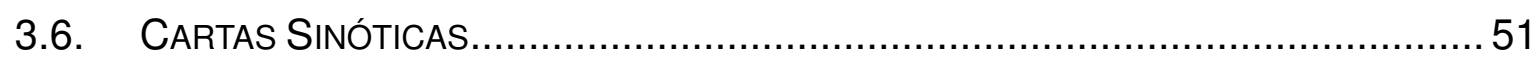

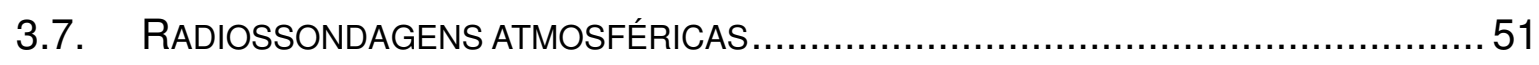

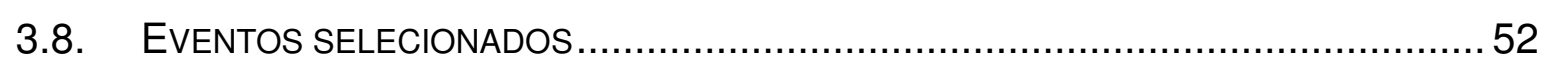


3.9. PROCEDIMENTOS PARA SIMULAÇÕES COM TOPMODEL ............................... 55

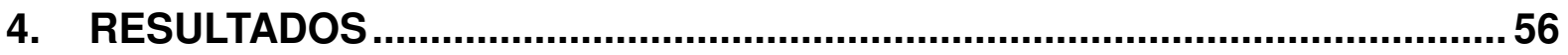

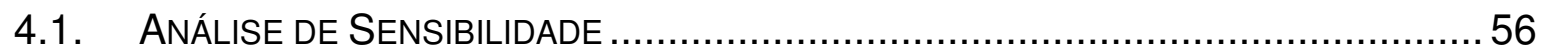

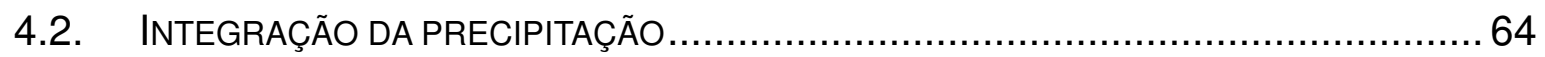

4.2.1. Comparação da precipitação média com precipitação pontual pelo radar

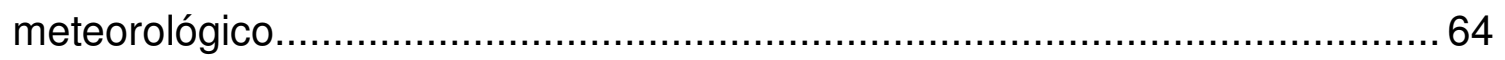

4.2.2. Resultados da integração ....................................................... 67

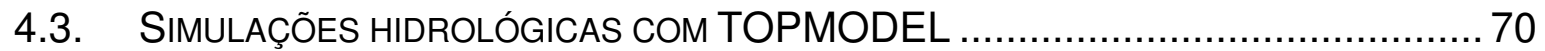

4.3.1. Sensibilidade do modelo à evapotranspiração .................................. 70

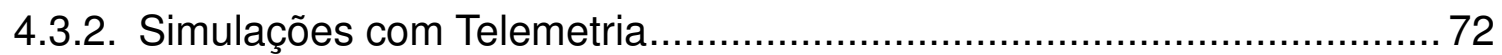

4.3.3. Simulações com Radar Meteorológico ............................................ 77

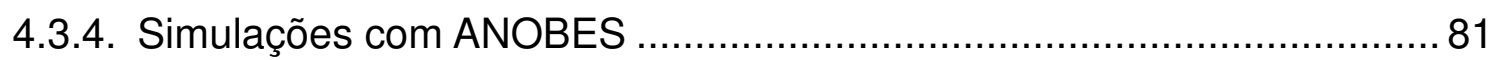

4.4. IMPACTO DOS SISTEMAS METEOROLÓGICOS NAS SIMULAÇÕES COM TOPMODEL 86

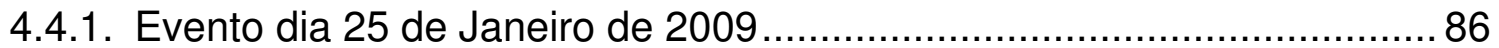

4.4.2. Evento dia 26 de Janeiro de 2009 ................................................... 92

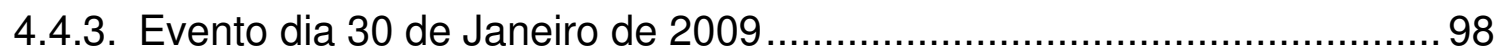

5. CONCLUSÕES E RECOMENDAÇÕES .................................................. 103

6. REFERÊNCIAS BIBLIOGRÁFICAS............................................................. 105

APÊNDICE A: DELINEAMENTO AUTOMÁTICO DA BACIA. ................................... 114

APÊNDICE B: Parâmetros calculados com o TOPMODEL...........................115 


\section{INDICE DE FIGURAS}

Figura 2.1: Representação espacial de terreno por meio de Modelo Numérico de Terreno (MNT). (a) grade regular; (b) grade triangular; (c) curvas de nível. Fonte: Rennó (2003).

Figura 3.1: Localização da Bacia do Rio Pirajuçara na Bacia do Alto Tietê. As linhas azuis representam a hidrografia dos Rios Tietê e Pinheiros, a porção em vermelho é a área da BRP, as linhas pontilhadas representam os raios concêntricos de $40 \mathrm{~km}$ do RSP. Fonte: SRTM, IBGE, Organização ROCHA FILHO, 2010.

Figura 3.2: Divisão política da Bacia do Rio Pirajuçara. As linhas pretas representam a divisão política da RMSP, a porção em vermelho é a área da BRP. Fonte: SRTM, IBGE, organização ROCHA FILHO, 2010. 18

Figura 3.3: Mapa Hipsométrico da Bacia do Rio Pirajuçara. A área sombreada representa a elevação em metros. As linhas em preto são as curvas de nível com intervalos de 20 metros. Fonte: SRTM, organização ROCHA FILHO, 2010.

Figura 3.4: Mapa Clinográfico da Bacia do Rio Pirajuçara. As diferentes cores representam distribuição espacial da declividade. As linhas azuis representam os principais cursos d'água. Fonte: CANIL,2006.

21

Figura 3.5: Ocupação do solo da bacia Pirajuçara. Diferentes cores representam o tipo de ocupação do solo. Fonte: DAEE, 1998.

Figura 3.6: Representação dos reservatórios e processos utilizados pelo modelo TOPMODEL: (a)condição não saturada;(b) condição saturada. Fonte: SILVA,200724

Figura 3.7: Índice topográfico médio e déficit local.Fonte: SILVA, 2005. 29

Figura 3.8: Distribuição de freqüência do índice de similaridade hidrológico da bacia do Rio Pirajuçara, para 30 classes de valores. 
Figura 3.9: Distribuição espacial do índice topográfico sobre a BRP. A área sombreada representa a distribuição espacial dos valores do índice de similaridade hidrológica.

Figura 3.10: Porção utilizada para o cálculo final do índice topográfico. A área sombreada representa a elevação do terreno (metros). Os pontos, vermelho e azul, representam os pontos de medição de altura do nível da água e precipitação, respectivamente. A área sombreada representa a elevação da BRP em metros. Fonte: SRTM, organização ROCHA FILHO, 2010. 37

Figura 3.11: Disposição física dos postos da rede do Alto Tietê. Os pontos vermelhos representam os postos telemétricos da RAT, as linhas azuis representam a hidrografia dos Rios Tietê e Pinheiros, as linhas pontilhadas representam os raios concêntricos de $40 \mathrm{~km}$ do RSP, as linhas contínuas pretas representam a divisão política da RMSP. Fonte: SAISP, IBGE, Organização ROCHA FILHO, 2010. 38

Figura 3.12: (a) Funcionamento do Pluviômetro de Báscula (Fonte: PISANI,1995), (b) Exemplo da Instalação de um pluviômetro utilizado pelo SAISP, (c) Interior do Pluviômetro. 39

Figura 3.13 : Sensor de nível por ultra som (a) e sensor de nível de pressão (b).... 39

Figura 3.14: Postos telemétricos utilizados nas medições de: (a) Nível da lâmina d'água, (b) Precipitação. 40

Figura 3.15: Localização dos postos telemétricos utilizados e topografia em metros da Bacia do Rio Pirajuçara. O ponto em azul escuro representa a posição geográfica do posto Córrego Poá. O ponto vermelho é a localização do posto Pirajuçara. As linhas em azul claro representam a hidrografia da BRP. Fonte: SRTM, SAISP, organização ROCHA FILHO, 2010.

Figura 3.16: Radar Meteorológico de SP - Município de Biritiba Mirim - SP. 43

Figura 3.17: Área de Abrangência do Radar Meteorológico de São Paulo. A área 
sombreada em branco representa a cobertura do RSP, As linhas pontilhadas são os raios concêntricos a cada $40 \mathrm{~km}$. As linhas cinza representam as divisões políticas municipais do Estado de SP e as linhas pretas, as divisões políticas dos estados e da RMSP. Fonte: IBGE, Organização ROCHA FILHO, 2010.

Figura 3.18: Disposição física dos postos telemétricos utilizados na integração sobre a Região Metropolitana de São Paulo. Os pontos em vermelho indicam a localização geográfica dos postos telemétricos. As linhas azuis mostram a hidrografia dos principais Rios da BAT. As linhas pontilhadas são os raios concêntricos de $40 \mathrm{~km}$ a partir do RSP.

Figura 3.19: Vazão observada, precipitação medida pela telemetria de superfície e precipitação média na bacia com Radar Meteorológico. As linhas pretas representam a vazão observada no posto Pirajuçara, as barras em azul representam a precipitação medida no posto Córrego Poá e a linha vermelha a precipitação média na bacia calculada com estimativas do Radar Meteorológico.

Figura 4.1: Análise de Sensibilidade dos parâmetros do modelo TOPMODEL para a BRP, entrada de precipitação: Rede de superfície (pluviômetros). (a) Parâmetros $m$, InTe, $\mathrm{Sr}_{0}, \mathrm{Sr}_{\max }, \mathrm{Td}$; (b) Parâmetros qsO, VCH, VR, KO, CD. 58

Figura 4.2: Análise de Sensibilidade dos parâmetros do modelo TOPMODEL para a BRP, entrada de precipitação: Radar Meteorológico.(a) Parâmetros m, InTe, SrO,Srmax, Td; (b) Parâmetros qsO, VCH, VR, KO, CD...................................... 60

Figura 4.3: Análise de Sensibilidade dos parâmetros do modelo TOPMODEL para a BRP, entrada de precipitação: ANOBES.(a) Parâmetros m, InTe, SrO,Srmax,Td; (b)

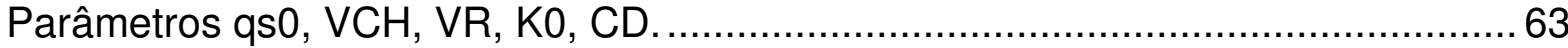

Figura 4.4: Comparação entre: (a) Precipitação média na bacia pelo Radar Meteorológico (Vermelho sólido), pixel sobre telemetria pelo radar meteorológico (pontilhado) e Telemetria (barras azuis); (b) Vazões simuladas para 5 eventos (Eventos 11,12,13, 14 e 15 da tabela 3.3)..... 66 
Figura 4.5: Comparação entre as precipitações médias entre medidas com pluviômetro, radar meteorológico e precipitação integrada com ANOBES para a bacia do Rio Pirajuçara para o período de calibração: (a) Eventos compreendidos no período: 05 de Outubro de 2008 à 22 de Dezembro de 2008; (b) Eventos compreendidos no período: 24 de Dezembro de 2008 à 20 de Janeiro de 2009. As barras em azul representam a precipitação medida pela telemetria, as linhas vermelha e verde representam as precipitações médias na bacia estimadas pelo RSP e integrada pelo ANOBES, respectivamente 68

Figura 4.6: Comparação entre as precipitações médias entre medidas com pluviômetro, radar meteorológico e precipitação integrada com ANOBES para a bacia do Rio Pirajuçara para o período de verificação: (a) Eventos compreendidos no período: 25 de Janeiro de 2009 à 07 de Fevereiro de 2009; (b) Eventos compreendidos no período: 08 de Fevereiro de 2009 à 26 de Outubro de 2009. As barras em azul representam a precipitação medida pela telemetria, as linhas vermelha e verde representam as precipitações médias na bacia estimadas pelo RSP e integrada pelo ANOBES, respectivamente

Figura 4.7: Simulação de controle para a avaliação do impacto da evapotranspiração no modelo. As linhas azul (contínua) e verde (pontilhada) representam a vazão simulada com evapotranspiração nula e climatológica, respectivamente. A área preenchida com a cor cinza representa a vazão observada.

Figura 4.8: Resultado da Calibração do modelo TOPMODEL para a BRP utilizando a precipitação medida pela Telemetria, Eficiência máxima atingida (Nash-Sutcliffe) : 0.31. A porção preenchida em cinza representa a vazão observada na secção, a linha em azul representa a vazão simulada para o período de calibração, com entrada de precipitação da telemetria de superfície. As linhas, vermelha, roxa e laranja, representam os diferentes níveis de alerta utilizados pelo SAISP nesta secção do Rio Pirajuçara. 74

Figura 4.9: Vazão simulada versus Observada para o período de verificação, modelo calibrado a partir de entrada de precipitação medida pela telemetria de superfície. A 
porção preenchida em cinza representa a vazão observada na secção, a linha em azul representa a vazão simulada para o período de calibração, com entrada de precipitação da telemetria de superfície. As linhas, vermelha, roxa e laranja, representam os diferentes níveis de alerta utilizados pelo SAISP nesta secção do Rio Pirajuçara

Figura 4.10: Simulações efetuadas com os parâmetros calibrados com a precipitação medida pela Telemetria para o período de verificação: (a) Precipitação Radar Meteorológico; (b) Precipitação integrada (ANOBES). As linhas, vermelha, roxa e laranja, representam os diferentes níveis de alerta utilizados pelo SAISP nesta secção do Rio Pirajuçara

Figura 4.11: Resultado da Calibração do modelo TOPMODEL para a BRP utilizando a precipitação estimada pelo Radar Meteorológico, Eficiência máxima atingida (Nash-Sutcliffe) foi de 0.51 . A porção preenchida em cinza representa a vazão observada na secção, a linha em vermelho representa a vazão simulada para 0 período de calibração, com entrada de precipitação média do Radar Meteorológico. As linhas, vermelha, roxa e laranja, representam os diferentes níveis de alerta utilizados pelo SAISP nesta secção do Rio Pirajuçara. 78

Figura 4.12: Vazão simulada versus Observada para o período de verificação, modelo calibrado a partir de entrada de precipitação estimada pelo Radar Meteorológico. A porção preenchida em cinza representa a vazão observada na secção, a linha em vermelho representa a vazão simulada para o período de calibração, com entrada de precipitação média do Radar Meteorológico. As linhas, vermelha, roxa e laranja, representam os diferentes níveis de alerta utilizados pelo SAISP nesta secção do Rio Pirajuçara. 79

Figura 4.13: Simulações efetuadas com os parâmetros calibrados com a precipitação estimada pelo Radar Meteorológico para o período de verificação: (a) Precipitação Telemetria; (b) Precipitação integrada (ANOBES). As linhas, vermelha, roxa e laranja, representam os diferentes níveis de alerta utilizados pelo SAISP nesta secção do Rio Pirajuçara. 80 
Figura 4.14: Resultado da Calibração do modelo TOPMODEL para a BRP utilizando a precipitação integrada pelo esquema ANOBES, Eficiência máxima atingida (NashSutcliffe) foi de 0.42 . A porção preenchida em cinza representa a vazão observada na secção, a linha em verde representa a vazão simulada para o período de calibração, com entrada de precipitação média do Radar Meteorológico integrada com a telemetria de superfície. As linhas, vermelha, roxa e laranja, representam os diferentes níveis de alerta utilizados pelo SAISP nesta secção do Rio Pirajuçara... 83

Figura 4.15: Vazão simulada versus Observada para o período de verificação, modelo calibrado a partir de entrada de precipitação integrada pelo esquema ANOBES. A porção preenchida em cinza representa a vazão observada na secção, a linha em verde representa a vazão simulada para o período de calibração, com entrada de precipitação média do Radar Meteorológico integrada com a telemetria de superfície. A 84

Figura 4.16: Simulações efetuadas com os parâmetros calibrados com a precipitação estimada pelo Radar Meteorológico para o período de verificação: (a) Precipitação Telemetria; (b) Precipitação integrada (ANOBES. As linhas, vermelha, roxa e laranja, representam os diferentes níveis de alerta utilizados pelo SAISP nesta secção do Rio Pirajuçara 85

Figura 4.17: Cartas sinóticas produzidas pelo CPTEC/INPE dos dias 25 e 26 de Janeiro de 2009. As figuras (a) e (c) são relativos aos níveis baixos (1000 hPa) e altos (hPa) para o dia 25 de Janeiro de 2009 respectivamente. As figuras (b) e (d) são relativos aos níveis baixos e altos para o dia 26 de Janeiro de 2009 , respectivamente.

Figura 4.18: Sondagem atmosférica das 1200 UTC do dia 25 de Janeiro de 2009. Fonte: http://weather.uwyo.edu/upperair/sounding.html 88

Figura 4.19: Evolução da precipitação sobre a RMSP medida pelo RSP no dia 25/01/2009. A área sombreada representa a precipitação acumulada em 10 minutos em milímetros, as linhas pretas são a divisão política da RMSP. (a) 2100 UTM;(b) 2130 UTM; (c) 2200 UTM ; (d) 2230 UTM; (e) 2240 UTM; (f) 2250 UTM 89 
Figura 4.20: Evolução da precipitação sobre a BRP medida pelo RSP no dia 25/01/2009. A área sombreada representa a precipitação acumulada em 10 minutos em milímetros, utilizando o CAPPI de $3 \mathrm{Km}$ com resolução $2 \times 2 \mathrm{Km}$ do RSP, as linhas pretas são os divisores de água que compõe a BRP. (a) 2130 UTM; (b) 2200 UTM; (c) 2210 UTM; (d) 2220 UTM; (e) 2230 UTM; (f) 2240 UTM; (g) 2250 UTM; (h)2300 UTM; (i)2310 UTM. 91

Figura 4.21: Similar à Fig. 4.17, exceto para 27 de Janeiro de 2009. 93

Figura 4.22: Simular à 4.18 exceto para 1200 UTC de 25 de Janeiro de 2009....... 93

Figura 4.23: Similar à Fig. 4.19, exceto para dia 26 de janeiro de 2009. (a) 1700 UTC; (b)1830 UTC; (c) 1840 UTC; (d) 1850 UTC; (e)1900 UTC; (f)1910 UTC 94

Figura 4.24: Evolução da precipitação sobre a BRP medida pelo RSP no dia 26/01/2009. A área sombreada representa a precipitação acumulada em 10 minutos, em milímetros, utilizando o CAPPI de $3 \mathrm{Km}$ com resolução $2 \times 2 \mathrm{Km}$ do RSP, as linhas pretas são os divisores de água que compõe a BRP. (a) 1800 UTC ; (b) 1810 UTC; (c)1830 UTC; (d) 1840 UTC; (e)1850 UTC; (f) 1900 UTC; (g) 1910 UTC; (h) 1920 UTC; (i) 1930 UTC; 97

Figura 4.25: Cartas sinóticas produzidas pelo CPTEC/INPE do dia 27 de Janeiro de 2009. As figuras (a) e (b) são relativos aos níveis baixos (1000 hPa) e altos (250 $\mathrm{hPa})$. 98

Figura 4.26: Evolução da precipitação sobre a Área de abrangência do RSP no dia 30/01/2009. A área sombreada representa a precipitação acumulada em 10 minutos em milímetros, CAPPI de $3 \mathrm{Km}$ com resolução $2 \times 2 \mathrm{Km}$, as linhas pretas são a divisão política da RMSP e litoral. (a) 2000 UTC; (b) 2030UTC; (c) 2040 UTC; (d) 2320 UTC 99 
Figura 4.27: Efeito de advecão em uma célula que se desloca zonalmente para leste. O radar mede a célula em $\mathbf{t} 1$ e em $\mathbf{t} 2$ quando ela já deslocou subestimando na acumulação a chuva que ocorreu entre os intervalos das medições (em azul claro). Fonte: CALVETTI (2003) 101

Figura 4.28: Evolução da precipitação sobre a BRP medida pelo RSP no dia 30/01/2009. A área sombreada representa a precipitação acumulada em 10 minutos em milímetros, utilizando o CAPPI de $3 \mathrm{Km}$ com resolução $2 \times 2 \mathrm{Km}$, as linhas pretas são os divisores de água que compõe a BRP. (a) 2000 UTC ; (b)2020 UTC; (c) 2030 UTC; (d) 2040 UTC; (e) 2050 UTC; (f) 2310 UTC; (g) 2320 UTC; (h) 2330 UTC; (i) 2340 UTC 102

Figura A.6.1: Quadricula $(x, y)=(27,17)$ de $6000 \times 6000$ pontos contendo a elevação digital de terreno, obtidas diretamente do sitio do projeto SRTM. 115

Figura A.6.2: Domínio retirado após a primeira iteração do processo de delineamento automático da bacia 115

Figura A.6.3: Sub-bacias delimitadas automaticamente pelo software Mapwindow. 117

Figura A.4: Resultado da extração da bacia a partir da malha de id's identificados pelo Mapwindow. A área verde escuro representam as regiões externas a bacia. As diferentes cores representam as elevações em metros. As linhas pretas representam a grade de 90 metros de resolução utilizada no trabalho. 118 


\section{INDICE DE TABELAS}

Tabela 3.1: Parâmetros utilizados pelo modelo TOPMODEL.

Tabela 3.2: Características técnicas do Radar Meteorológico de São Paulo 43

Tabela 3.3: Data e classificação dos eventos selecionados. Data e hora indicada no formato MM/DD/AAAA HHMM.

Tabela 4.1: Valores de eficiência (NS), erro quadrático médio (EMQ) e Viés Médio para as simulações efetuadas com todas as entradas de precipitações. Modelo calibrado com precipitação medida pela telemetria de superfície.

Tabela 4.2: Valores de eficiência (NS), erro quadrático médio (EQM) e Viés para as simulações efetuadas com todas as entradas de precipitações. Modelo calibrado com precipitação estimada pelo Radar Meteorológico

Tabela 4.3: Valores de eficiência (NS), erro quadrático médio (EQM) e Viés Médio para as simulações efetuadas com todas as entradas de precipitações. Modelo calibrado com precipitação integrada pelo método ANOBES.

Tabela A.1: Exemplo de header utilizado em uma matriz para abertura no software Mapwindow 116

Tabela B.1 - Valores obtidos na etapa de calibração com o modelo TOPMODEL, para entradas de precipitação telemetria, radar meteorológico e ANOBES, respectivamente 118 


\section{LISTA DE ABREVIATURAS}

ASTER Advanced Spaceborne Thermal Emission and Reflection Radiometer ascii American Standard Code for Information Interchange

ASI Agenzia Spaziale Italiana

ANOBES Análise Objetiva Estatística

BAT Bacia do Alto Tietê

BRP Bacia do Rio Pirajuçara

CAPPI Constant Altitude Plain Position Indicator

CETESB Companhia de Tecnologia de Saneamento Ambiental

DAEE Departamento de Águas e Energia Elétrica do Estado de São Paulo

DCA Departamento de Ciências Atmosféricas

DLR Deutsches Zentrum für Luft- und Raumfahrt

ERSDAC Earth Remote Sensing Data Analysis Center

EQM Erro Quadrático Médio

ESP Estado de São Paulo

IBGE Instituto Brasileiro de Geografia e Estatística

GIS Geographic Information System

GLUE Generalized Likelihood Uncertainty Estimation

geotiff Georeferencing Tagged Image File Format

MNT Modelo Numérico de Terreno

NASA National Aeronautics and Space Administration

NE Nordeste

NW Noroeste

NEXRAD Next-Generation Radar

NSE Coeficiente de Nash e Sutcliffe

R Project for Statistical Computing

RSP Radar de São Paulo

RMSP Região Metropolitana de São Paulo

SAISP Sistema de Alerta à Inundações de São Paulo

SRTM Shuttle Radar Topography Mission

SE Sudeste

SW Sudoeste 
TOPMODEL Topography-based hydrological model

UTC Universal Time Coordinated (Tempo Coordenado Universal)

VCAN Vórtice Ciclônico de Altos Níveis

ZCAS Zona de Convergência do Atlântico Sul

ZCOU Zona de Convergência de Umidade 


\section{INTRODUÇÃO}

Ao final da década de 1940, 30\% da população urbana no Brasil encontravase em ambientes urbanos, números que em 2006 alcançam 81\% (IBGE, 2007). Na região sudeste a população em grandes centros urbanos é de $92 \%$. Este processo de urbanização ocorreu de forma acentuada e resultou em centros sem infraestruturas, principalmente na década de 80 , quando investimentos foram reduzidos (TUCCl et. al. 1995).

A urbanização acelerada tem exercido diversas alterações, tais como, uso ou ocupação do solo. Estas alterações tem como resultado sistemático, a degradação do ambiente e as conseqüências podem ser observadas em escalas maiores ou menores (CANIL, 2006; HART, 1986; PANIZZA, 1987; DOUGLAS, 1983). As alterações antrópicas afetam diretamente os fluxos naturais. Dentre estes, 0 escoamento de águas pluviais, que resulta em grande impacto no balaço de água como, vazão de pico, escoamento superficial e tempo de pico (COLTRINARI, 1996). MEYER et. al. (2004) mostrou que entre as décadas de 60 e 90, a área urbanizada da Região Metropolitana de São Paulo (RMSP) aumentou cerca de 40\%. Áreas de cobertura vegetal foram retiradas e substituídas por vias pavimentadas, principalmente regiões de fundos de vales.

Dentro dos domínios da RMSP, encontra-se a Bacia do Alto Tietê, que drena uma área de aproximadamente 6000 km² e deve alcançar em 2010, 20 milhões de habitantes (FUSP, 2002). O aumento da mancha urbana traz consigo altos índices de impermeabilização e faz com que cheias locais se agravem (SILVA e PORTO, 2003). FUSP (2002) destaca que o problema é decorrente da ineficiência ou ausência do planejamento do uso e regulação do uso do solo. PEREIRA FILHO et al. (2002) apud HALLAK (2007) citam que eventos meteorológicos explosivos freqüentemente causam perdas materiais e humanas. Economicamente, as inundações produzem inúmeros problemas, como congestionamentos, fechamento de comércios, aeroportos e estradas, paralisação de diversos setores produtivos, entre outros (PEREIRA FILHO, 2000; PEREIRA FILHO ET AL., 2002, HALLAK, 2007).

Dentro deste contexto, a Bacia do Rio Pirajuçara, localiza-se na zona Oeste da RMSP e abrange os municípios de São Paulo, Taboão da Serra e Embu. É 
afluente na margem esquerda do Rio Pinheiros e é afetada por eventos de inundações a décadas. Vários estudos apontam como principais causas dos problemas, as ocupações desordenadas e a falta de obras hidráulicas (EMPLASA, 1985; CANHOLI, 1995).

Medidas estruturais são executadas desde o final da década de 1960 (DAEE, 1999), como por exemplo, a primeira canalização do trecho de $2 \mathrm{~km}$ desde a foz da bacia. Obras deste tipo têm sido realizadas nas décadas seguintes, com o objetivo de readequação e aumento da eficiência hidráulica, por meio de novas canalizações e redução de vazões de pico, com reservatórios de retenção (piscinões). CANHOLI (2005) ressalta que apesar das intervenções, é preciso conhecer o mecanismo de formação do principal problema da região, o grande volume escoado a partir de eventos intensos de precipitação.

Neste caso a modelagem hidrológica se apresenta como uma ferramenta de baixo custo computacional na análise dos processos hidrológicos, além de oferecer a possibilidade de simulação e previsão de vazão. BEVEN (2001) cita que os modelos hidrológicos são um meio de se estimar variáveis hidrológicas no espaço e no tempo, com suporte à tomada de decisões, como por exemplo, prever inundações, planejar o uso de recursos hídricos etc.

Silva (2005) cita que a limitação no uso dos modelos hidrológicos em ampla escala, ainda é, a dificuldade de aquisição ou estimativa dos parâmetros necessários para as simulações, principalmente no que diz respeito às informações geomorfológicas, tais como topografia, tipo e uso do solo etc. Nos últimos anos, a disponibilidade de modelos de elevação digital tem aumentado significativamente (BEVEN, 1997), assim como softwares livres do tipo Geographic Information System (GIS), que integrados com modelos hidrológicos podem facilitar a derivação de informações necessárias.

O TOPMODEL (BEVEN \& KIRKBY, 1979) é um modelo hidrológico semidistribuído conceitual, baseado nas características topográficas da bacia. O modelo considera que regiões com as mesmas características topográficas respondem de forma semelhante aos fluxos. Apresenta baixo tempo de processamento e disponibilização livre de seu código fonte. É amplamente utilizado em diversas aplicações e destacam-se a previsão de profundidade do lençol freático (LAMB et. al. 1997, SEIBERT et. al. 1997), previsão de vazão (FREER et. al. 2004, LAMB et. al. 1997, MINE e CLARKE, 1996), determinação de áreas saturadas dentro de uma 
bacia hidrográfica (SANTOS et. al. 2008), entre outros.

A principal forçante do modelo TOPMODEL é a precipitação. Esta variável deve ser medida ou estimada com menor erro possível para simulações consistentes e confiáveis. As redes telemétricas são em geral limitadas quanto à representação da variabilidade espacial da precipitação, além dos problemas relativos à exposição, que pode resultar em subestimativas de até $20 \%$ nas medições (LEGARTES e DELIBERTY, 1993). Há necessidade de técnicas de medições alternativas, tais como o sensoriamento remoto. Radares meteorológicos permitem uma estimativa com resolução espaço-temporal elevada, porém com várias fontes de erro (CALVETTI et. al., 2003).

Vários estudos foram realizados para a avaliação do impacto de estimativas de radar em modelos hidrológicos. PEREIRA FILHO (1989) utilizou dados do radar meteorológico de São Paulo para simular vazões na bacia do rio Tamanduateí, zona leste de São Paulo. Para a previsão de vazão, dados previstos de chuva, obtidos de uma técnica de extrapolação linear de deslocamento de varreduras consecutivas foram utilizados. Os resultados demonstraram uma melhora sensível do desempenho do modelo hidrológico auto-regressivo, utilizado principalmente em bacias urbanas. SANTOS e PEREIRA FILHO (2000) utilizaram a precipitação estimada pelo Radar Meteorológico de São Paulo em simulações de nível com um modelo de redes neurais artificiais na bacia do Rio Tamanduateí. Os resultados se mostraram mais satisfatórios do que os realizados com modelos auto-regressivos.

CARPENTER et al. (2001) utilizaram dados de radares meteorológicos do NEXRAD para a comparação de modelos hidrológicos distribuídos e concentrados operacionais. Concluíram que as diferenças são pouco significativas e estatisticamente semelhantes. Ressaltaram que testes incluindo outras características distribuídas (uso do solo, tipo do solo e características climáticas, por exemplo), devem ser levados em conta em novos estudos. CREUTIN e BORGA (2003) citam que cada vez mais bacias de montanha são ocupadas, seja por moradias, práticas de ecoturismo ou mesmo utilizadas para fins esportivos. Em sua maioria, não são monitoradas com telemetria, o que evidencia a importância da utilização do radar meteorológico na antecipação de eventos com vitimas humanas.

GONÇALVES et al. (2004) apresentaram resultados ao utilizar dados de precipitação originários de pluviômetros e estimados por radar, para o cálculo da precipitação média sobre uma bacia. Utilizou-se como dado de entrada em 
simulação hidrológica com o modelo hidrológico TOPMODEL. Executaram-se simulações individuais com as duas medidas de precipitação isoladas. A vazão se mostrou mais próxima à observada para casos de eventos extremos quando se utilizou estimativas de radar.

MOREIRA (2005) realizou simulações com o modelo hidrológico IPH II para a comparação de diferentes entradas de precipitação. Os resultados indicaram que a utilização do radar resultou em uma melhora na representação espacial da chuva, porém, com relação aos picos da vazão o mesmo apresenta muitas superestimativas ou subestimativas, recomendando-se a integração dos dados de radar e pluviômetros. GONÇALVES (2005) mostrou que as vazões simuladas com o modelo hidrológico $C A B C$ sofreram significativa melhora para estimativas de radar corrigidas por uma rede de pluviômetros pelo método de Brandes.

BORGA et al. (2006) avaliaram o impacto das incertezas nas estimativas de precipitação de um radar meteorológico, com um modelo conceitual de balanço hídrico e o método GLUE (BEVEN e BINLEY,1992). Mostrou-se que o viés das medições de chuva contribui como um fator multiplicativo na vazão simulada, e depende do sinal do mesmo. Ainda, com a correção das medidas do radar, foram removidos o viés local e os erros aleatórios, fazendo com que um grande percentual dos valores simulados esteja dentro dos limites calculados pelo GLUE.

CREUTIN et al. (2009) realizaram um estudo sobre responsabilidade social no gerenciamento de risco de bacias de rápida resposta na França e Itália. Concluiu-se que o radar meteorológico possui grande importância no processo de tomada de decisões que envolvem evacuação de regiões ribeirinhas. WERNER e CRANSTON (2009) compararam simulações hidrológicas de três bacias no interior da Escócia utilizando informações de nowcasting do sistema Nimrod, e uma rede de pluviômetros. Mostrou-se maiores eficiência nas precipitações médias estimadas pela previsão com radar. Porém, estas incluem incertezas significativas na utilização do modelo. Existe ainda uma relação direta do tamanho da bacia com a magnitude do erro.

ROBBINS e COLLIER (2005) compararam as incertezas entre as simulações com um modelo de drenagem urbana para entradas de precipitação de pluviômetros e radar meteorológico. Concluiu-se que as os pluviômetros adicionam erros menores na saída do modelo para chuvas uniformes. Casos com precipitações isoladas os erros aumentaram significativamente. COLLIER (2009) utilizou-se de 
estimativas simples de viés e erro médio absoluto na medida da precipitação extraída de radar meteorológico na avaliação d a incerteza introduzida em alguns modelos hidrológicos. Concluiu-se que o erro produzido depende da estrutura do modelo e ainda recomenda a previsão por conjunto com os pesos para cada membro sendo os respectivos erros

As medições (Telemetria) e estimativas (Radar) da precipitação podem ser integradas para diminuir as diversas fontes de erro (PEREIRA FILHO e CRAWFORD, 1995). Técnicas de análise objetiva têm sido propostas com objetivo de interpolação de campos meteorológicos (SILVA, 2006). A análise objetiva estatística foi desenvolvida por GANDIN (1963) e posteriormente aplicada por PEREIRA FILHO e CRAWFORD (1995) para reduzir erros observacionais e melhorar resultados de simulações e previsões hidrológicas.

Este estudo tem como objetivo principal, a modelagem hidrológica da bacia do Rio Pirajuçara com o modelo semi-distribuido TOPMODEL (BEVEN e KIRKBY 1979). Utiliza-se como dados de entrada a precipitação medida por uma rede telemétrica, a precipitação média na bacia estimada pelo Radar Meteorológico de São Paulo e precipitação integrada pelo método ANOBES (PEREIRA FILHO e CRAWFORD, 1995) com a resolução temporal de 10 minutos. Avaliam-se os resultados quanto a antecipações das vazões críticas e ajustes dos picos dos hidrogramas. Secundariamente, pretende-se delimitar e extrair a área da bacia de interesse a partir de um modelo de elevação digital de terreno de domínio público. 


\section{Revisão Bibliográfica}

\subsection{Modelagem Hidrológica}

Um modelo é a tentativa de representação simplificada da realidade por meio de equações matemáticas. Estas ocorrem devido a, não se conhecer todos os processos físicos que ocorrem em um sistema, à impossibilidade de representação destes processos em suas respectivas escalas temporais e espaciais, limitações computacionais e complexidade das equações matemáticas. RENNÓ (2003) citando STEYAERT (1993), diz que "a possibilidade de expressar os processos físicos como um conjunto de equações matemáticas detalhadas pode não existir, ou as equações podem ser muito complexas, exigindo simplificações para seu uso".

\subsubsection{Classificação de Modelos Hidrológicos}

Com base em PONCE (1989), RENNÓ (2003), SINGH (1995) apud SILVA (2005), COLLISCHONN (2001), os modelos hidrológicos são divididos de acordo com: os tipos de variáveis utilizadas (estocástico ou determinístico), forma de representação das variáveis de entrada (contínuo ou discreto), representação dos processos dentro da estrutura matemática do modelo (empírico ou de base conceitual), discretização ou não da variabilidade espacial das variáveis (concentrado ou distribuído) e o mesmo do anterior, somente para variabilidade temporal (estático ou dinâmico). Um modelo hidrológico pode aliar mais de uma das características citadas acima, não necessariamente pertencendo a somente um grupo.

Estocásticos ou determinísticos; se um modelo é baseado em equações que descrevem o comportamento de variáveis aleatórias, ou ao menos uma de suas variáveis possui comportamento deste tipo, este é classificado com um modelo estocástico. Se os conceitos de probabilidade não estiverem presentes na formulação do modelo, este é considerado determinístico. RENNÓ (2003) ressalta, no entanto, que se uma variável de entrada (precipitação, por exemplo) for aleatória, o modelo continua sendo determinístico. SILVA (2005) citando BARNSLEY (2004), diz que comportamentos considerados aleatórios podem ser provenientes tanto de processos aleatórios verdadeiros, quanto a processos não aleatórios considerados desta forma por não se ter o conhecimento necessário para o entendimento do 
mesmo.

Empíricos ou de base conceitual; quando um modelo é baseado em equações cujos coeficientes tenham sidos ajustados a séries de observações, este modelo é classificado como empírico. Este modelo fica restrito a aplicações somente nos locais onde as relações que governam os processos foram ajustados, além de não possuírem a capacidade de alteração de propriedades inerentes aos mesmos, como por exemplo, espessura efetiva do solo ou cobertura da superfície. Em casos onde o modelo é baseado em processos, estes podem ser divididos em dois tipos; os conceituais e os de base física. Modelos conceituais são os que descrevem os processos de acordo com as leis da física, porém, com o uso de relações empíricas. Já os modelos de base física, são aqueles, em que seus parâmetros possuem significado físico e os processos presentes são representados por meio de equações diferenciais baseados nas leis físicas que regem cada passo.

Contínuos ou discretos; todos os fenômenos naturais ocorrem de forma contínua no tempo, porém para a sua representação matemática, é necessário uma discretização, comumente chamada de passo de tempo ou resolução temporal. A resolução temporal deve ser escolhida com base no processo de interesse, isto inclui muitas vezes um estudo prévio do fenômeno a ser modelado, como por exemplo, tempo de pico de um hidrograma de cheia de uma bacia, no caso de previsão de cheias.

Concentrado ou distribuído; modelos concentrados são aqueles que não consideram a variabilidade espacial de seus parâmetros e variáveis, apenas o tempo é uma variável independente. Nos modelos distribuídos, os parâmetros, as variáveis de entrada e saída possuem variabilidade espacial e temporal. Inicialmente os modelos distribuídos apresentavam como dificuldades, o alto número de iterações, que resulta em alto custo computacional, a necessidade de uma amostragem de dados bastante extensa, além da obtenção das condições de contorno, como modelos numéricos de terreno e softwares do tipo GIS para o tratamento e derivação das informações necessárias.

A escolha de determinado tipo de modelo, deve ser feita de acordo com 0 processo que se deseja simular. Para isto deve-se observar o embasamento teórico do mesmo, assim como a disponibilidades de dados requeridos pelo modelo. BEVEN (1991) cita que modelos distribuídos e de base física são os que melhores representam os processos dentro de uma bacia hidrográfica. 


\subsubsection{Discretização espacial de bacias hidrográficas}

A representação espacial de uma bacia pode-se dar de maneiras distintas. A mais simplificada é a homogênea, com características médias e constantes para todo o domínio. Na utilização em modelos hidrológicos, este tipo de aplicação é pouco representativa, pois grande parte dos fluxos possui dependência com a topografia, uso ou tipo do solo. Modelos distribuídos exigem a necessidade de uma representação da variabilidade espacial dos componentes da bacia, como por exemplo, inclinação do terreno, características dos canais de drenagem, orientação das vertentes, comprimento da rampa, limites da bacia e conexões entre áreas que definem a forma com que a água se desloca (MOORE et al. 1991) apud RENNÓ (2003). Em representações desta natureza, utilizam-se modelos de elevação digital de terreno ou MNT, juntamente com alguns métodos para o processamento e derivação. Entre estes métodos, encontram-se na literatura três diferentes formas: grade regular retangular ou quadrada, grade triangular ou curvas de nível (Fig. 2.1).

MOORE (1993) cita que grades do tipo Triangular Irregular Network (TIN) (Fig. 2.1b) representam com mais eficiência a topografia frente a malhas regulares, pois se trata de apenas três pontos, que definem apenas um plano, e se adaptam a mudanças abruptas do terreno. Devido a esta característica, este tipo de representação, é amplamente utilizada em modelos dinâmicos (PALACIOS-VÉLEZ \& CUEVAS-RENAUD (1986) e JONES, WRIGHT \& MAIDMENT (1990)). A dificuldade na utilização de grades triangulares ocorre onde as facetas dos triângulos não possuem orientação, dificultando as linhas de fluxo (RENNÓ,2003) (Fig. 2.1b).

Uma maneira natural de estruturação de modelos hidrológicos é a utilização de curvas de nível (Fig. 2.1c), pois fluxos são respostas a gradientes (MOORE, 1991). Este tipo de representação requer mais espaço computacional para armazenagem (tipicamente trata-se de arquivos no formato "shape") e não apresentam melhorias significativas em ganhos computacionais. 


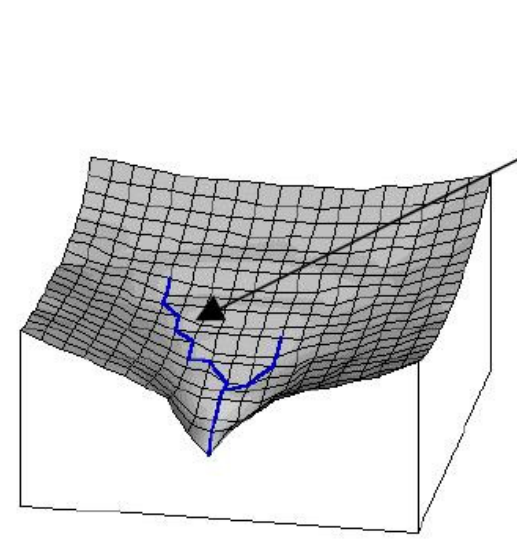

(a)

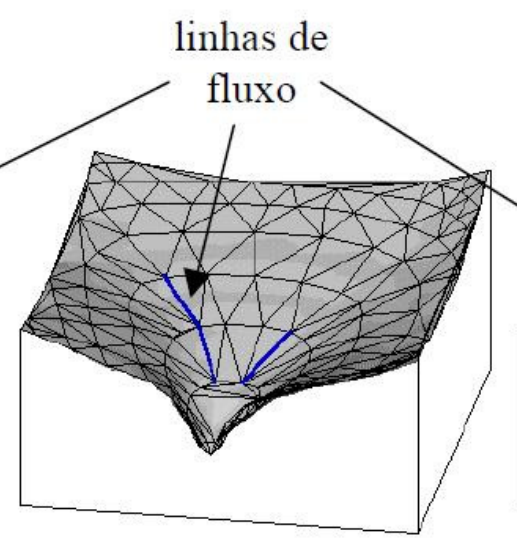

(b)

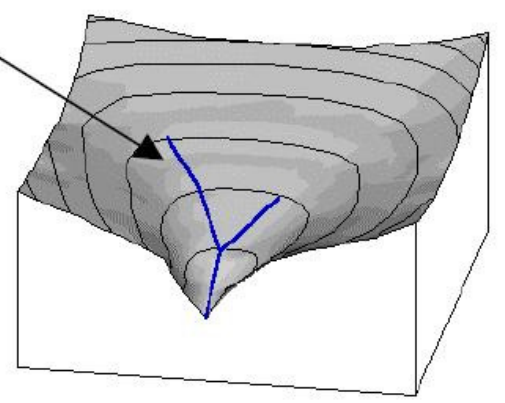

(c)

Figura 2.1: Representação espacial de terreno por meio de Modelo Numérico de Terreno (MNT). (a) grade regular; (b) grade triangular; (c) curvas de nível. Fonte: Rennó (2003).

RENNÓ (2003) cita que grades do tipo regular não representam bem mudanças abruptas na topografia, e que isto tem relação direta com a resolução da grade utilizada. Além disto, grades regulares tendem a formar linhas de fluxo em "zig-zag", não representando o fluxo real (Fig. 2.1a). Segundo GUERCIO e SOCCODATO (1996), grades regulares não representam bem encostas, convergências, divergências, convexidades ou concavidades, não recomendada sua utilização para simular processos hidrológicos dinâmicos.

COLLINS e MOON (1981) citam que umas das estruturas mais difundidas na representação de um MNT é a grade regular retangular ou mesmo quadrada, pois é de fácil implementação e alta eficiência computacional. Outro fato a favor das grades regulares é a atual disponibilidade pública de informações deste tipo. 0 projeto "Shuttle Radar Topography Mission" (SRTM), cooperação entre as agências espaciais Americana (NASA), Italiana (ASI) e Alemã (DLR), disponibiliza para todo o globo, modelos de elevação digital de terreno com noventa metros de resolução em formato ascii ou geotiff. O projeto "Advanced Spaceborne Thermal Emission and Reflection Radiometer" (ASTER) do ano de 1999, uma cooperação entre a NASA e a agência espacial japonesa (ERSDAC), e disponibiliza modelos de elevação digital de terreno com trinta metros de resolução em formato geotiff gratuitamente. 


\subsubsection{Calibração de modelos hidrológicos}

Modelos distribuídos possuem um número de parâmetros elevados, se comparados a modelos do tipo concentrados. Este número dependente da quantidade de elementos discretizados de uma bacia. COLLISCHONN et al. (2003) citam que o ajuste dos parâmetros de um modelo hidrológico, é a etapa mais trabalhosa para o usuário, pois o mesmo necessita do conhecimento da relação entre a representatividade dos parâmetros e os resultados obtidos, assim como a qualidade dos dados hidrológicos utilizados. A etapa de calibração consiste em estabelecer o conjunto de parâmetros para o qual o modelo atinja eficiência ótima. Existem vários conjuntos de parâmetros com resultados semelhantes. BEVEN e BINLEY (1992) definiram como equifinidade, quando dois ou mais conjunto de parâmetros distintos entre si atingem o mesmo resultado final. Existem técnicas de calibração distintas utilizadas desde o inicio do desenvolvimento de modelos hidrológicos, as técnicas manuais (i) e automáticas (ii).

\section{i. Técnicas manuais}

É a técnica mais antiga e utilizada até os dias atuais. A tentativa e erro é a primeira delas. Consiste no conhecimento avançado e prévio do modelo por parte do usuário, e possui a desvantagem da dificuldade de transferência para outros. As vantagens deste método consistem no fato do usuário possuir experiência e conhecimento dos parâmetros e suas dependências com os resultados. Ajustes são efetuados de acordo com os objetivos, como por exemplo, vazões máximas, mínimas, volumes totais, forma do hidrograma, tempo de concentração da bacia, entre outros. Os resultados são comparados visualmente ou mesmo comparados com valores de funções objetivo. COLLISCHONN et. al. (2003) citam que em casos como este, onde o usuário já possui a experiência de calibrações seguidas em bacias diferentes, esta etapa se torna simples, rápida, e com funções multi-objetivo implícitas no processo.

\section{ii. Técnicas automáticas}

$\mathrm{Na}$ ausência do conhecimento prévio, a calibração automática pode ser uma solução. Os processos de calibração automática são baseados em funções objetivo, 
que podem ser derivadas de erros ou critérios de ajustes pré-estabelecidos. Este é um ponto de geração de críticas de alguns autores. BOYLE et al. (2000) citam que funções objetivo não representam as complexas funções implícitas no processo de calibração manual.

COLLISCHON (2001) citando BURNASH (1995) diz que hidrólogos experientes criticam as formas de calibração automáticas, principalmente por: o usuário do modelo passa por uma fase de aprendizado no processo manual, que não existirá no processo automático; o conjunto de valores dos parâmetros encontrados depende do valor de uma função objetivo, e não necessariamente é o conjunto que melhor representa o comportamento da bacia; o usuário perde a sensibilidade do comportamento do modelo e pode não reconhecer ou compreender suas limitações; os parâmetros encontrados como o melhor conjunto, podem ter valores fisicamente inválidos. COLLISCHONN (2001) cita que as grandes parcelas destas críticas estão depositadas sobre os primeiros métodos de calibração automática, baseados em otimização local, como por exemplo, o método de Rosenbrock (ROSENBROCK, 1960), que pode neste caso, gerar resultados pouco confiáveis.

Nos últimos anos, vários métodos de calibração automática baseados em metodologias diversas têm sidos desenvolvidos. Alguns exemplos são, os baseados em "clustering" ou "multistart", os baseados em algoritmos evolucionais aliados a métodos de mínimos locais (SCE-UA, DUAN et al., 1992 e MOCOM-UA, YAPO et al., 1998), os baseados em estratégia combinada de identificação de mínimos globais e baseados em redução da área de busca e "reescaneamento" da região pré-determinada ("adaptive cluster covering”) (SOLOMATINE,1999).

Dentre as funções objetivo mais citadas na literatura estão: $N S$ ou NASH, é o coeficiente de NASH e SUTCLIFFE (1970) (Eq. 2.1); $N S_{l o g}$,(Eq. 2.2) é o coeficiente de NASH aplicado ao logaritmo das variáveis; $\Delta V$ (Eq. 2.3), é a relação entre os valores simulados e observados dos volumes; EQM é o erro quadrático médio (Eq. 2.4).O coeficiente de Nash (NS) assume valores entre - $-\infty$ e 1 , onde o valor 1 (um) é considerado ótimo. Valores acima de 0.75 são considerados bons, valores entre 0.36 e 0.75 são considerados aceitáveis (GOTSCHALK E MOTOVILOV, 2000). COLLISCHON (2001) cita que o valor é fortemente influenciado pelas vazões máximas. Valores próximos a 1 indicam um bom ajuste para cheias ou picos do hidrograma. O coeficiente de Nash para o logaritmo $\left(N S_{l o g}\right)$ possui as mesmas 
fronteiras do coeficiente anterior, porém, mais sensível as vazões mínimas, valores próximos a 1 indicam bons ajustes nas recessões do hidrograma.

$$
\begin{gathered}
N S=1-\frac{\sum\left(Q_{o b s}(t)-Q_{c a l}(t)\right)^{2}}{\sum\left(Q_{o b s}(t)-\overline{\left.Q_{o b s}(t)\right)^{2}}\right.} \\
N S_{\log }=1-\frac{\sum\left(\ln \left(Q_{o b s}(t)\right)-\overline{\left.\ln \left(Q_{c a l}(t)\right)\right)^{2}}\right.}{\sum\left(\ln \left(Q_{o b s}(t)\right)-\overline{\left.\ln \left(Q_{o b s}(t)\right)\right)^{2}}\right.} \\
\Delta V=\frac{\sum\left(Q_{c a l}(t)-Q_{o b s}(t)\right)}{\sum Q_{o b s}(t)} \\
E Q M=\sqrt{\frac{1}{N} \sum_{t=1}^{N}\left(Q_{o b s}(t)-Q_{c a l}(t)\right)^{2}}
\end{gathered}
$$

Onde, $Q_{c a l}(t)$ é a variável simulada ou calculada no instante de tempo $t$, $Q_{o b s}(t)$ é a variável observada no instante de tempo $t$.

Um dos métodos mais citados e utilizados na literatura, para estimativa ou minimização das incertezas, é a calibração multi-objetivo (COLLISCHON, 2001; COLLISCHON et al. 2003; GUPTA et al., 1998; MADSEN, 2000). Utilizam-se várias funções objetivo simultaneamente para se aproximar ao máximo do processo manual de calibração.

BEVEN e BINLEY (1992) propuseram o método "Generalized Likelihood Uncertainty Estimation" (GLUE), que utiliza o método de Monte Carlo para a geração aleatória de uma série de conjuntos de parâmetros, baseado em distribuições uniformes de probabilidade. Neste caso, o conjunto que superar valores de uma determinada função objetivo, é utilizado para as simulações. A função objetivo utilizada como critério de qualidade, deve ser escolhida pelo usuário, com base em seus objetivos (representação de máximos, mínimos, volumes). 
Em BEVEN (2001) encontram-se os passos para utilização do método GLUE: (i) Determinação dos intervalos dos parâmetros, este passo pode ser efetuado a partir de medições de campo ou mesmo da revisão de valores utilizados na literatura; (ii) Escolha de um método para efetuar a distribuição dos parâmetros a serem testados dentro do intervalo definido no passo anterior; (iii) Escolha da função objetivo, que como citado anteriormente, depende do objetivo do usuário; (iv) Critério para que o conjunto de parâmetros seja aceito ou rejeitado, dependendo diretamente da função objetivo e do nível de qualidade requerido; (v) Escolha da metodologia utilizada no refinamento ("updating") dos conjuntos, determinados pelo peso das incertezas.Dentre todos os métodos de calibração de modelos hidrológicos, nenhum destes, ou mesmo nenhum modelo, pode representar a realidade. Incertezas estão incluídas em diversas etapas, como por exemplo, nos dados de entrada, parâmetros obtidos na etapa de calibração ou na estrutura do modelo (HAAN, 1989). 


\subsection{Radar Meteorológico}

O Radar é a abreviação para "RAdio Detection And Ranging", é a técnica que se utiliza de ondas eletromagnéticas para detectar e estimar a distância de um objeto ou alvo. Segundo RINEHART (1994), o radar é um instrumento eletrônico ativo, que emite certa quantidade de energia eletromagnética e a partir da porção retro-espalhada pelo alvo e determina vários aspectos do mesmo. O sensor ativo emite um feixe de abertura pequena, em um intervalo de tempo regular. Os feixes são disparados por uma antena rotativa, que cobre os $360^{\circ}$ de azimute. A antena possui vários níveis de elevação para cada giro completo, desta forma uma varredura completa tanto na vertical (elevações) quanto na horizontal (azimute) é efetuada. Os alvos que são iluminados pelo feixe e podem interagir de três formas: absorvendo ou espalhando a energia incidente e a combinação entre as duas. Após esta interação, a parte da energia retornada ao sensor é utilizada para estimar sua distância, conhecendo-se o tempo entre o feixe emitido e a energia refletida, além de sua intensidade. A intensidade da energia refletida possui dependência do volume do alvo iluminado. A refletividade é diretamente proporcional ao espectro de tamanho de gotas (RINEHART, 1994), e é representado pela Eq. 2.5 .

$$
Z=\int_{0}^{\infty} N(D) D^{6} d D
$$

Onde,

$Z$ é a refletividade em $\mathrm{mm}^{6} \mathrm{~m}^{-3}$

$N(D)$ é o número de gotas com diâmetro $D$

O principal produto de um radar meteorológico é mensurar a precipitação. Segundo MARSHALL \& PALMER (1948), conhecendo-se a distribuição do espectro de gotas dentro de um volume que gerou uma refletividade ao sensor ativo, pode ser estimada a taxa de precipitação. Esta relação é descrita por (BATTAN, 1973) (Eq. 2.6): 


$$
R=\frac{\pi}{6} \int_{0}^{\infty} N(D) D^{3} V t(D) d D
$$

Onde,

$R$ é a taxa de precipitação $\left(m m h^{-1}\right)$;

$Z$ é a refletividade em $\mathrm{mm}^{6} \mathrm{~m}^{-3}$;

$N(D)$ é o número de gotas com diâmetro $D$;

$V t(D)$ é a velocidade terminal da gota com diâmetro $D$, é a velocidade na qual as forças de resistência do ar e empuxo (ou flutuabilidade) se igualam a força da gravidade;

Assim, se existe uma relação entre a dependência da refletividade do radar meteorológico com a distribuição do espectro do tamanho de gotas, e uma relação entre a dependência da taxa de precipitação com o espectro do tamanho de gotas, determina-se diretamente a relação entre a taxa de precipitação e refletividade dos alvos iluminados. MARSHALL e PALMER (1948), com uma série de dados de precipitação coletados durante o verão de 1946 em Ottawa (Canadá), desenvolveram uma relação entre refletividade-taxa de precipitação:

$$
Z=a R^{b}
$$

Onde:

$Z$ é a refletividade $\left(\mathrm{mm}^{6} \mathrm{~m}^{-3}\right)$;

$R$ é a taxa de precipitação $\left(m m h^{-1}\right)$;

$a$ e $b$ são constantes estimadas;

$\mathrm{Na}$ utilização de radar meteorológico para a estimativa de chuva, podem ocorrer erros devidos a vários fatores, entre eles alguns são descritos por BATTAN (1973), AUSTIN, (1987) e TUCCI (1993);

Propagação anômala ocorre se um feixe de energia transmitido atinge uma camada se ar com propriedades elevadas de refração, isto pode causar um desvio do feixe, desta forma precipitação estimada fora de sua posição real. Ainda pode 
causar a interceptação do feixe pelo solo, indicando células de chuvas inexistentes e acumulados não confiáveis de precipitação.

A precipitação sobre o radar ou mesmo ao longo do feixe, pode causar atenuações do mesmo.

- Evoluções convectivas com grande variabilidade vertical de espectro de gotas, podem causar uma estimativa pouco confiável da precipitação.

- $\quad$ Presença de velocidades ascendentes ou descendentes intensas dentro de nuvens de tempestade, fato este muito comum em células convectivas, alteram os valores de $V t$ das gotas, desta forma a relação entre $R$ e distribuição do tamanho de gotas são alterados, e conseqüentemente a relação Z-R .

- Resolução espacial, a resolução do radar meteorológico pode não representar bem o fenômeno observado, principalmente se os de sub-escala. Assim a precipitação pode ser subestimadas.

- Efeito de banda brilhante causa, tipicamente, uma superestimativa das medições de precipitação em radares sem multipolarização.

- $\quad$ Área de amostragem, enquanto um pluviômetro amostra uma área de poucos centímetros quadrados, cada célula de amostragem do radar estima áreas da ordem de $1 \mathrm{~km}^{2}$. A precipitação é altamente variável no tempo e no espaço, a precipitação acumulada pelo testemunho de terra não ser significativa para toda a área de amostragem do radar e vice versa. 


\section{MATERIAIS E MÉTODOS}

\section{1. Área de Estudo}

\subsubsection{Características físicas da bacia do Rio Pirajuçara}

A bacia hidrográfica do Rio Pirajuçara, afluente pela margem esquerda do Canal Inferior do rio Pinheiros, está localizada no setor oeste da Região Metropolitana de São Paulo (Fig. 3.1) e drena uma área de 73,1 km² (DAEE, 1998). A bacia abrange três municípios, São Paulo, com 40,6 km², Taboão da Serra, com 23,4 km² e Embu, com 12,3 km² (Fig. 3.2).

\section{Localização da Bacia do Rio Pirajuçara na Bacia do Alto Tietê}

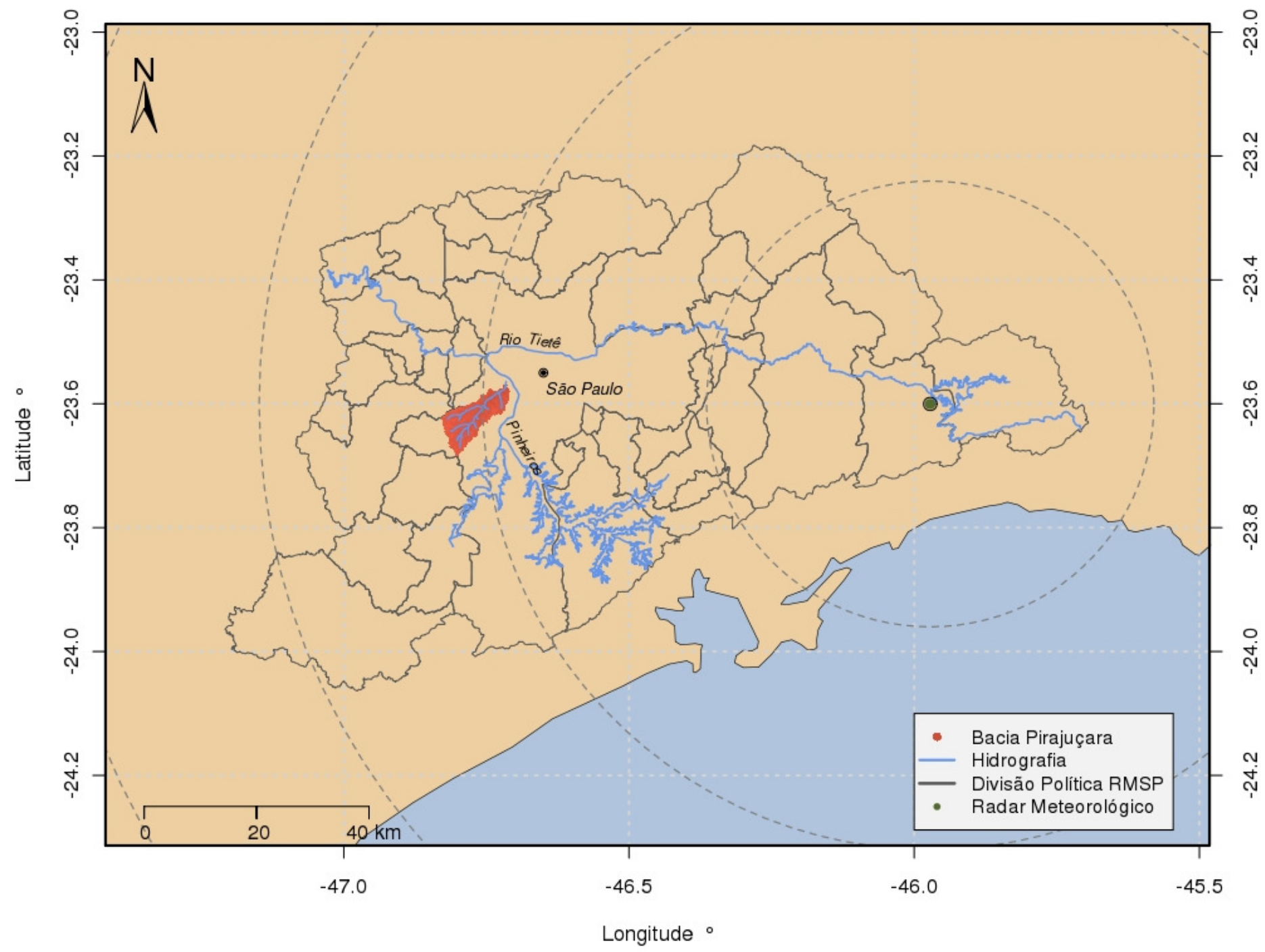

Figura 3.1: Localização da Bacia do Rio Pirajuçara na Bacia do Alto Tietê. As linhas azuis representam a hidrografia dos Rios Tietê e Pinheiros, a porção em vermelho é a área da $\mathrm{BRP}$, as linhas pontilhadas representam os raios concêntricos de $40 \mathrm{~km}$ do RSP. Fonte: SRTM, IBGE, Organização ROCHA FILHO, 2010. 
Fisiográficamente, a bacia tem formato alongado, orientada na direção SW$\mathrm{NE}$. Sua largura média, nos trechos baixos e médios, varia de 3 a $5 \mathrm{~km}$, ampliada para 6-7 km no terço de montante. A densidade da drenagem é considerada de média a alta com padrão paralelo (DAEE, 1998). As nascentes do Rio Pirajuçara, se encontram no município de Embu (margem esquerda) e São Paulo (margem direita, região do Campo Limpo) (CANIL, 2006).A extensão total do curso principal é de 18.577 metros, onde 6.285 metros são canalizados. Grande parte dos afluentes deste é de dimensões geográficas pequenas, destaca-se apenas o Córrego Poá, com 8.960 metros de comprimento, este desemboca na margem esquerda do Rio Pirajuçara em seu terço final, próximo a divisa do município de São Paulo com Taboão da Serra (Figura 3.3).

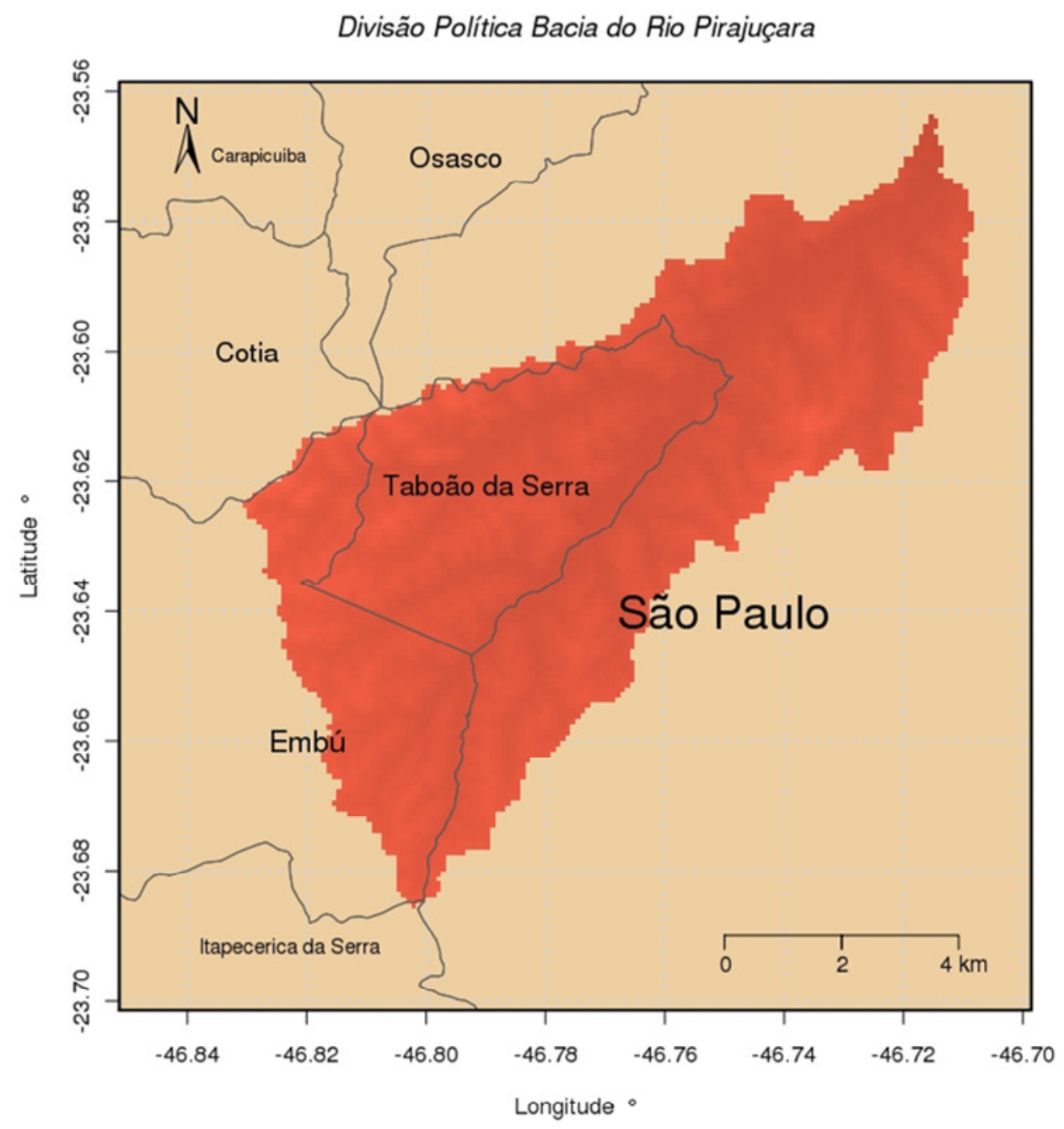

Figura 3.2: Divisão política da Bacia do Rio Pirajuçara. As linhas pretas representam a divisão política da RMSP, a porção em vermelho é a área da BRP. Fonte: SRTM, IBGE, organização ROCHA FILHO, 2010. 
A altimetria da bacia (Fig. 3.3) mostra variação de altitude entre a foz e a cabeceira do Rio Pirajuçara de aproximadamente 175 metros. Valores mais altos se encontram nas nascentes do Córrego Poá e nas elevações mais altas, que separam o Córrego Poá do Rio Pirajuçara. Os valores mais baixos encontram-se na foz do Pirajuçara, região da Cidade Universitária (USP). Em praticamente todo o restante da bacia, predomina-se altitudes entre 750 e 810 metros. O relevo é classificado como de colina. Após a confluência do Córrego Poá com o Rio Pirajuçara, configurase a "planície fluvial", com altitudes entre 740 e 710 metros até a foz do Rio Pirajuçara no Rio Pinheiros.

\section{Mapa Hipsométrico - Bacia do Rio Pirajuçara}

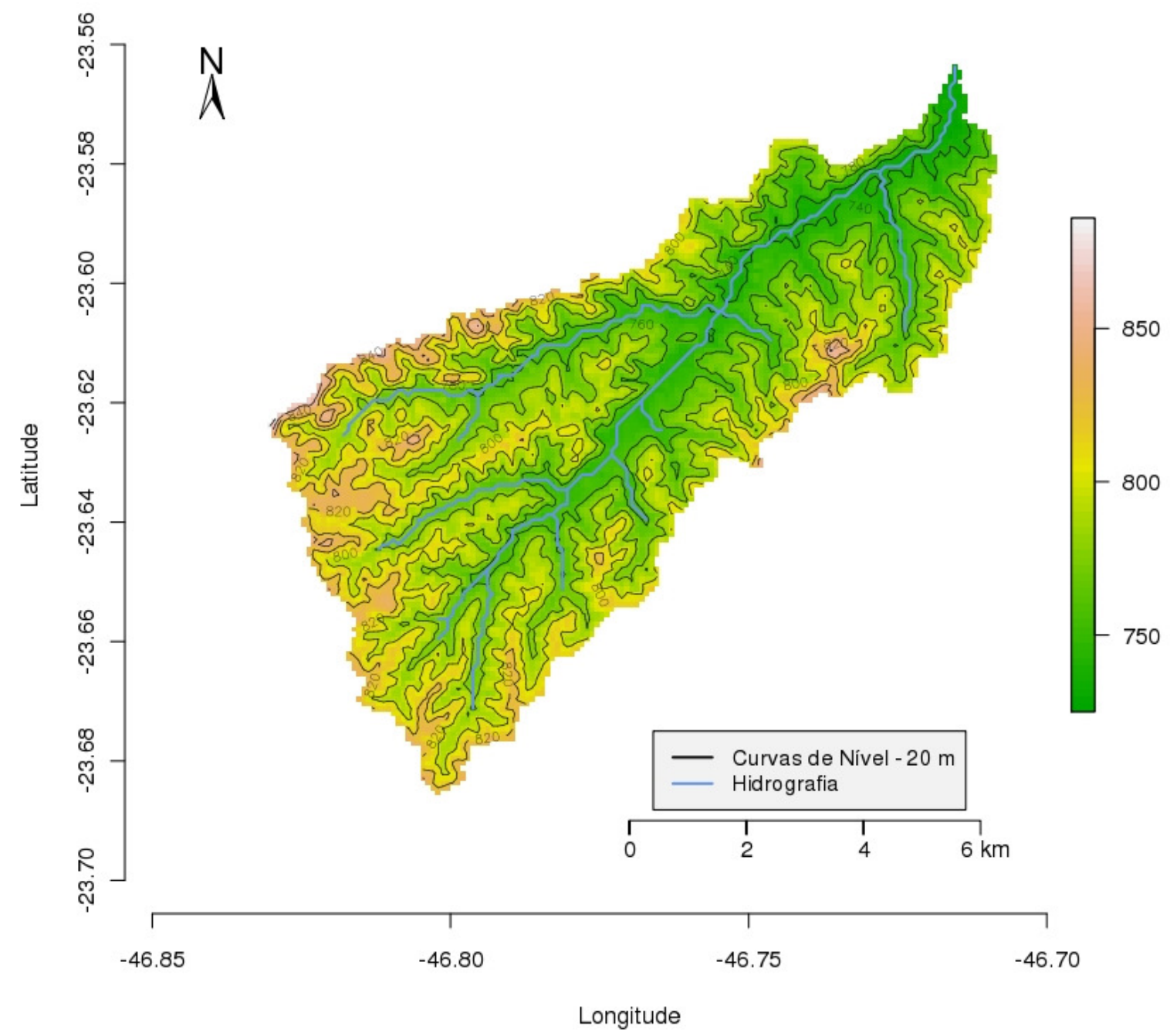

Figura 3.3 - Mapa Hipsométrico da Bacia do Rio Pirajuçara. A área sombreada representa a elevação em metros. As linhas em preto são as curvas de nível com intervalos de 20 metros. Fonte: SRTM, organização ROCHA FILHO, 2010. 
Geomorfologicamente, a bacia pode ser classificada como de "colinas pequenas" ou "morrotes", que são áreas com inclinações inferiores à $20 \%$. Localmente, pode ser classificada como "morros baixos" com inclinações de até $30 \%$. No mapa clinográfico (Fig. 3.4), observa-se que os maiores valores de declividade, superiores a $30 \%\left(11^{\circ}\right)$, se encontram na porção noroeste da bacia, margem esquerda do Córrego Poá. Na porção mais elevada central, margem esquerda do curso principal, são observados valores significativos de $20 \%$ a $30 \%$ (7-1 - $11^{\circ}$.Na margem direita do Rio Pirajuçara, observa-se a predominância de declividades mais suaves, variando de $6 \%$ a $30 \%\left(3^{\circ}-11^{\circ}\right)$. Após a confluência dos dois cursos principais, como já descrito no mapa hipsométrico, observa-se a predominância da planície fluvial, e conseqüentemente, valores mais suaves deste parâmetro. Valores de altas declividades indicam maiores disponibilidade para geração de escoamento superficial a montante do elemento de terreno. Os baixos tempos de concentração desta bacia resultam em um tempo para tomada de decisões muito curto.

No estudo realizado por DAEE (1998), onde o objetivo foi classificar os tipos de solo para determinação de coeficientes de escoamento para todas as sub-bacias do Alto Tietê, foi determinado que os tipos de solos que compõe a bacia do Rio Pirajuçara, são na verdade uma mistura de solos. Sua classificação de acordo com U.S. Conservation Service, é de solos do tipos A (14\%), B (30,6\%), C (27\%) e D $(28,4 \%)$ o que indica um solo com elevado grau de escoamento. 


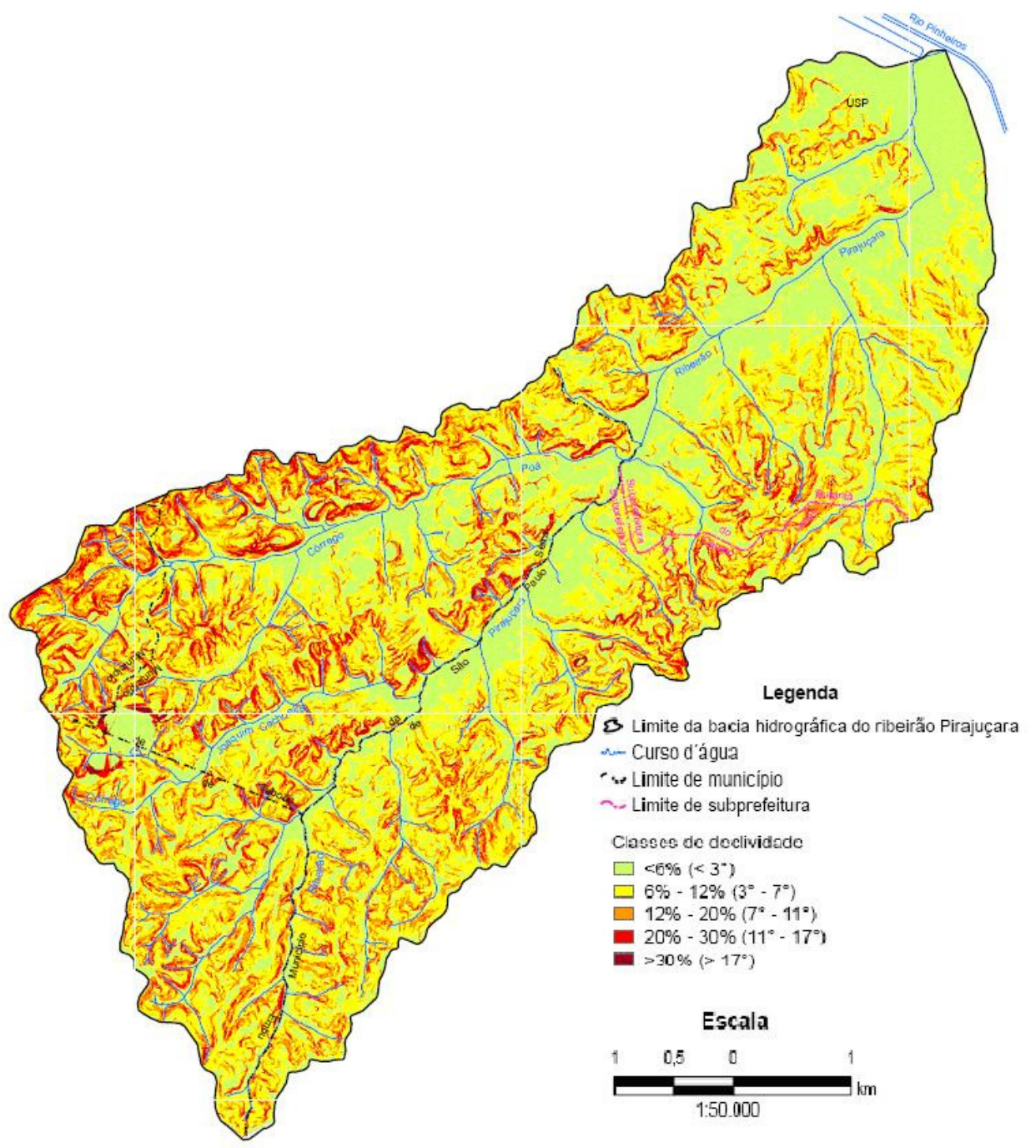

Figura 3.4 - Mapa Clinográfico da Bacia do Rio Pirajuçara. As diferentes cores representam distribuição espacial da declividade. As linhas azuis representam os principais cursos d'água. Fonte: CANIL, 2006.

\subsubsection{Usos do solo na bacia}

A utilização do solo foi inferida por meio de das imagens TM/Landsat (DAEE, 1998) obtidos em 1997 e são classificadas como áreas urbanas de alta densidade. Nas regiões de moradias, edifícios e pavimentação atingem porcentagem da área maior que $90 \%$ e áreas urbanas de densidade média e baixa em regiões onde a porcentagem está entre $50-90 \%$ de construções. A ocupação da bacia é bastante heterogênea e varia entre bolsões de vegetação densa na cabeceira do Córrego Poá e regiões de intensas áreas com urbanização bastante elevadas, principalmente no município de São Paulo. 
Desta forma, a área correspondente a ocupação de áreas urbanas densas são de $65.7 \%$ da área total da bacia, a área correspondente a ocupação urbana média e baixa corresponde à $23.25 \%$ da área total, por fim a área com vegetação totaliza $10.78 \%$ do total. O resultado do estudo de DAEE (1998) mostra que com esta configuração de solos juntamente com ocupação, a impermeabilização da bacia é de $70 \%$. Com a tendência da continuidade da expansão urbana, o percentual de impermeabilização também tende a aumentar com os anos.

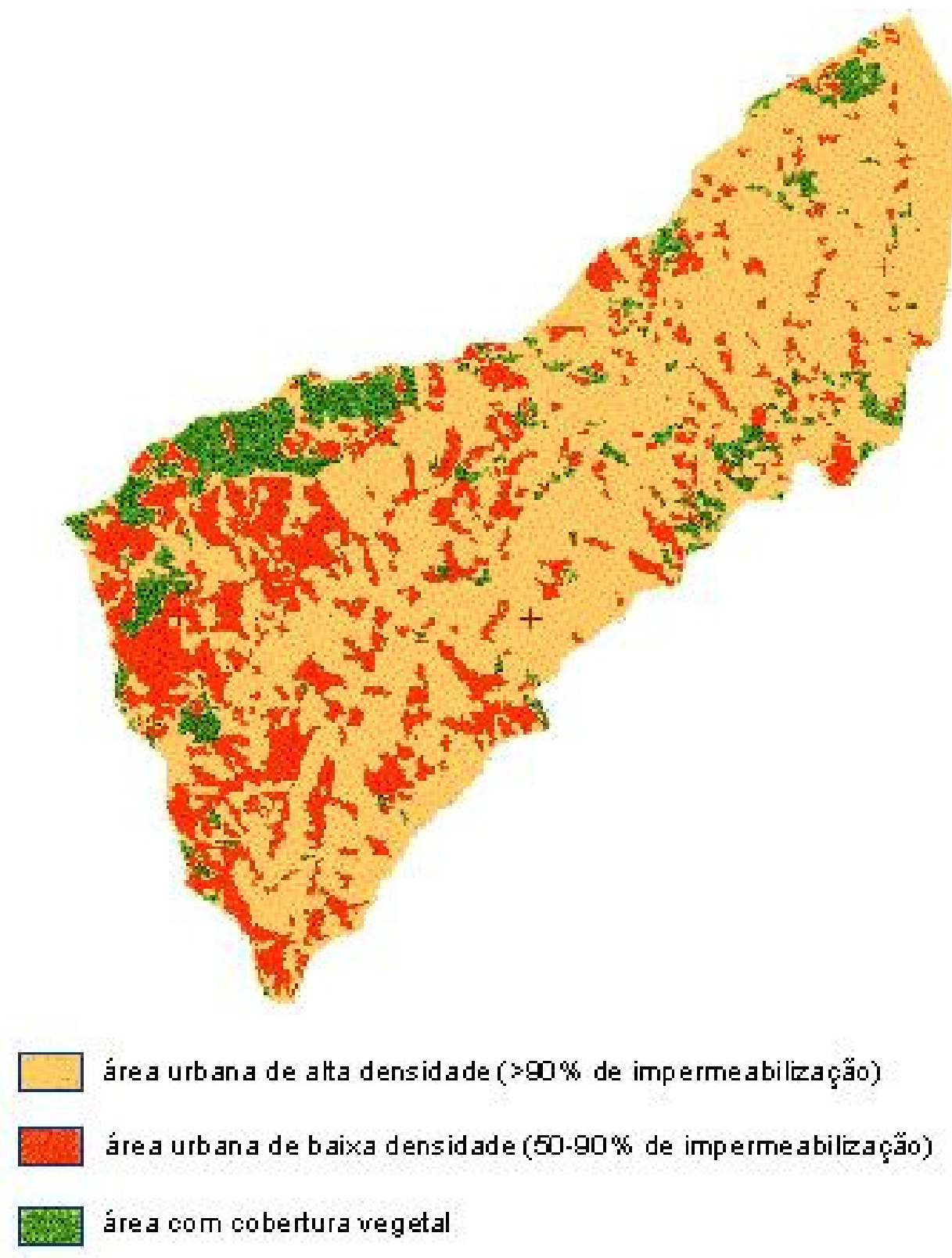

Figura 3.5: Ocupação do solo da bacia Pirajuçara. Diferentes cores representam o tipo de ocupação do solo. Fonte: DAEE, 1998. 


\subsection{TOPMODEL}

Diversos estudos durante a década de 1970 (DUNNE AND BLACK, 1970; HEWLETT e NUTTER, 1970; DUNNE, 1978) mostraram que as zonas saturadas são as principais responsáveis pela produção de escoamento superficial. Estas se expandem e se contraem sazonalmente ou durante chuvas de curta duração. $O$ conceito para representar estas áreas saturadas é o conceito de área de contribuição variável que pode ser encontrado com detalhes em BETSON (1964) e HEWLETT e HIBBERT (1967). Segundo FRANCINI (1996), dois componentes podem ser encontrados na grande maioria dos modelos hidrológicos, o primeiro é o balanço de água nas camadas do solo (dependente da compartimentação tratada pelo modelo) e trata-se do processo de transformação chuva-vazão, e o segundo, a propagação do escoamento por um canal de drenagem.

O modelo TOPMODEL (Topography-based hydrological model) é classificado como um modelo conceitual de base física. É considerado semi-distribuído, pois apenas as variabilidades espaciais dos parâmetros que descrevem a topografia são consideradas. A estrutura do modelo que descreve o balanço de água no solo é o que caracteriza o modelo. CORDOVA e RODRIGUEZ-ITURBE (1983) resumiram a importância deste processo com: "o problema é mais do que produzir, e sim como produzir". A descrição a seguir foi retirada dos trabalhos de SILVA (2005), FRANCINI (1996) e XAVIER (2002).

$\mathrm{Na}$ formulação do TOPMODEL, três reservatórios representam o processo de geração do escoamento, e são a resposta média da bacia de capacidade homogênea. Na Fig. 3.6 (SILVA, 2005) são representados os processos e reservatórios utilizados pelo modelo. Três reservatórios são identificados: $S_{R Z}$, reservatório da zona de raízes expresso em déficit; $S_{U Z}$, reservatório da zona não saturada expresso em déficit; $S_{S Z}$, reservatório da zona saturada expresso em déficit ou profundidade ( $S$ ou $z$ ). Os processos representados na figura são: Escoamento sub-superficial na zona saturada $\left(q_{b}\right)$, escoamento sub-superficial vertical na zona não saturada $\left(q_{v}\right)$, Escoamento superficial na saturação $\left(q_{o f}\right)$. Na mesma figura, $a^{\prime}$ é a área superficial da célula, $r^{\prime}$ é a precipitação sobre a célula, $\beta$ é a declividade da célula, $c$ é o perímetro de cada célula, $\eta$ é a porosidade do solo, $D$ é a profundidade até a área saturada e $a c^{\prime}$ é a área acumulada a montante da célula. 


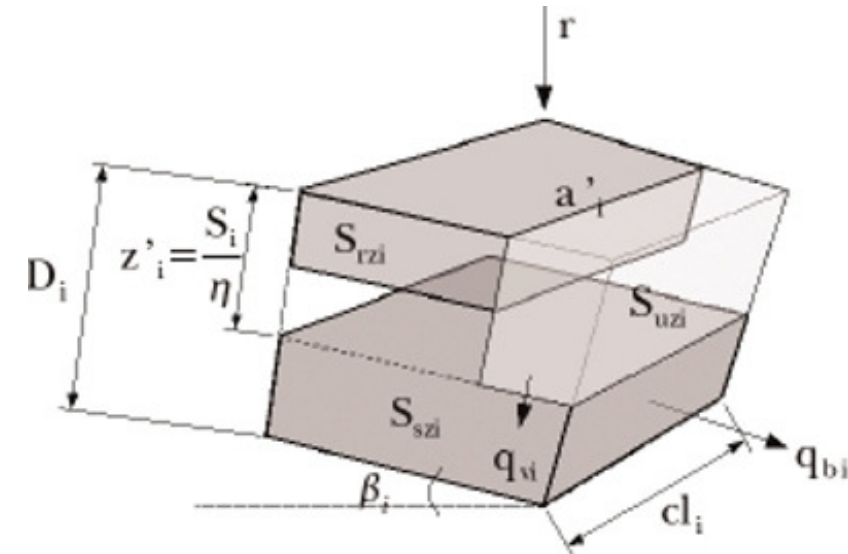

(a)

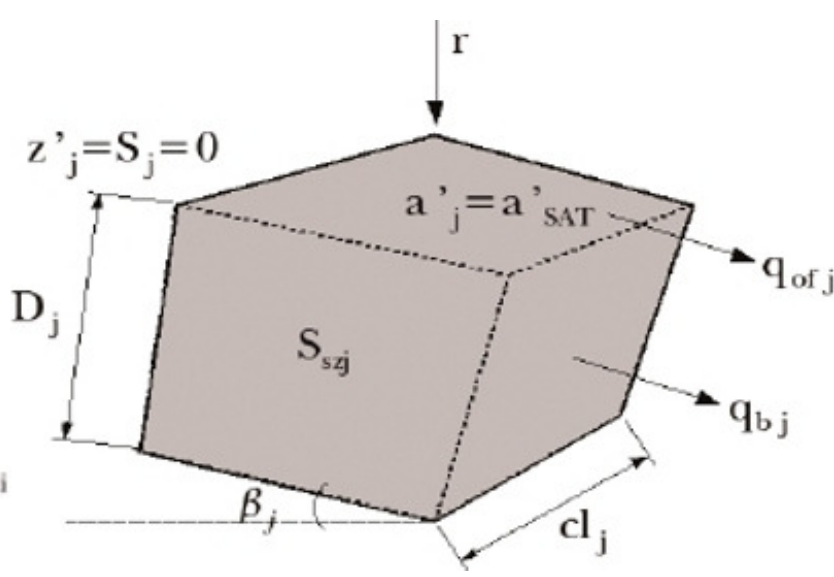

(b)

Figura 3.6: Representação dos reservatórios e processos utilizados pelo modelo TOPMODEL: (a)condição não saturada;(b) condição saturada. Fonte: SILVA, 2005

\subsubsection{Escoamento Subsuperficial na Zona Saturada $\left(q_{b}\right)$}

O escoamento subsuperficial foi estudado inicialmente pelo engenheiro Henri Darcy no final do século 19. Darcy propôs que para um fluxo horizontal de um fluido monofásico, a vazão que atravessa uma amostra de meio poroso, de comprimento $\Delta Z$ é dada por:

$$
q_{d}=-K \frac{\Delta H}{\Delta Z}
$$

Onde,

$q_{d}$ é a velocidade de Darcy;

$K$ é a condutividade hidráulica saturada;

$\Delta \mathrm{H}$ é o gradiente de potencial hidráulico;

Observa-se que para mesmas condições geométricas e de gradiente hidráulico, o fluxo de água através de um meio poroso é diretamente proporcional a condutividade hidráulica. SCHEIDEGGER (1974) cita que a condutividade hidráulica é não somente uma propriedade do meio poroso ou do fluido, mas sim uma interação dinâmica entre ambos. 
A primeira suposição do TOPMODEL é em consideração a condutividade hidráulica. BEVEN e KIRKBY (1979) propuseram que a variação da condutividade hidráulica da zona saturada pode ser representada por uma função exponencial negativa:

$$
K_{s}\left(z^{\prime}\right)=K_{0} e^{-f z}
$$

Onde $K_{s}\left(z^{\prime}\right)$ é a condutividade hidráulica saturada na profundidade $z^{\prime}, K_{0}$ é a condutividade hidráulica saturada na profundidade zero (superfície) e $f$ é um parâmetro que representa a taxa de decaimento da condutividade com a profundidade. Para obter a transmissividade hidráulica saturada, pode-se integrar a equação 3.2 para todo o perfil do solo:

$$
T=\int K_{s}\left(z^{\prime}\right)=\int K_{0} e^{-f z} d z=\frac{K_{0}}{f} e^{-f z}
$$

A transmissividade saturada é máxima quando a profundidade é zero (superfície), e decai com taxa $f$ com a profundidade $z^{\prime}$. O modelo propõe também um escoamento uniforme (laminar) do fluido, desta forma, a declividade da área impermeável (lençol freático) é paralela a inclinação da superfície.

$$
\Delta H=\tan (\beta)
$$

Substituindo-se (3.4) e (3.3) em (3.1), a lei de Darcy fica:

$$
q_{b}=\frac{1}{f} K_{0} e^{-f z} \tan (\beta)
$$

Ainda, a profundidade pode ser expressa em termos de déficit de armazenamento ou saturação (SILVA (2005) citando HORNBERGER et al. (1998))

$$
z^{\prime}=\frac{S}{\eta}
$$


Desta forma, de (3.6) e (3.4) vem que:

$$
q_{b}=\frac{1}{f} K_{0} e^{-f\left(\frac{s}{\eta}\right)} \tan (\beta)
$$

O termo $f / \eta$ pode ser substituído por $1 / m$, pois ambos são parâmetros e não tem dependência com variáveis da bacia, e desta forma $m$ ainda representa um parâmetro de decaimento da condutividade. Com este mesmo procedimento, $K_{0} / f$ pode ser substituído por $T_{0}$, a transmissividade para profundidade zero (superfície), então a equação (3.7) para cada célula da bacia fica:

$$
q_{b i}=T_{0} e^{-\left(\frac{S}{m}\right)} \tan (\beta i)
$$

IORGULESCU e JORDAN (1994) citam que no modelo é considerada a hipótese de déficit negativo para casos de saturação. $O$ parâmetro $m$ representa a camada ativa do solo que irá contribuir para a geração do escoamento. Valores elevados de $m$ indicam uma camada mais espessa e resulta em um processo mais lento de geração de vazão. O parâmetro $T_{0}$ representa a transmissividade lateral do solo. Altos valores de $T_{0}$ representam um solo permeável e favorecem a rápida propagação da água subterrânea e uma queda abrupta no hidrograma. A vazão especifica para cada célula fica:

$$
q_{b i}=r_{i} a_{i}
$$

Onde $r_{i}$ é a taxa de precipitação sobre a célula $i$ e $a_{i}$ é área drenada por unidade de comprimento $\left(a c_{i}^{\prime} / c l_{i}\right)$.

De (3.8) e (3.9) vem que:

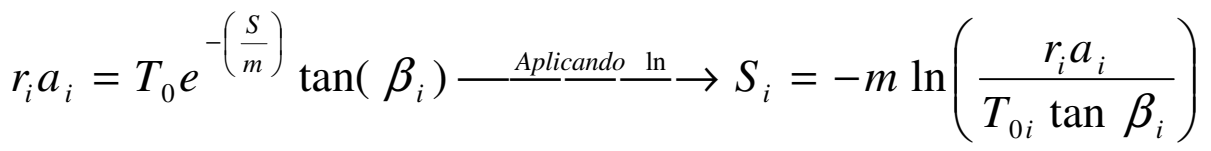

$$
\begin{aligned}
& S_{i}=-m \ln \left(\frac{r_{i} a_{i}}{T_{0 i} \tan \beta_{i}}\right)=-m \ln \left(\frac{r_{i}}{T_{0 i}}\right)-m \ln \left(\frac{a_{i}}{\tan \beta_{i}}\right)
\end{aligned}
$$


$\mathrm{Na}$ Eq. 3.11, observa-se que o déficit é função de dois termos. O primeiro é diretamente dependente da taxa de precipitação sobre a célula e da transmissividade saturada na superfície para aquela célula. No segundo termo, observa-se a dependência do déficit com a declividade de um elemento de área. Este termo $\left(\ln \left(\frac{a_{i}}{\tan \beta_{i}}\right)=\lambda_{i}\right)$ é o índice topográfico de BEVEN e KIRKBY (1979), que caracteriza regiões que possuem o mesmo valor deste índice, como regiões com resposta hidrológica semelhantes.

Baseado nesta hipótese, o modelo computa em forma de histograma, frações da área total da bacia com os mesmos valores do índice topográfico, e efetua os cálculos de déficit para grupos ou classes destes índices. Elimina-se desta forma, a necessidade de cálculo célula a célula dos processos de geração de vazão e aumenta-se significativamente o desempenho computacional. Desde que o modelo considere apenas a variação espacial dos parâmetros de topografia, o déficit de saturação a ser utilizado deve ser um valor médio para a bacia:

$$
S=\frac{1}{A} \int_{1}^{A} S_{i} d A=\frac{1}{A} \int_{1}^{A}\left\langle-m \ln \left(\frac{r_{i}}{T_{0 i}}\right)-m \ln \left(\frac{a_{i}}{\tan \beta_{i}}\right)\right\rangle d A
$$

Como na formulação do TOPMODEL $\frac{d r_{i}}{d A}=0$ e $\frac{d T_{0}}{d A}=0$, a Eq. 3.12 fica:

$$
\begin{aligned}
& \bar{S}=-m \ln \left(\frac{R}{T_{0}}\right)-m \frac{1}{A} \int_{1}^{A} \ln \left(\frac{a_{i}}{\tan \beta_{i}}\right) d A \cong \\
& -m \ln \left(\frac{R}{T_{0}}\right)-m \frac{1}{A} \sum_{1}^{N} \ln \left(\frac{a_{i}}{\tan \beta_{i}}\right) a_{i}^{\prime}=-m \ln \left(\frac{R}{T_{0}}\right)-m \bar{\lambda}
\end{aligned}
$$

Onde $\frac{1}{A} \sum_{1}^{N} \ln \left(\frac{a_{i}}{\tan \beta_{i}}\right) a_{i}{ }^{\prime}=\bar{\lambda}$ pode ser considerado o índice topográfico médio da bacia. 
A condição de saturação ocorre quando o déficit de armazenamento é menor ou igual a zero $\left(S_{i} \leq 0\right)$, ou:

$$
-m \ln \left(\frac{R}{T_{0}}\right)-m \overline{\lambda_{i}} \leq 0
$$

De (3.13) vem que:

$$
\frac{R}{T_{0}}=e^{-\left[\frac{(\bar{S}+m \bar{\lambda})}{m}\right]}
$$

A Equação (3.14) pode ser reescrita como:

$$
\begin{aligned}
& -m \ln \left(e^{-\left[\frac{(\bar{S}+m \bar{\lambda})}{m}\right]}\right)-m \lambda_{i} \leq 0 \Rightarrow-m\left(-\left[\frac{\bar{S}+m \bar{\lambda}}{m}\right]\right)-m \lambda_{i} \leq 0 \\
& \Rightarrow-\bar{S}-m \bar{\lambda}-m \lambda_{i} \leq 0
\end{aligned}
$$

Chegando a condição necessária para a ocorrência de saturação:

$$
\lambda_{i}=\ln \left(\frac{a_{i}}{\tan \beta_{i}}\right) \geq \frac{\bar{S}}{m}-\bar{\lambda}
$$

Segundo BEVEN et al. (1995), elementos de terreno com alto grau de declividade apresentam menor disposição para gerar escoamento, enquanto que elementos localizados em regiões de convergência são propícios a geração de escoamentos sobre os mesmos. Na Fig. 3.7 observa-se o esquema do modelo para a compartimentação do solo em camadas que representam os reservatórios e a aproximação do gradiente de potencial hidráulico a inclinação do elemento de área. 


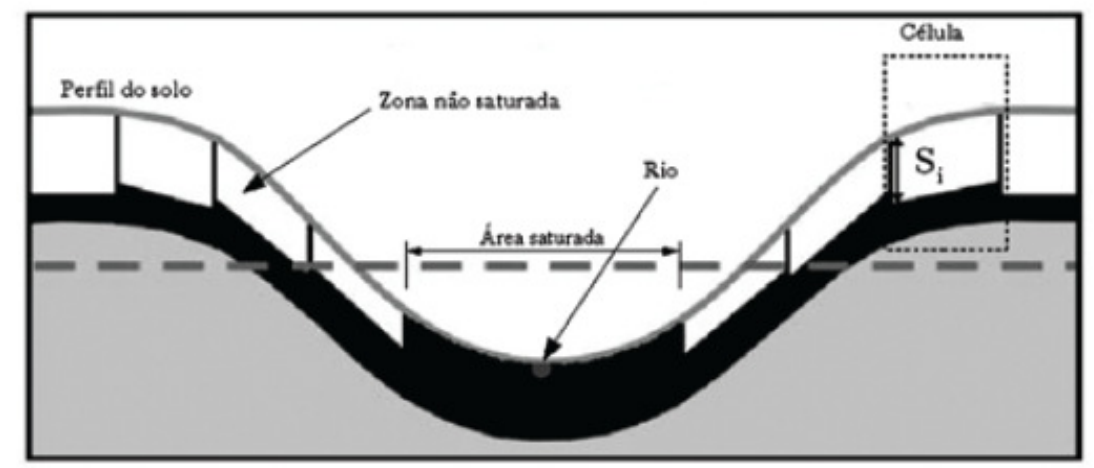

- - Índice topográfico médio: $\lambda=\frac{1}{\mathrm{~A}} \sum_{\mathrm{i}=1}^{\mathrm{N}} \ln \left(\frac{\mathrm{a}_{\mathrm{i}}}{\tan \beta_{\mathrm{i}}}\right) \mathrm{a}^{\prime}{ }_{\mathrm{i}}$

Zona saturada

Camada impermeável

Figura 3.7: Índice topográfico médio e déficit local.Fonte: SILVA, 2005.

\subsubsection{Escoamento Subsuperficial na Zona não saturada $\left(q_{v}\right)$}

O fluxo entre os reservatórios $S_{U Z}$ e $S_{S Z}$ é expressa por BEVEN (1995) como:

$$
q_{v i}=\frac{S_{U Z}}{S_{i} T_{D}}
$$

Onde $S_{U Z}$ é o armazenamento na zona não saturada $(\mathrm{m})$;

$T_{D}$ é um parâmetro do modelo que representa o retardo da frente de umidade entre as zonas não-saturada e saturada $(\mathrm{h} / \mathrm{m})$;

$S i$ é o déficit de saturação local $(m)$.

Nota-se da Eq. 3.18 que o fluxo na zona não saturada é representada linearmente pelo déficit local de saturação. HORNBERGER et al. (1985) cita que o escoamento vertical é significativo apenas em regiões com valores de saturação acima da capacidade de campo $\left(S_{R \max }\right)$. Desta forma, este fluxo ocorre somente após o reservatório da zona de raízes $\left(S_{R Z}\right)$ se apresentar completamente preenchido. A partir deste momento, o volume é deslocado para a zona saturada. $\mathrm{O}$ parâmetro $T_{D}$ é tempo de retardo. SCHULER et al. (2000) citam que baixos valores de $T_{D}$ representam um solo bastante permeável, o que ocasiona uma intensa 
percolação entre as zonas não saturadas e saturadas. Desta forma, para valores elevados de $T_{0}$ (alta permeabilidade), são necessários valores também elevados de $T_{D}$ para causar um atraso significativo e uma possível boa representação do escoamento de base. BEVEN et al.(1995) propôs um novo equacionamento para a recarga da zona saturada por unidade de célula, baseada na lei de Darcy:

$$
q_{v i}=\nabla \Phi K_{0} e^{-f z^{\prime}}
$$

Onde, $\nabla \Phi$ é o gradiente de potencial hidráulico efetivo;

$z^{\prime}$ é a profundidade da camada impermeável;

$K_{0}$ é a condutividade hidráulica saturada.

Como uma das hipóteses do modelo, é que a recarga da zona saturada é uniforme para toda a bacia, a recarga total $Q_{v}$ dever ser a somatória de todas as células que se encontram em estado de saturação:

$$
Q_{v}=\sum_{i=1}^{N} q_{i v} A_{i}
$$

Onde, $N$ é o número de classes de índice topográfico;

$A_{i}$ é a área percentual associado à classe do índice topográfico.

O reservatório $S_{R Z}$ (reservatório da zona de raízes) representa no modelo somente a precipitação interceptada pela vegetação, desta forma não influencia nos fluxos entre os reservatórios não saturados e saturados (FRANCINI et al. ,1996). Quando valores de déficit de saturação são positivos neste reservatório, a percolação não ocorre, e a única maneira deste reservatório ser esvaziado é por meio de da taxa de evapotranspiração por passo de tempo, fornecida como variável de entrada. Este esvaziamento ocorre na taxa:

$$
E_{a}=E_{p}\left(1-\frac{S_{R Z}}{S_{R \max }}\right)
$$

Onde $E_{p}$ é a evapotranspiração potencial fornecida. 


\subsubsection{Escoamento Superficial $\left(q_{o f}\right)$}

O escoamento superficial ocorre somente para as células, ou para os valores de índice de similaridade hidrológico, em condição de saturação $\left(S_{U Z} \geq S_{i}\right)$ em determinado passo de tempo:

$$
q_{o f i}=r_{i} a_{S A T i}^{\prime}
$$

Onde, $r_{i}$ é a taxa de precipitação $(m / d t)$;

$a_{S A T i}^{\prime}$ é a área saturada da bacia;

\subsubsection{Propagação do escoamento}

O escoamento superficial gerado é propagado pela bacia a partir de uma variante do método de tempo-área de Clark. Admite-se propagação à velocidade constante $R V$ e o tempo necessário para a vazão em um ponto $i$ alcançar a saída da bacia é dado por:

$$
t_{C}=\sum_{i=1}^{N} \frac{l i}{R V \tan \beta_{i}}
$$

Onde, $l i$ é o comprimento $(m)$ do segmento do escoamento com declividade igual a $\tan \beta_{i}$.

$N$ é o numero de segmentos e $R V(\mathrm{~m} / \mathrm{h})$ é a velocidade de "roteamento". SILVA (2005) citando BEVEN e KIRKBY (1979), diz que esta relação é satisfatória para bacias menores que $1.000 \mathrm{~km}^{2}$. 


\subsubsection{Composição dos hidrogramas}

Para computar o escoamento total, é necessário obter a somatória dos fluxos de cada um dos escoamentos descritos até o momento, desta forma, o escoamento subsuperficial total é:

$$
Q_{b}=\sum_{i=1}^{N} q_{b, l} l_{i}
$$

Onde, $l_{i}$ é o comprimento do trecho de cada canal $i$;

Né o número de canais.

Substituindo (3.8) em (3.24) vem que:

$$
Q_{b}=\sum_{i=1}^{N} l_{i} T_{0} e^{-\left(\frac{s_{i}}{m}\right)} \tan \left(\beta_{i}\right)
$$

Combinando (3.13) e (3.15) temos:

$$
S_{i}=S+m\left(\bar{\lambda}-\lambda_{i}\right)
$$

Substituindo (3.26) em (3.25):

$$
Q_{b}=\sum_{i=1}^{N} l_{i} T_{0} e^{-\left(\lambda_{i}-\frac{\bar{s}}{m}-\bar{\lambda}\right)} \tan \left(\beta_{i}\right)
$$

Ou para toda a área:

$$
Q_{b}=\sum_{i=1}^{N} a_{i} l_{i} e^{\ln \left(T_{0}\right)} e^{-\left(\frac{\bar{S}}{m}-\bar{\lambda}\right)}
$$

Onde $\sum_{i=1}^{N} a_{i} l_{i}$ é a área de contribuição total da bacia (A), a equação (3.28) fica: 


$$
Q_{b}=A e^{\ln \left(T_{0}\right)} e^{-\bar{\lambda}} e^{-\left(\frac{\bar{S}}{m}\right)}
$$

A taxa de recarga da zona saturada é dada por:

$$
Q_{v}=\sum_{i=1}^{N} q_{v i} a_{i}^{\prime}
$$

O escoamento superficial total é computado a partir das regiões que se encontram em situação de saturação:

$$
Q_{o f}=\sum_{i=1}^{N} r_{i} a_{S A T i}^{\prime}
$$

Como a precipitação é considerada constante para toda a bacia, (3.31) pode ser escrita como:

$$
Q_{o f}=R \sum_{i=1}^{N} a_{S A T i}^{\prime}
$$

Com base BEVEN et al. (1995), BEVEN (1997), BEVEN (2001) e HORNBERGER et. al. (1998), SANTOS (2000) resumiu a base conceitual do modelo, seus principais componentes são: armazenamento e fluxo na zona não saturada, armazenamento e fluxo na zona saturada e propagação de fluxo na bacia. As hipóteses são descritas:

i- A dinâmica da zona saturada pode ser obtida por sucessivas representações do estado permanente ("steady-state");

ii- Gradiente hidráulica da zona saturada pode ser representada pela declividade da topografia local;

iii- A variabilidade horizontal da transmissividade é zero, porém varia exponencialmente com o déficit de armazenamento e com a profundidade do lençol de água. Mudanças verticais das propriedades hidráulicas de muitos tipos de solo podem ser explicadas pelo declínio exponencial na condutividade vertical do solo (BEVEN, 1986);

iv- A taxa de recarga $(\mathrm{m} / \mathrm{h})$ da zona saturada é homogênea no espaço para um determinado passo de tempo.

$v$ - A precipitação pode ser considerada uniforme sobre a bacia. 


\subsubsection{Versão utilizada}

Neste trabalho foi utilizado a implementação do modelo TOPMODEL em linguagem R. A versão 0.7.0 disponibilizada no dia 16 de Agosto de 2009 no sitio do projeto $R$ (http://cran.r-project.org/). Esta implementação foi inspirada inicialmente na versão 95.02 disponibilizada em FORTRAN. As vantagens da utilização desta versão em linguagem $R$ são:

- Continuidade do software: Com constantes releases, o modelo está em constante atualização e conseqüentemente melhorias são implementadas a cada nova versão;

Automatização: com sintaxe similar a linguagens consagradas como $\mathrm{C}$ ou MATLAB, o modelo possui a possibilidade de ser automatizado em batch com facilidade;

- $\quad$ Tempo de processamento: Com processadores de níveis mais elevados, a conseqüência de se utilizar linguagem de baixo nível, não interfere na eficiência computacional do modelo;

- Integração gráfica: Com uma poderosa interface para geração de gráficos e figuras, o pós-processamento pode ser automatizado juntamente com o modelo, assim como estatísticas em relação ao resultado.

Os parâmetros do modelo nesta versão são:

Tabela 3.1: Parâmetros utilizados pelo modelo TOPMODEL.

\begin{tabular}{|c|c|}
\hline Parâmetro & Significado \\
\hline qs0 & Fluxo sub superficial inicial $\left[m h^{-1}\right]$ \\
\hline $\ln T e$ & $\begin{array}{l}\text { Logaritmo da média de T0 para toda } \\
\text { a area a bacia }\left[\mathrm{m}^{2} \mathrm{~h}^{-1}\right]\end{array}$ \\
\hline $\mathrm{m}$ & $\begin{array}{l}\text { Parâmetro que descreve a taxa de decaimento da } \\
\text { transmissividade com o perfil }[\mathrm{m}]\end{array}$ \\
\hline SrO & Déficit inicial na zona de raízes $[\mathrm{m}]$ \\
\hline Srmáx & Déficit máximo da zona de raízes [ $\mathrm{m}]$ \\
\hline $\mathrm{Td}$ & $\begin{array}{l}\text { Tempo de resposta da frente de umidade na zona } \\
\text { não-saturada, em termos de déficit }\left[\mathrm{h} \mathrm{m}^{-1}\right]\end{array}$ \\
\hline vch & Velocidade do fluxo no canal principal [ $m h-1]$ \\
\hline $\mathrm{vr}$ & Velocidade de roteamento das sub-bacias [ $m$ h-1] \\
\hline k0 & Condutividade hidráulica vertical média da superfície [ $m h-1]$ \\
\hline $\mathrm{dt}$ & Passo de tempo (h) \\
\hline
\end{tabular}




\subsection{7. Índice de Similaridade Hidrológico da bacia do Rio Pirajuçara}

Os processos para o delineamento da bacia e extração da são necessários para o calculo do índice topográfico e geração do histograma de freqüências da fração da área versus índice topográfico. Os procedimentos estão descritos no apêndice $A$. $O$ índice de similaridade hidrológico foi calculado para toda a bacia e a distribuição de freqüência do mesmo em função da área total de drenagem pode ser encontrada na Fig. 3.8. Para o cálculo foram utilizadas as funções topidx e make.classes do software R, pacote topmodel. Na Fig. 3.9, observa-se a distribuição espacial do índice topográfico calculado a partir da função topidx. Os maiores valores deste índice estão relacionados com regiões de baixa declividade, e são mais propensos a geração de vazão (BEVEN et al., 1995).

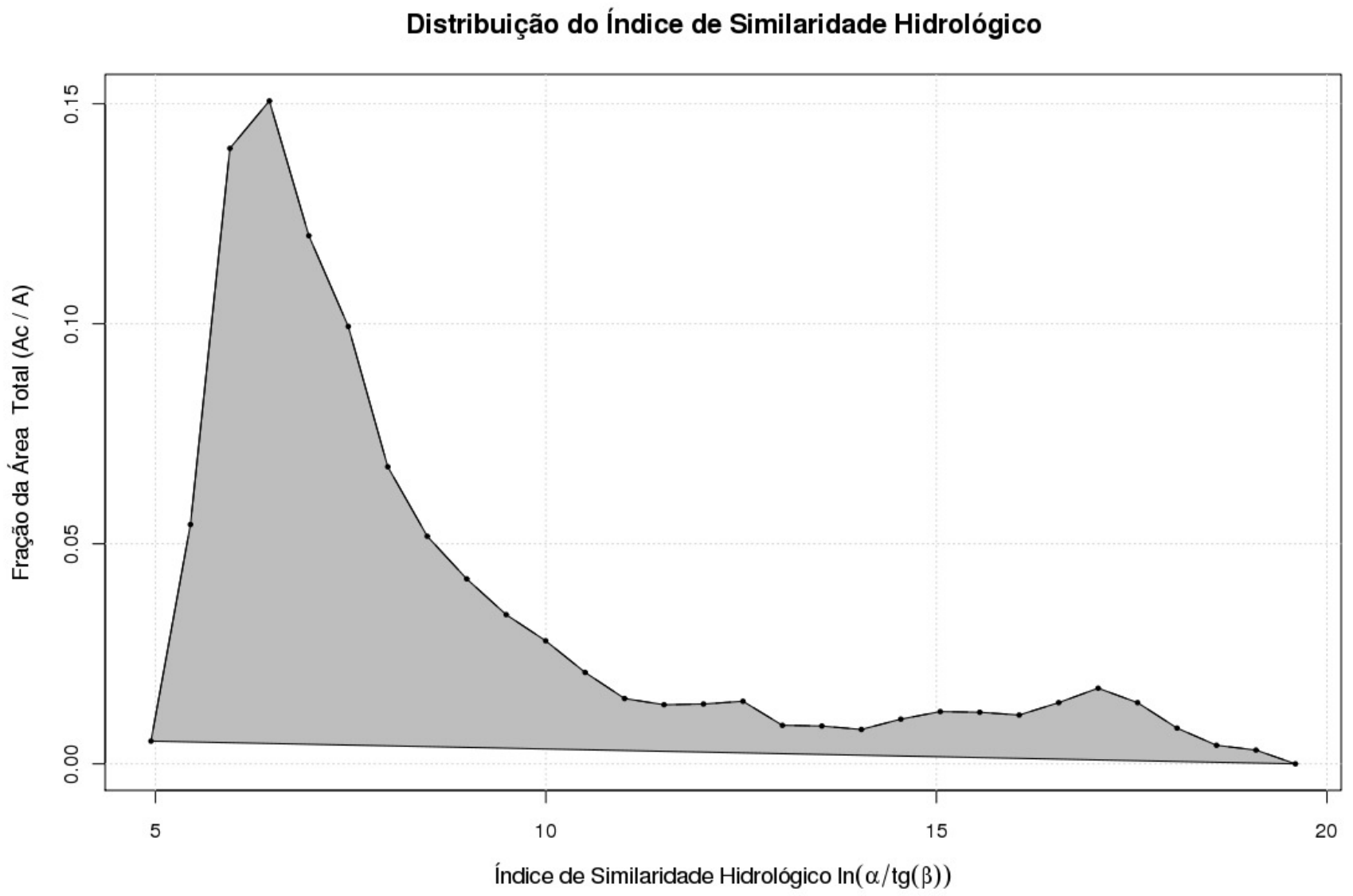

Figura 3.8: Distribuição de freqüência do índice de similaridade hidrológico da bacia do Rio Pirajuçara, para 30 classes de valores. 


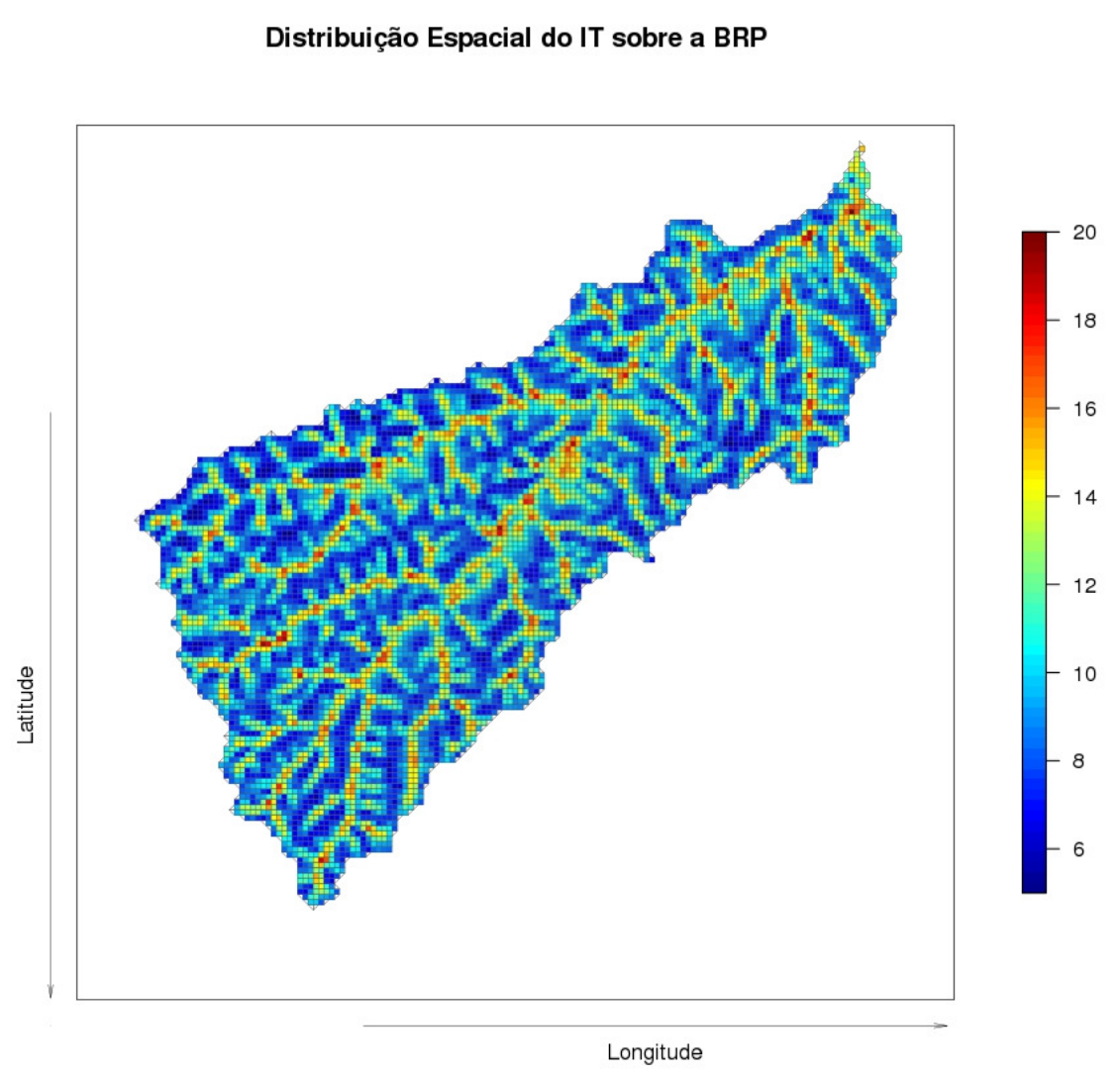

Figura 3.9: Distribuição espacial do índice topográfico sobre a BRP. A área sombreada representa a distribuição espacial dos valores do índice de similaridade hidrológica.

Como o ponto de medição utilizado no trabalho não se localiza no exutório da bacia, escolheu-se utilizar para o cálculo da distribuição do índice topográfico, apenas a porção a montante do posto que contribua para o escoamento. $O$ resultado deste segundo "corte" na área utilizada pode ser observado na Fig. 3.10 


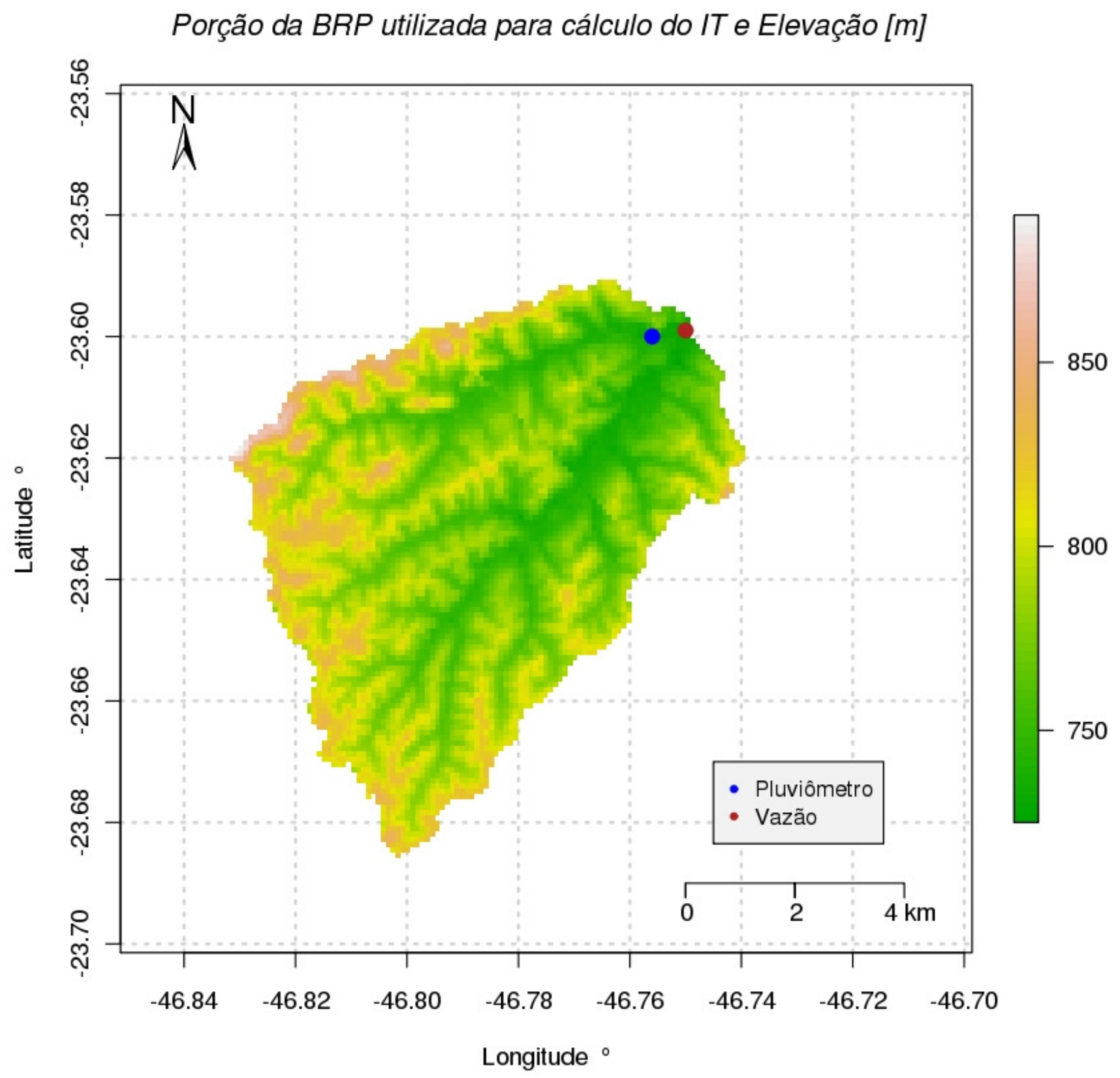

Figura 3.10: Porção utilizada para o cálculo final do índice topográfico. A área sombreada representa a elevação do terreno (metros). Os pontos, vermelho e azul, representam os pontos de medição de altura do nível da água e precipitação, respectivamente. A área sombreada representa a elevação da BRP em metros. Fonte: SRTM, organização ROCHA FILHO, 2010. 


\subsection{Rede Telemétrica do Alto Tietê}

Os dados de telemetria utilizados fazem parte da Rede Telemétrica do Alto Tietê (BRAGA, 1989) de propriedade do Departamento de Águas e Energia Elétrica do estado de São Paulo (DAEE) e operada pelo Sistema de Alerta a Inundações de São Paulo (SAISP). A Rede Telemétrica do Alto Tietê conta atualmente com 42 postos (Fig. 3.11) operando ininterruptamente e coletando informações com resolução temporal de dez minutos em modo normal.

\section{Rede Telemétrica do Alto Tietê}

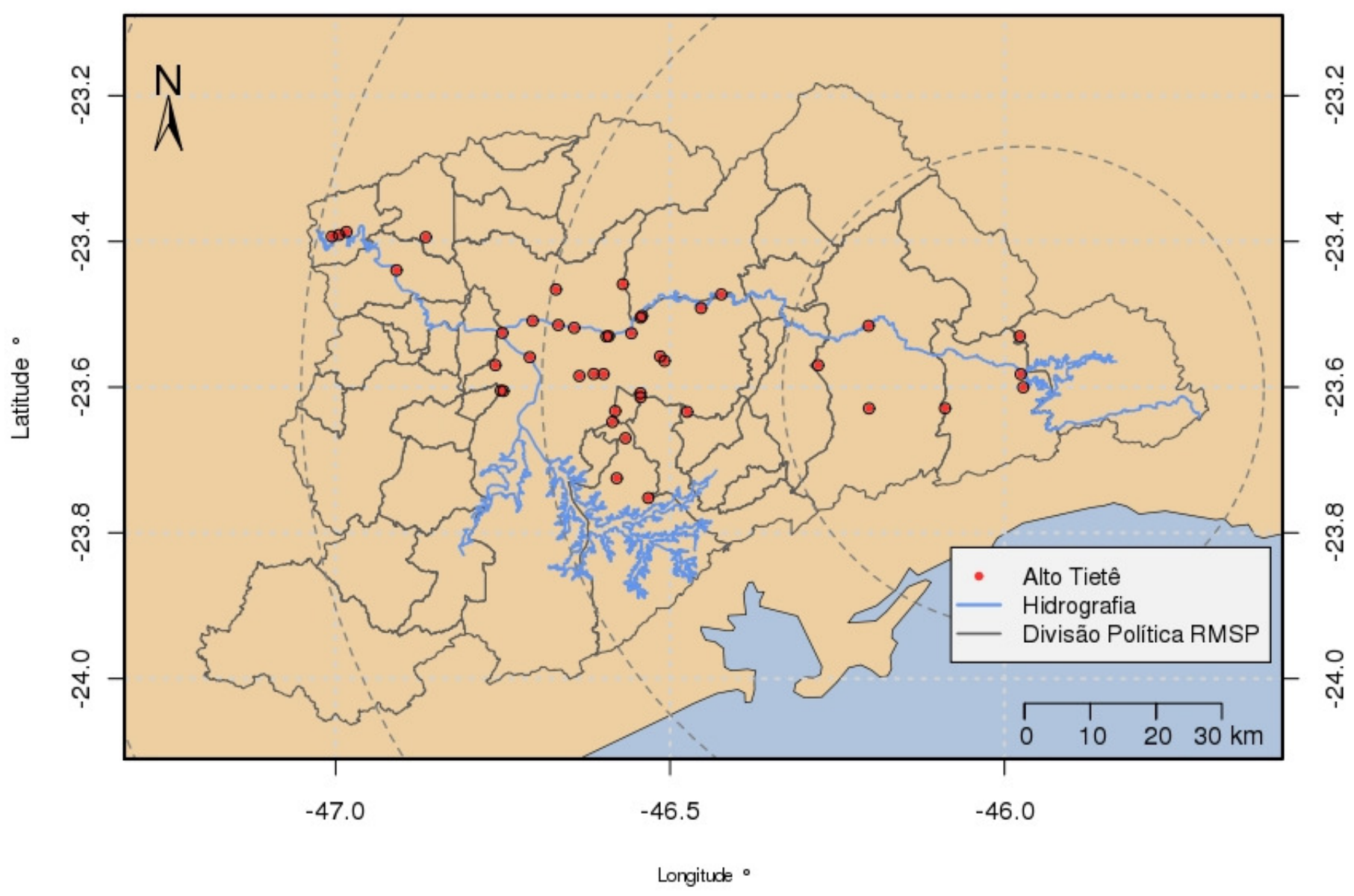

Figura 3.11: Disposição física dos postos da rede do Alto Tietê. Os pontos vermelhos representam os postos telemétricos da RAT, as linhas azuis representam a hidrografia dos Rios Tietê e Pinheiros, as linhas pontilhadas representam os raios concêntricos de $40 \mathrm{~km}$ do RSP, as linhas contínuas pretas representam a divisão política da RMSP. Fonte: SAISP, IBGE, Organização ROCHA FILHO, 2010. 
Os postos estão instalados em regiões criticas do ponto de vista de inundações na RMSP. Cada posto telemétrico é composto tipicamente por dois instrumentos de medição, um pluviômetro e um medidor de nível d'água (Fig. 3.12 e 3.13 respectivamente).

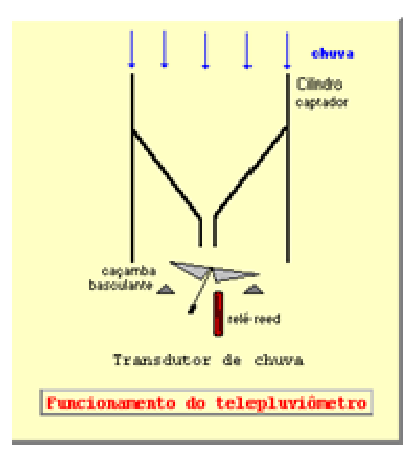

(a)

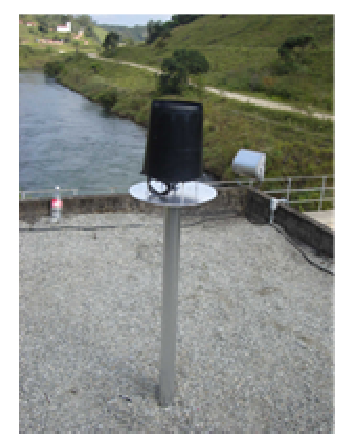

(b)

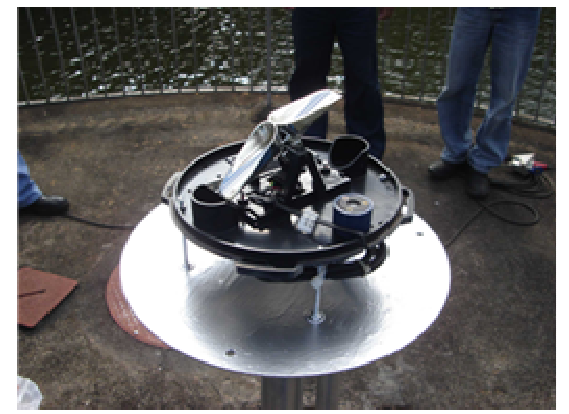

(c)

Figura 3.12: (a) Funcionamento do Pluviômetro de Báscula (Fonte: PISANI,1995), (b) Exemplo da Instalação de um pluviômetro utilizado pelo SAISP, (c) Interior do Pluviômetro.

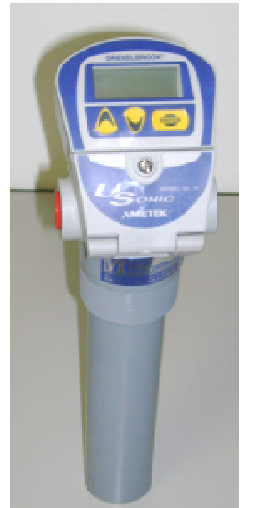

(a)

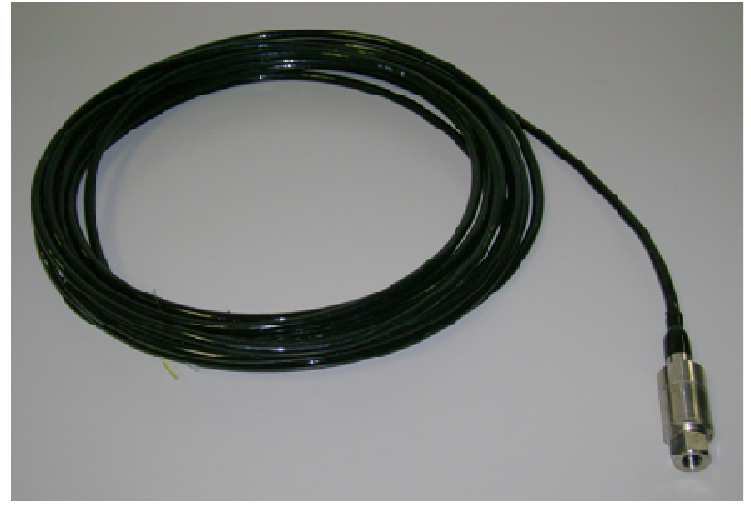

(b)

Figura 3.13 : Sensor de nível por ultra som (a) e sensor de nível de pressão (b).

A água da chuva é coletada por um cilindro padrão e é armazenada num recipiente tipo caçamba basculante, que bascula ao atingir o volume de água correspondente a $0.2 \mathrm{~mm}$ de chuva (Fig. 3.12a). Neste recipiente está acoplado um imã que, no movimento de basculação, passa por um relé emitindo um sinal para a estação remota que incrementa $0,2 \mathrm{~mm}$ ao valor armazenado. As Fig. 3.12b e 3.12c mostram um exemplo de um pluviômetro instalado e seu interior, respectivamente.

Para as medições de nível da lamina d'água, dados são coletados, a cada 10 
minutos, por um transdutor de nível, que pode ser do tipo de pressão (Fig. 3.13a) ou do tipo ultra-som (Fig. 3.13b). O sensor de nível por ultra-som tem como principal vantagem não entrar em contato com a água. O sensor de pressão é utilizado em locais em que não existe a possibilidade de se construir uma estrutura de sustentação para o sensor de nível por ultra-som.

Neste trabalho foi utilizado para a medição de nível, o posto Pirajuçara (Fig. 3.14a) e para a medição de precipitação o posto Córrego Poá (Fig. 3.14b), ambos pertencentes à Rede Telemétrica do Alto Tietê. No local da medição de nível, o Rio Pirajuçara já se encontra totalmente canalizado sob a Avenida Pirajuçara, como se pode observar na fig. 3.14a.

A localização de ambos os postos na Bacia do Rio Pirajuçara pode ser observada na figura 3.15. O posto Pirajuçara se encontra a jusante da confluência do Córrego Poá e foi utilizado para as medições de nível d'água. Para a transformação do nível de água em vazão, foi utilizada a curva-chave levantada após a última intervenção de obras hidráulicas neste trecho da bacia.

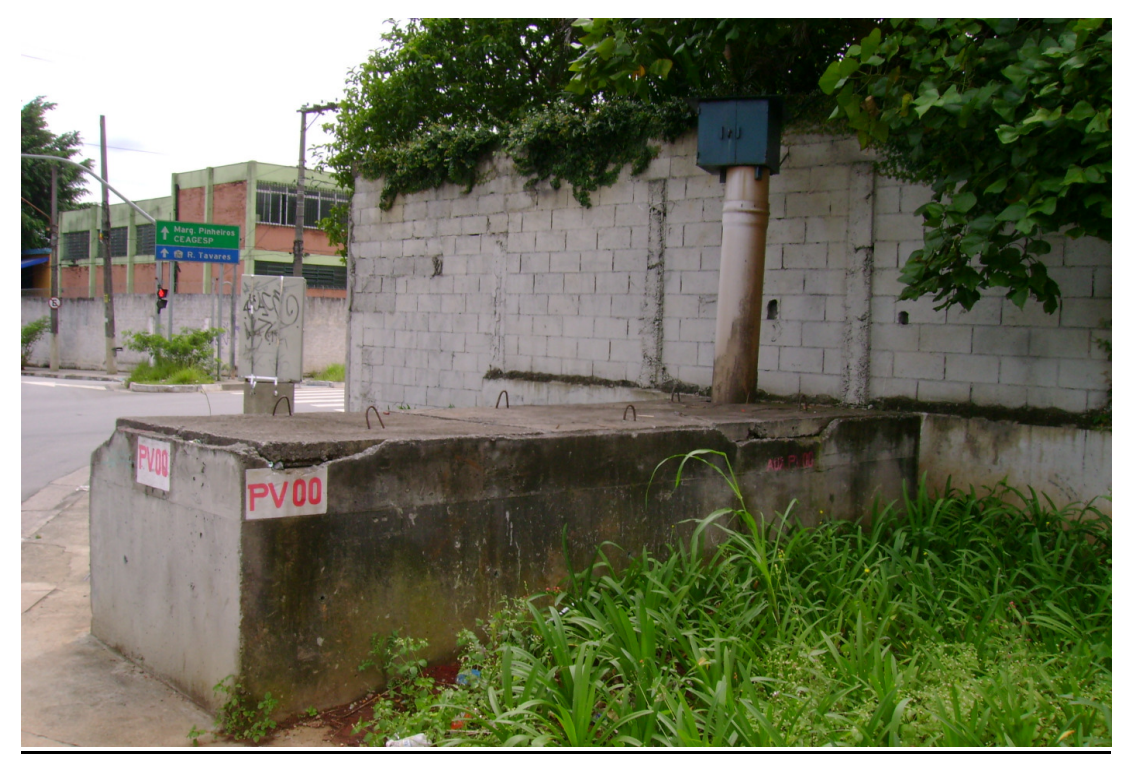

(a)

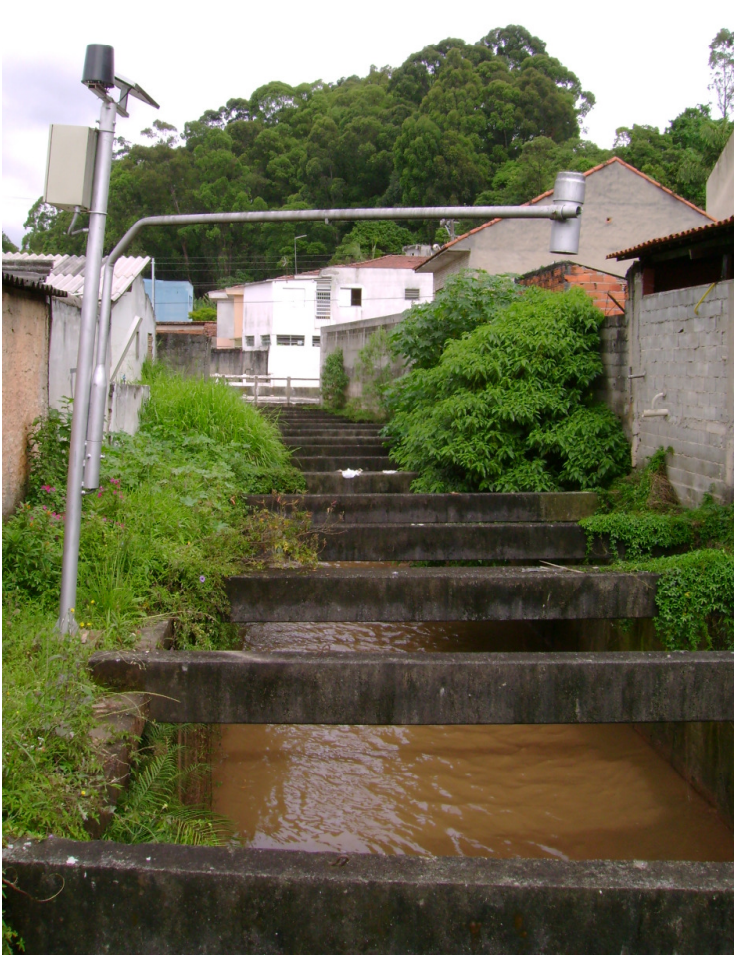

(b)

Figura 3.14: Postos telemétricos utilizados nas medições de: (a) Nível da lâmina d'água, (b) Precipitação. 
Localização dos Postos Telemétricos e Topografia da BRP [m]

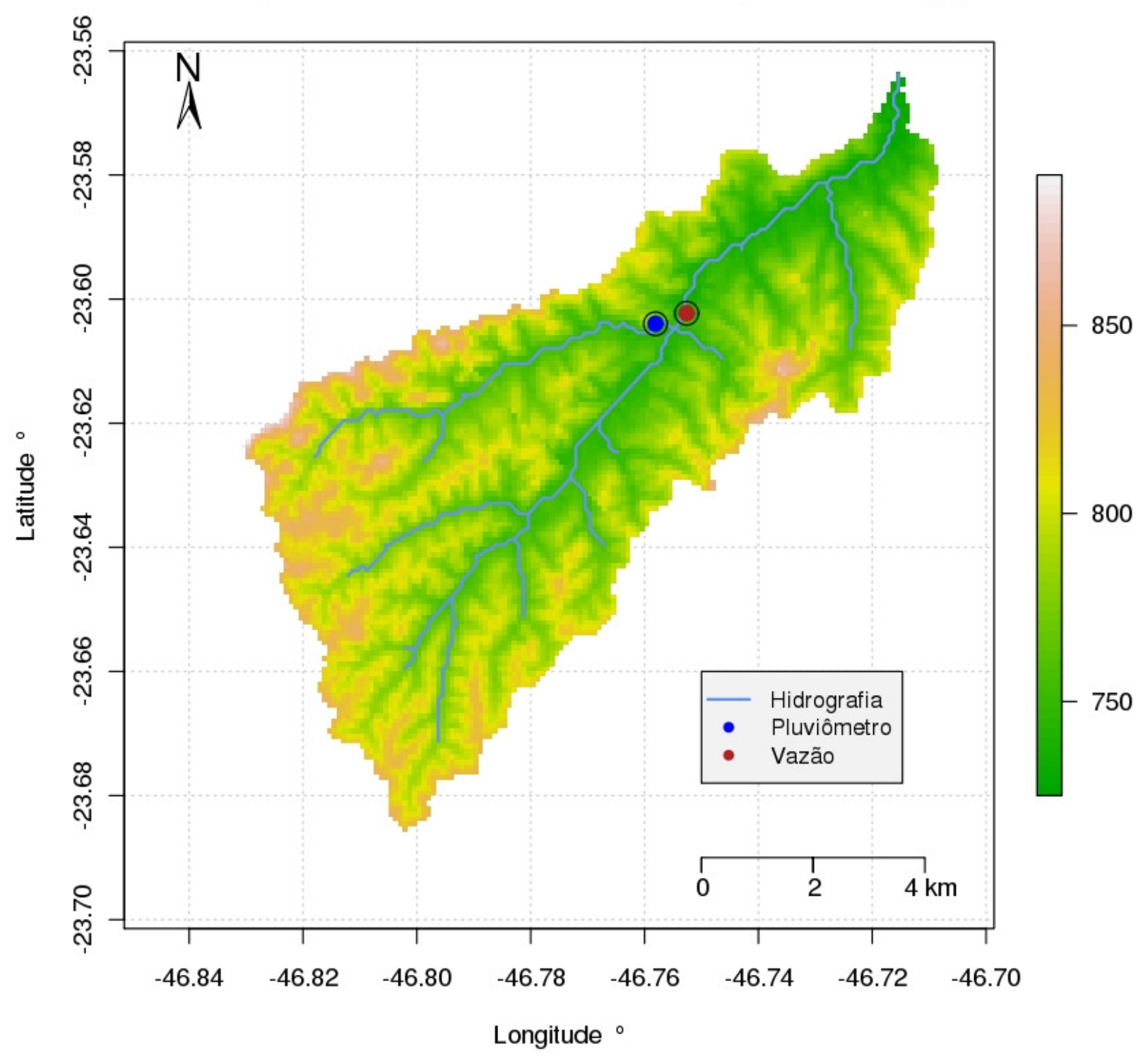

Figura 3.15: Localização dos postos telemétricos utilizados e topografia em metros da Bacia do Rio Pirajuçara. O ponto em azul escuro representa a posição geográfica do posto Córrego Poá. O ponto vermelho é a localização do posto Pirajuçara. As linhas em azul claro representam a hidrografia da BRP. Fonte: SRTM, SAISP, organização ROCHA FILHO, 2010. 


\subsection{Radar Meteorológico de São Paulo}

O Radar Meteorológico de São Paulo (Fig. 3.16) está localizado no município de Biritiba-Mirim (São Paulo), na Barragem de Ponte Nova, cabeceira do Rio Tietê. O radar foi fabricado pela Universidade de McGill do Canadá e é propriedade do Departamento de Águas e Energia Elétrica do Estado de São Paulo (DAEE). Um resumo das características técnicas do radar se encontra na Tabela 3.2. O radar banda S possui uma resolução espacial horizontal padrão de $2 \times 2 \mathrm{~km}$, com raio de alcance quantitativo de $240 \mathrm{~km}$. Pode-se chegar a resolução máxima de $1 \times 1 \mathrm{~km}$, com alcance de $120 \mathrm{~km}$. A área máxima de abrangência é de $129.600 \mathrm{~km}^{2}$ (Fig. 3.17). A resolução espacial vertical possui 18 níveis de amostragem, distribuída entre as alturas de 1.5 e $18 \mathrm{~km}$.

O radar possui uma resolução temporal de cinco minutos em modo chuva, e os dados (volume scans) são transmitidos para a central de processamento no SAISP por meio de uma linha privada de comunicação, onde são processados para geração dos produtos. Para as estimativas de precipitação na bacia foram utilizados os campos de refletividades no formato "Constant Altitude Plain Position" (CAPPI) de $3 \mathrm{~km}$ de altura, com resolução espacial de $2 \times 2 \mathrm{~km}$ e inicialmente transformados em taxa de precipitação $\left(m m h^{-1}\right)$, com a relação Z-R (Eq.. 3.33) de MARSHALL \& PALMER (1948).

$$
Z=200 R^{1,6}
$$

Onde, $Z$ é a refletividade medida pelo radar $(d B z)$;

$\mathrm{R}$ é a taxa de precipitação $\left(m m h^{-1}\right)$. 
Tabela 3.2: Características técnicas do Radar Meteorológico de São Paulo

\begin{tabular}{ll}
\hline Características técnicas do Radar Meteorológico de SP & \\
Freqüência de Operação & 2,7 a 2,9 GHZ - comprimento de onda $(8-10 \mathrm{~cm})$ \\
Potência de Pico & $650 \mathrm{~kW}$ \\
Duração do pulso & $2 \mathrm{mseg}$ \\
Freqüência do pulso & $250 \mathrm{PPS}$ (pulsos por segundo) \\
Ganho da antena & $38,00 \mathrm{DB}$ \\
Largura do feixe & 1.50 \\
Mínimo sinal detectável & $17 \mathrm{dBz}$ \\
Polarização & Vertical \\
\hline
\end{tabular}

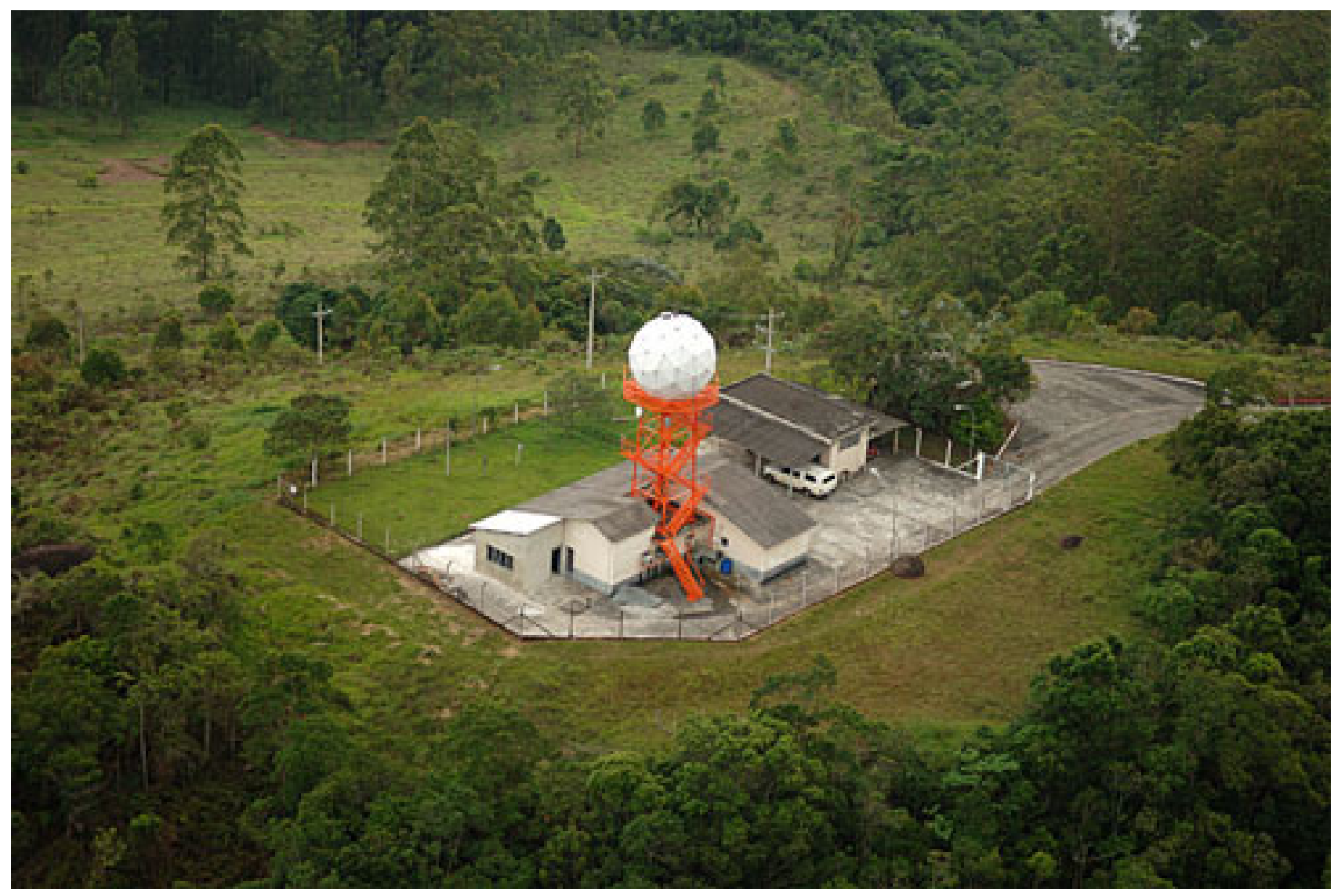

Figura 3.16: Radar Meteorológico de SP - Município de Biritiba Mirim - SP. 


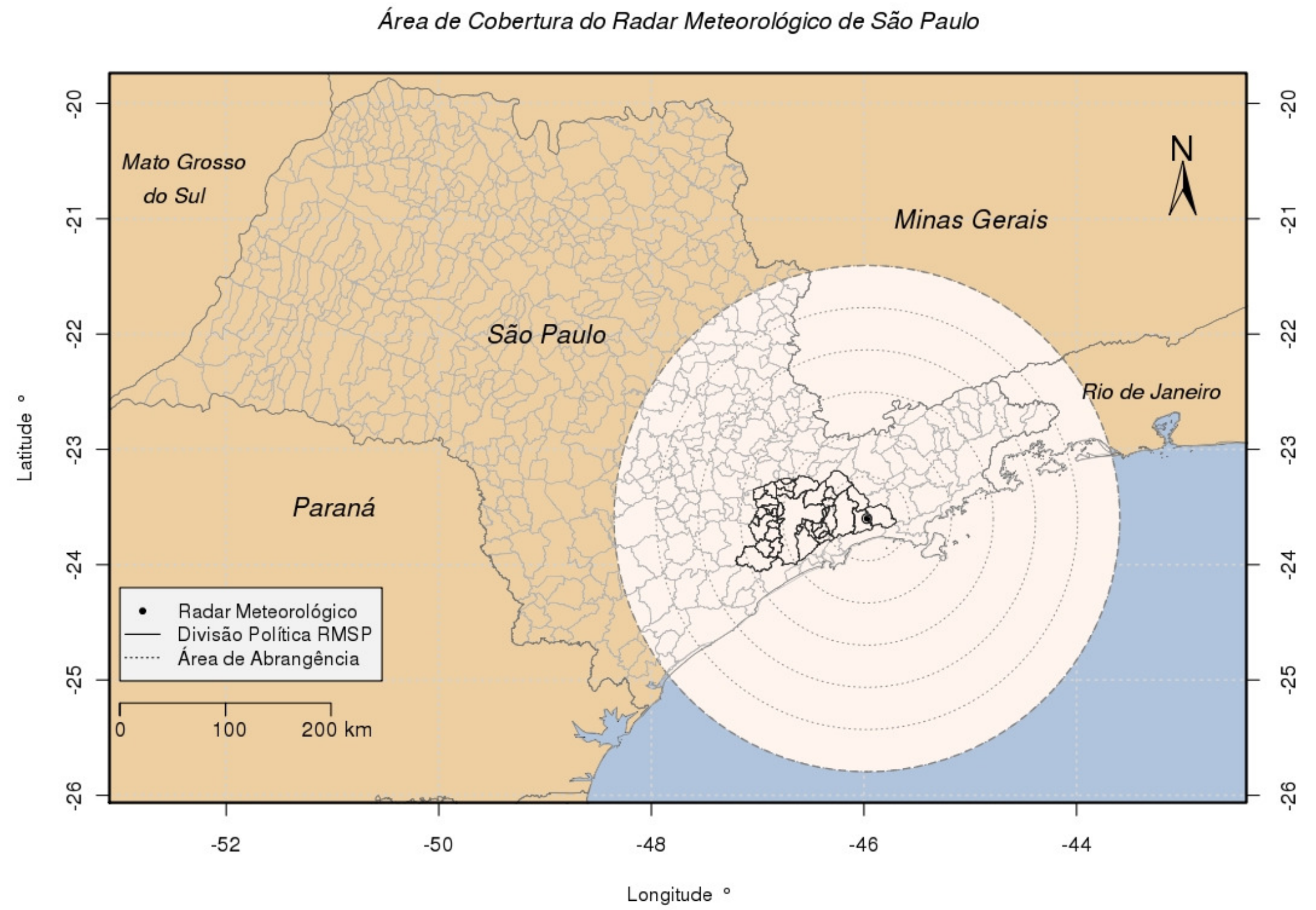

Figura 3.17: Área de Abrangência do Radar Meteorológico de São Paulo. A área sombreada em branco representa a cobertura do RSP, As linhas pontilhadas são os raios concêntricos a cada $40 \mathrm{~km}$. As linhas cinza representam as divisões políticas municipais do Estado de SP e as linhas pretas, as divisões políticas dos estados e da RMSP. Fonte: IBGE, Organização ROCHA FILHO, 2010. 


\subsection{Análise Objetiva Estatística (ANOBES)}

A precipitação é principal forçante dos modelos hidrológicos e deve ser estimada com o menor erro possível. Medidas efetuadas com pluviômetro tendem a subestimar a precipitação, principalmente no final do espectro, devido às limitações mecânicas dos mesmos (LEGARTES e DELIBERTY, 1993). O radar meteorológico apresenta, igualmente, erros inerentes a medição da precipitação, citadas no item 2.2 .

A integração de dados de estimativa de precipitação por radar e dados medidos pluviômetros, é uma ferramenta que visa minimizar os erros que ocorrem em ambos os tipos de medição. Uma das metodologias utilizadas para este tipo de integração foi a denominada Análise Objetiva Estatística (ANOBES) (PEREIRA FILHO e CRAWFORD, 1995).

O esquema ANOBES é um dos mais eficientes esquemas de interpolação de dados existentes. Este método foi inicialmente desenvolvido por GANDIN (1963 apud PEREIRA FILHO e CRAWFORD, 1995) e posteriormente recomendado pela Organização Meteorológica Mundial, para interpolação de dados hidrometeorológicos. Este método de interpolação foi pouco aplicado operacionalmente até recentemente (CRAWFORD, 1979; CREUTIN e OBLED, 1982) devido às limitações de processamento.

A precipitação analisada num dado ponto de grade é obtida da adição entre a precipitação estimada pelo radar no ponto de grade (background) e a soma do produto dos pesos das diferenças entre as precipitações medidas (observadas) e as estimadas pelo radar, respectivamente. O erro da variância é definido pela soma dos quadrados das diferenças entre o valor observado (ou estimado) e o valor verdadeiro (que é desconhecido). Assim, os pesos das análises são derivados da variância do erro da estimativa de precipitação do radar (variância do erro de fundo ou de background). As propriedades estatísticas dos sistemas precipitantes são incorporadas nas análises tais que a variância do erro da analise é menor do que a variância mínima do erro da observação.

SILVA (2006) demonstrou que na área de abrangência do RSP, o viés do radar em comparação com a precipitação medida pela telemetria é normalmente positivo, e ainda, que ocorre uma significante correlação espacial destes erros para 
diferentes tipos de sistemas precipitantes. Foi mostrado que a ANOBES reduziu significantemente os erros apresentados.

MOREIRA (2005) utilizou esta mesma técnica para a modelagem hidrológica da Bacia do Rio Barigui no Paraná, demonstrando que as vazões simuladas com medidas de telemetria perdem eficiência para eventos isolados e vazões simuladas com medidas de precipitação de um radar meteorológico tendem a subestimar a vazão simulada ou produzir resultados imprecisos. Desta forma, o autor realizou a integração das medidas com a técnica ANOBES e mostrou que as melhoras na eficiência do modelo foram significativas.

\subsubsection{Esquema da ANOBES}

O esquema da ANOBES tem por objetivo, reduzir a variância do erro da análise, frente à estimativa efetuada pelo radar meteorológico. A equação da ANOBES (PEREIRA FILHO et al., 1998) é:

$$
P_{a}\left(x_{i}, y_{i}\right)=P_{r}\left(x_{i}, y_{i}\right)+\sum_{K=1}^{K} w_{i K}\left[P_{p}\left(x_{K}, y_{K}\right)-P_{r}\left(x_{K}, y_{K}\right)\right]
$$

Onde,

$P_{a}\left(x_{i}, y_{i}\right)$ é a precipitação analisada $(m m)$ no ponto de grade $\mathrm{i}$;

$P_{r}\left(x_{i}, y_{i}\right)$ é a precipitação estimada pelo radar $(m m)$ no ponto de grade $\mathrm{i}$;

$P_{p}\left(x_{K}, y_{K}\right)$ é a medida da precipitação do pluviômetro $(\mathrm{mm})$ para uma estação em um ponto $k$;

$P_{r}\left(x_{K}, y_{K}\right)$ é a precipitação estimada pelo radar $(\mathrm{mm})$ para uma estação em um ponto $k$;

$w_{i K}$ é o peso a posteriori;

$k$ = número de pluviômetros;

$(\mathrm{x}, \mathrm{y})$ são as coordenadas em padrão UTM $(\mathrm{km})$. 
Para derivar os pesos, assume-se que os erros de observação e a precipitação estimada pelo radar não têm correlação e não tenham viés. A variância esperada do erro da análise é minimizada em relação aos pesos $W_{i}$. A expressão normalizada para os pesos é dada por:

$$
\sum_{i=1}^{K} W_{i}\left(\rho_{k l}+\varepsilon_{k}^{2}\right)=\rho_{k i}
$$

Onde,

$\rho_{k l}$ é a correlação entre o erro do valor inicial dos pluviômetros $k$ e l;

$\varepsilon_{k}^{2}$ é o erro observacional normalizado;

$\rho_{k i}$ é a correlação entre o erro do valor inicial do pluviômetro $i$ e o ponto de grade $k$.

A normalização é obtida por meio das matrizes das covariâncias dos erros estimados, com algoritmos descritos em DALEY (1991). A normalização pode ser utilizada na estimativa da distribuição espacial da variância do erro da análise e sua redução para cada ponto de análise. A matriz das covariâncias dos erros do valor inicial, utilizada para normalizar as equações 3.34 e 3.35, é a componente mais importante do método ANOBES. A exatidão da análise depende em grande parte desta matriz.

Em PEREIRA FILHO et al. (1998) apud SILVA (2006) se encontra o desenvolvimento completo das equações 3.34 e 3.35. Portanto, o método ANOBES combina simplicidade e robustez para maximizar a precisão da estimativa de chuva em pontos de grade e, ao mesmo tempo, minimizar o erro da análise, tal que este seja menor que o menor erro observacional. As vantagens principais deste método são:

- A variância esperada do erro da análise é minimizada;

- O método ANOBES se utiliza de propriedades estatísticas dos sistemas precipitantes;

- Apenas pontos próximos ao ponto de análise são utilizados na interpolação;

- O método é simples e relacionado às propriedades físicas de interesse; 


\subsubsection{Dados Utilizados para integração}

Para a integração, foram utilizados os postos telemétricos operados pela Fundação Centro Tecnológico de Hidráulica. A especificação técnica dos postos é descrita no item 3.3. Foi utilizado um total de 28 estações telemétricas e a disposição física das estações selecionadas pode ser vista na Fig. 3.18.

No modelo TOPMODEL utiliza-se a precipitação média na bacia. As estimativas com o RSP e a precipitação integrada com ANOBES possuem espaçamento regular de grade. Desta forma, utilizou-se a média aritmética das quadrículas (Eq. 3.36) sobre a bacia. Somente as quadrículas do RSP sobre a área mostrada na Fig. 3.10, pois a precipitação ocorrida à jusante deste ponto não contribui para a geração do escoamento na secção de medição do nível d'água. No caso da precipitação medida pela telemetria, foi utilizado somente um ponto de medição interno à bacia.

$$
P_{M}=\frac{1}{N} \sum_{i=1}^{N} P_{i}
$$

Onde,

$P_{M}$ é a precipitação média na bacia.

$P_{i}$ é a precipitação na quadrícula $i$.

Né o número de quadrículas sobre a bacia. 


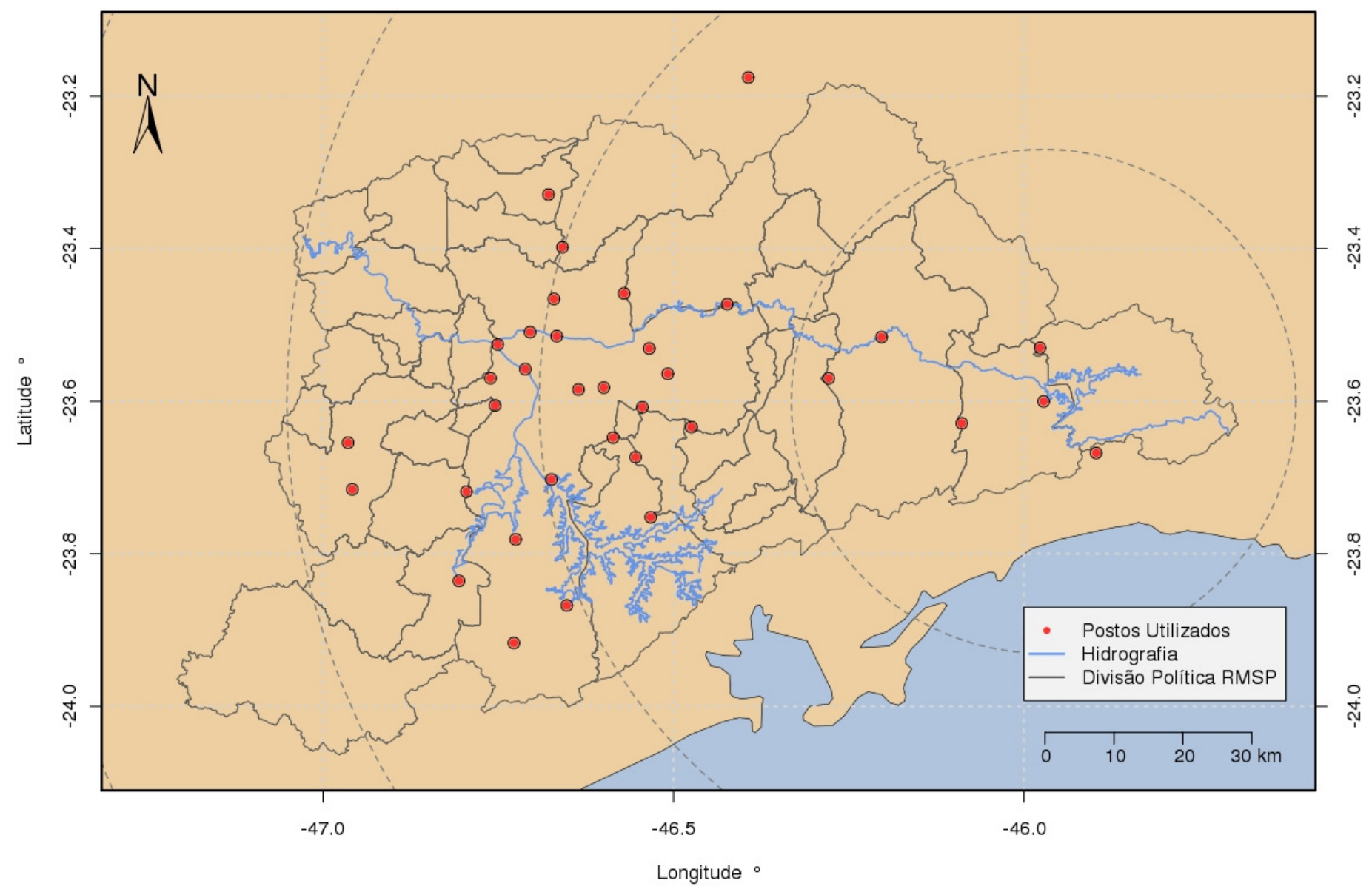

Figura 3.18: Disposição física dos postos telemétricos utilizados na integração sobre a Região Metropolitana de São Paulo. Os pontos em vermelho indicam a localização geográfica dos postos telemétricos. As linhas azuis mostram a hidrografia dos principais Rios da BAT. As linhas pontilhadas são os raios concêntricos de $40 \mathrm{~km}$ a partir do RSP. 


\subsubsection{Procedimento para integração}

O processo de integração foi dividido em cinco partes. Todos os passos foram executados a partir de códigos escritos em linguagem Fortran 90, abaixo o procedimento;

i) Seleção e classificação dos eventos: Selecionados os eventos que causaram impactos relevantes na bacia, os mesmo foram classificados pelo tipo, como $\mathrm{Cl}$ (Convecção Isolada), BM (Brisa Marítima), BD (Banda Dispersa), FF (Frente Fria) ou LI (Linha de instabilidade), com a finalidade da inclusão das características estatísticas de cada tipo de sistema na análise objetiva.

ii) Seleção dos postos utilizados na integração: procurou-se selecionar os postos com o critério de distribuição espacial uniforme (Figura 3.18), pois segundo SILVA (2006), o esquema do ANOBES possui melhor eficiência para redes com este tipo de distribuição.

iii) Acumulação da precipitação: Escolheu-se o tempo de acumulação de trinta minutos para a execução da análise. Foi então necessário, o processamento das medições, tanto de radar meteorológico, quanto da telemetria, pois a resolução temporal dos mesmos é de cinco e dez minutos respectivamente.

iv) Efetuada a integração, o resultado da mesma foi comparado ao acumulado pelo radar meteorológico e então gerada a matriz com fatores de correção para cada ponto de grade. A partir desta matriz, aplicou-se a correção para os acumulados de dez minutos do radar meteorológico. $O$ resultado deste processo é a desconvolução da precipitação de 30 para 10 minutos.

v) Finalmente, com a chuva analisada, é calculada a precipitação média sobre a bacia. 


\subsection{Cartas Sinóticas}

Cartas sinóticas de superfície e altitude são produzidas em regime automático pelo grupo de previsão do tempo do CPTEC, diariamente às 0000 UTC. Plotam-se os campos de pressão $(\mathrm{hPa})$, altura geopotencial $(\mathrm{m})$, informações observacionais, tais como, temperatura e temperatura do ponto de orvalho $\left({ }^{\circ} \mathrm{C}\right)$, pressão observada $(\mathrm{hPa})$, direção e intensidade do vento e sistemas desta escala são traçados. Neste trabalho utilizou-se para identificação das condições percussoras dos eventos selecionados posteriormente às simulações com 0 TOPMODEL.

\subsection{Radiossondagens atmosféricas}

Radiossondagens do aeródromo de Campo de Marte são realizadas duas vezes ao dia, às 000UTC e 1200 UTC. Mede-se a velocidade $\left(\mathrm{m} \mathrm{s}^{-1}\right)$ e a direção (graus) do vento, a pressão atmosférica ( $\mathrm{hPa}$ ), a temperatura do $\operatorname{ar}\left({ }^{\circ} \mathrm{C}\right)$ e a umidade relativa do ar (\%). Os arquivos com estas medidas também disponibilizam a altura geopotencial $(m)$, temperatura do ponto de orvalho $\left({ }^{\circ} \mathrm{C}\right)$, razão de mistura do vapor d'água $\left(\mathrm{g} \mathrm{kg}^{-1}\right)$, temperatura potencial $(K)$, temperatura potencial equivalente $(K)$ e temperatura potencial virtual $(K)$. Estes arquivo contêm índices de instabilidade de showalter, de levantamento, $\mathrm{K}$, total totals, energia potencial convectiva disponível [CAPE $\left(\mathrm{J} \mathrm{kg}^{-1}\right)$ ], energia potencial convectiva disponível calculada a partir da temperatura virtual [CAPEV $\left(\mathrm{J} \mathrm{kg}^{-1}\right)$ ], inibição de convecção [CINI (J kg1)], inibição de convecção calculada a partir da temperatura virtual [CINIV (J kg-1)], número de Richardson global [BRN (adimensional)], espessura entre $1000 \mathrm{hPa}$ e $500 \mathrm{hPa}$ (mgp) água precipitável $(\mathrm{mm})$ para toda a coluna vertical da sondagem.

Neste trabalho utilizou-se as figuras skewT-logP geradas pela Universidade do Wyoming: http://weather.uwyo.edu/upperair/sounding.html. As sondagens foram utilizadas para avaliação das condições que precederam a formação de eventos posteriormente selecionados. 


\subsection{Eventos selecionados}

Para as simulações, foram selecionados somente os eventos para os quais: (i) a vazão atingiu picos significativos; (ii) As estimativas do RSP não sofreram interrupções temporais ou existiram a ocorrência de propagação anômala; (iii) Registro contínuo das medições de nível e precipitação por ambos os postos utilizados. Os eventos selecionados são do período chuvoso de 2008-2009, e estão compreendidos entre os dias 05 de Outubro de 2008 e 26 de Outubro de 2009. A escolha do período se deve ao intervalo da ocorrência de obras hidráulicas na bacia.

Tabela 3.3 - Data e classificação dos eventos selecionados. Data e hora indicada no formato MM/DD/AAAA HHMM.

\begin{tabular}{cccl}
\hline Evento & Data Inicial (UTC) & Data Final (UTC) & Classificação do Evento \\
1 & $10 / 05 / 20080110$ & $10 / 05 / 20081800$ & Linha de Instabilidade \\
2 & $10 / 18 / 20081100$ & $10 / 18 / 20081900$ & Frente Fria \\
3 & $12 / 21 / 20081500$ & $12 / 22 / 20080100$ & Convecção Isolada \\
4 & $12 / 22 / 20081500$ & $12 / 23 / 20080300$ & Conecção Isolada \\
5 & $12 / 24 / 20082000$ & $12 / 25 / 20081000$ & Bandas Dispersas \\
6 & $01 / 11 / 20090200$ & $01 / 11 / 20091000$ & Bandas Dispersas \\
7 & $01 / 13 / 20092300$ & $01 / 14 / 20090800$ & Convecção Isolada \\
8 & $01 / 14 / 20091900$ & $01 / 15 / 20090600$ & Linha de Instabilidade \\
9 & $01 / 16 / 20092000$ & $01 / 17 / 20090800$ & Bandas Dispersas \\
10 & $01 / 20 / 20091500$ & $01 / 20 / 20092200$ & Convevção Isolada \\
11 & $01 / 25 / 20092000$ & $01 / 26 / 20090700$ & Bandas Dispersas \\
12 & $01 / 26 / 20091600$ & $01 / 27 / 20090350$ & Convecção Isolada \\
13 & $01 / 30 / 20091800$ & $01 / 31 / 20090700$ & Linha de Instabilidade \\
14 & $02 / 07 / 20091900$ & $02 / 08 / 20090400$ & Linha de Instabilidade \\
15 & $02 / 08 / 20091700$ & $02 / 09 / 20090100$ & Brisa Marítima \\
16 & $02 / 12 / 20090000$ & $02 / 12 / 20090600$ & Bandas Dispersas \\
17 & $03 / 03 / 20091600$ & $03 / 03 / 20092300$ & Convecção Isolada \\
18 & $10 / 26 / 20091500$ & $10 / 27 / 20091000$ & Bandas Dispersas \\
\hline
\end{tabular}

Do total de eventos selecionados, 33,4 \% foram classificados como Bandas dispersas (BD) associados a Zonas de Convergência de Umidade ou grandes áreas de instabilidade, 33.4\% foram classificados como Convecção Isolada $(\mathrm{Cl}), 22.2 \%$ dos eventos como Linhas de Instabilidade (LI) e apenas do 5,5\% de eventos de Frentes Frias (FF) e Brisa Marítima (BM). O período de calibração foi determinado 
entre os eventos 1 e 10, que compreende 05 de Outubro de 2008 à 20 de Janeiro de 2009. O período de verificação compreende os eventos de 11 a 18, de 25 de janeiro de 2009 a 26 de Outubro de 2009. Nas Fig. 3.19a e 3.19b são ilustrados para ambos os períodos, os dados de vazão observada, precipitações médias na bacia pelo RSP e medida pelo posto Córrego Poá.

Observa-se para ambos os períodos a grande amplitude da variação da vazão em um curto período de tempo. A vazão de base sem incidência de precipitação é de $23 \mathrm{~m}^{3} \mathrm{~s}^{-1}$, chegando a picos que ultrapassam os $200 \mathrm{~m}^{3} \mathrm{~s}^{-1}$ (evento 18). Devido a este baixo tempo de ascensão do hidrograma, foi determinado 0 passo tempo para as simulações como sendo de 10 minutos, a máxima resolução temporal possível, limitada pela telemetria. A precipitação estimada pelo RSP possui resolução temporal de 5 minutos, foi necessária a acumulação desta informação para as simulações.

Para a integração, SILVA (2006) cita que para tempos de acumulação de 30 minutos a correlação espacial entre a telemetria e estimativas do RSP atinge valores abaixo de 50\% para distancias maiores que 3-4 km, quando sistemas do tipo Brisa Marítima são analisados. Para casos de bandas dispersas, a correlação espacial atinge os mesmos valores de correlação para distancias acima de $10 \mathrm{~km}$. Sistemas do tipo convecção isolada, distancias acima de $5 \mathrm{~km}$ já apresentam pouca correlação espacial. Os maiores valores de correlação espacial das medidas para este tempo de acumulação, foi encontrada no caso de Frentes Frias, onde o sistema apresenta uma estrutura espacial bem definida. Como o ponto de monitoramento em superfície se encontra a aproximadamente $10 \mathrm{Km}$ do ponto mais distante da bacia, foi escolhido o tempo de 30 minutos como sendo o tempo mínimo de acumulação para a integração pelo método ANOBES.

Desde que se quer é avaliar a modelagem hidrológica como uma ferramenta para alertas a inundações, optou-se por realizarem-se as simulações com os extremos das resoluções temporais. Escolheu-se o tempo de acumulação de 30 minutos para a integração da precipitação 


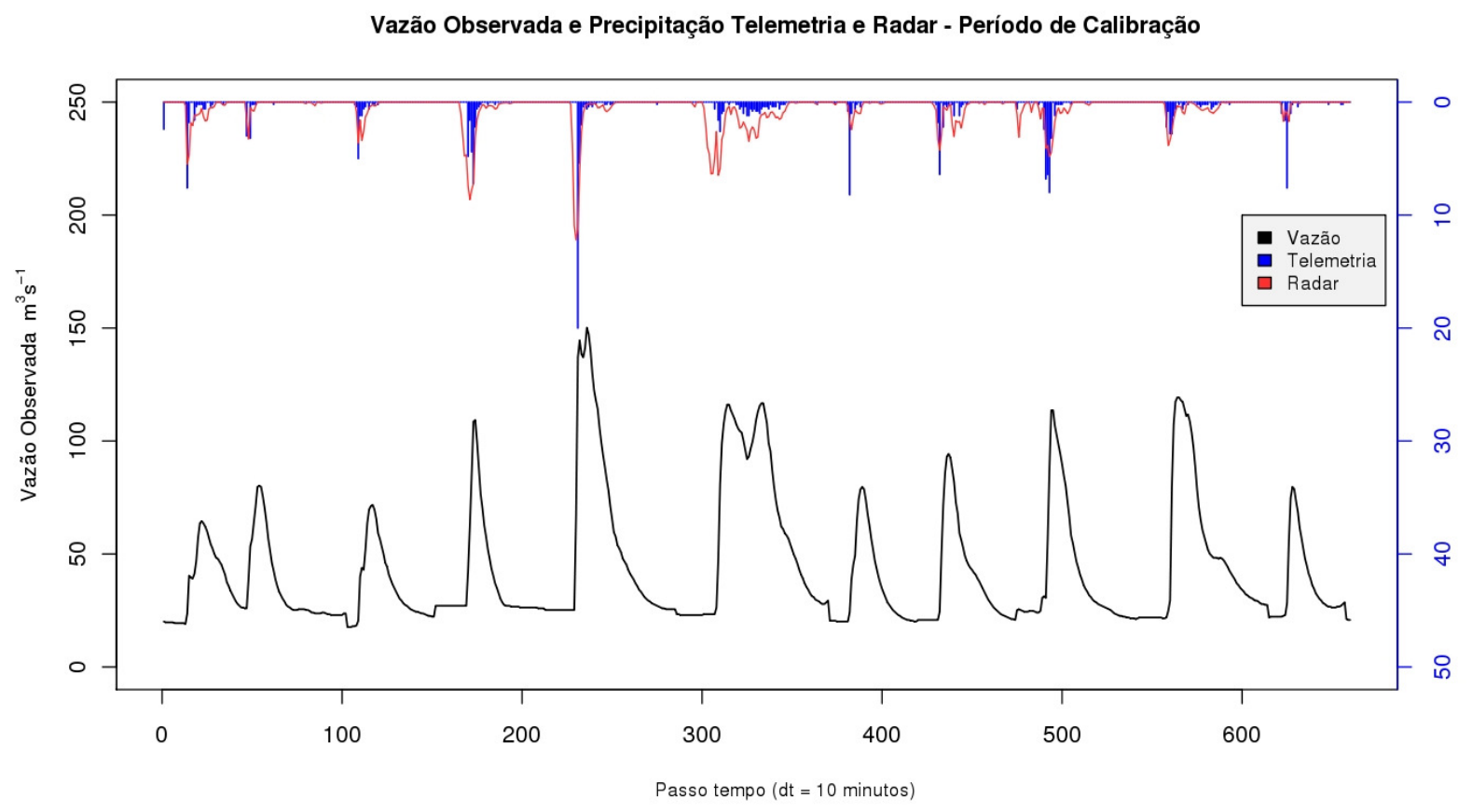

(a)

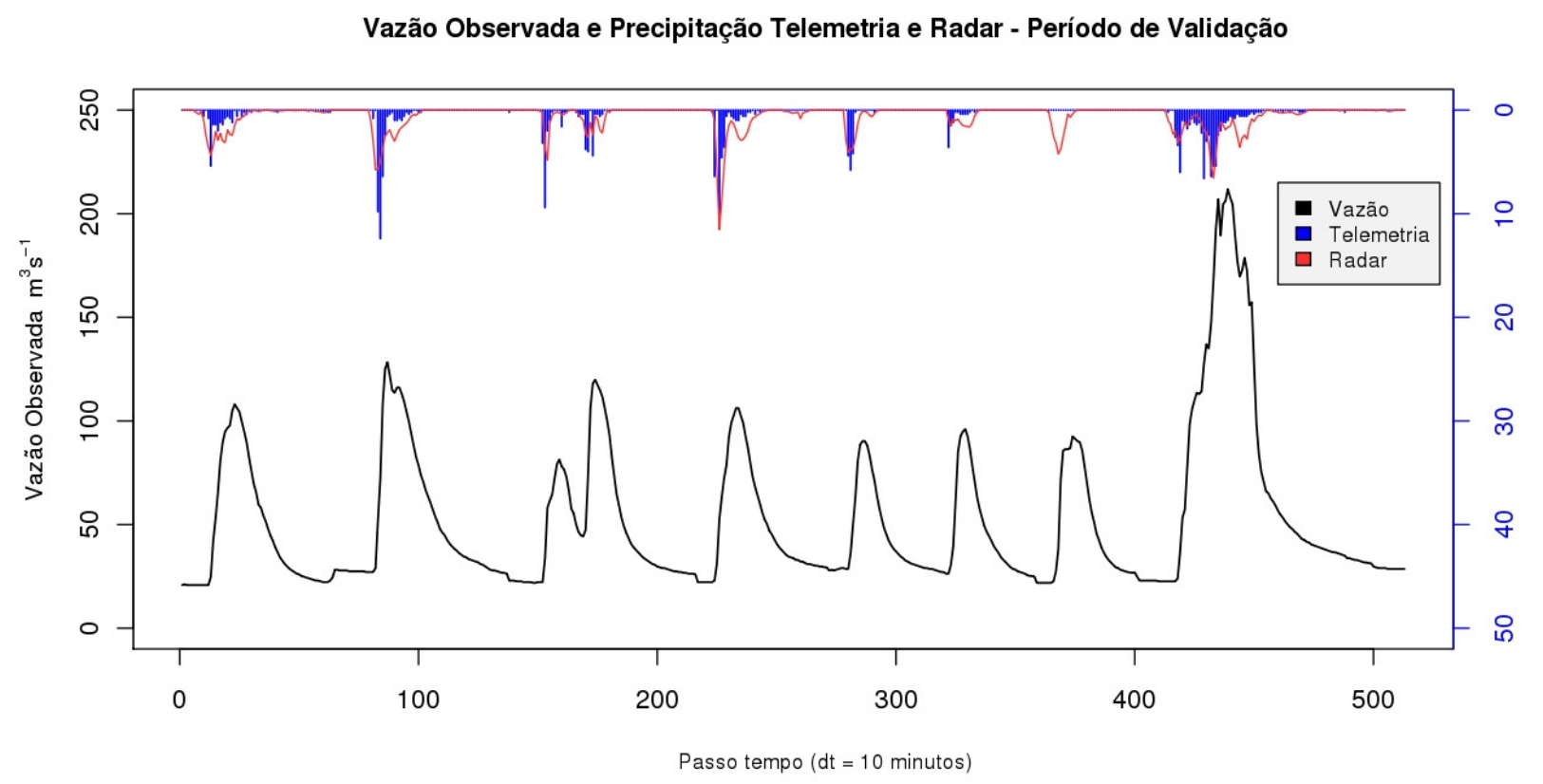

(b)

Figura 3.19: Vazão observada, precipitação medida pela telemetria de superfície e precipitação média na bacia com Radar Meteorológico. As linhas pretas representam a vazão observada no posto Pirajuçara, as barras em azul representam a precipitação medida no posto Córrego Poá e a linha vermelha a precipitação média na bacia calculada com estimativas do Radar Meteorológico. 


\subsection{Procedimentos para simulações com TOPMODEL.}

A seqüência de operações para as simulações com o TOPMODEL é:

- $\quad$ Análise de sensibilidade.

- Integração da precipitação (ANOBES).

- $\quad$ Comparação da precipitação média sobre a bacia versus precipitação pontual estimadas pelo RSP.

- $\quad$ Avaliação do impacto da evapotranspiração nas simulações.

- Calibração TOPMODEL com precipitação Telemetria.

- Verificação com precipitação Telemetria.

- Verificação com precipitação Radar.

- Verificação com precipitação ANOBES.

- Calibração TOPMODEL com precipitação Radar.

- Verificação com precipitação Telemetria.

- Verificação com precipitação Radar.

- Verificação com precipitação ANOBES.

- $\quad$ Calibração TOPMODEL com precipitação ANOBES.

- Verificação com precipitação Telemetria.

- Verificação com precipitação Radar.

- Verificação com precipitação ANOBES.

- $\quad$ Avaliação dos problemas apresentados nas simulações. 


\section{Resultados}

\subsection{Análise de Sensibilidade}

A análise de sensibilidade visa identificar os parâmetros do modelo que melhoram o desempenho do mesmo. Para esta verificação, foram utilizadas simulações com entradas de precipitação proveniente das três formas abordadas neste trabalho, precipitação medida pela rede de superfície, estimada pelo radar meteorológico de São Paulo e integrada pelo método ANOBES. Utilizou-se na análise de sensibilidade o método de Monte Carlo para determinar os valores ótimos de cada parâmetro. Efetuou-se $40 \mathrm{mil}$ simulações para cada entrada de precipitação. Os resultados estão nas Fig. 4.1, 4.2. e 4.3.

A análise dos parâmetros para precipitação medida pela telemetria (Fig. 3.20), mostra que o modelo possui grande sensibilidade ao parâmetro $m$ e uma sensibilidade moderada ao parâmetro InTe. SCHULER et al. (2000) demonstrou que para períodos com mais de 15 dias de simulação, o modelo apresentou características similares em relação a sensibilidade apenas dos parâmetros de profundidade efetiva do solo. Os demais parâmetros como se pode observar, não influenciam no desempenho do modelo. Nota-se também, que os maiores índices de eficiência são atribuídos a valores de $m$ entre $5 \times 10^{-3}$ e $2 \times 10^{-2}$ metros e InTe aproximadamente $10 \mathrm{~m}^{2} \mathrm{~h}^{-1}$.

Para 0 modelo inicializado com precipitação estimada pelo Radar Meteorológico (Fig. 4.2a e 4.2b), observou-se que além dos parâmetros $m$ e InTe, o parâmetro $T_{D}$ também possui influencia nas simulações. $O$ parâmetro $T_{D}$ representa o retardo da frente de umidade no fluxo entre a zona não saturada e a zona de saturação, e indica que para estas simulações a percolação influencia nas simulações. Observa-se também, que o máximo de eficiência para o parâmetro $m$ se encontra deslocado para valores maiores em relação ao modelo iniciado com precipitação medida pela telemetria, com valores de $\ln T e$ praticamente iguais. Se para a representação da mesma vazão observada, o modelo necessitou de uma maior profundidade efetivo do solo, isto indica que na média, a precipitação inserida pelo RSP é maior frente a telemetria 

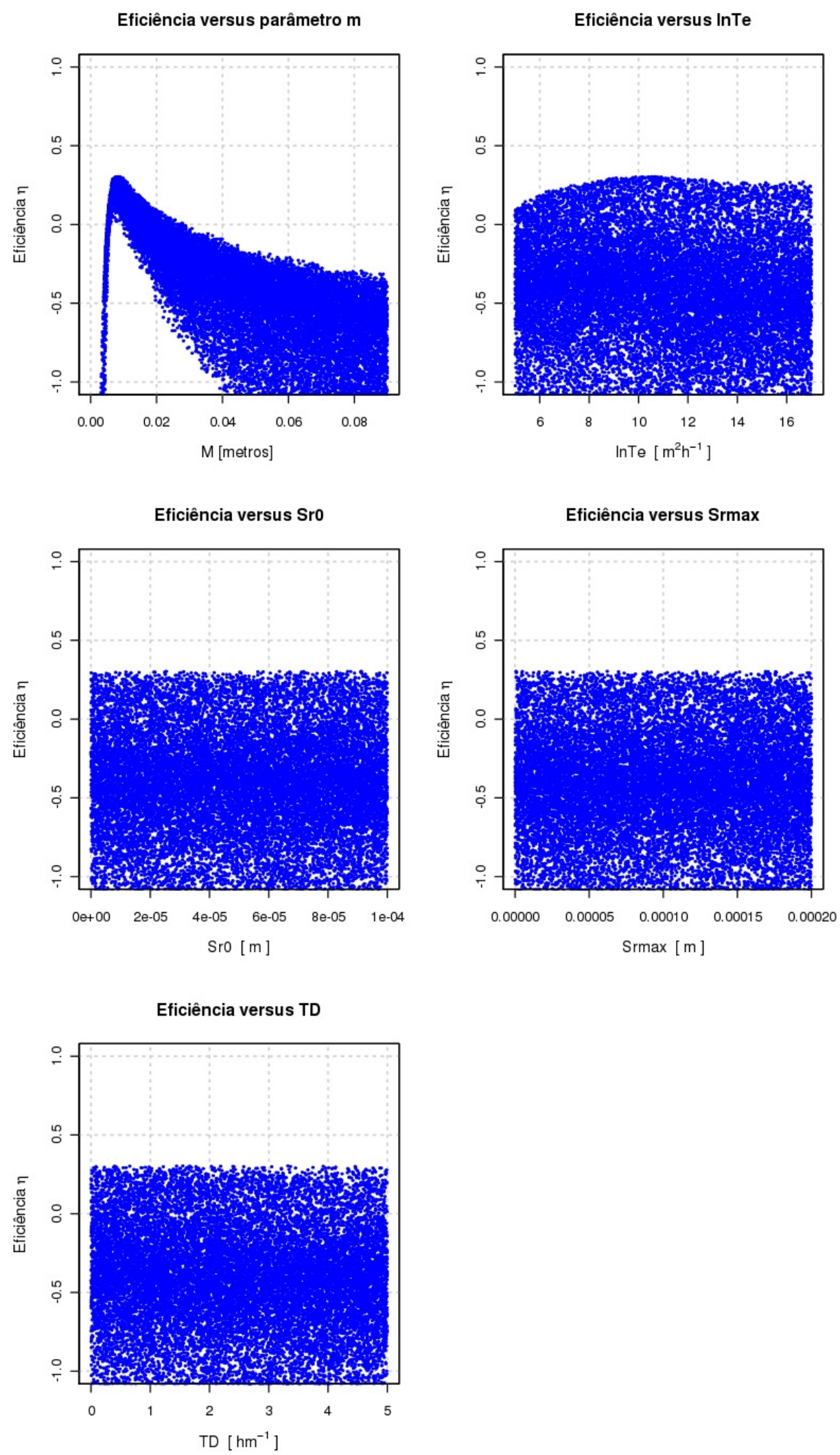

(a) 

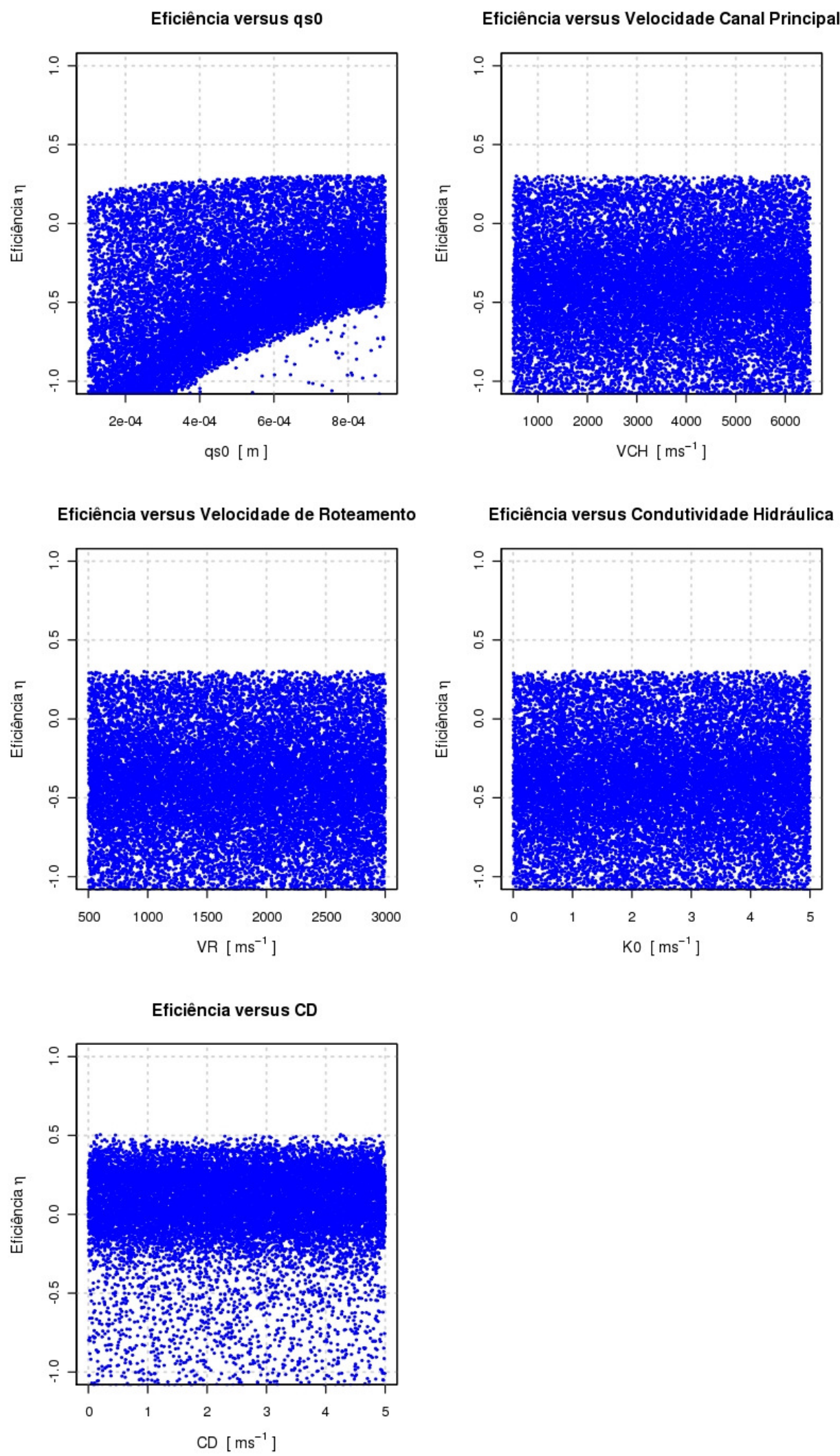

(b)

Figura 4.1: Análise de Sensibilidade dos parâmetros do modelo TOPMODEL para a BRP, entrada de precipitação: Rede de superfície (pluviômetros). (a) Parâmetros $m$, InTe, $S r_{0}, S r_{\max }, T d$; (b) Parâmetros qsO, VCH, VR, KO, CD. 

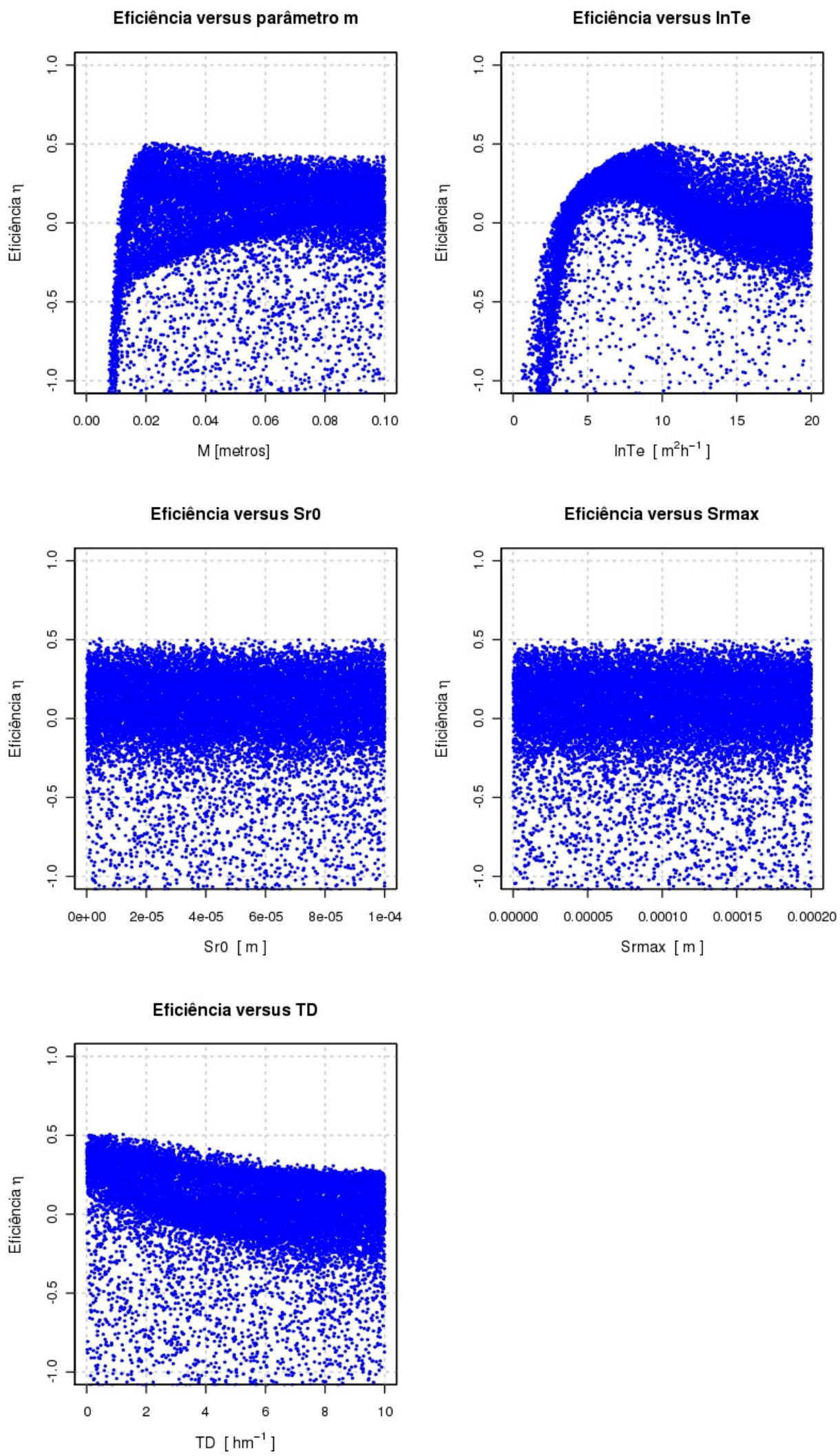

(a) 

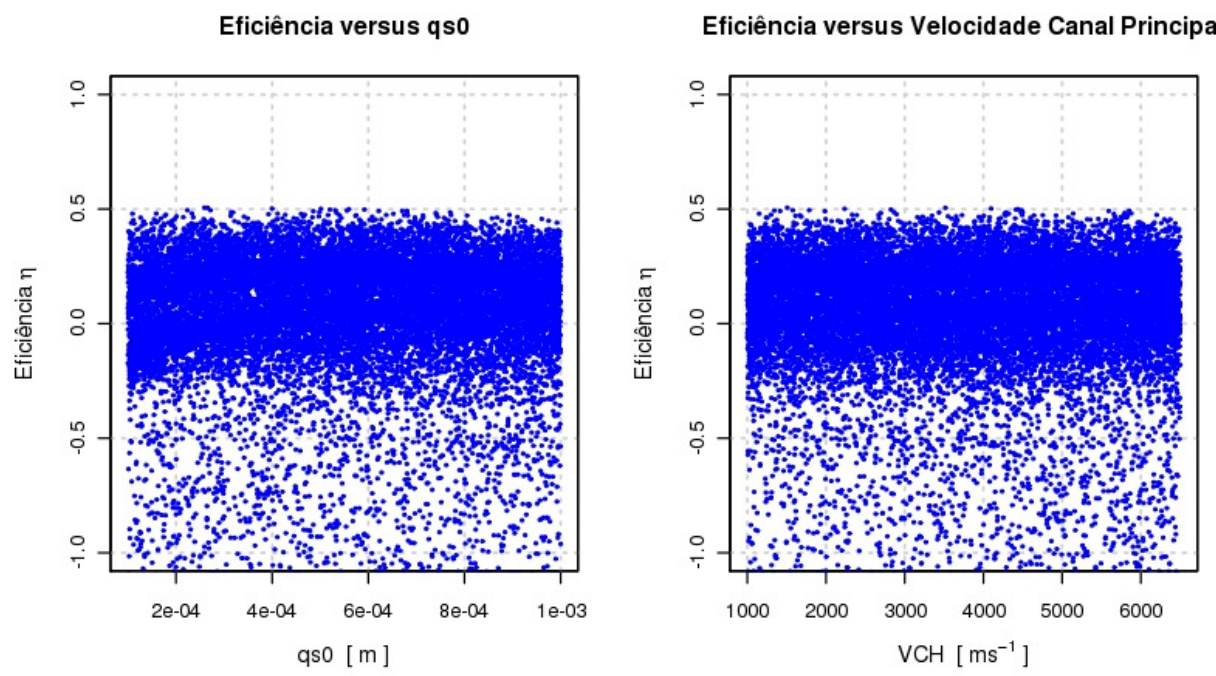

Eficiência versus Velocidade de Roteamento

Eficiência versus Condutividade Hidráulica
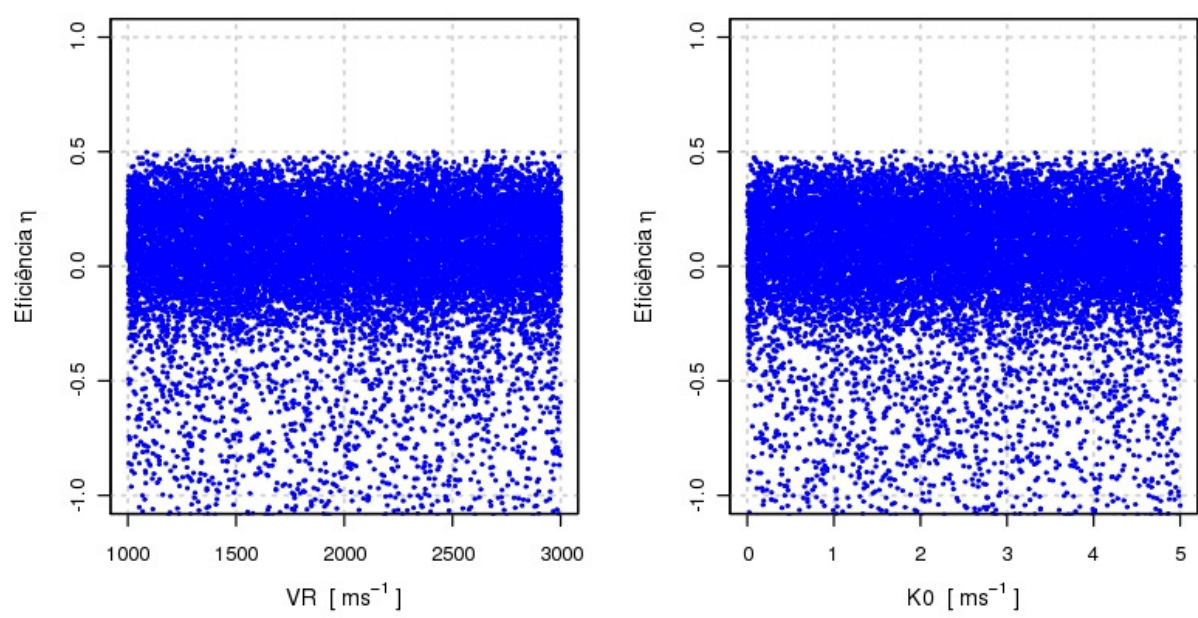

Eficiência versus CD

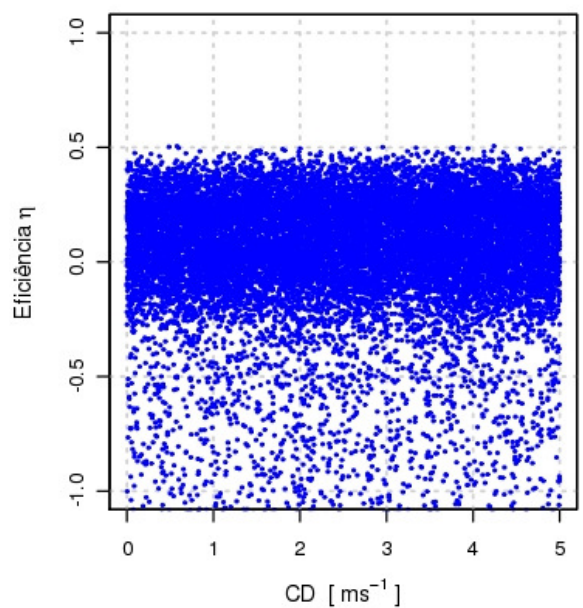

(b)

Figura 4.2: Análise de Sensibilidade dos parâmetros do modelo TOPMODEL para a BRP, entrada de precipitação: Radar Meteorológico.(a) Parâmetros m, InTe, Sro,Srmax,Td; (b) Parâmetros qsO, $V C H, V R, K O, C D$. 
Para as simulações com entrada de precipitação integrada pelo ANOBES, observou-se um comportamento bastante semelhante às simulações utilizando precipitação medida pela rede de superfície, apenas com pequena sensibilidade ao parâmetro qs0. Este parâmetro representa a vazão subsuperficial inicial e possui importância apenas no inicio das simulações. Os valores de maior eficiência versus parâmetro $m$ se apresentam relativamente deslocados para maiores valores em relação a telemetria. Nestas simulações, o modelo se mostrou sensível também ao parâmetro InTe.

Para as entradas com telemetria e ANOBES, notou-se sensibilidade baixa, porém presente, do parâmetro qs0. Este parâmetro é a condição inicial da vazão subsuperficial e só produz influencias nos passos iniciais do modelo.

Em relação aos demais parâmetros, pouca sensibilidade foi notada para todas as entradas de precipitação. A insensibilidade do modelo para os parâmetros $S r_{0}$ e $S_{r_{M a x}}$, são indicativos de que a evapotranspiração é irrelevante para o resultado das simulações. A insensibilidade aos parâmetros $T_{D}$ e $K 0$ nos casos das Figs. 3.20 e 3.23 indicam que a percolação de água não possui importância para simulações naquelas condições, ou seja, a geração de vazão é prioritariamente no sentido horizontal, seja da forma de contribuição lateral ou escoamento superficial.

Em relação aos parâmetros $\mathrm{VCH}$ e RV, observou-se que para todas as entradas de precipitação, estes parâmetros não mostraram sensibilidade. Este resultado é citado também por SCHULER et al.(2000) VARELLA e CAMPANA (2000), XAVIER (2002) e SILVA (2005) que efetuaram testes de sensibilidade com o TOPMODEL. 

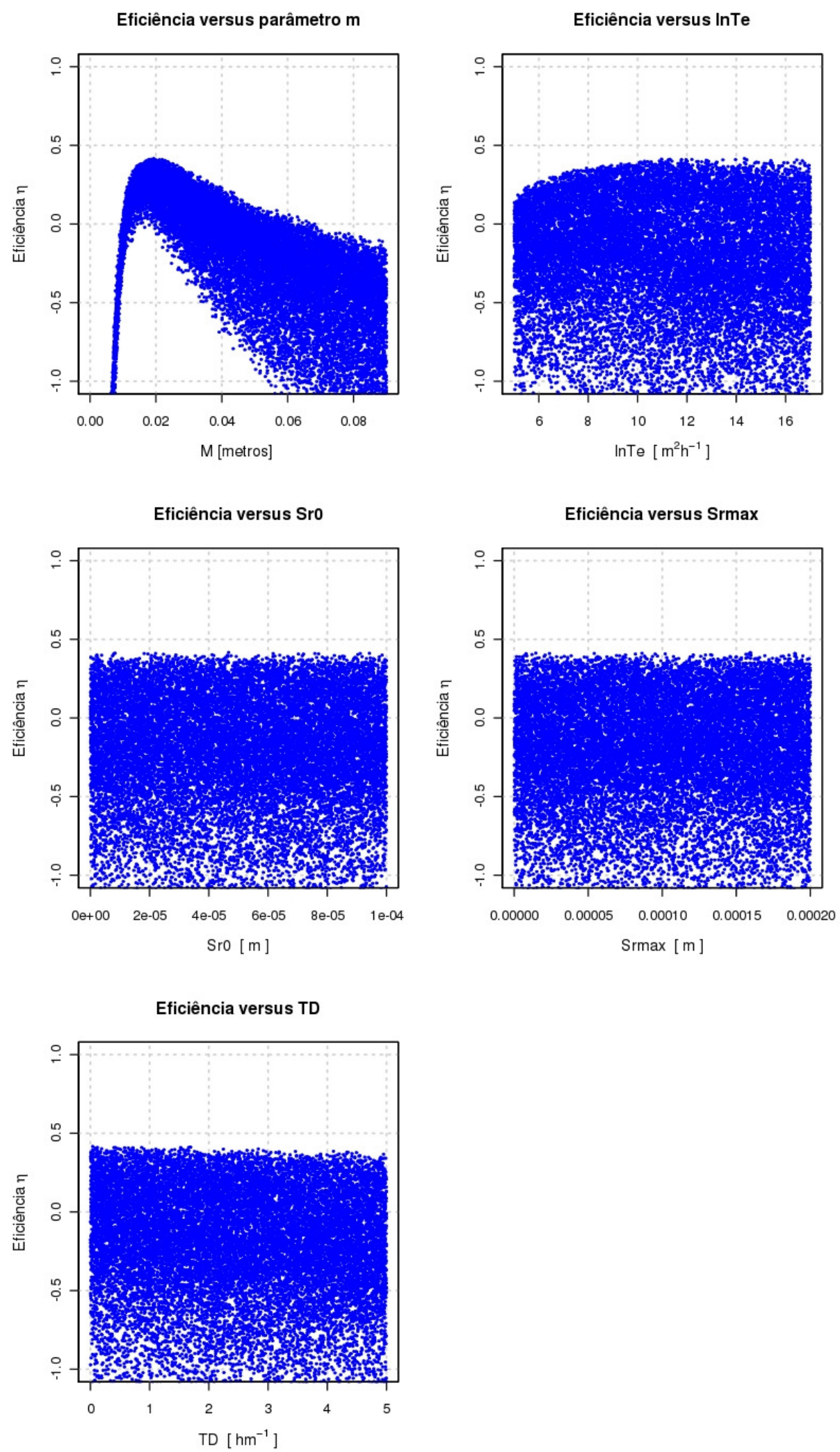

(a) 

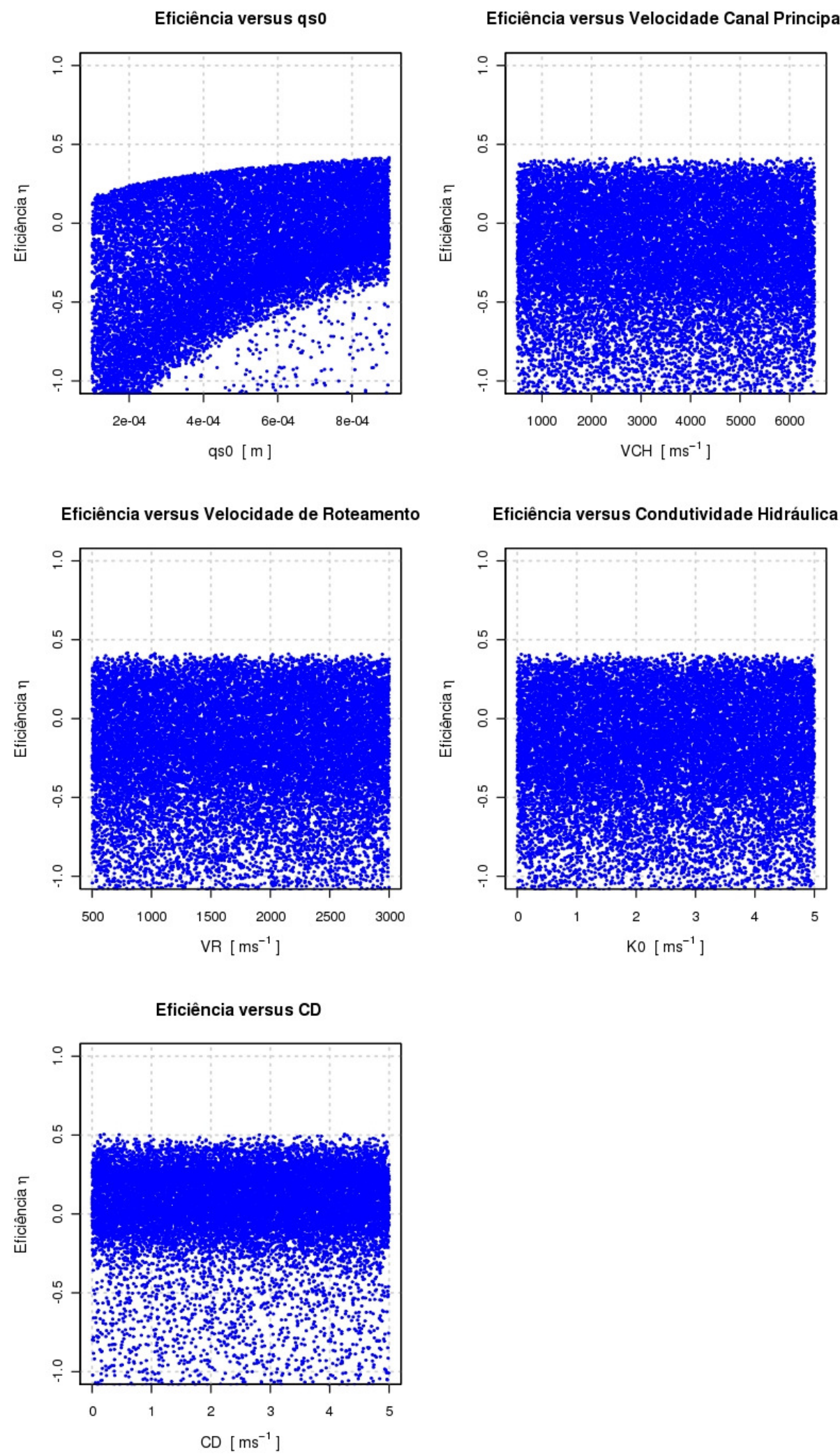

(b)

Figura 4.3: Análise de Sensibilidade dos parâmetros do modelo TOPMODEL para a BRP, entrada de precipitação: ANOBES.(a) Parâmetros m, InTe, Sro,Srmax,Td; (b) Parâmetros qs0, VCH, VR, KO, CD. 


\subsection{Integração da precipitação}

\subsubsection{Comparação da precipitação média com precipitação pontual pelo radar meteorológico}

Nesta etapa, foi realizada uma comparação entre a precipitação média na bacia e a precipitação medida pelo radar meteorológico sobre o ponto de medição da telemetria de superfície com objetivo de se estabelecer o comportamento do RSP e determinação da precipitação utilizada. A precipitação pontual é relativa ao pixel de coordenadas $(x, y)=(81,121)$. As coordenadas $x$ e $y$ são relativas ao posicionamento cartesiano da matriz de $240 \times 240$ pontos do RSP, que se encontra na posição $(x, y)=(120,120)$. Foi calibrado então o modelo TOPMODEL para entradas de precipitação pontual e média do RSP e efetuadas simulações para os eventos selecionados nesta etapa.

$\mathrm{Na}$ Fig. 4.4a e 4.4b respectivamente, pode-se observar a comparação das precipitações e vazões simuladas para 5 eventos pertencentes ao período de verificação, eventos 11, 12, 13 , 14 e 15 da Tabela 3.3. Como esperado, a precipitação pontual do RSP apresenta variações com freqüências maiores se comparadas às precipitações médias na bacia.

No evento 11, a precipitação sobre o pixel da telemetria superestimou a precipitação medida em superfície no início do evento. Após o pico de intensidade, as medidas pontuais do radar se aproximam bastante do pluviômetro, ainda abaixo da média na bacia, e resultou na subestimativa da vazão simulada para este evento. A simulação utilizando a precipitação média na bacia simulou bem a vazão observada, e indica, portanto uma representação relativamente melhor na precipitação. A descrição detalhada deste evento e seu impacto na simulação hidrológica se encontram na secção 4.4.1 a seguir.

O evento 12 também apresentou problemas na simulação com precipitação pontual, com um atraso considerável do pico do hidrograma, com pouca ou nenhuma utilidade do ponto de vista de alerta. O hidrograma resultante da simulação com precipitação média mostra a vazão de pico com superestimativas, porém com antecipação da vazão crítica. Na série temporal da precipitação (Fig. 4.4a), observam-se valores inferiores no horário de máxima intensidade, em relação ao pluviômetro. O sistema que gerou este evento será descrito com detalhes na 
secção 4.4.2, onde será avaliada, sua evolução temporal, espacial e sua relação com os erros na vazão simulada. No evento 13 observa-se a subestimativa da vazão por ambas as entradas de precipitação. Os motivos para este erro sistemático da simulação com radar são encontrados com detalhes na descrição deste evento na seção 4.4.3.

O evento 14, classificado com linha de instabilidade, observa-se que para ambas as entradas de precipitação a vazão foi superestimada. A precipitação medida pela telemetria indica um caso clássico de linha de instabilidade, com acumulados maiores na passagem de sua porção convectiva, seguido de precipitação estratiforme na retaguarda. Porém para as medições com radar no ponto sobre a telemetria, observa-se superestimativas da porção estratiforme da precipitação, que se deve à presença da banda brilhante, comumente presente na retaguarda destes sistemas.

A simulação para o evento 15 mostra que o modelo não gerou vazão para a entrada de precipitação pontual do RSP. Na comparação da precipitação, observase que apesar da telemetria ter detectado a precipitação, a estimativa pelo RSP sobre a respectiva não detectou a precipitação. Fatores diversos podem causar erros na estimativa de chuva com radar meteorológico (Secção 2.2). A simulação com precipitação média na bacia obteve um resultado melhor, apenas com antecipação do pico, fator considerado positivo do ponto de vista do alerta.

Conclui-se que, para as simulações dos cinco eventos selecionados, a precipitação estimada pontualmente sobre a quadrícula da telemetria sofre com problemas da representatividade espacial da precipitação, assim como as medidas com pluviômetro, além dos erros já implícitos das estimativas com radar meteorológico. Desta forma foi escolhida a precipitação média na bacia para a execução das simulações. 


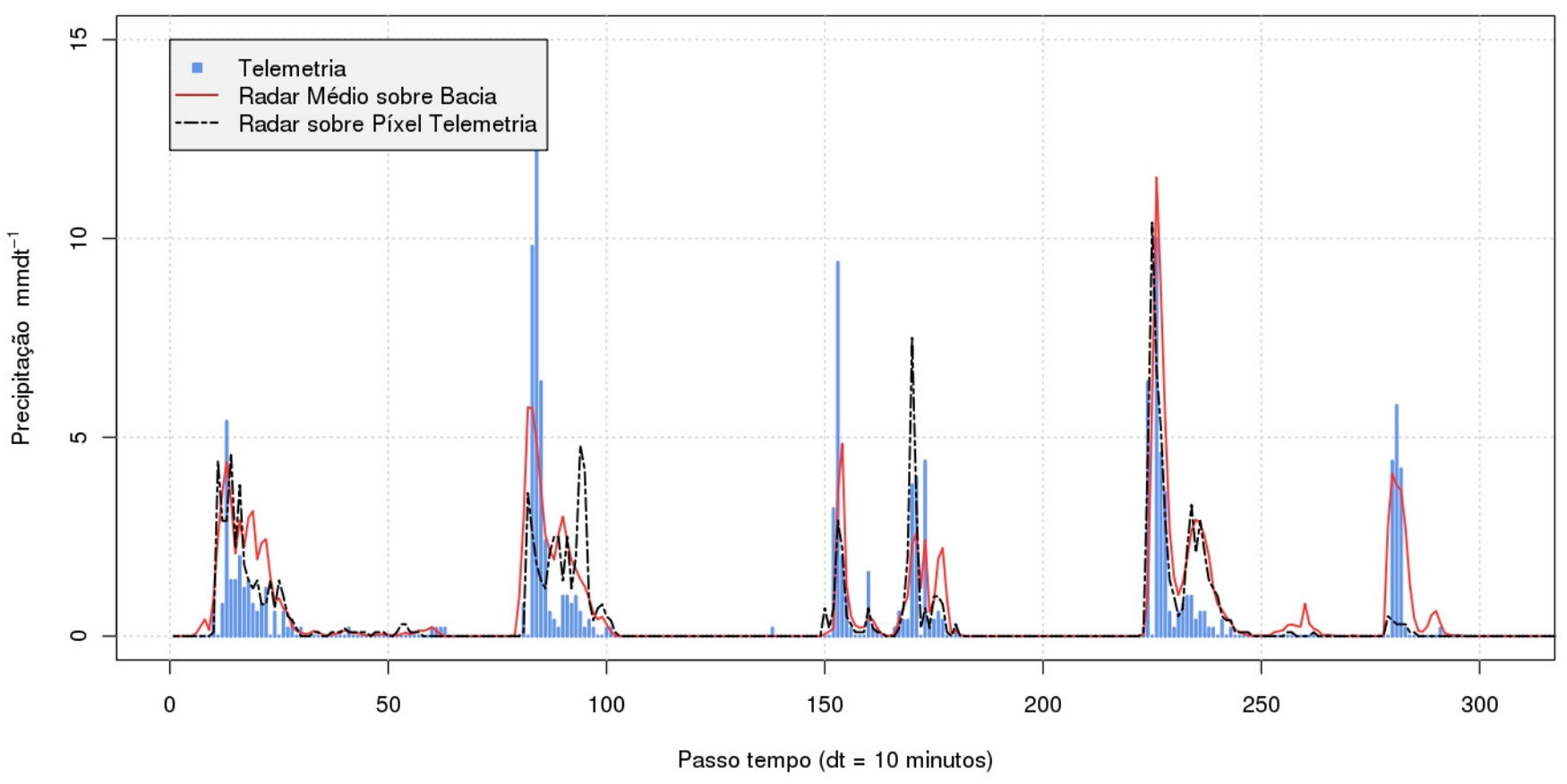

(a)

Vazão Observada versus Simulada - Precipitação Pixel Radar x Média

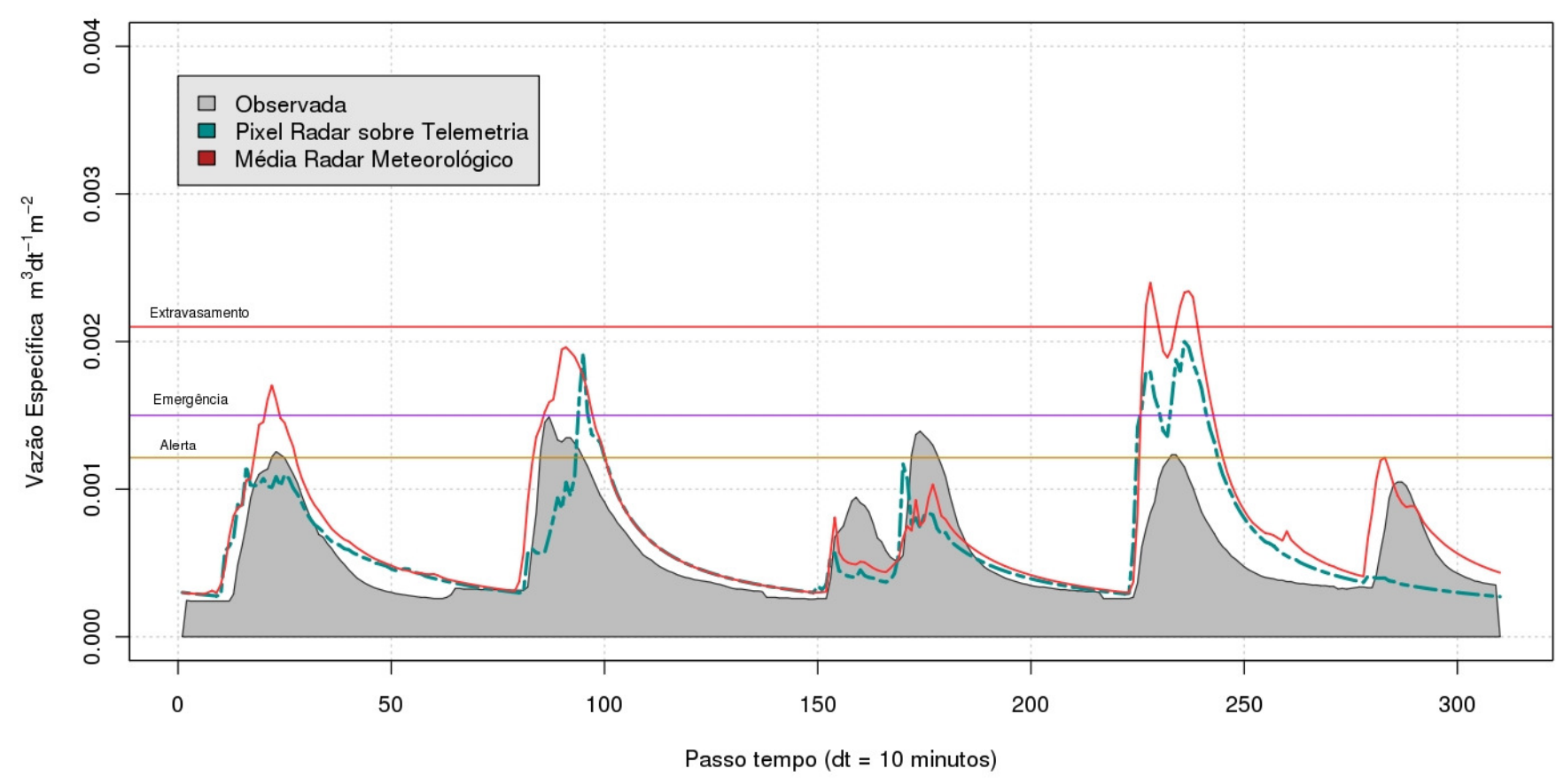

(b)

Figura 4.4: Comparação entre: (a) Precipitação média na bacia pelo Radar Meteorológico (Vermelho sólido), pixel sobre telemetria pelo radar meteorológico (pontilhado) e Telemetria (barras azuis); (b) Vazões simuladas para 5 eventos (Eventos 11,12,13, 14 e 15 da tabela 3.3). 


\subsubsection{Resultados da integração}

As Fig. 4.5 e 4.6 mostram os resultados da integração pelo método ANOBES para períodos de calibração e verificação, respectivamente. A diferença no padrão temporal das precipitações medidas pela telemetria e estimadas pelo radar meteorológico é evidente. Sugere-se que a falta de representatividade espacial do pluviômetro seja um fator limitante. Por outro lado, o radar meteorológico permite uma amostragem espaço-temporal dos sistemas precipitantes sobre a bacia muito maior.

Ressalta-se que a precipitação média na bacia obtida com o RSP e com o método ANOBES, considera todas as quadrículas sobre a área de bacia de interesse a montante do exutório (Fig. 3.10). Assim, sistemas precipitantes que ocorram de forma isolada apenas sobre os divisores de água da bacia, ou seja, somente sobre alguns "pixels" da mesma, terão a precipitação média baixa.

Para uma avaliação mais precisa das diferenças entre as precipitações é necessário a comparação com variáveis independentes, pois com base apenas na precipitação média, diversos fatores podem influenciar nos valores. Neste caso 0 modelo hidrológico também pode ser utilizado como uma ferramenta para a verificação das medições de precipitação. A vazão é uma variável independente e a relação pode indicar erros em medidas ou estimativas. 
Comparação entre as Precipitações - Período de Calibração

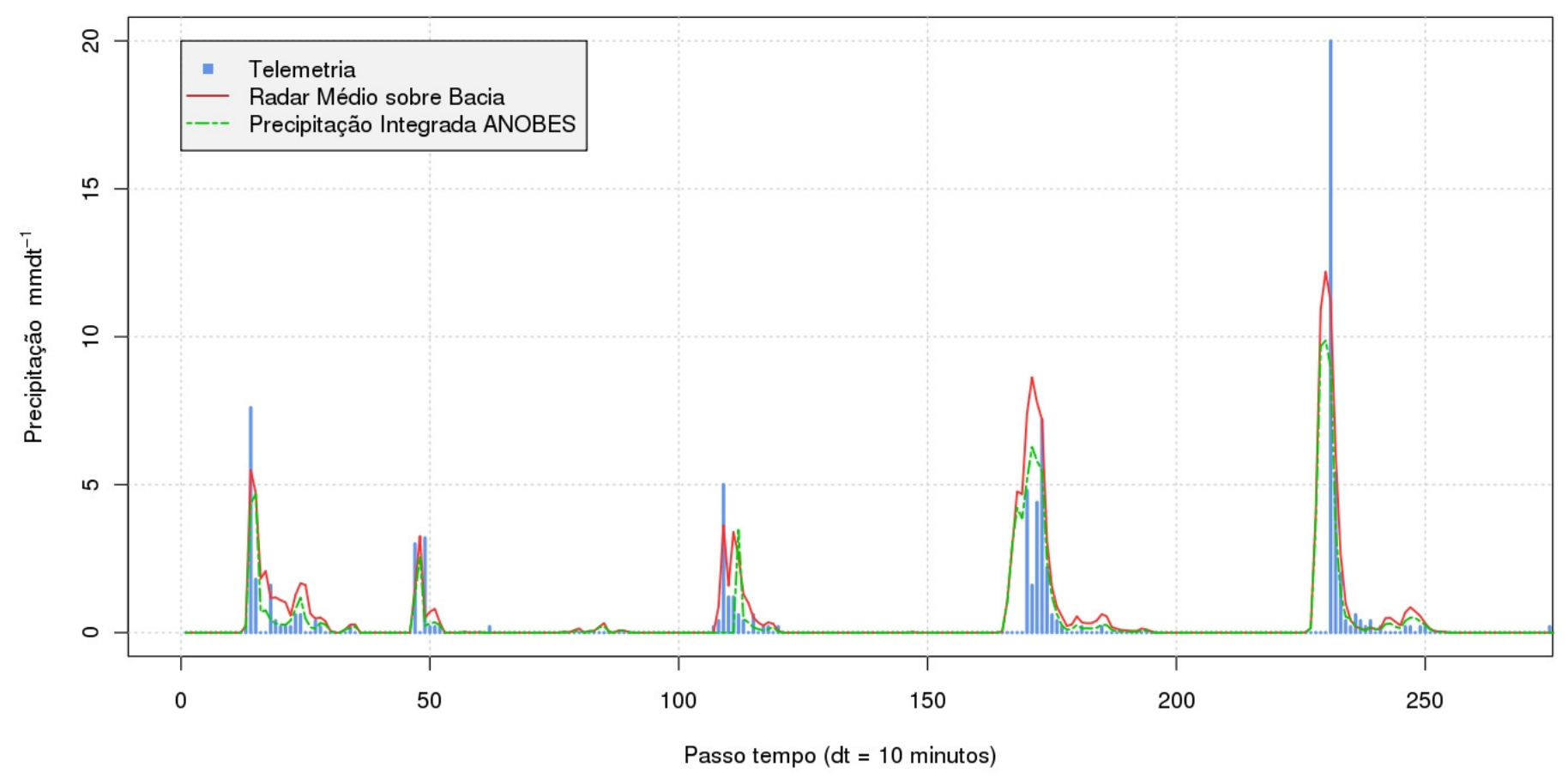

(a)

Comparação entre as Precipitações - Período de Calibração

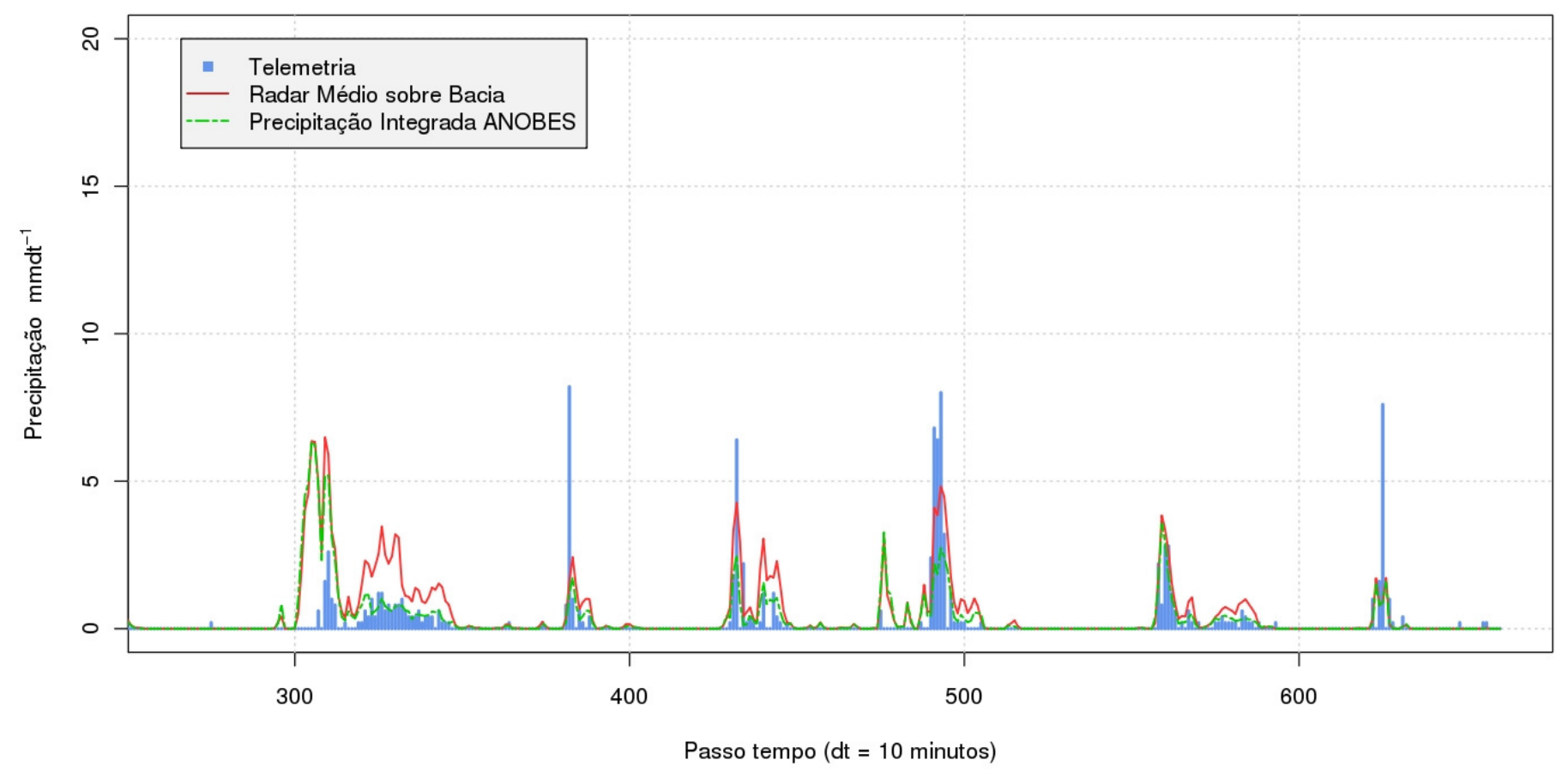

(b)

Figura 4.5: Comparação entre as precipitações médias entre medidas com pluviômetro, radar meteorológico e precipitação integrada com ANOBES para a bacia do Rio Pirajuçara para o período de calibração: (a) Eventos compreendidos no período: 05 de Outubro de 2008 à 22 de Dezembro de 2008; (b) Eventos compreendidos no período: 24 de Dezembro de 2008 à 20 de Janeiro de 2009. As barras em azul representam a precipitação medida pela telemetria, as linhas vermelha e verde representam as precipitações médias na bacia estimadas pelo RSP e integrada pelo ANOBES, respectivamente 


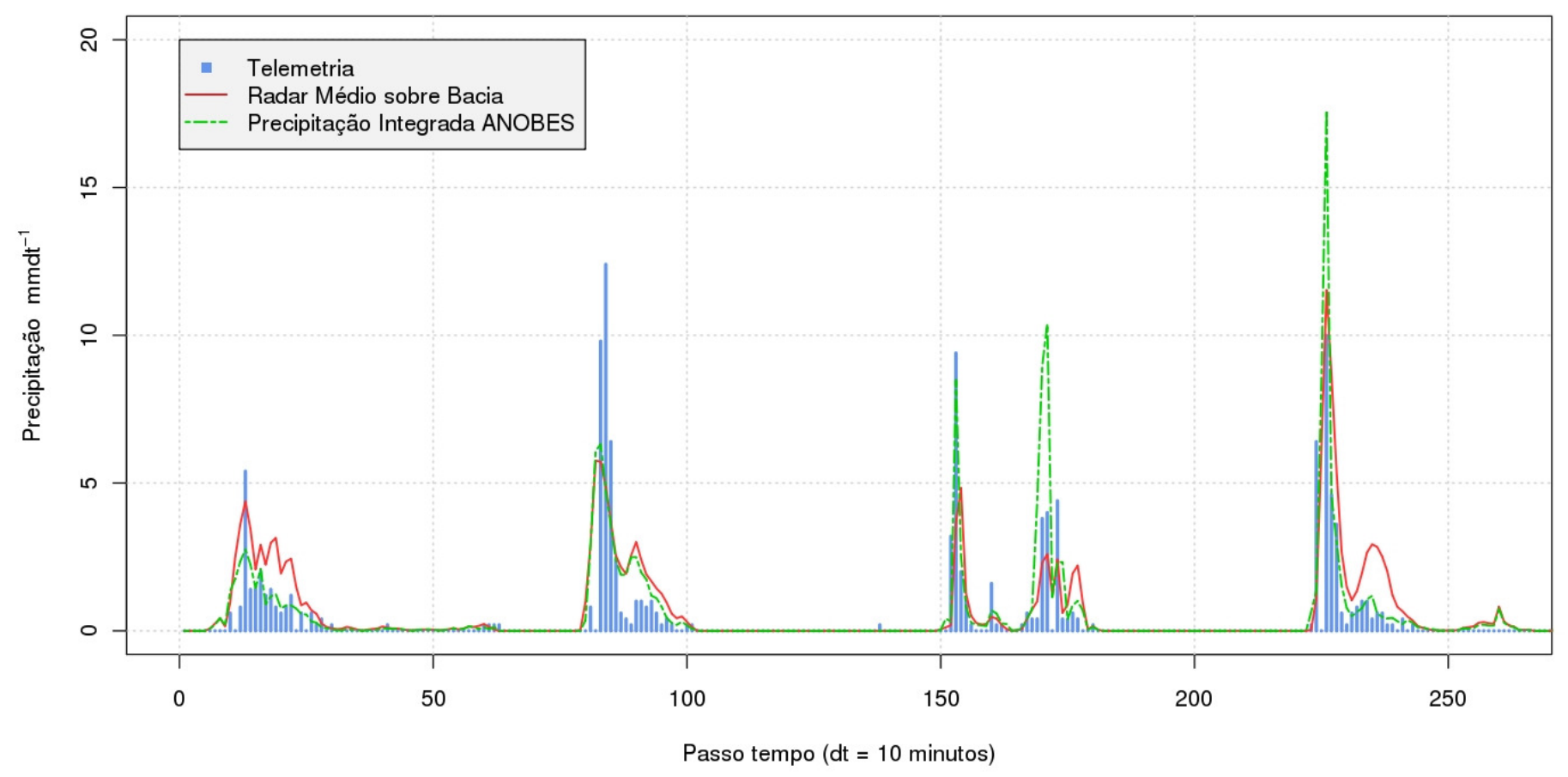

(a)

Comparação entre as Precipitações - Período de Validação

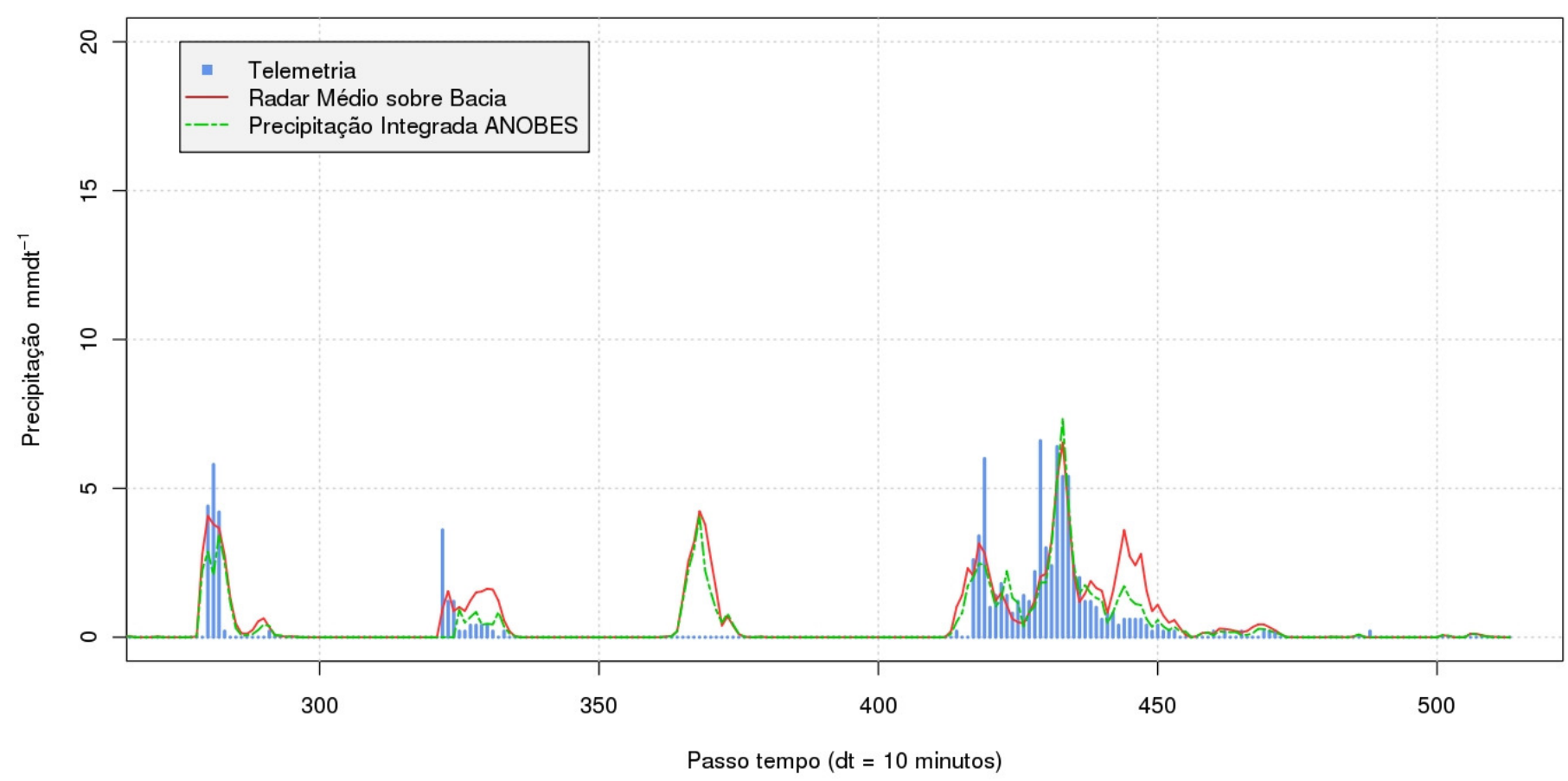

(b)

Figura 4.6: Comparação entre as precipitações médias entre medidas com pluviômetro, radar meteorológico e precipitação integrada com ANOBES para a bacia do Rio Pirajuçara para o período de verificação: (a) Eventos compreendidos no período: 25 de Janeiro de 2009 à 07 de Fevereiro de 2009; (b) Eventos compreendidos no período: 08 de Fevereiro de 2009 à 26 de Outubro de 2009. As barras em azul representam a precipitação medida pela telemetria, as linhas vermelha e verde representam as precipitações médias na bacia estimadas pelo RSP e integrada pelo ANOBES, respectivamente 


\subsection{Simulações hidrológicas com TOPMODEL}

\subsubsection{Sensibilidade do modelo à evapotranspiração}

Uma simulação de controle foi realizada para avaliar o impacto da evapotranspiração nas simulações. Para tal, foram utilizados os eventos 3 , 4 e 5 da Tab. 3.3 e precipitação média na bacia estimada pelo Radar Meteorológico. Foram utilizadas 2 entradas de evapotranspiração, a primeira é a evapotranspiração climatológica para o mês de Dezembro para a cidade de São Paulo medida pela estação meteorológica do INMET (Mirante do Santana) e a segunda, evapotranspiração zero para todos os passos de tempo. Nota-se no resultado desta simulação (Fig. 4.7) que os resultados são praticamente idênticos.

\section{Simulação de Controle: Evapotranspiração}

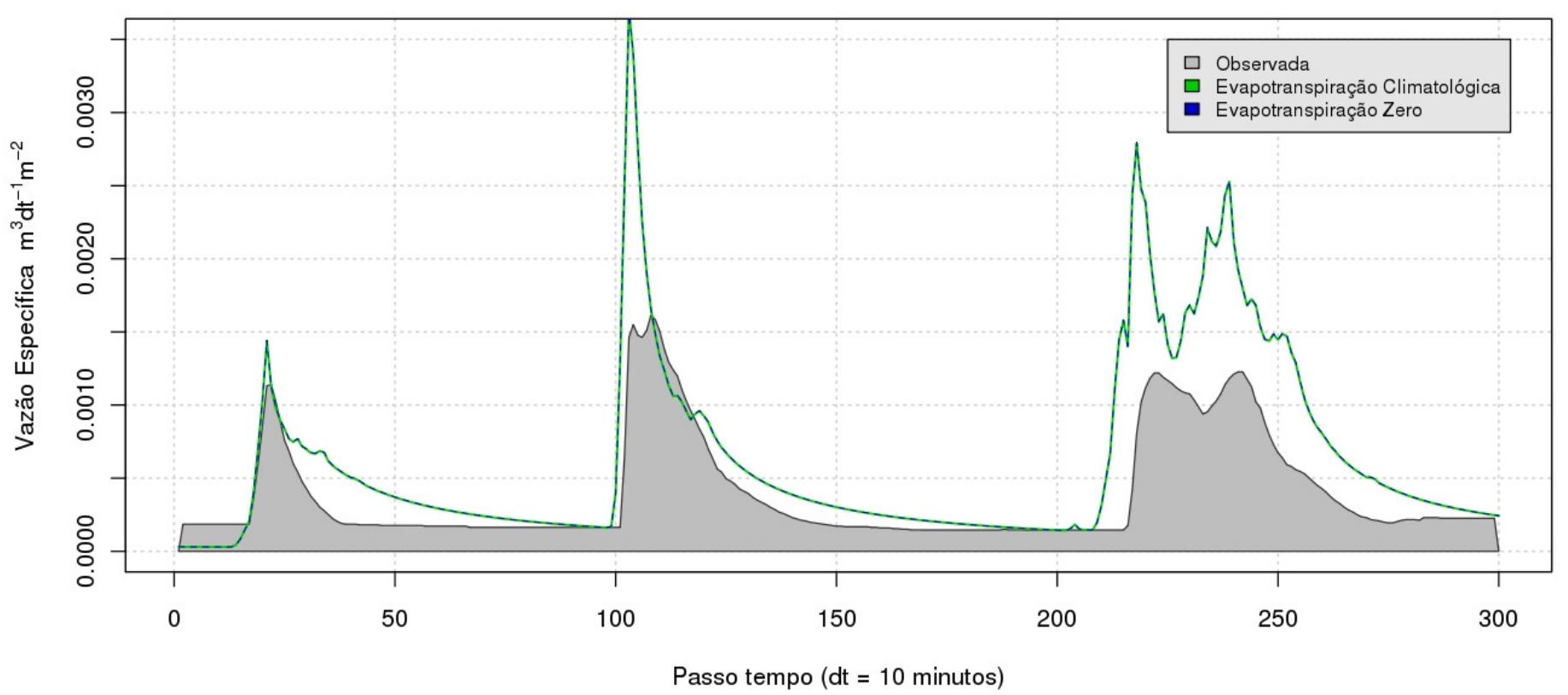

Figura 4.7: Simulação de controle para a avaliação do impacto da evapotranspiração no modelo. As linhas azul (contínua) e verde (pontilhada) representam a vazão simulada com evapotranspiração nula e climatológica, respectivamente. A área preenchida com a cor cinza representa a vazão observada.

TUCCl et al.(1995) diz que as perdas por evapotranspiração em bacias urbanas sofrem grandes alterações. O escoamento é gerado e ocorre em um espaço de tempo bastante inferior ao anterior a urbanização da bacia. $O$ escoamento gerado atinge os dutos, sarjetas e canais rapidamente. Esta diminuição 
no tempo de permanência da água na superfície, assim como a ausência de vegetação, causa diminuição de até $40 \%$ na evapotranspiração. A porção mais importante ocorre em dias de temperaturas elevadas devido à energia armazenada no asfalto, telhados e outros pavimentos. A redução no tempo de permanência da água na superfície da bacia pode também, causar subestimativas na representação deste fenômeno no equacionamento do modelo devido a problemas de escala de tempo na ocorrência dos fenômenos (geração da vazão versus evaporação). Sugere-se também que para os eventos selecionados, o volume evaporado seja irrelevante quando comparado ao volume escoado. 


\subsubsection{Simulações com Telemetria}

Para o período de calibração, o máximo de eficiência foi de 0,31 (Fig. 4.8). Este valor é considerado baixo, se levado em conta apenas este tipo de função objetivo. Na Tab. 4.1 encontram-se os valores de eficiência, erro quadrático médio e viés médio entre as vazões simuladas com o modelo TOPMODEL calibrado a partir da precipitação medida pelo posto Córrego Poá e validado com todos os tipos de precipitação. Observa-se que para o período de calibração a maioria dos eventos foram subestimados, com viés médio negativo de $-2,3 \times 10^{-4}$ e EQM de $5,9 \times 10^{-3}$. Sugere-se que a falta da representatividade espacial do pluviômetro seja o principal fator, agravada pela alta resolução temporal. Igualmente, o evento convectivo sobre o pluviômetro superestimou a média da precipitação na bacia. Nota-se ainda que o evento com maior pico de vazão neste período foi simulado adequadamente quanto à vazão de pico, porém com antecipação da vazão crítica, não ocorrida.

Para o período de verificação (Fig.4.9) ocorreu uma melhora significativa no resultado, o valor de eficiência atingido nesta etapa foi de 0,59, com diminuição do EQM para $4,2 \times 10^{-3}$ e redução em magnitude do viés médio, porém este ainda aponta subestimativa no conjunto geral. Na Fig.4.9 observa-se que as vazões de pico não foram bem representadas em sua maioria, porém para o critério da detecção da ascensão do hidrograma, o desempenho pode ser considerado satisfatório. Observa-se que para $62,5 \%$ dos eventos, a vazão crítica foi detectada com uma pequena antecedência ou mesmo no passo de tempo correto. O evento 18 é um caso positivo desta verificação, observa-se que apesar da vazão de pico ter sido bastante superestimada, a vazão crítica de extravasamento foi detectada pouco antes da ocorrência. O evento 11 foi subestimado e é analisado na Secção 4.4.

As verificações com o modelo calibrado com telemetria (Fig. 4.10) resultaram

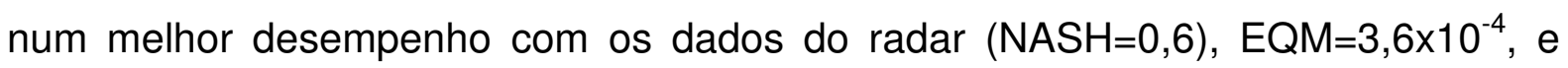
viés médio $=1,6 \times 10^{-5}$. Observa-se na Fig. 4.10a que grande parte dos picos de vazão foram superestimados, o que evidencia o resultado mostrado por SILVA (2006), ou seja, as medidas efetuadas pelo RSP apresentam sempre viés médio positivo quando comparado com pluviômetros. A tempo de pico foi melhor simulado com os dados de precipitação do RSP. 
Tabela 4.1: Valores de eficiência (NS), erro quadrático médio (EMQ) e Viés Médio para as simulações efetuadas com todas as entradas de precipitações. Modelo calibrado com precipitação medida pela telemetria de superfície.

\begin{tabular}{|l|c|c|c|}
\hline Calibração - Precipitação Telemetria & NS & EQM & Viés \\
\hline Verificação & 0,31 & $5,9 \times 10^{-3}$ & $-2,3 \times 10^{-4}$ \\
\hline Radar & & & \\
\hline & 0,60 & $3,6 \times 10^{-4}$ & $1,6 \times 10^{-5}$ \\
\hline Telemetria & & & $-1,8 \times 10^{-4}$ \\
\hline & 0,59 & $4,2 \times 10^{-3}$ & \\
\hline Anobes & & & $-7,8 \times 10^{-5}$ \\
\hline
\end{tabular}


Vazão Observada versus Simulada - Período Calibração

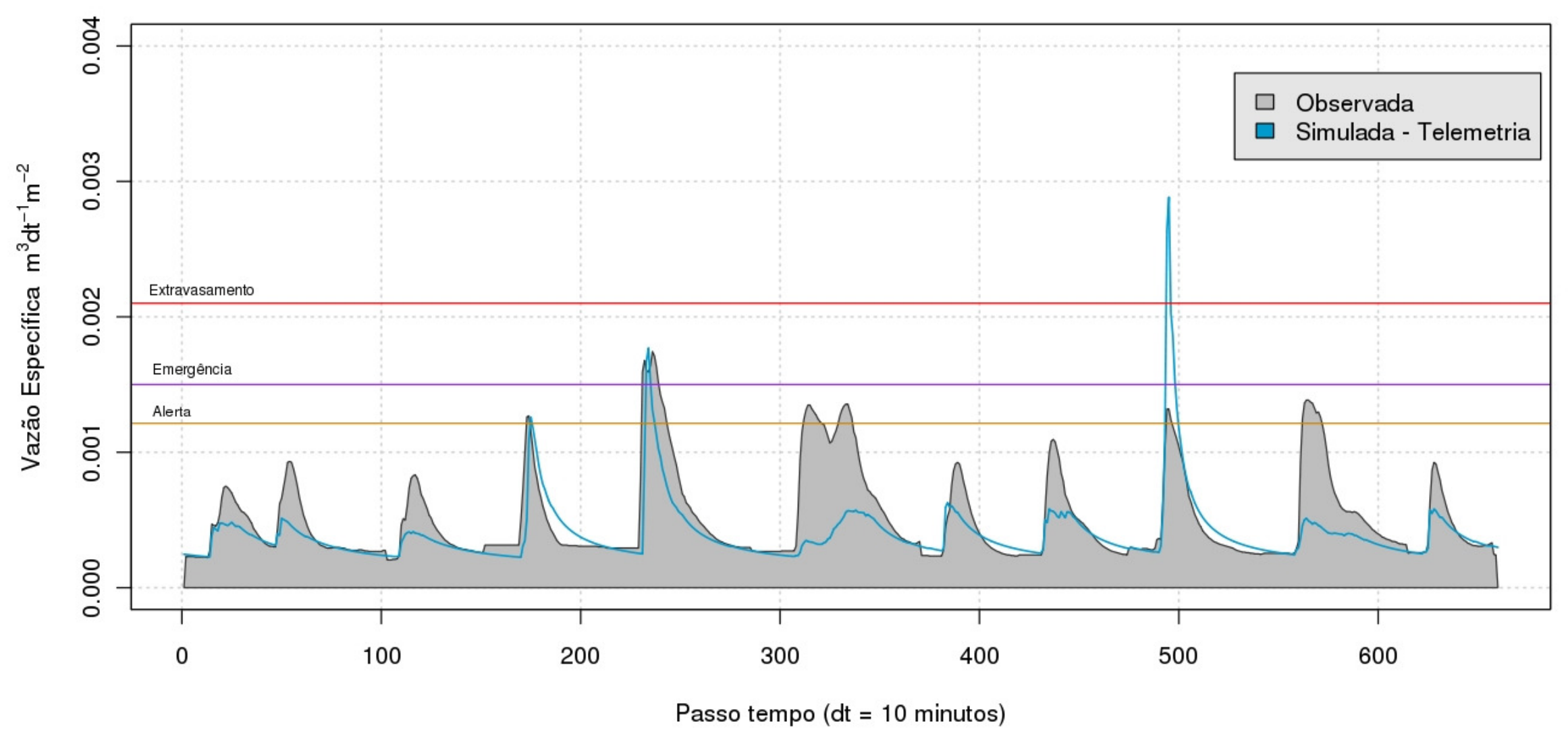

Figura 4.8: Resultado da Calibração do modelo TOPMODEL para a BRP utilizando a precipitação medida pela Telemetria, Eficiência máxima atingida (Nash-Sutcliffe) : 0.31. A porção preenchida em cinza representa a vazão observada na secção, a linha em azul representa a vazão simulada para o período de calibração, com entrada de precipitação da telemetria de superfície. As linhas, vermelha, roxa e laranja, representam os diferentes níveis de alerta utilizados pelo SAISP nesta secção do Rio Pirajuçara. 
Vazão Observada versus Simulada - Calibração Telemetria - Precipitação Telemetria

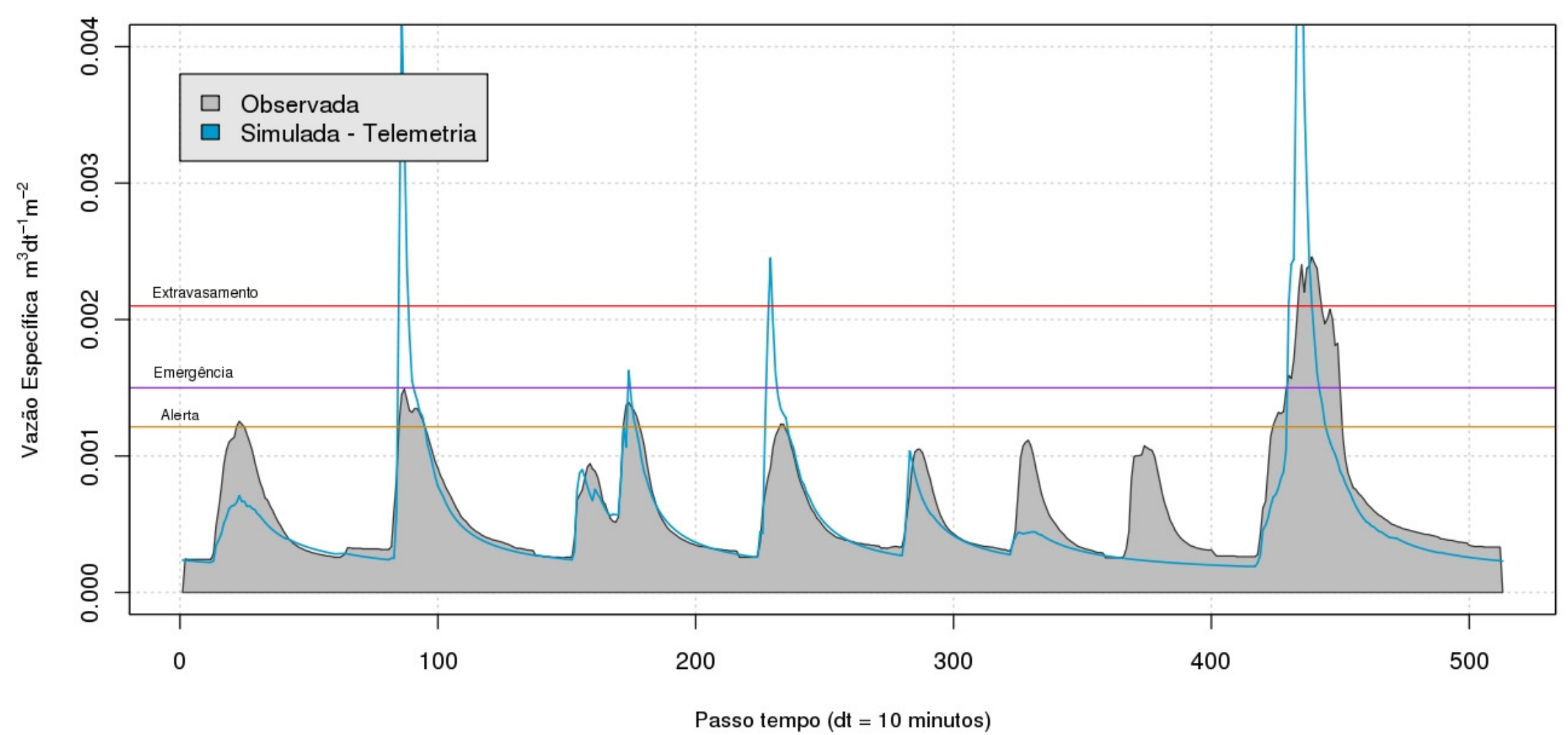

Figura 4.9: Vazão simulada versus Observada para o período de verificação, modelo calibrado a partir de entrada de precipitação medida pela telemetria de superfície. A porção preenchida em cinza representa a vazão observada na secção, a linha em azul representa a vazão simulada para o período de calibração, com entrada de precipitação da telemetria de superfície. As linhas, vermelha, roxa e laranja, representam os diferentes níveis de alerta utilizados pelo SAISP nesta secção do Rio Pirajuçara. 


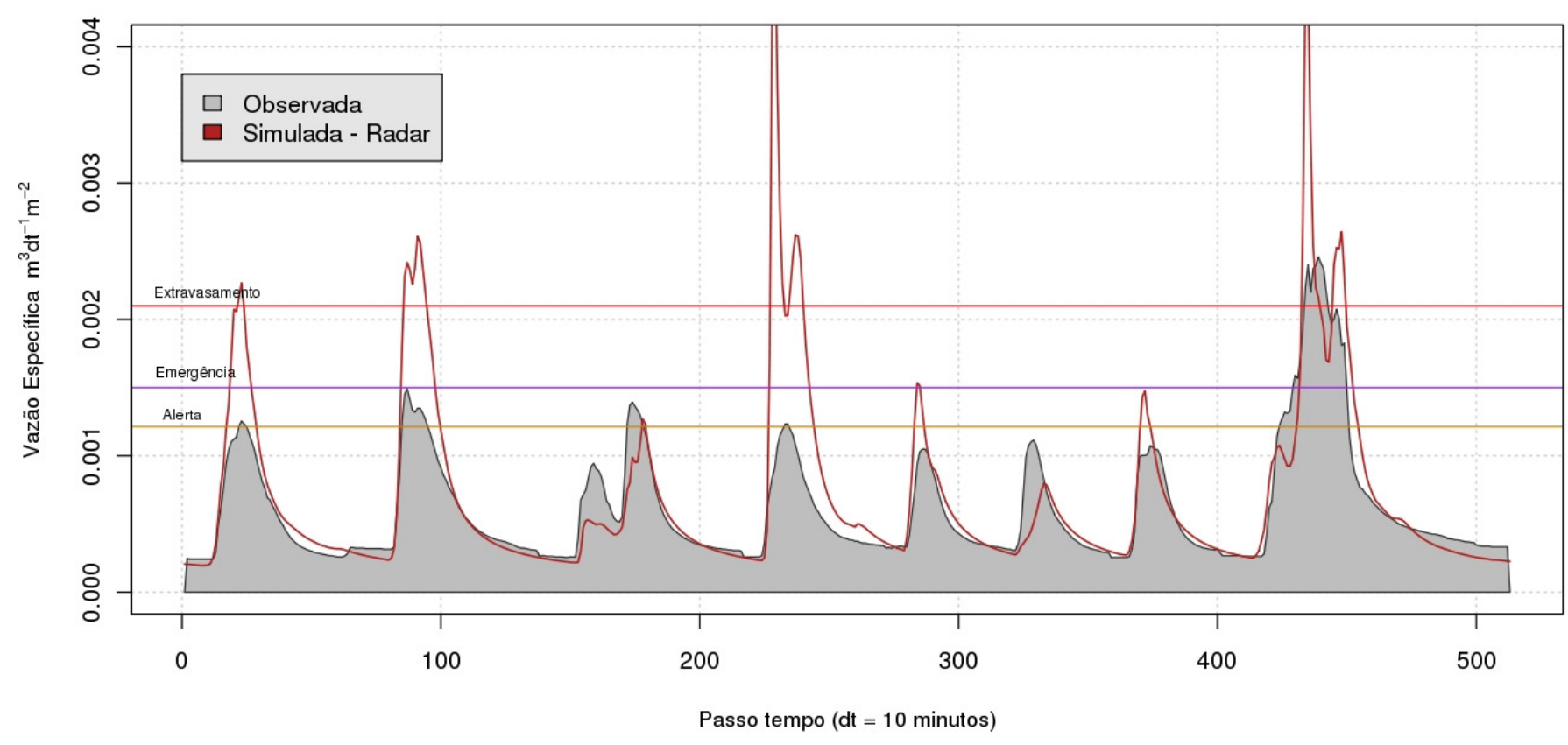

(a)

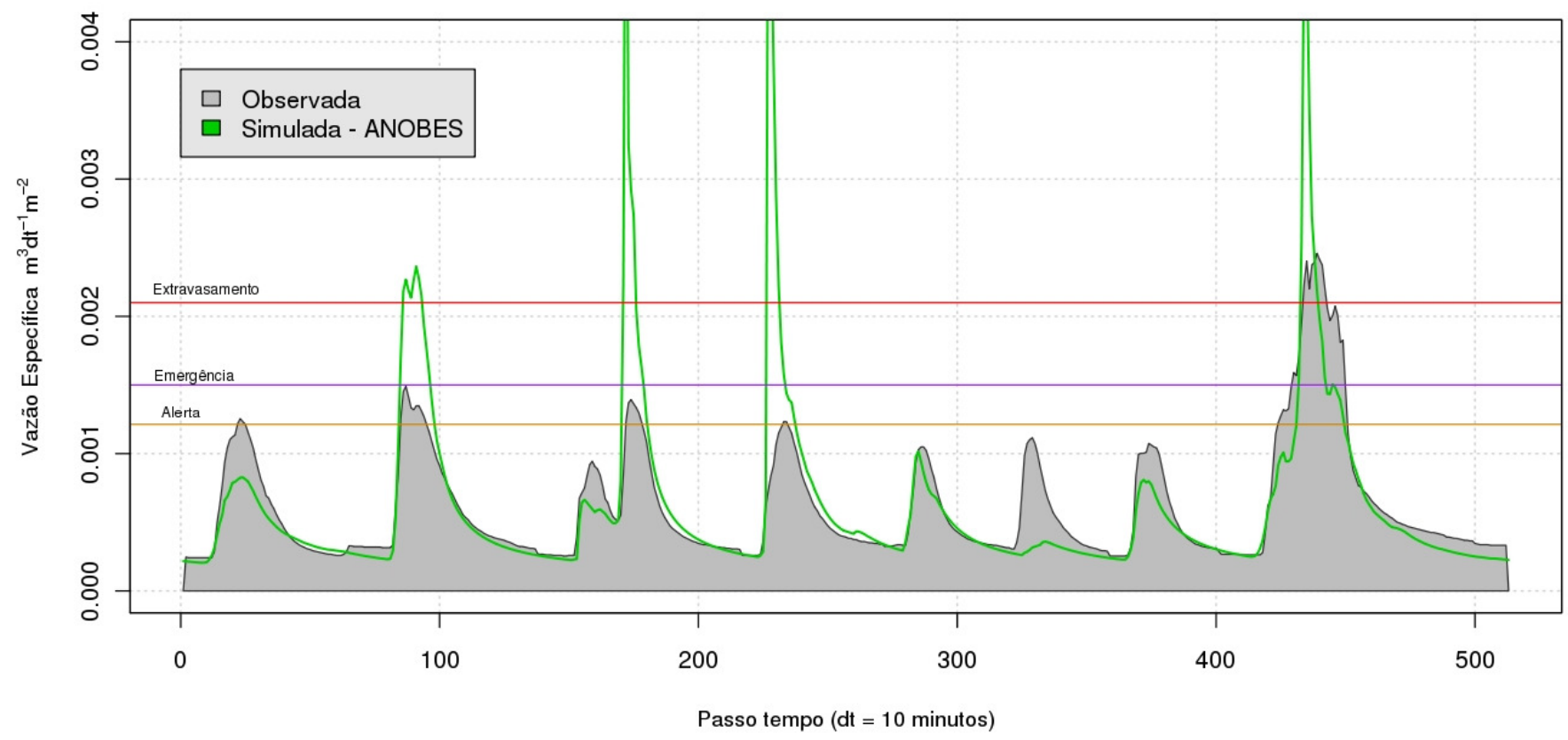

(b)

Figura 4.10: Simulações efetuadas com os parâmetros calibrados com a precipitação medida pela Telemetria para o período de verificação: (a) Precipitação Radar Meteorológico; (b) Precipitação integrada (ANOBES). As linhas, vermelha, roxa e laranja, representam os diferentes níveis de alerta utilizados pelo SAISP nesta secção do Rio Pirajuçara. 


\subsubsection{Simulações com Radar Meteorológico}

Para o período de calibração do modelo com precipitação de entrada, a média na bacia para o RSP, o valor máximo de eficiência atingido foi de 0.51 (Tab. 4.2), considerado um valor aceitável (GOTSCHALK E MOTOVILOV, 2000). Observam-se na Fig. 4.11, eventos com grandes superestimativas, eventos bem representados e também eventos onde o modelo praticamente não gerou vazão, o viés médio positivo indica uma vazão maior do que a observada na média para todo o conjunto.

Para o período de verificação (Fig. 4.12) a eficiência calculada melhorou significativamente, com valor de $\mathrm{NASH}$ de 0,69 , assim como o erro quadrático médio reduzido de $75 \%$ em comparação com o período de calibração. Observa-se na Fig. 4.12 que $75 \%$ dos eventos simulados apresentam antecipação da vazão crítica, independentemente do ajuste de pico, e apenas $25 \%$ dos eventos foram subestimados. O caso de subestimativa do evento 13 da Tab. 3.3 é discutido na secção 4.4.3 a seguir.

Em comparação com as entradas de precipitação distintas (Fig. 13), observase que para esta calibração, a simulação com o RSP obteve o melhor resultado de eficiência e o menor erro quadrático médio. $O$ viés médio positivo indica que no geral, a vazão simulada superestimou a observada. Para a simulação com telemetria, observa-se o menor valor de eficiência, o maior erro quadrático médio e maior viés em magnitude, que indica pouca correlação entre os dois tipos de medidas de precipitação.

Tabela 4.2: Valores de eficiência (NS), erro quadrático médio (EQM) e Viés para as simulações efetuadas com todas as entradas de precipitações. Modelo calibrado com precipitação estimada pelo Radar Meteorológico

\begin{tabular}{|l|c|c|c|}
\hline Calibração - Precipitação Radar & NS & EQM & Viés \\
\hline & 0,5 & $1,9 \times 10^{-3}$ & $7,4 \times 10^{-5}$ \\
\hline Verificação & & & \\
\hline Radar & 0,7 & $4,8 \times 10^{-4}$ & $2,1 \times 10^{-5}$ \\
\hline & & & \\
\hline Telemetria & 0,6 & $4,1 \times 10^{-3}$ & $-18,0 \times 10^{-5}$ \\
\hline & & & \\
\hline Anobes & 0,6 & $1,6 \times 10^{-3}$ & $-7,2 \times 10^{-5}$ \\
\hline
\end{tabular}


Vazão Observada versus Simulada - Período de Calibração

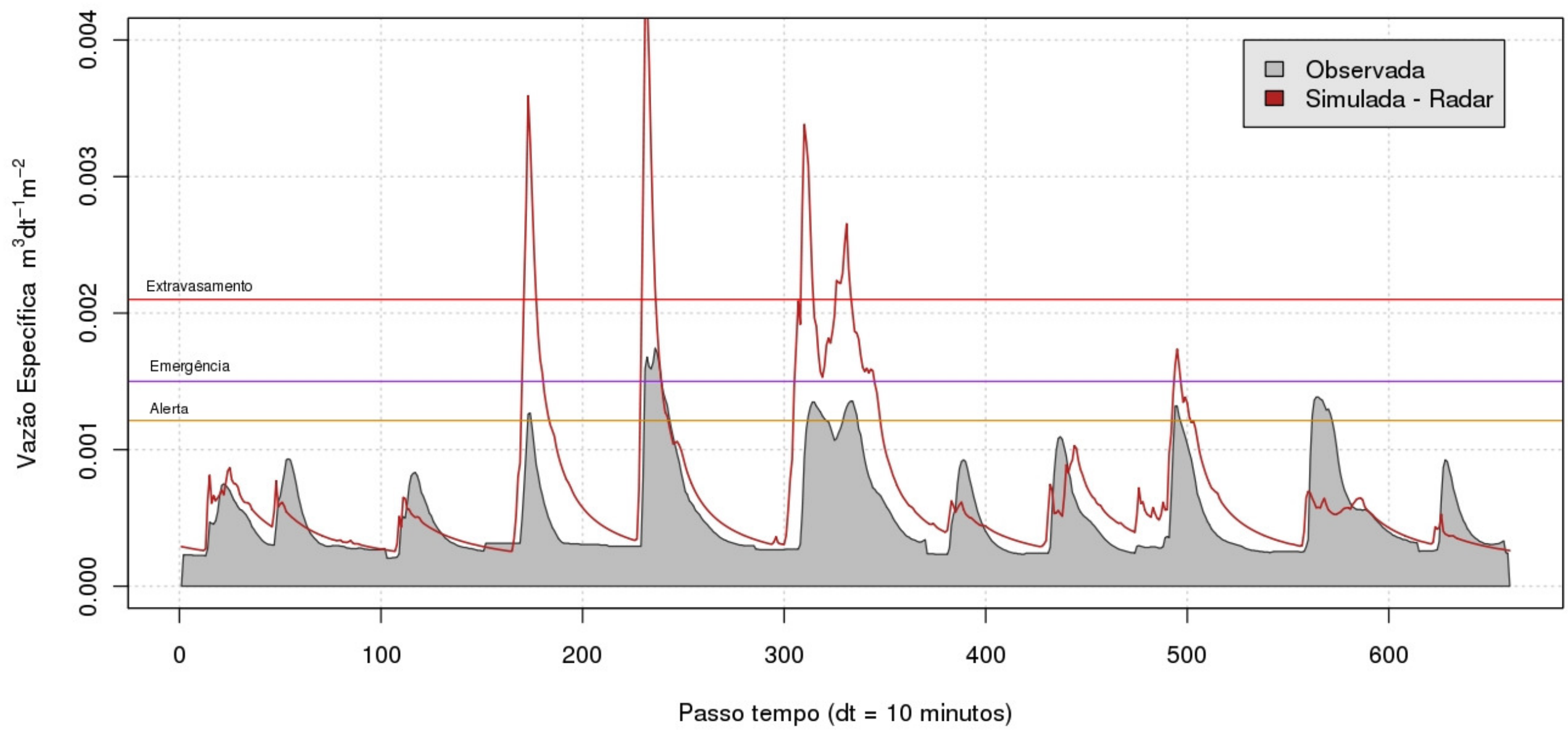

Figura 4.11: Resultado da Calibração do modelo TOPMODEL para a BRP utilizando a precipitação estimada pelo Radar Meteorológico, Eficiência máxima atingida (Nash-Sutcliffe) foi de 0.51 . A porção preenchida em cinza representa a vazão observada na secção, a linha em vermelho representa a vazão simulada para o período de calibração, com entrada de precipitação média do Radar Meteorológico. As linhas, vermelha, roxa e laranja, representam os diferentes níveis de alerta utilizados pelo SAISP nesta secção do Rio Pirajuçara. 
Vazão Observada versus Simulada - Período Validação - RADAR

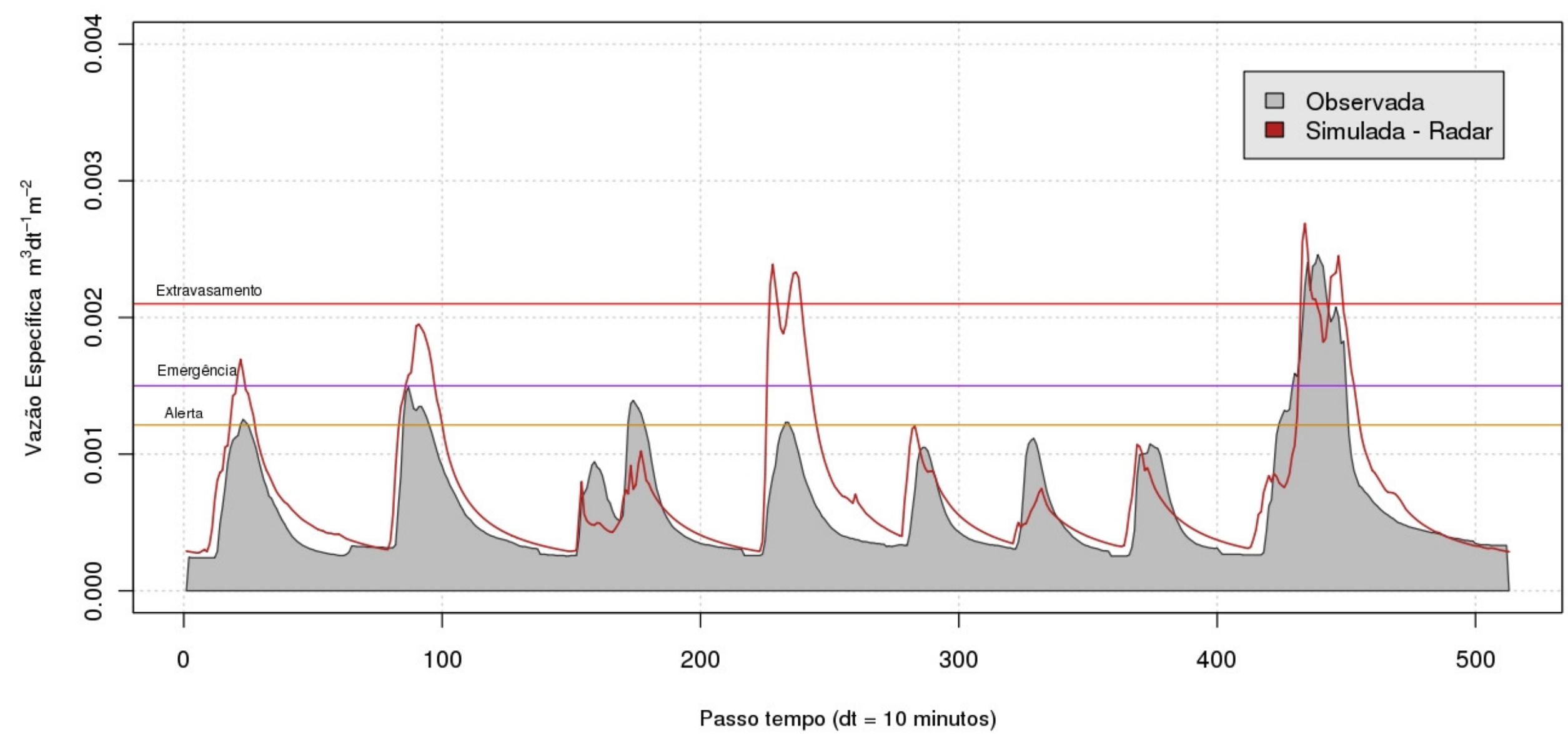

Figura 4.12: Vazão simulada versus Observada para o período de verificação, modelo calibrado a partir de entrada de precipitação estimada pelo Radar Meteorológico. A porção preenchida em cinza representa a vazão observada na secção, a linha em vermelho representa a vazão simulada para o período de calibração, com entrada de precipitação média do Radar Meteorológico. As linhas, vermelha, roxa e laranja, representam os diferentes níveis de alerta utilizados pelo SAISP nesta secção do Rio Pirajuçara. 


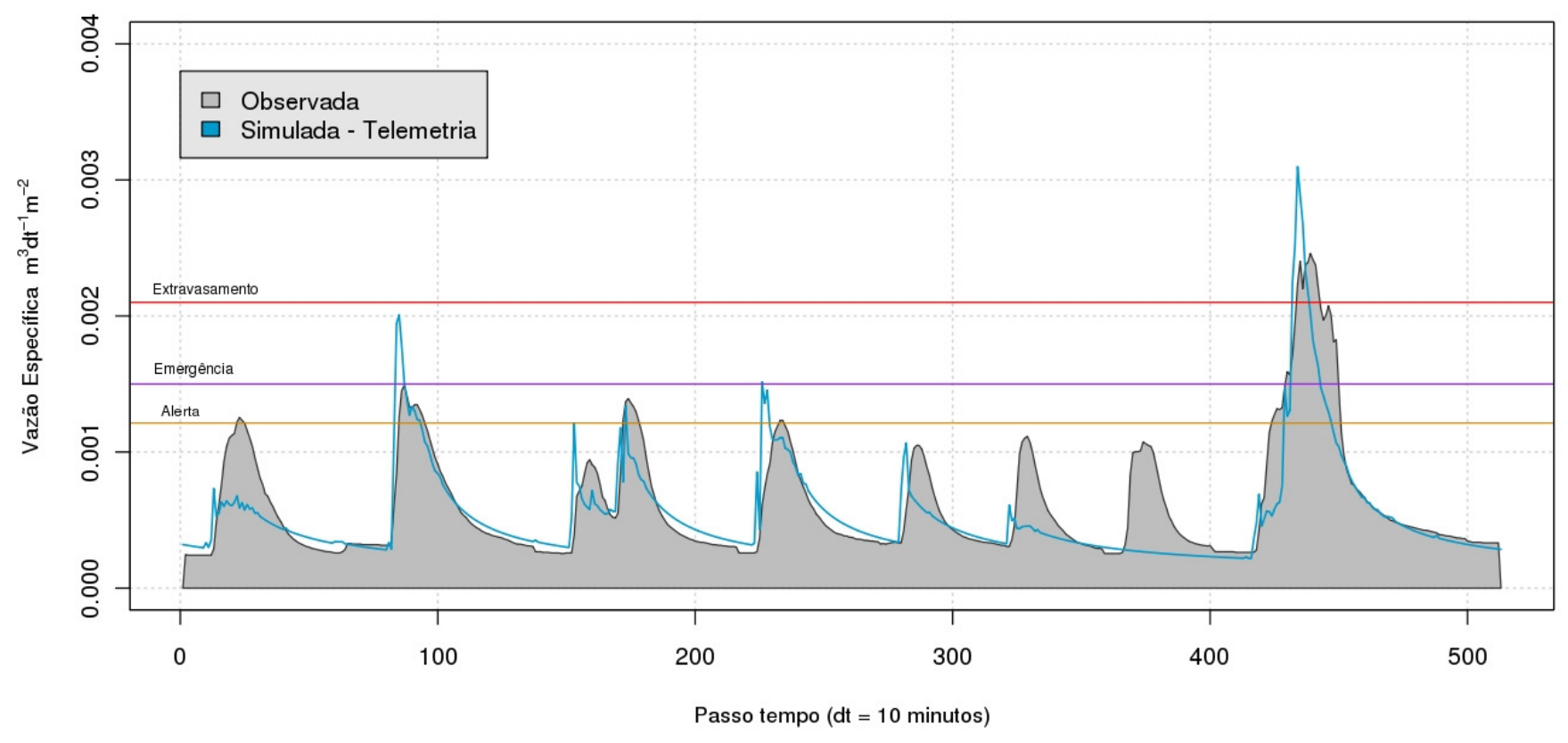

(a)

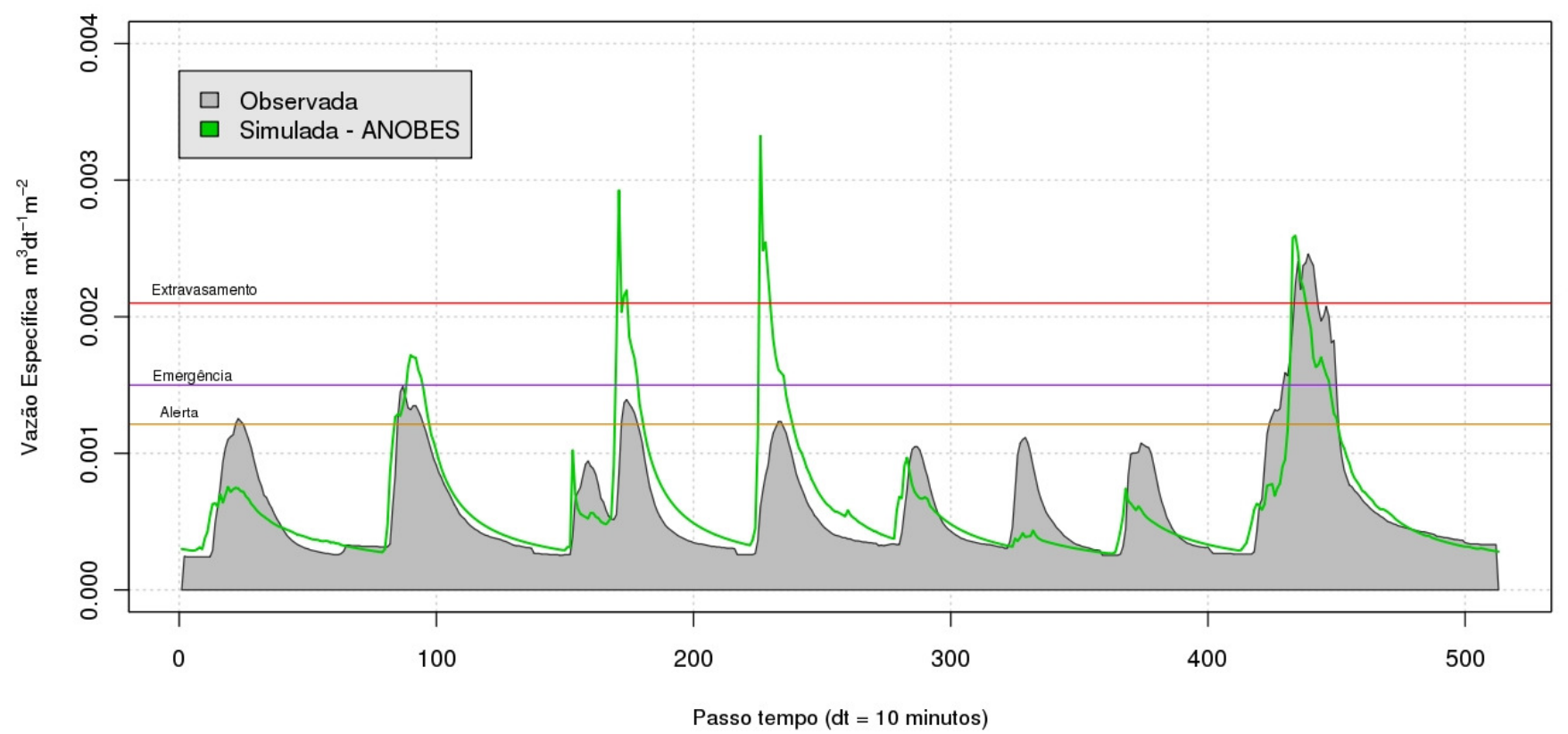

(b)

Figura 4.13: Simulações efetuadas com os parâmetros calibrados com a precipitação estimada pelo Radar Meteorológico para o período de verificação: (a) Precipitação Telemetria; (b) Precipitação integrada (ANOBES). As linhas, vermelha, roxa e laranja, representam os diferentes níveis de alerta utilizados pelo SAISP nesta secção do Rio Pirajuçara. 


\subsubsection{Simulações com ANOBES}

A calibração do TOPMODEL com entrada de precipitação média na bacia analisada pelo método ANOBES (Fig. 4.14) atingiu a eficiência máxima de 0,42. Observa-se na Tab. 4.3 um EQM alto para este período e o viés médio negativo indica que na média a vazão foi subestimada na média. Nota-se um comportamento das vazões simuladas similar às vazões com telemetria. Ainda, com exceção de três eventos compreendidos entre os passos de tempo 150 e 400, todos os eventos foram subestimados.

Para o período de verificação (Fig. 4.15) houve melhoras significativas nas vazões simuladas. $\mathrm{Na}$ Tab. 4.3 encontram-se os valores de eficiência, erro quadrático médio e viés médio para as três entradas de precipitação. Para a precipitação analisada, a eficiência foi de 0,62. Observa-se que em $50 \%$ dos eventos, o modelo conseguiu anteceder a vazão crítica, porém superestimando a vazão de pico em todos os casos. Nos demais casos, todos os eventos foram subestimados, evidenciado pelo viés médio negativo para este período. Nota-se ainda que, assim como para o período de calibração, as simulações com precipitação analisada resultaram em comportamento bastante similar às simulações com telemetria, ou seja, no processo de integração a precipitação analisada foi bastante influenciada por esta medida.

Pode-se observar que o maior valor de eficiência foi atingido quando se utilizou a precipitação estimada pelo radar meteorológico (Fig. 4.16b) assim como a menor incerteza da previsão e magnitude do viés médio. Do ponto de vista do alerta à vazões críticas, esta simulação foi a que apresentou melhor resultado nesta calibração, pois antecipou $75 \%$ dos eventos, contra $50 \%$ e $37.5 \%$ das simulações com ANOBES e telemetria respectivamente. Segundo PEREIRA FILHO (2010, contato pessoal), as simulações utilizando a precipitação integrada foram afetadas principalmente pela baixa qualidade das informações de telemetria. 
Tabela 4.3: Valores de eficiência (NS), erro quadrático médio (EQM) e Viés Médio para as simulações efetuadas com todas as entradas de precipitações. Modelo calibrado com precipitação integrada pelo método ANOBES.

\begin{tabular}{|l|c|c|c|}
\hline Calibração - Precipitação ANOBES & NS & EQM & Viés \\
\hline & 0,4 & $2.5 \times 10^{-3}$ & $-1.5 \times 10^{-4}$ \\
\hline Verificação & & & \\
\hline Radar & 0,7 & $4.2 \times 10^{-4}$ & $1.82 \times 10^{-5}$ \\
\hline & & & $-18,0 \times 10^{-5}$ \\
\hline Telemetria & 0,7 & $4.1 \times 10^{-3}$ & \\
\hline & & & $-7.5 \times 10^{-5}$ \\
\hline Anobes & 0,6 & $1.7 \times 10^{-3}$ & \\
\hline
\end{tabular}




\section{Vazão Observada versus Simulada - Calibração}

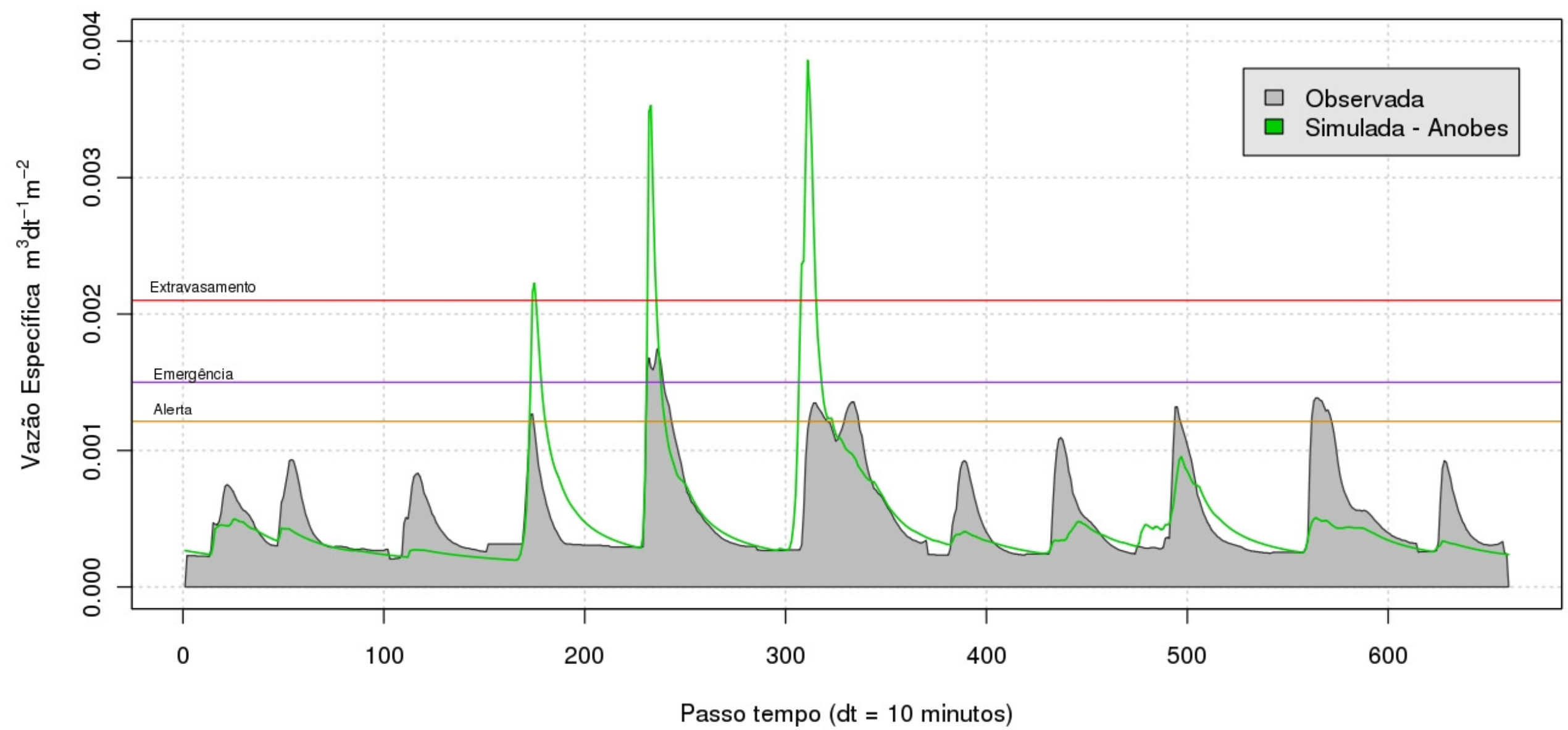

Figura 4.14: Resultado da Calibração do modelo TOPMODEL para a BRP utilizando a precipitação integrada pelo esquema ANOBES, Eficiência máxima atingida (Nash-Sutcliffe) foi de 0.42. A porção preenchida em cinza representa a vazão observada na secção, a linha em verde representa a vazão simulada para o período de calibração, com entrada de precipitação média do Radar Meteorológico integrada com a telemetria de superfície. As linhas, vermelha, roxa e laranja, representam os diferentes níveis de alerta utilizados pelo SAISP nesta secção do Rio Pirajuçara. 


\section{Vazão Observada versus Simulada - Calibração ANOBES - Precipitação ANOBES}

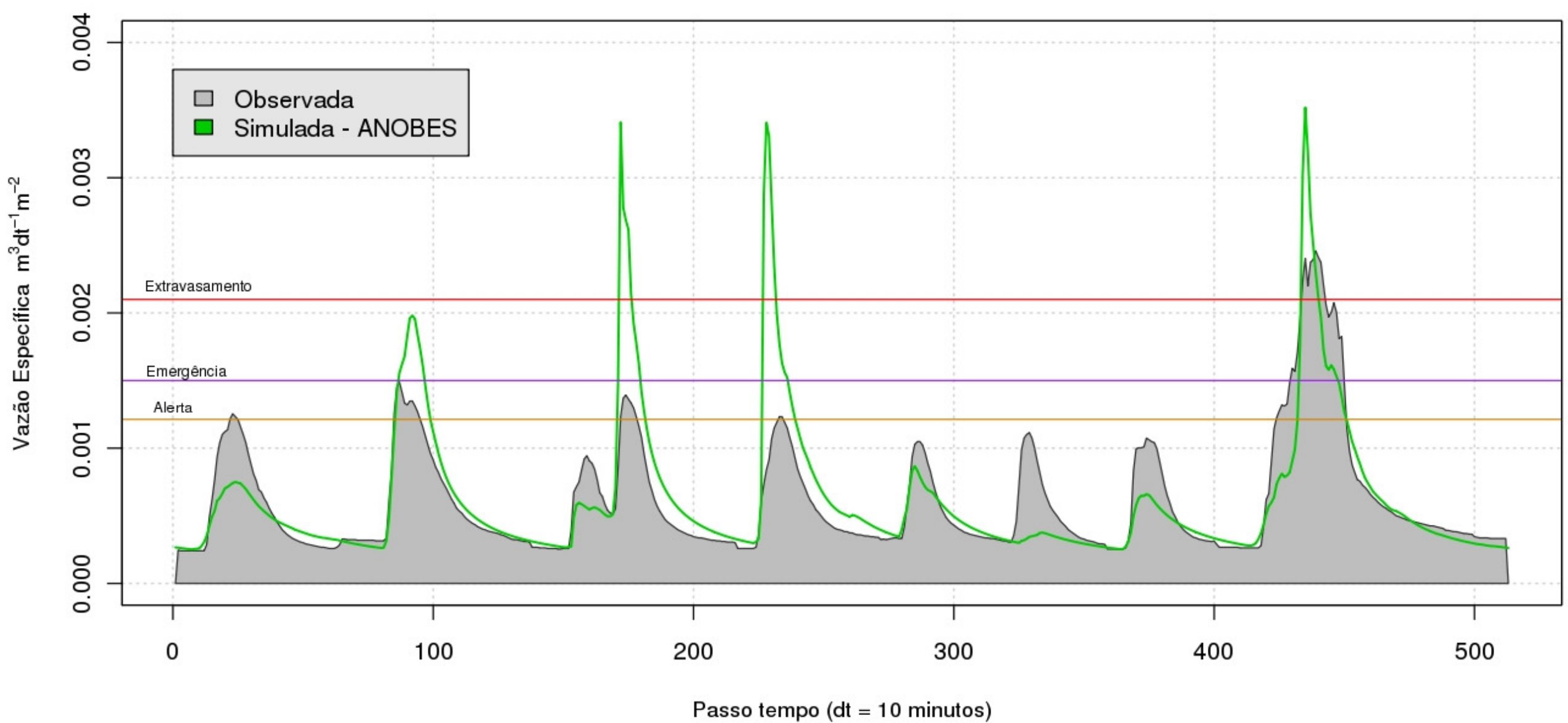

Figura 4.15: Vazão simulada versus Observada para o período de verificação, modelo calibrado a partir de entrada de precipitação integrada pelo esquema ANOBES. A porção preenchida em cinza representa a vazão observada na secção, a linha em verde representa a vazão simulada para o período de calibração, com entrada de precipitação média do Radar Meteorológico integrada com a telemetria de superfície. A s linhas, vermelha, roxa e laranja, representam os diferentes níveis de alerta utilizados pelo SAISP nesta secção do Rio Pirajuçara. 


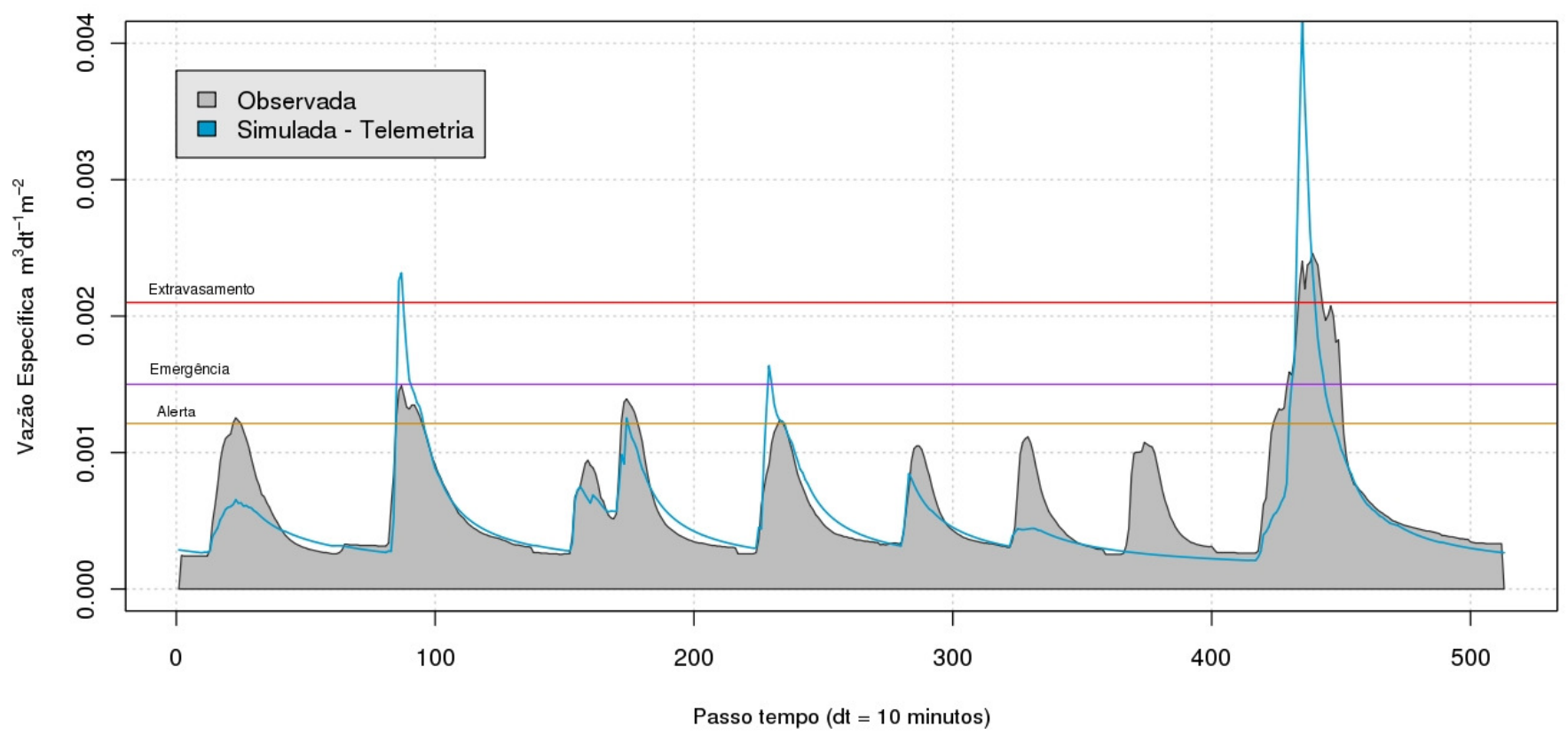

(a)

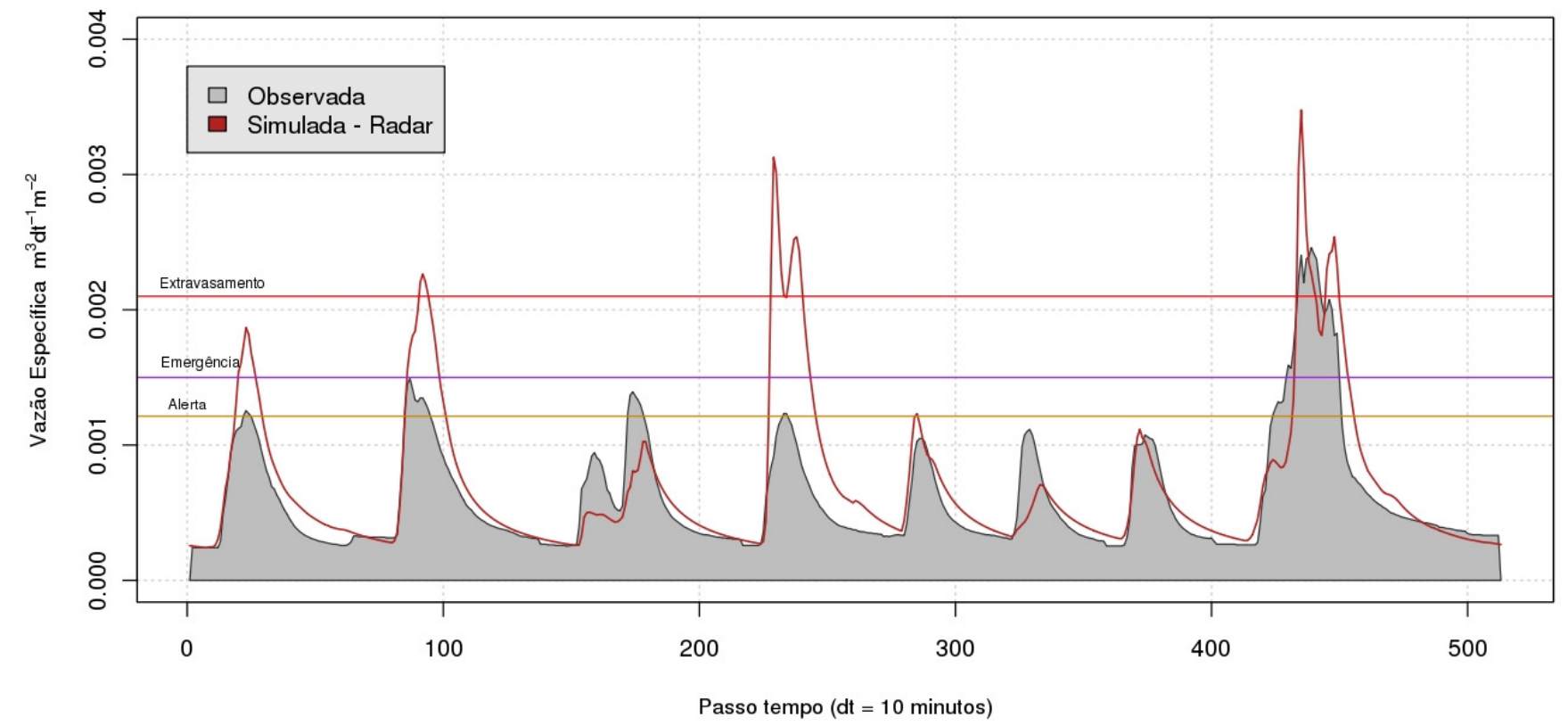

(b)

Figura 4.16: Simulações efetuadas com os parâmetros calibrados com a precipitação estimada pelo Radar Meteorológico para o período de verificação: (a) Precipitação Telemetria; (b) Precipitação integrada (ANOBES. As linhas, vermelha, roxa e laranja, representam os diferentes níveis de alerta utilizados pelo SAISP nesta secção do Rio Pirajuçara. 


\subsection{Impacto dos sistemas meteorológicos nas simulações com TOPMODEL}

Foram selecionados três eventos para o período de verificação com finalidade da avaliação do tipo de precipitação, do ponto de vista espacial e temporal do mesmo e suas conseqüências nas simulações hidrológicas. O critério para escolha dos eventos levou em consideração o impacto na simulação. Foi escolhido um evento para um caso de subestimativa da vazão, um evento para superestimativa da vazão e por fim, um evento para um caso de bom ajuste das vazões de pico para as simulações com telemetria. Neste processo se comparou também o comportamento das simulações com as entradas de precipitação do RSP e precipitação analisada pela ANOBES.

\subsubsection{Evento dia 25 de Janeiro de 2009}

O evento ocorrido entre às 2000 UTC do dia 25 de Janeiro e 0700 UTC do dia 26 de Janeiro (Evento 11, Tab. 3.3) foi classificado como bandas dispersas, e resultou em uma vazão de pico de $110 \mathrm{~m}^{3} \mathrm{~s}^{-1}$. Observou-se pelas cartas sinóticas de superfície das 0000 UTC dos dias 25 e 26 de Janeiro de 2009 (Fig. 4.17a e 4.17b respectivamente) o escoamento de grande escala dominado por uma grande região de alta pressão em superfície, que resultou em ventos de escala sinótica relativamente fracos. Em altos níveis (Fig. 4.17c) observa-se em destaque os fortes ventos sobre o leste do estado de SP. Na sondagem das 1200 UTC (Fig. 4.18) deste dia, este fato pode ser confirmado. Observa-se gradiente vertical de velocidade intenso, principalmente entre os níveis baixos (1000 hPa) e médios (500 hPa). Entre estes níveis também se observa uma diferença significativa entre a umidade na camada, o que intensifica a instabilidade. É importante notar ainda na sondagem deste dia, que o valor de CINE é zero. Valores de CINE baixos ou nulos indicam condições favoráveis para convecção generalizada, porém com intensidade inferior a tempestades que se formam em dias de CINE significativo. 


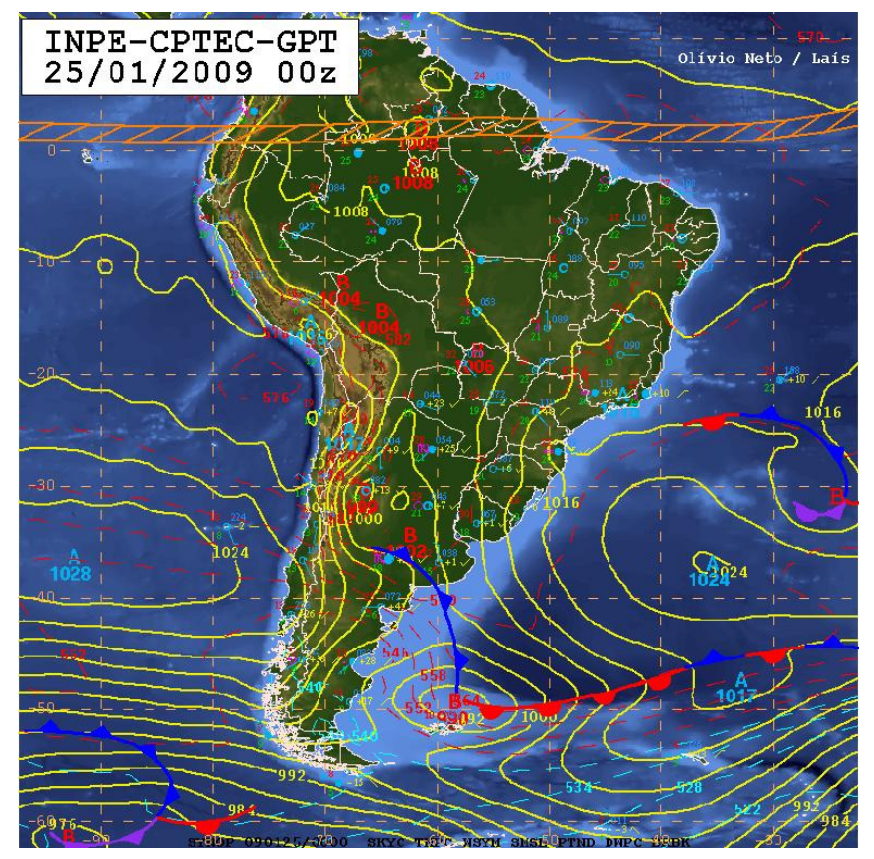

(a)

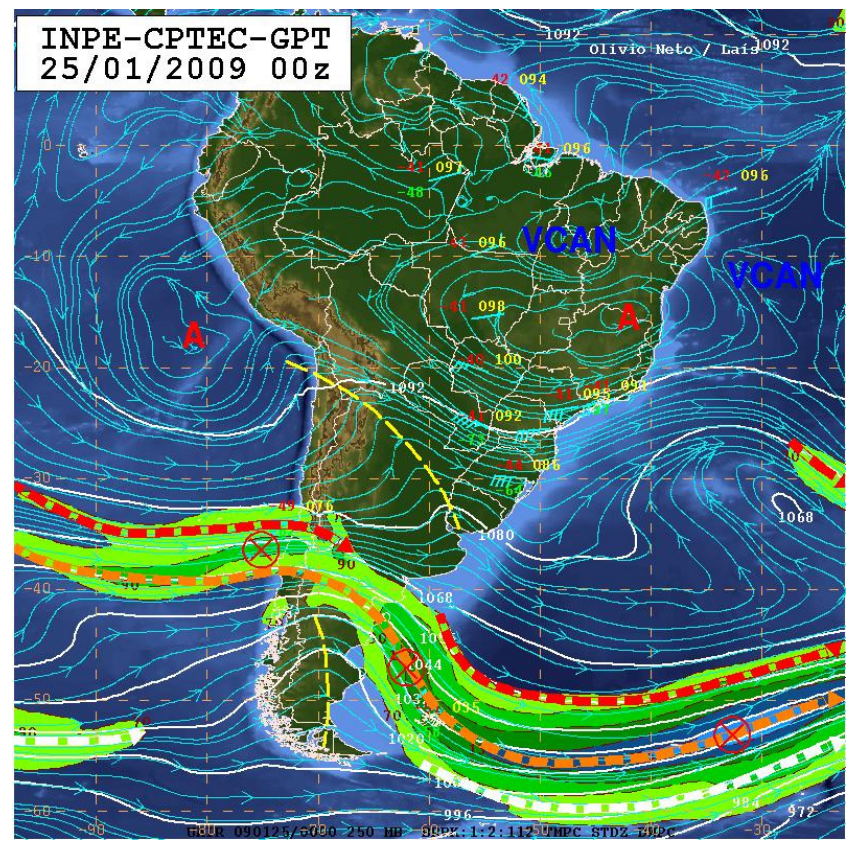

(c)

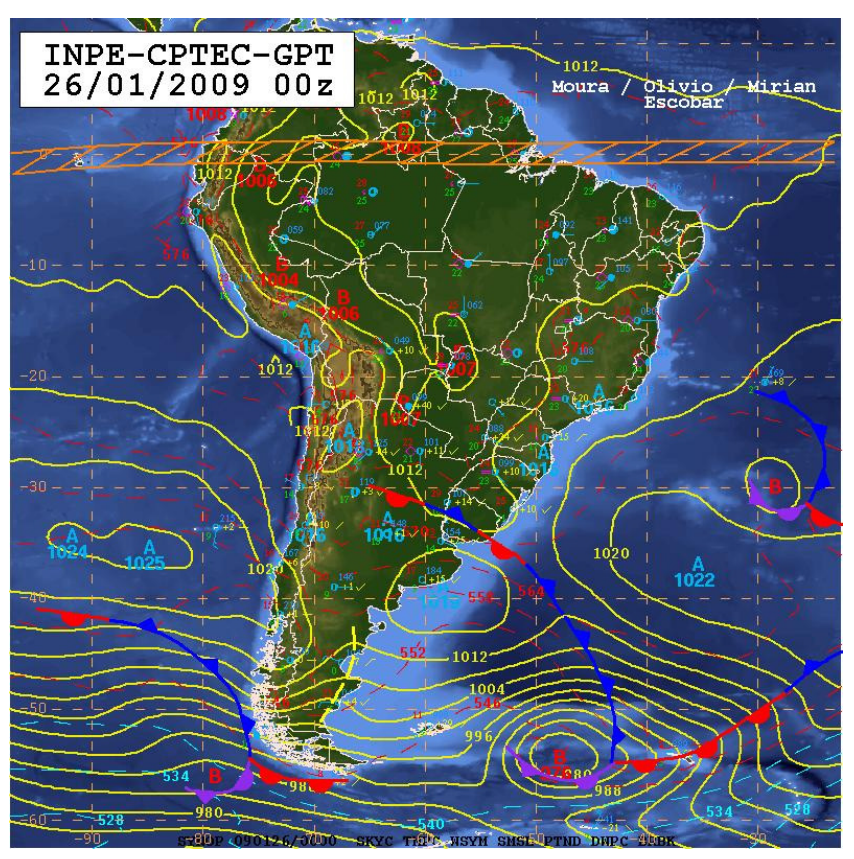

(b)

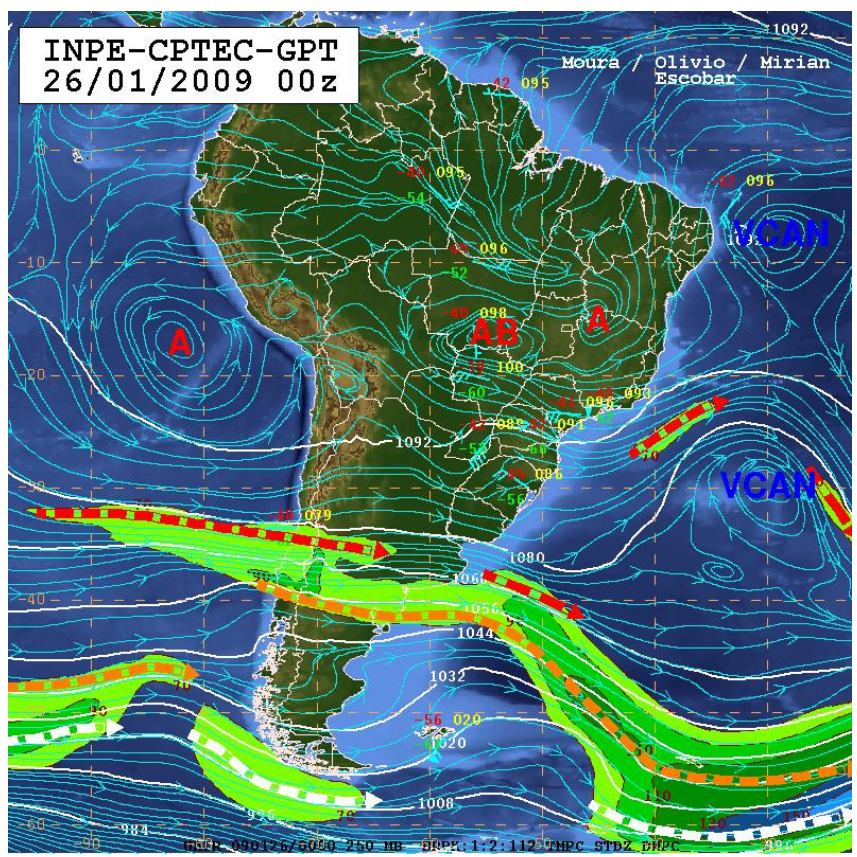

(d)

Figura 4.17: Cartas sinóticas produzidas pelo CPTEC/INPE dos dias 25 e 26 de Janeiro de 2009. As figuras (a) e (c) são relativos aos níveis baixos (1000 hPa) e altos ( $\mathrm{hPa}$ ) para o dia 25 de Janeiro de 2009 respectivamente. As figuras (b) e (d) são relativos aos níveis baixos e altos para o dia 26 de Janeiro de 2009, respectivamente.

Fonte: http://www.cptec.inpe.br/tempo. 


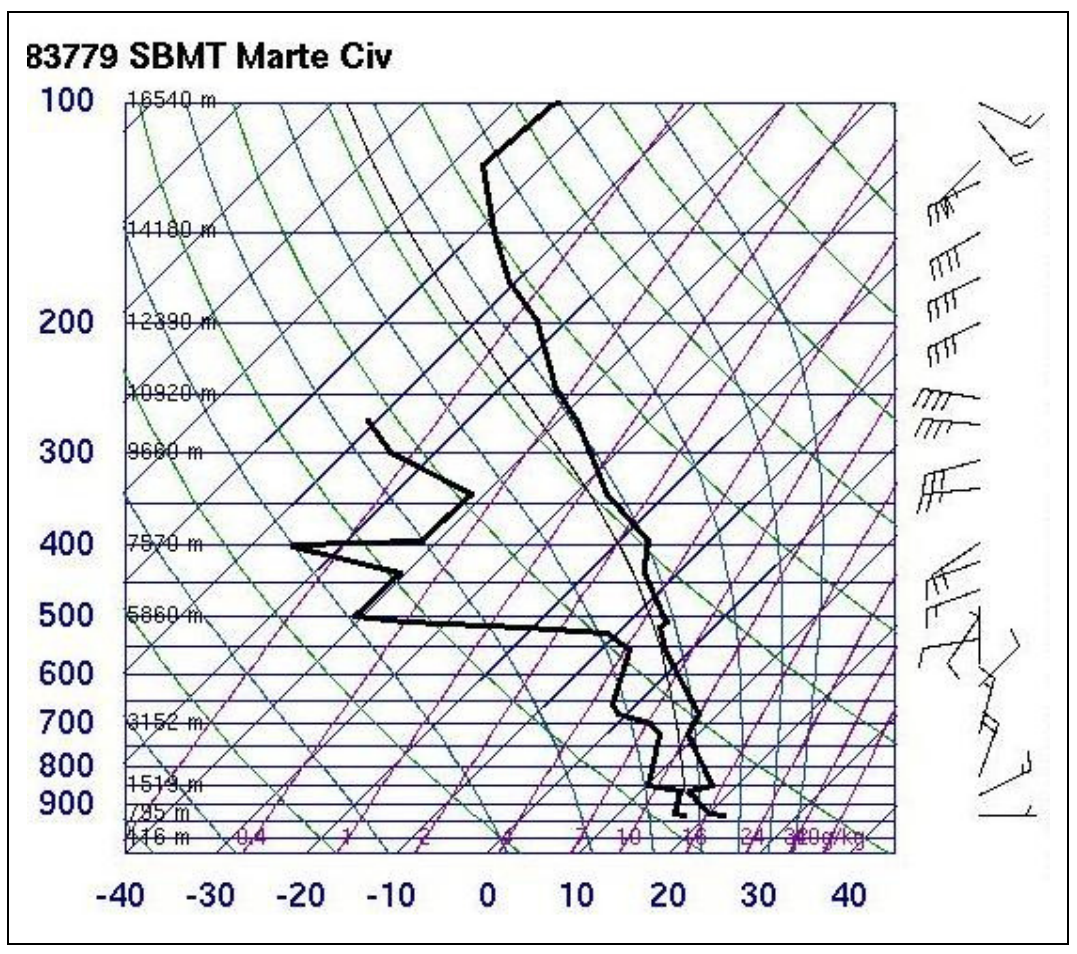

Figura 4.18: Sondagem atmosférica das 1200 UTC do dia 25 de Janeiro de 2009. Fonte: http://weather.uwyo.edu/upperair/sounding.html

A ausência de ventos de escala sinótica em superfície proporcionou o aquecimento intenso da superfície e disparou convecção generalizada ao norte da RMSP. Esta área se deslocou e atingiu a bacia do Rio Pirajuçara por volta das 2200 UTC, a precipitação atingiu o pico da intensidade as 2230 UTC e a partir das 0010 UTC do dia 26 de Janeiro se desintensificou. Na Fig. 4.19 observa-se a seqüência de imagens da área de instabilidade formada ao norte da RMSP e deslocando-se no sentido NE-SW. 


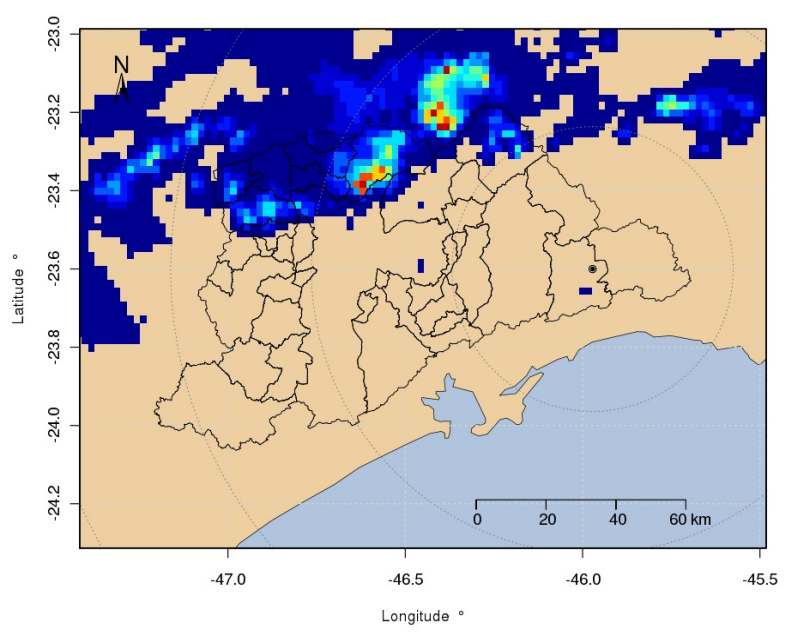

(a)

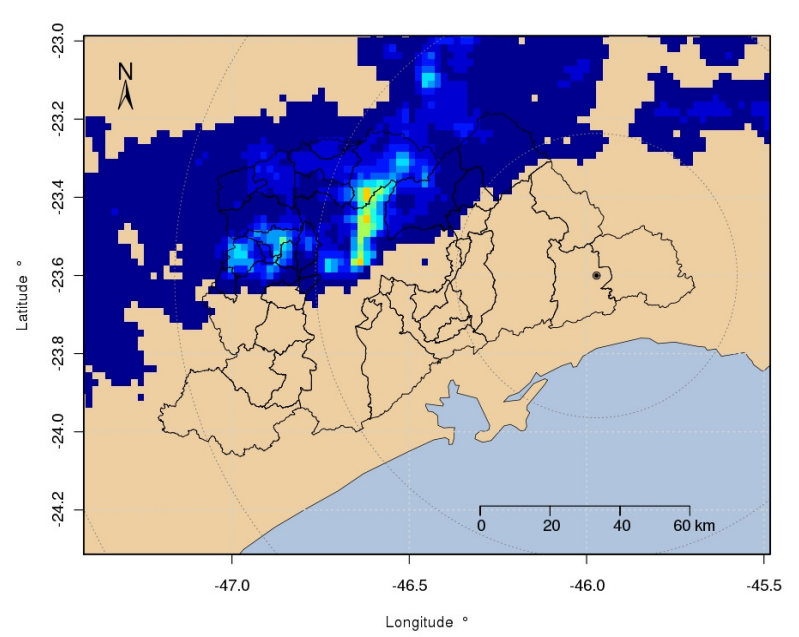

(c)

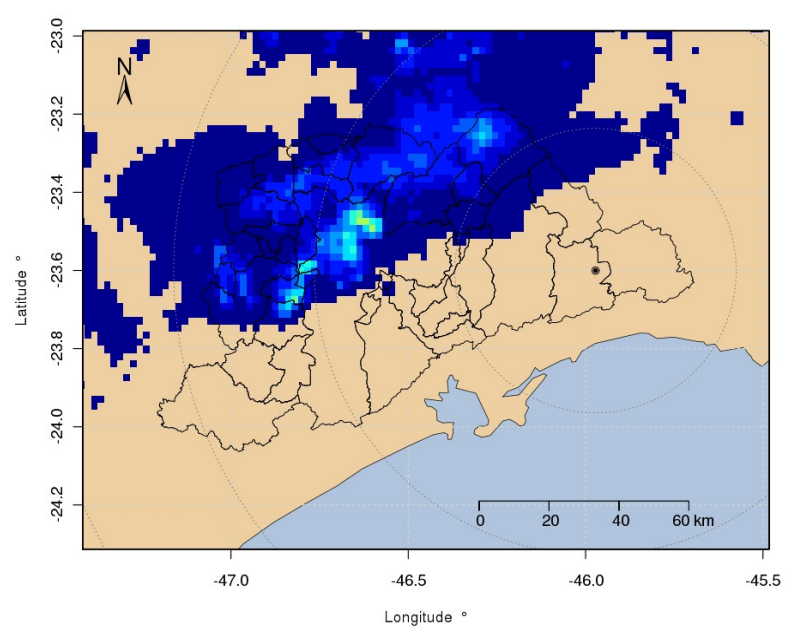

(e)

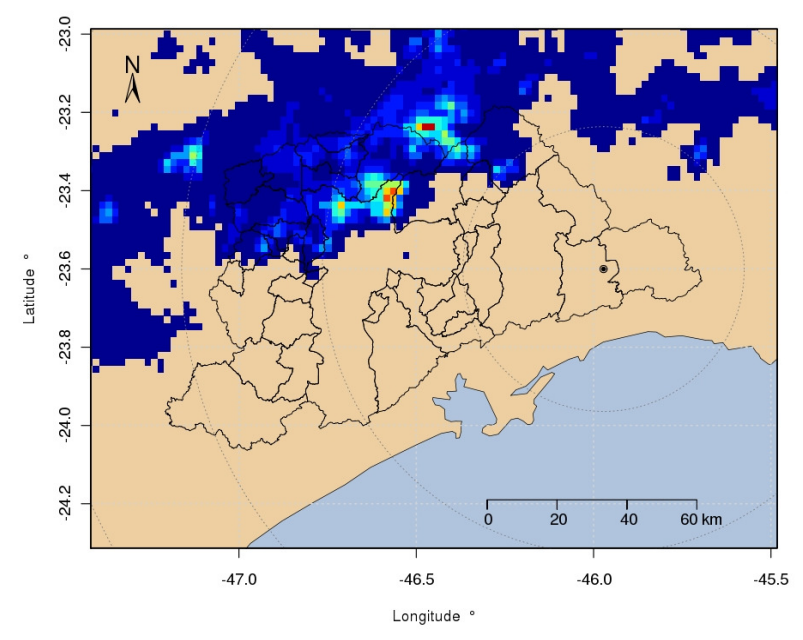

(b)

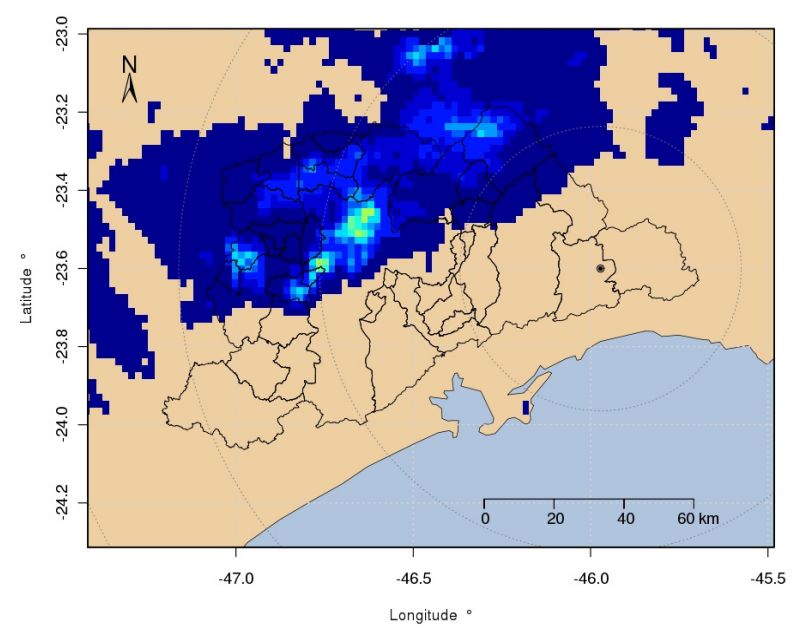

(d)

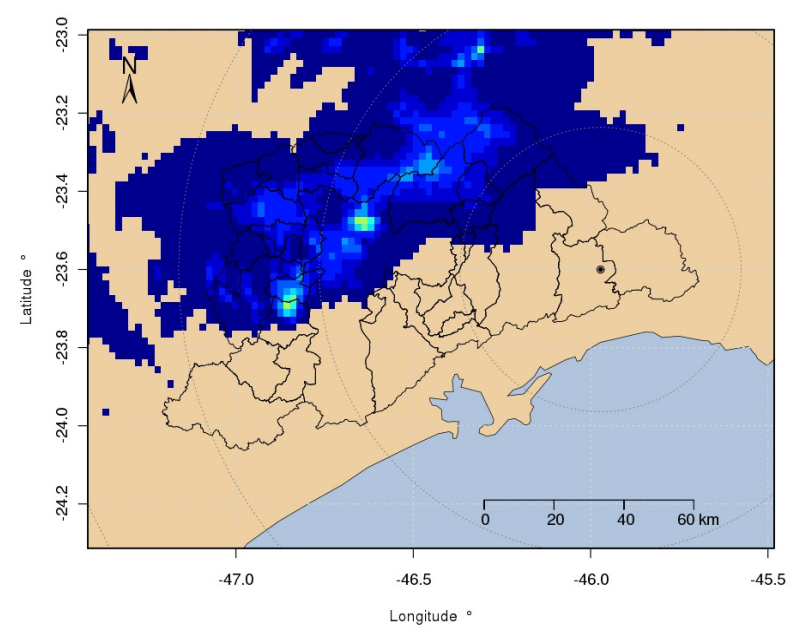

(f)

5

10

15

Figura 4.19: Evolução da precipitação sobre a RMSP medida pelo RSP no dia 25/01/2009. A área sombreada representa a precipitação acumulada em 10 minutos em milímetros, as linhas pretas são a divisão política da RMSP. (a) 2100 UTM;(b) 2130 UTM; (c) 2200 UTM ; (d) 2230 UTM; (e) 2240 UTM; (f) 2250 UTM. 
Na Fig. 4.20 observa-se a evolução temporal da precipitação sobre a BRP. Nota-se que o sistema precipitante se deslocou de montante para jusante da bacia. Neste caso, a telemetria de superfície captou de maneira correta o inicio da precipitação e por conseqüência, o início do hidrograma simulado se iniciou no passo de tempo correto (Fig. 4.9). Porém, o deslocamento da precipitação em direção a montante da bacia fez com que a telemetria não registrasse a precipitação mais intensa ocorrida nos tempos seguintes (Fig. 4.6), o que resultou na subestimativa do pico da vazão simulada. Este caso mostra a deficiência da representação espacial da precipitação por pluviômetros.

As estimativas da precipitação pelo RSP representaram melhor a chuva média na bacia. Na sondagem das 1200 UTC (Fig 4.18), observou-se que a isoterma de $0^{\circ} \mathrm{C}$ se encontra bastante acima da altura de $3 \mathrm{~km}$, assim pouco ou nenhuma influencia da banda brilhante na estimativa da intensidade da precipitação foi detectada. A vazão foi mais bem representada (Fig. 4.12) do que na simulação com telemetria, pois toda a evolução espacial e temporal da precipitação foi detectada com a utilização do RSP. Apesar da pequena superestimativa, do ponto de vista de alerta a eventos hidrológicos de cheia, esta simulação antecipou a fase da ocorrência de um determinado nível de alerta.

Nas simulações com precipitação integrada pelo ANOBES (Fig. 4.16), a vazão simulada subestimou a vazão observada. Este fato ocorreu ao mesmo instante em que o sistema precipitante se deslocou para a porção mais a montante do posto telemétrico, porém, ainda dentro do raio de influência do mesmo. Este fato pode ser observado na comparação das precipitações médias (Fig. 4.6) onde as precipitações médias calculadas pelo método ANOBES ficaram muito próximas as medidas efetuadas pela telemetria de superfície. 


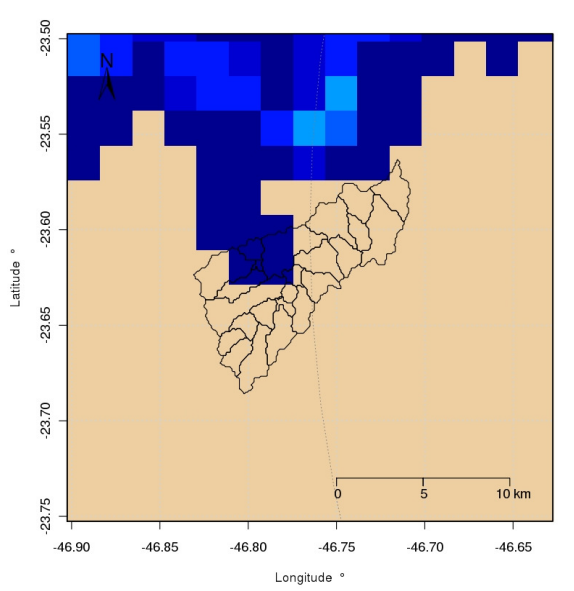

(a)

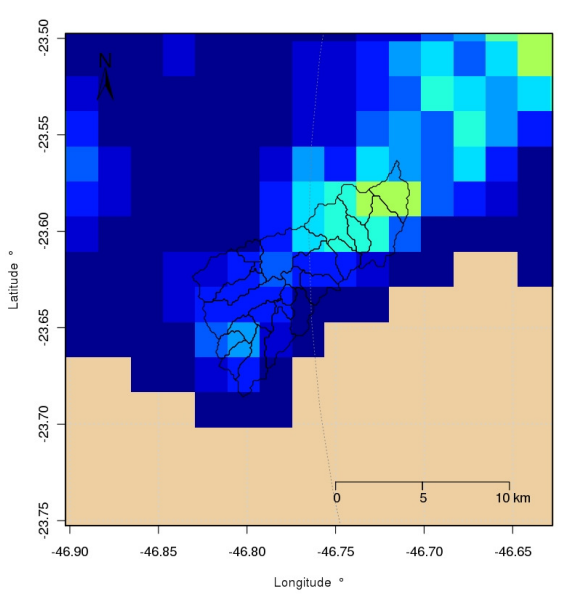

(d)

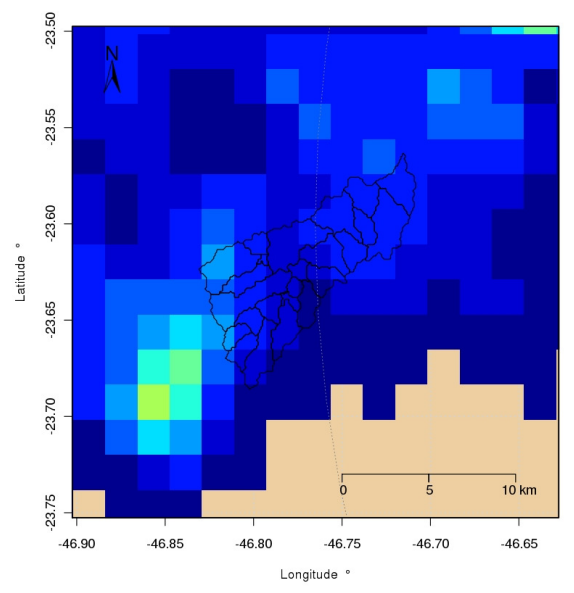

(g)

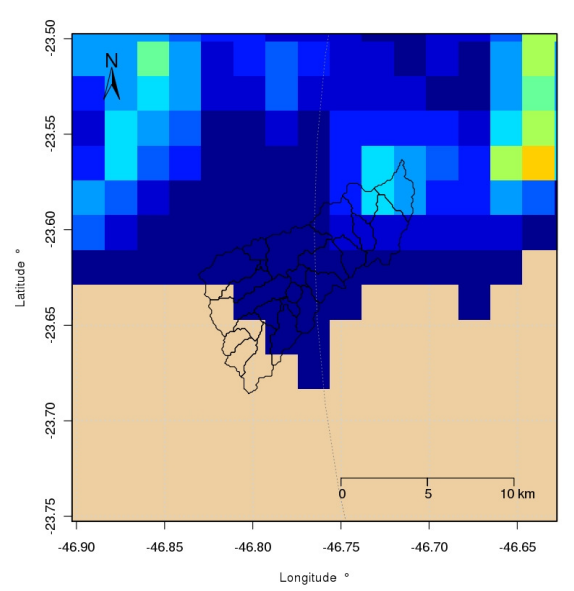

(b)

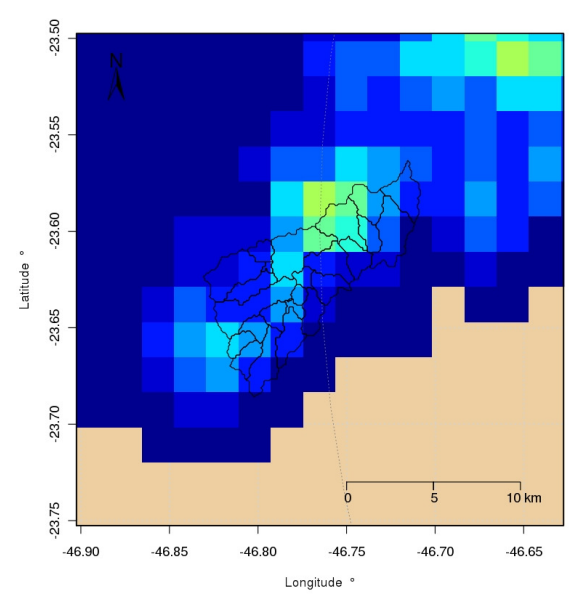

(e)

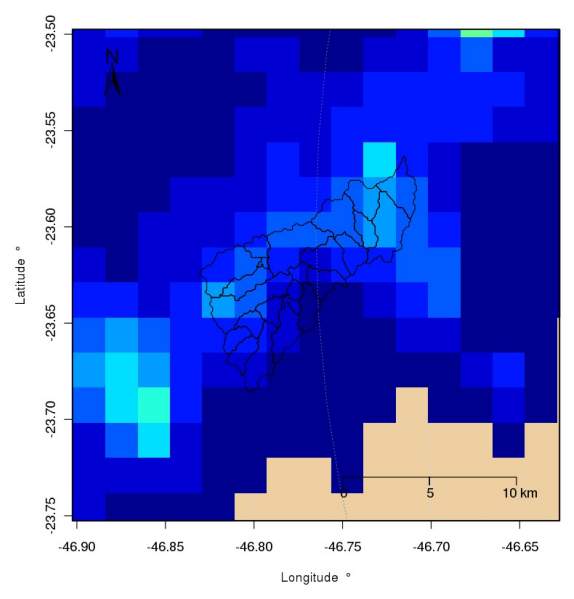

(h)

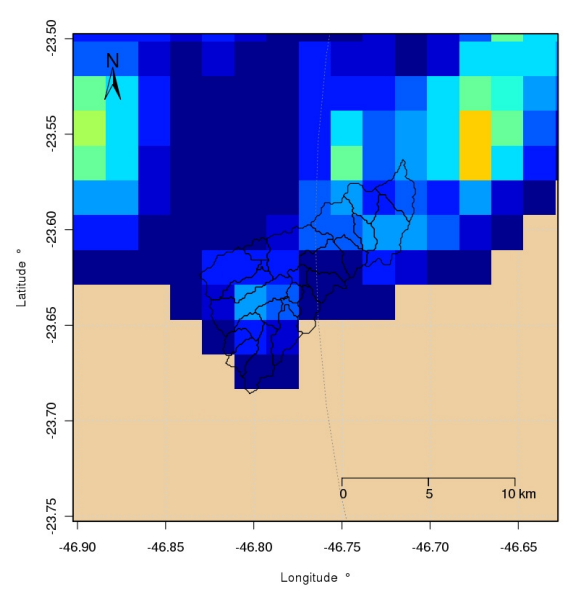

(c)

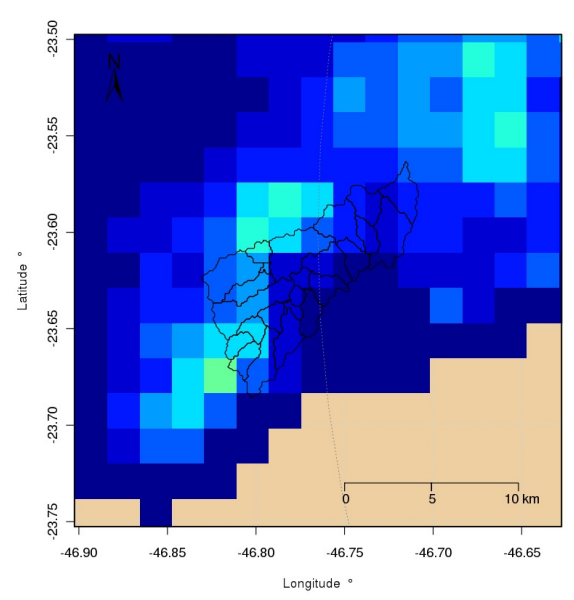

(f)

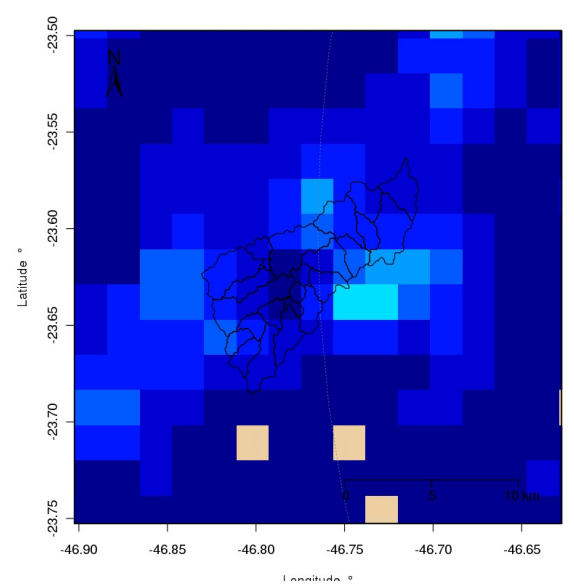

(i)

Figura 4.20: Evolução da precipitação sobre a BRP medida pelo RSP no dia 25/01/2009. A área sombreada representa a precipitação acumulada em 10 minutos em milímetros, utilizando o CAPPI de $3 \mathrm{Km}$ com resolução $2 \times 2 \mathrm{Km}$ do RSP, as linhas pretas são os divisores de água que compõe a BRP. (a) 2130 UTM; (b) 2200 UTM; (c) 2210 UTM; (d) 2220 UTM; (e) 2230 UTM; (f) 2240 UTM; (g) 2250 UTM; (h)2300 UTM; (i)2310 UTM. 


\subsubsection{Evento dia 26 de Janeiro de 2009}

Este evento foi classificado como um evento de convecção isolada, e trata-se do evento 12 da Tab. 3.3. Organizou-se sobre a BRP entre às 1600 UTC do dia 26 de Janeiro de 2009 até as 0350 UTC do dia 27 de Janeiro de 2009. O evento resultou em um pico de vazão de aproximadamente $130 \mathrm{~m}^{3} \mathrm{~s}^{-1}$. As condições sinóticas deste dia indicavam a persistência da circulação citada no evento do dia anterior (25 de Janeiro). Nas análises da carta de superfície dos dias 26 de Janeiro às 0000 UTC e do dia 27 de Janeiro às 0000 UTC (Fig. 4.17c e 4.21a respectivamente) nota-se a presença da mesma área de alta pressão sobre toda a faixa leste do estado de SP. Em altos níveis o destaque fica novamente pelo escoamento com velocidades altas, orientação praticamente zonal e uma pequena região de divergência entre as latitudes de $20^{\circ}$ e $25^{\circ} \mathrm{S}$ e longitude $40^{\circ}$ e $50^{\circ} \mathrm{W}$, ou seja, sobre a faixa leste e nordeste do estado de SP. Este tipo de configuração com ausência de ventos de escala sinótica em superfície e divergência de massa em níveis superiores da atmosfera favorece a formação de gradientes locais de temperatura mais intensos e, tipicamente, junto com a termodinâmica local, dá origem a sistemas precipitantes formados a partir de circulações locais ou convecção isolada.

Observa-se na sondagem atmosférica das 1200 UTC (Fig. 4.22) umidade em praticamente todo o perfil amostrado. O cisalhamento também é destacado, principalmente entre a superfície e os níveis acima de $300 \mathrm{hPa}$. No período da tarde deu-se inicio a convecção isolada em várias partes da RMSP, na Fig. 4.23 pode-se observar a evolução temporal e espacial das células que atingiram a região da BRP. Nota-se que várias células convectivas isoladas já se apresentavam formadas no sul da RMSP no horário das 1700 UTC. Nas imagens seguintes observa-se a ocorrência de formação de outras células nas regiões de confluência da frente de rajada de uma ou mais células ordinárias. Na imagem das 1830 UTC já se observa uma célula mais desenvolvida sobre o SW da RMSP e outra já em estado de desenvolvimento a NE desta. O que se observa nas imagens dos horários seguintes é uma célula intensa formada sobre a BRP. Nas imagens aproximadas sobre a bacia (Fig. 4.24), pode-se ter uma melhor visão do desenvolvimento desta célula sobre os limites da BRP. 


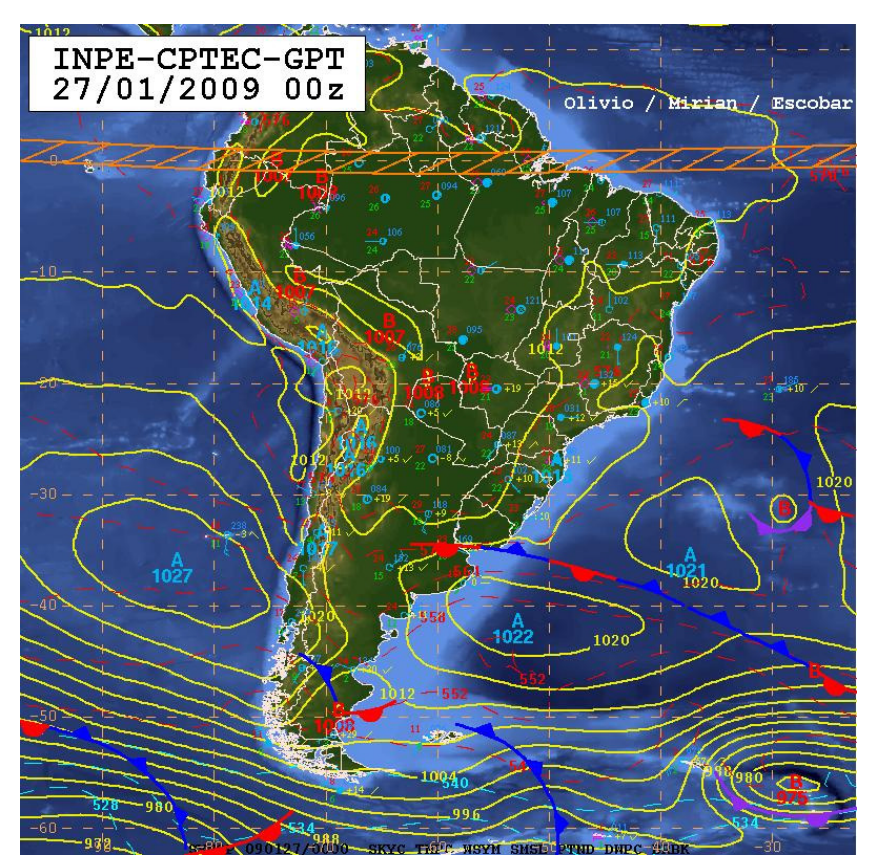

(a)

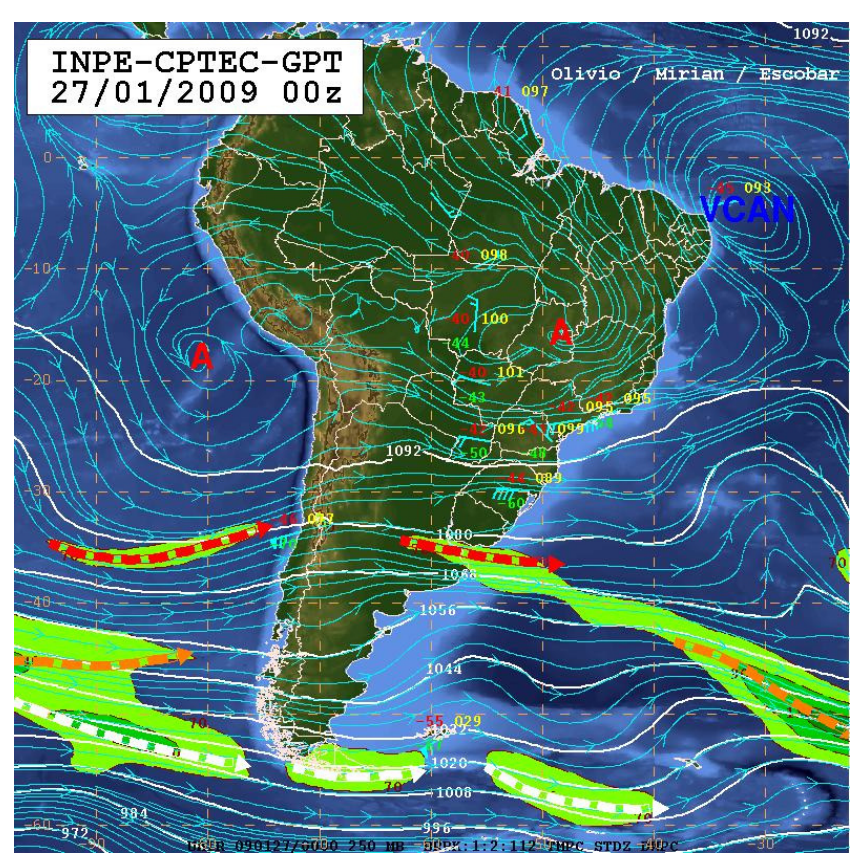

(b)

Figura 4.21: Similar à Fig. 4.17, exceto para 27 de Janeiro de 2009.

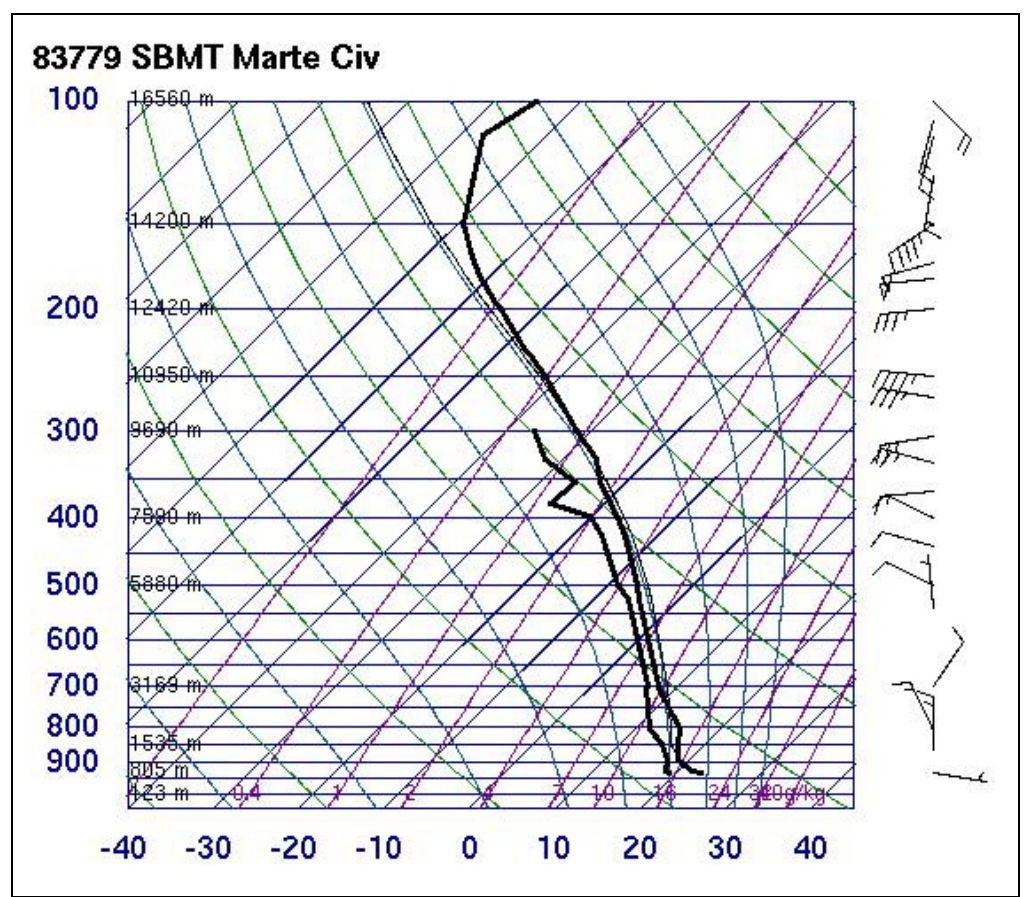

Figura 4.22 : Simular à 4.18 exceto para 1200 UTC de 25 de Janeiro de 2009. 


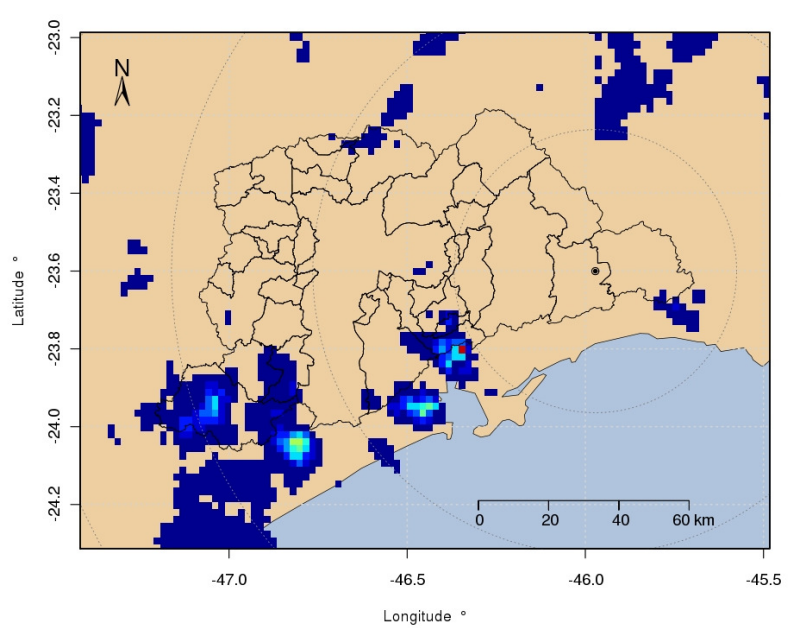

(a)

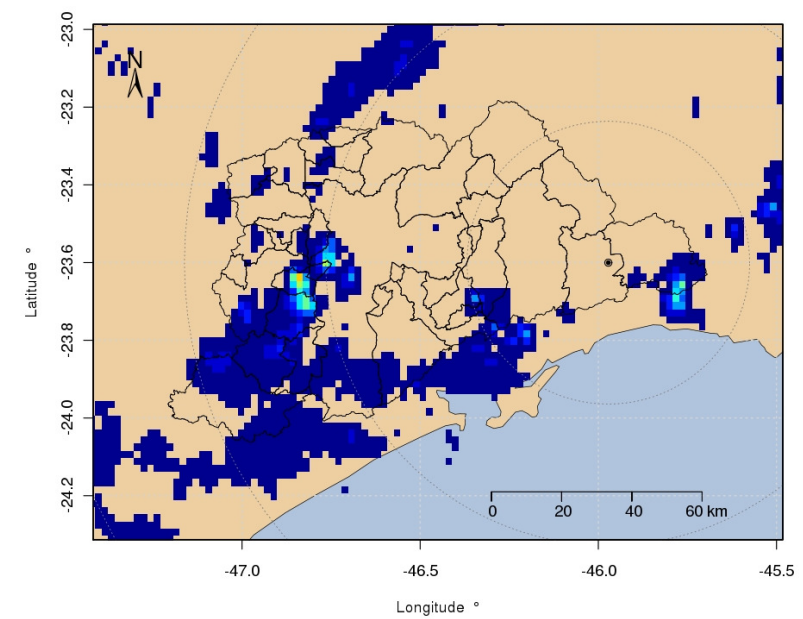

(c)

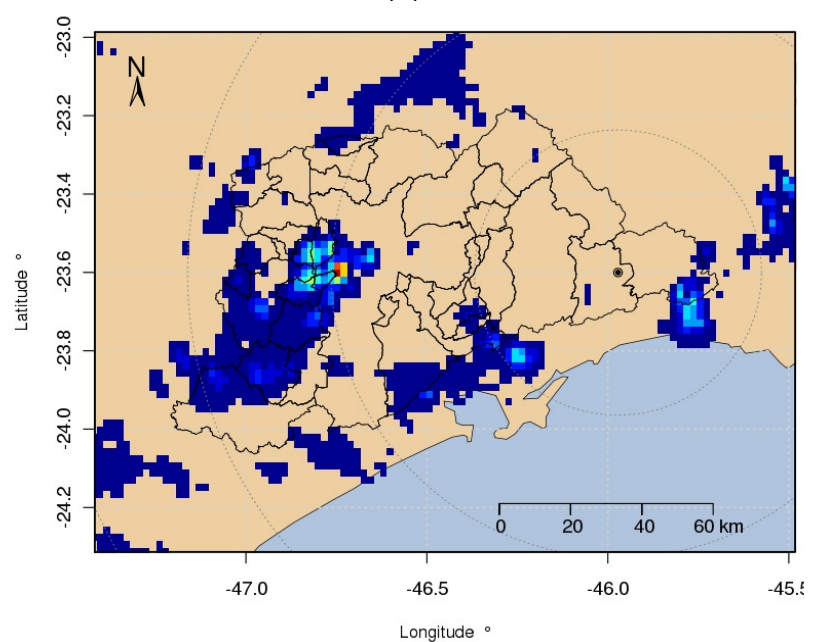

(e)

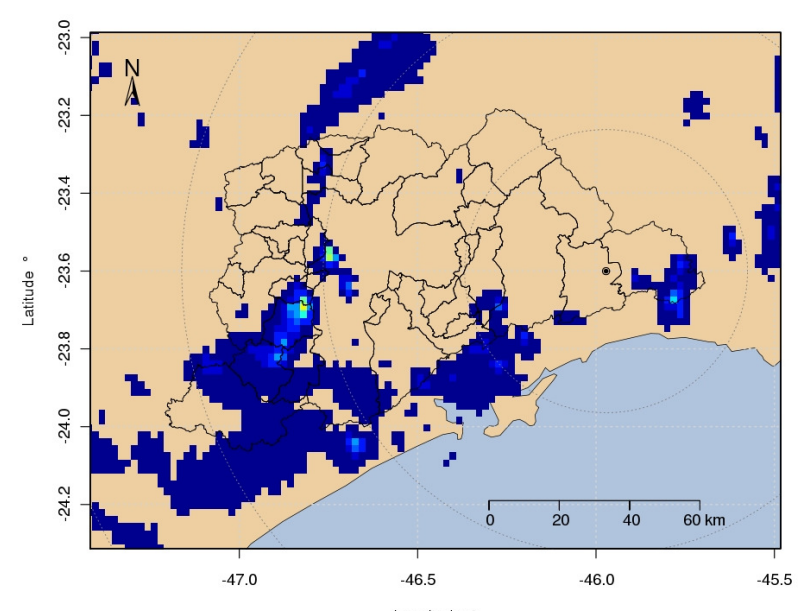

(b)

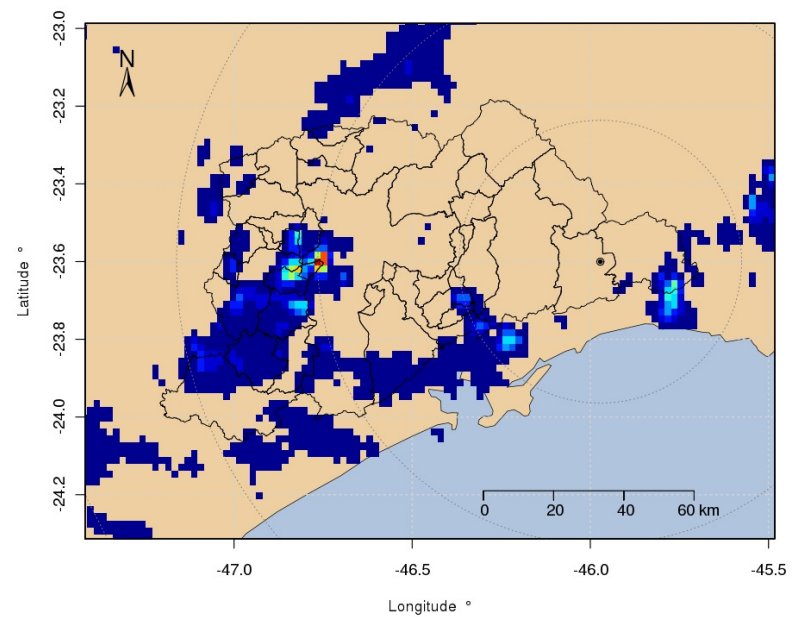

(d)

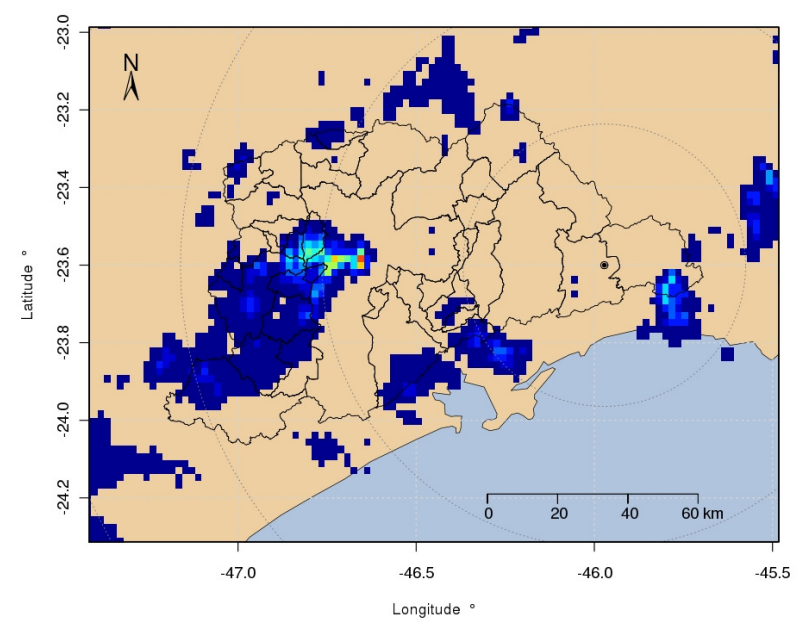

(f)

Figura 4.23: Similar à Fig. 4.19, exceto para dia 26 de janeiro de 2009. (a) 1700 UTC; (b) 1830 UTC; (c) 1840 UTC; (d) 1850 UTC; (e) 1900 UTC; (f)1910 UTC. 
A Fig. 4.24 mostra a evolução temporal do sistema precipitante sobre os limites da BRP. Observa-se na imagem das 1800 UTC e 1810 UTC uma célula em intensificação a SW da BRP que se desloca no sentido NE. A imagem das 1810 UTC mostra o primeiro sinal de precipitação acumulada posicionada sobre o norte da bacia. Na imagem das 1830 UTC já é clara a presença de duas células atuantes sobre os domínios da BRP, a primeira é a mais intensa dos horários anteriores, já sobre as cabeceiras SW da bacia e outra já desenvolvida sobre o terço final da mesma. Nos 3 horários seguintes (1840, 1850 e 19:00 UTC) observa-se a formação e intensificação de uma intensa célula disparada na zona de confluência das frentes de rajada das células citadas, com precipitações acumuladas em 10 minutos maiores do que $15 \mathrm{~mm}$ (intensidade superiores a $90 \mathrm{mmh}^{-1}$ ). Este pico de intensidade durou aproximadamente 20 minutos e ocorreu sobre o posto Córrego Poá, onde um acumulado de $23 \mathrm{~mm}$ em 20 minutos foi observado. A partir das 1910 UTC, a precipitação continuou seu deslocamento sentido NE, e passou a atingir pontos da bacia que não contribuem para a geração de vazão no ponto de medição. Observou-se apenas precipitações estratiforme durante um curto período nas imagens seguintes.

Este pico de precipitação localizada exatamente sobre o ponto de medição da telemetria gerou um pulso de grande intensidade na vazão simulada pelo modelo e causou uma grande superestimativa na vazão simulada com telemetria (Fig. 4.9). Porém, do ponto de vista de alerta, a antecipação da vazão crítica ocorreu de forma satisfatória. A recessão foi bem representada. Neste caso fica novamente evidente a falta da representatividade espacial da medição da precipitação apenas com pluviômetros, pois sistemas isolados deste tipo podem causar acumulados elevados de precipitação e não representar corretamente a chuva acumulada sobre toda a bacia.

As vazões simuladas com entrada de precipitação média na bacia pelo RSP (Fig. 4.12) também se mostraram com superestimativa do pico, porém com valores máximos bastante inferiores as simulações com telemetria. A antecipação dos valores de vazão crítica também ocorreu de forma satisfatória. A recessão foi superestimada pelo fato do pico também ser superestimado, pois se observa que a vazão de recessão simulada é praticamente paralela a observada, apenas deslocada. 
As simulações para precipitação integrada (Fig. 4.15) foram bastante próximas as vazões observadas. A vazão de pico foi bem representada e o hidrograma apresentou muito similaridade com o resultante para a simulação com radar meteorológico. As vazões críticas foram antecipadas de forma satisfatória e a recessão do hidrograma também foi bem representada. A precipitação média analisada foi praticamente a mesma observada pelo RSP. Atribui-se este fato, a precipitação analisada ser a média nas quadriculas sobre a bacia. No momento de maior intensidade sobre a área de influência do pluviômetro, as quadriculas localizadas sobre a porção das cabeceiras da bacia registravam precipitação pouco intensa, o resultado é a média sobre todo o domínio não é influenciada com as altas freqüências da precipitação pontual sobre o pluviômetro. 


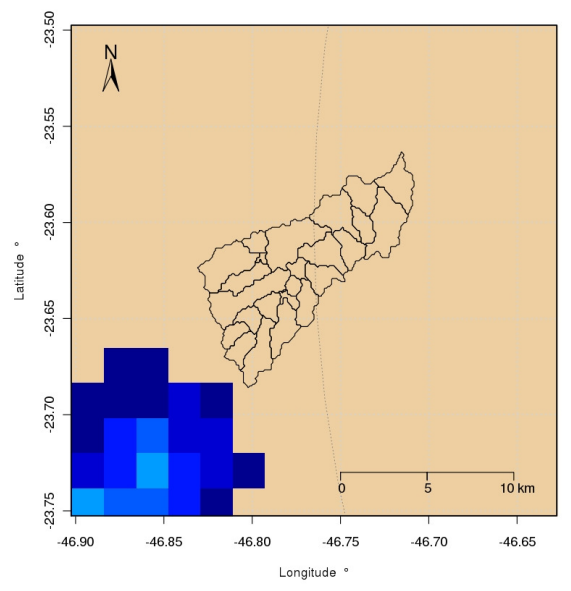

(a)

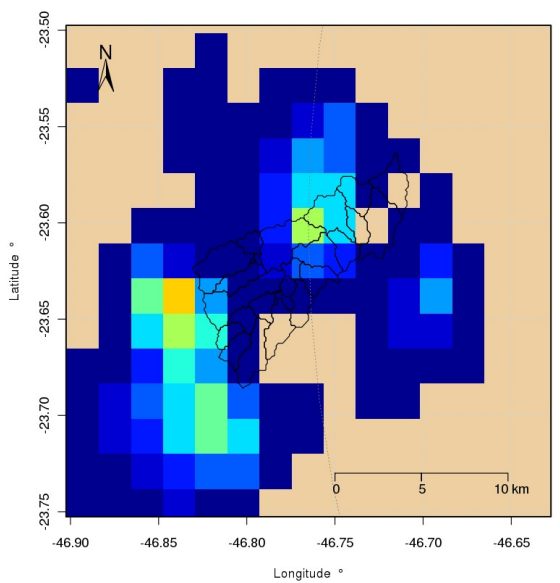

(d)

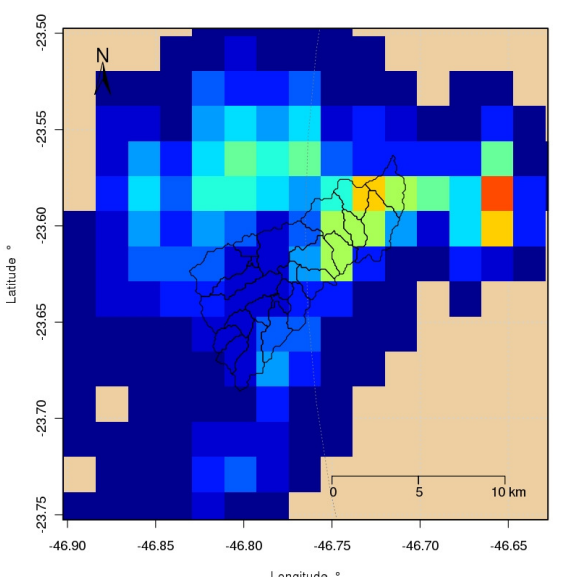

(g)

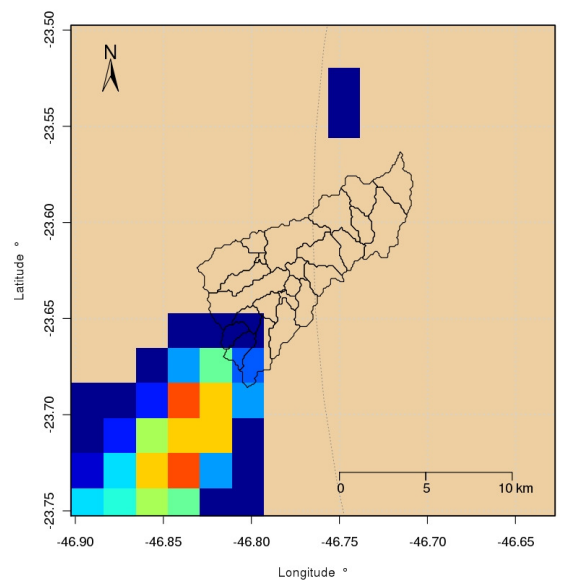

(b)

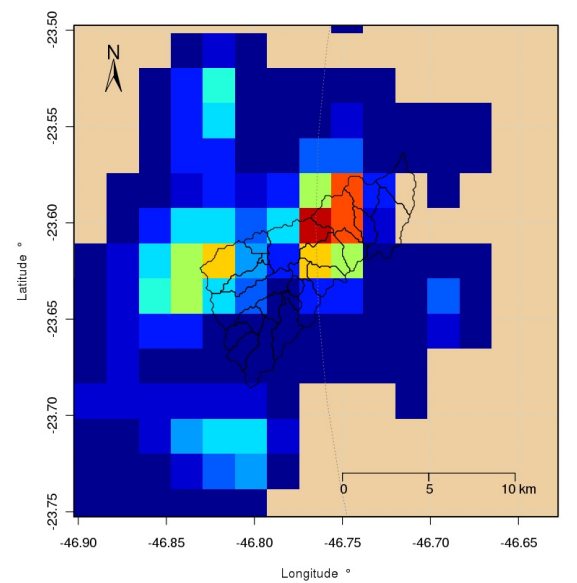

(e)

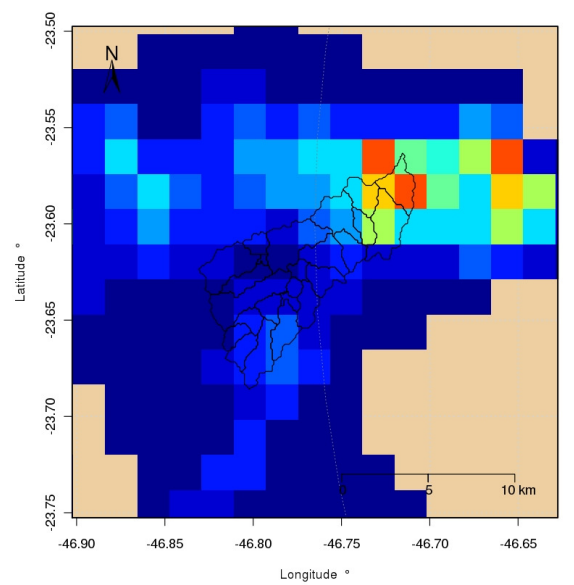

(h)

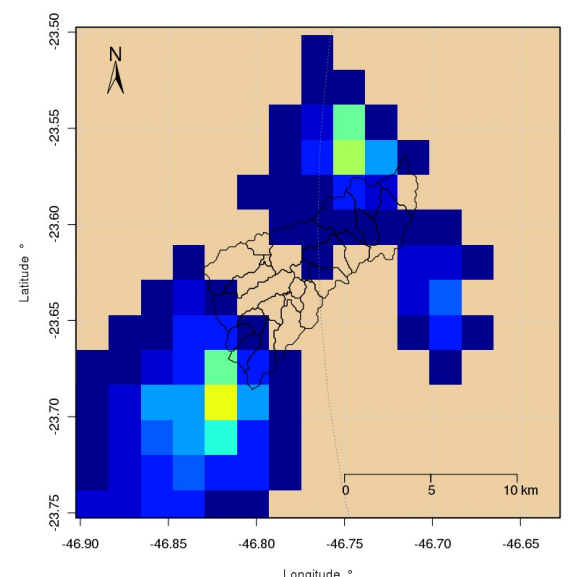

(c)

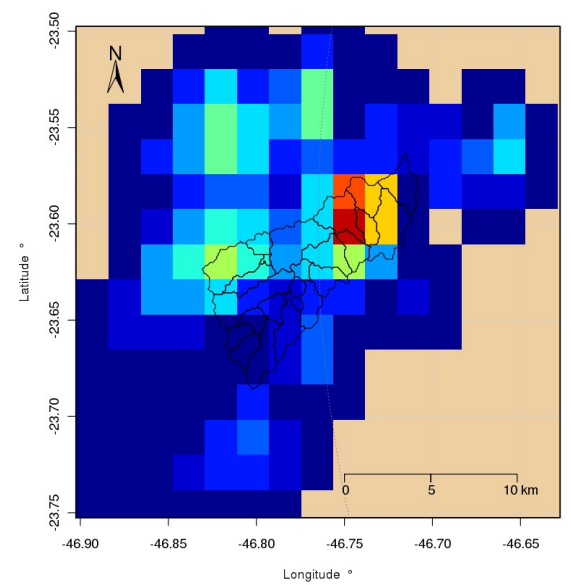

(f)

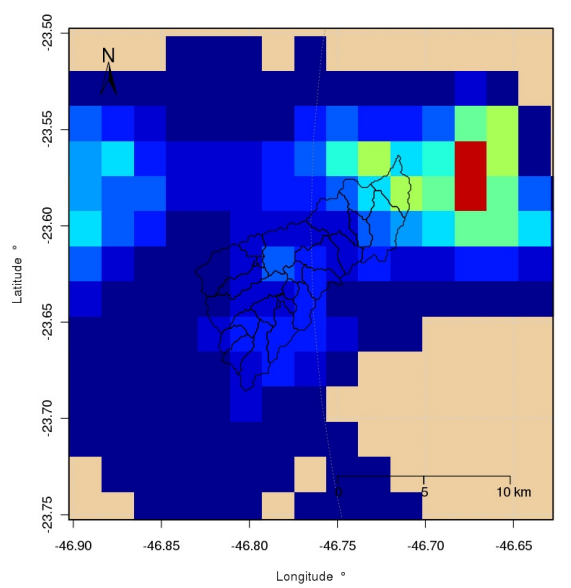

(i)

Figura 4.24: Evolução da precipitação sobre a BRP medida pelo RSP no dia 26/01/2009. A área sombreada representa a precipitação acumulada em 10 minutos, em milímetros, utilizando o CAPPI de $3 \mathrm{Km}$ com resolução $2 \times 2 \mathrm{Km}$ do RSP, as linhas pretas são os divisores de água que compõe a BRP. (a) 1800 UTC ; (b)1810 UTC; (c)1830 UTC; (d) 1840 UTC; (e)1850 UTC; (f) 1900 UTC; (g) 1910 UTC; (h) 1920 UTC; (i) 1930 UTC; 


\subsubsection{Evento dia 30 de Janeiro de 2009}

O evento ocorrido no dia 30 de janeiro de 2009 foi classificado com linha de instabilidade com bandas dispersas e trata-se do evento 13 da Tab. 3.3. Resultou em um pico de vazão de aproximadamente $120 \mathrm{~m}^{3} \mathrm{~s}^{-1}$. Na análise sinótica para este dia, as cartas sinóticas de altitude das 0000 UTC (Fig. 4.25b), mostram a presença de 2 circulações bastante marcadas agindo em conjunto sobre o estado de SP. Uma grande circulação de alta pressão com centro a Norte de SP e um intenso VCAN com eixo levemente inclinado no sentido SW-NE posicionado sobre a divisa da Argentina com os estados do Sul do Brasil. Esta engrenagem posiciona ventos bastante intensos sobre os estados do Sul, Centro-Oeste e SP, com suporte a ZCOU observada na carta de superfície (Fig. 4.25a). Este tipo de circulação promove advecção intensa de parcelas úmidas desde o Sul amazônico até os estados do Sul/Sudeste do Brasil. Tipicamente eventos que ocorrem dentro de um período de ZCOU ou ZCAS, são classificados como eventos de bandas dispersas, pois a convecção ocorre generalizada sobre grandes áreas e ausência de estrutura espacial. Durante este evento, uma linha de instabilidade formou-se no SW do Estado de SP e propagou-se no sentido W-E. Atingiu os domínios da BRP por volta das 2020 UTC.

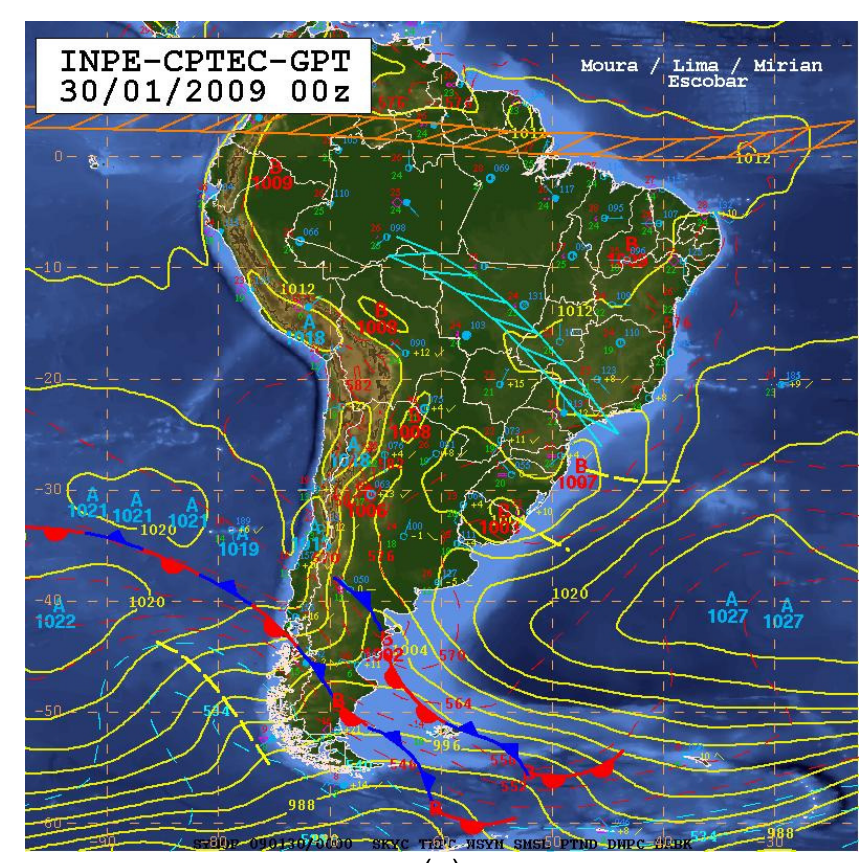

(a)

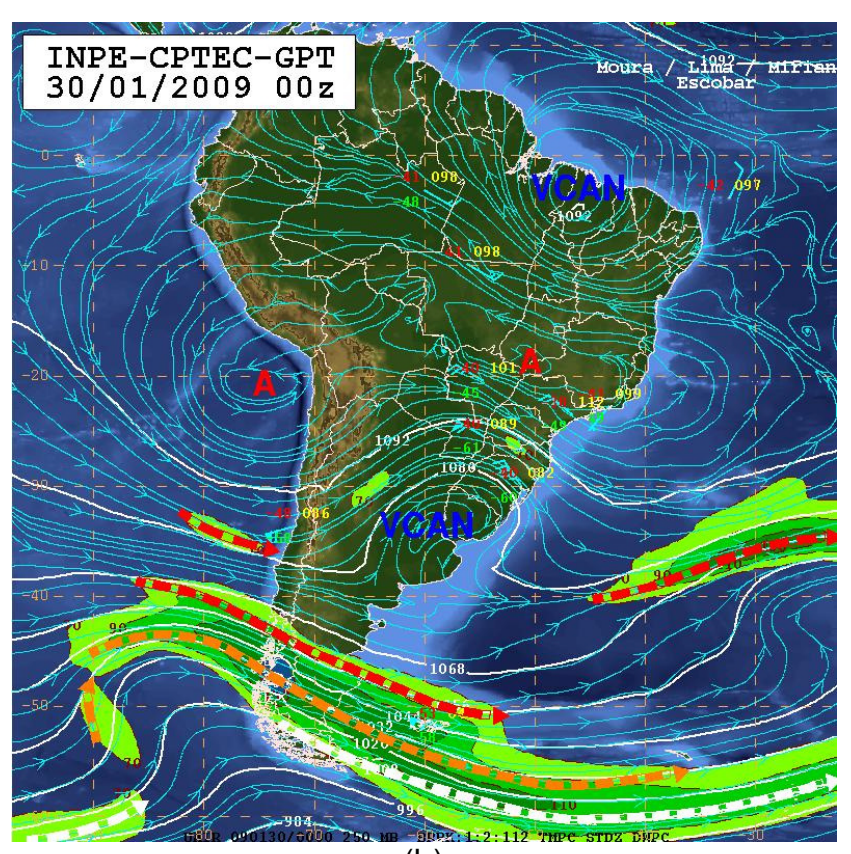

(b)

Figura 4.25: Cartas sinóticas produzidas pelo CPTEC/INPE do dia 27 de Janeiro de 2009. As figuras (a) e (b) são relativos aos níveis baixos (1000 hPa) e altos (250 hPa). 


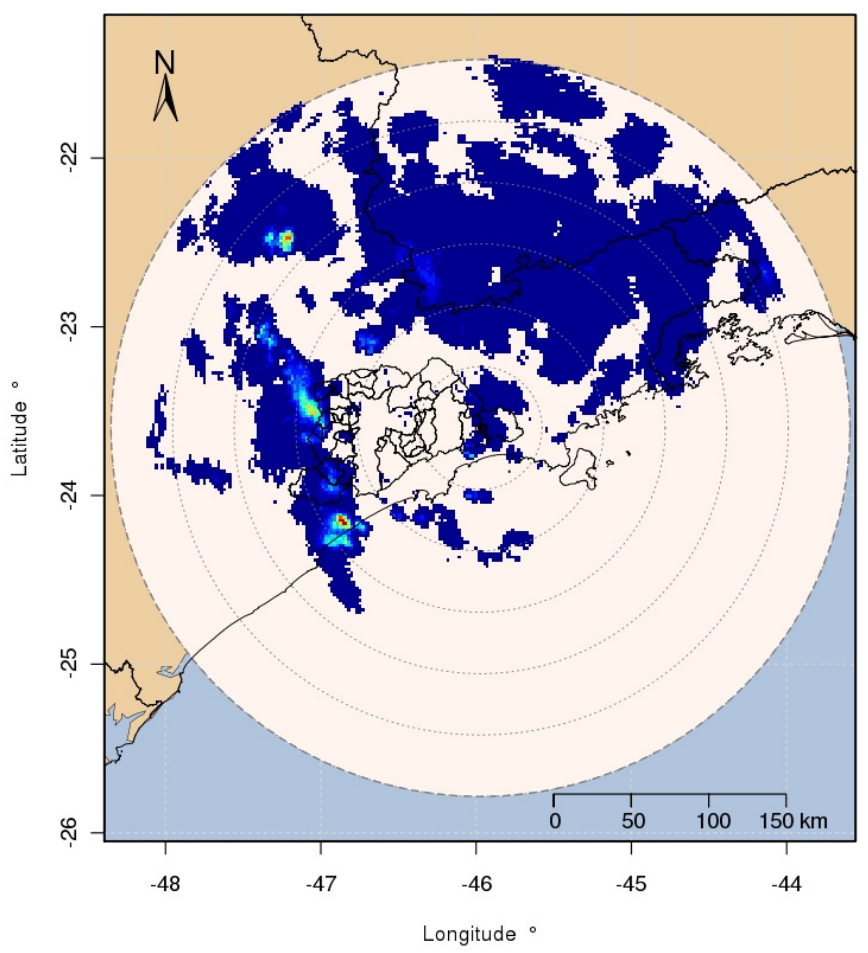

(a)

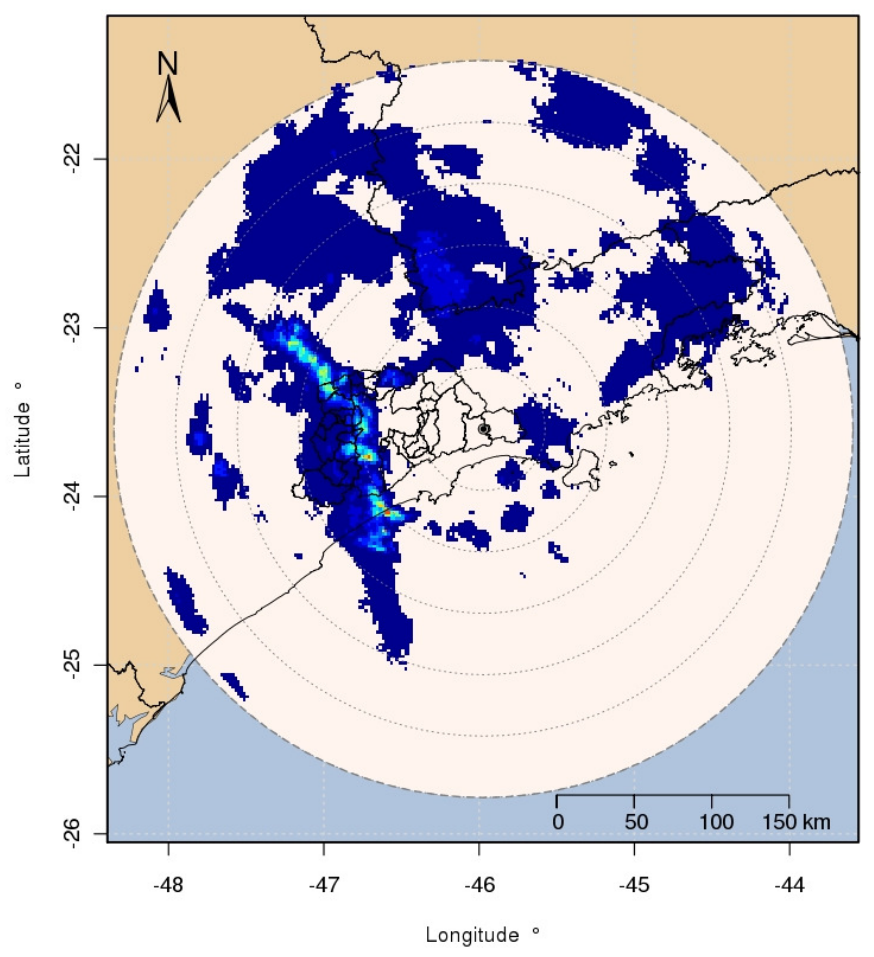

(c)

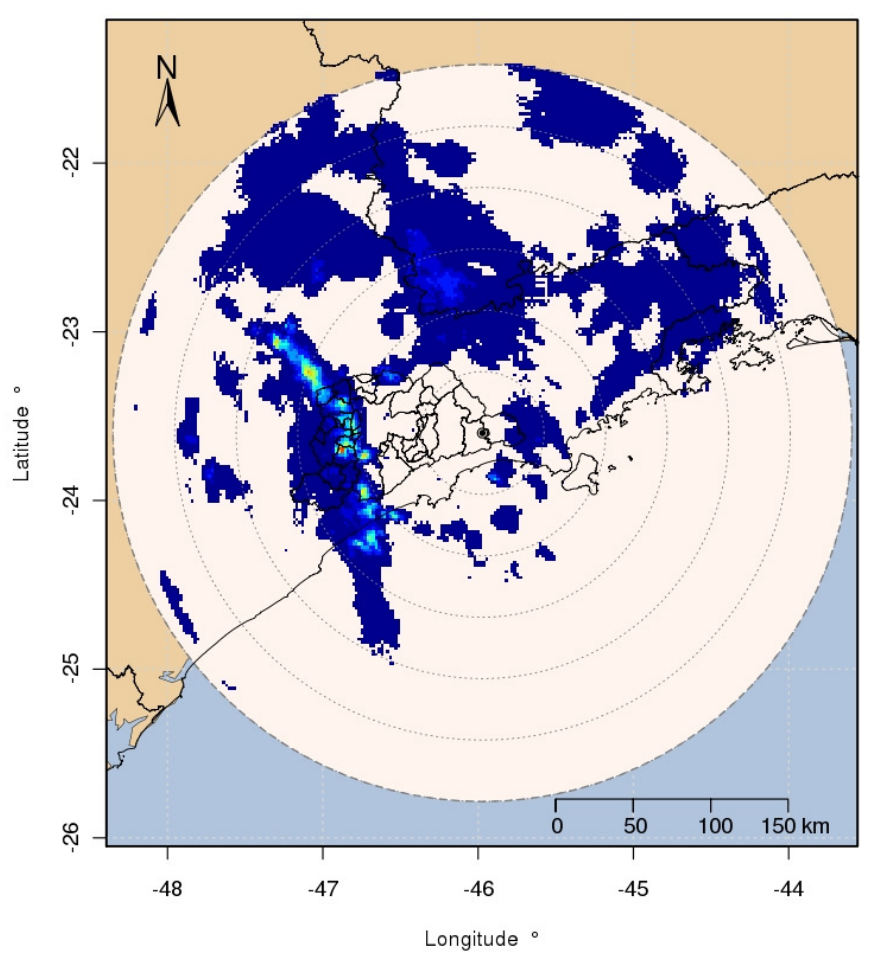

(b)

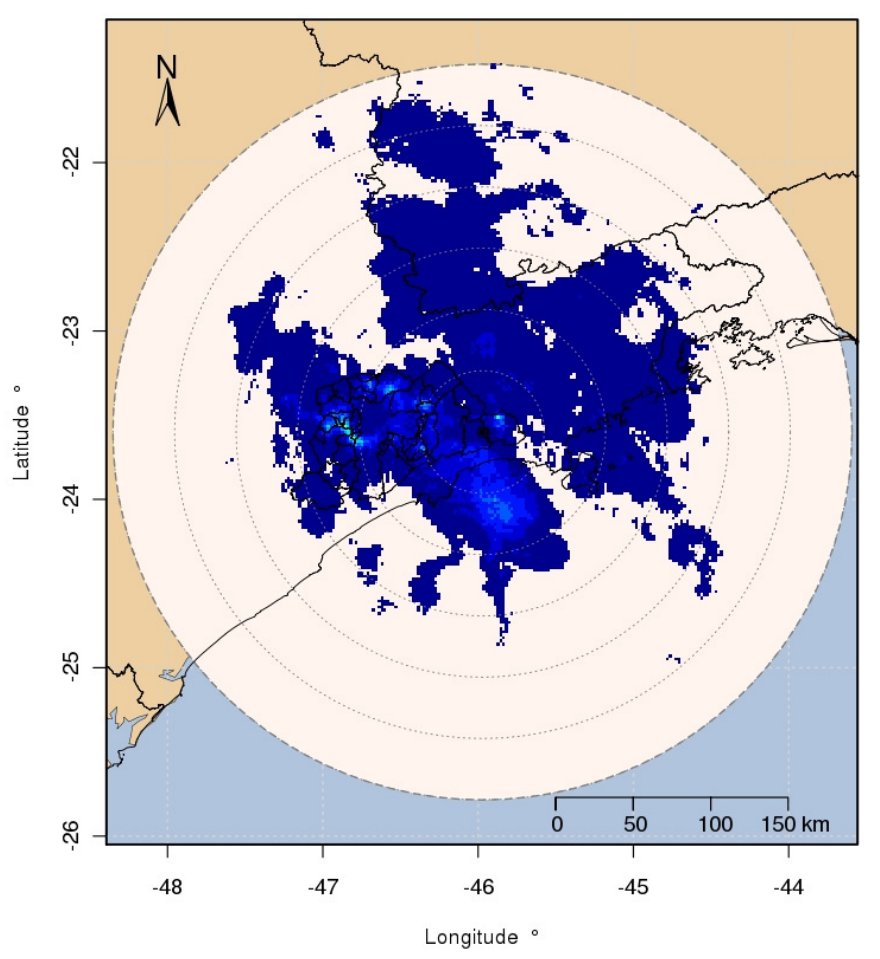

(d)

Figura 4.26: Evolução da precipitação sobre a Área de abrangência do RSP no dia 30/01/2009. A área sombreada representa a precipitação acumulada em 10 minutos em milímetros, CAPPI de $3 \mathrm{Km}$ com resolução $2 \times 2 \mathrm{Km}$, as linhas pretas são a divisão política da RMSP e litoral. (a) 2000 UTC; (b) 2030UTC; (c) 2040 UTC; (d) 2320 UTC. 
A Fig. 4.26 mostra a seqüência de imagens do RSP para o dia 30 de Janeiro de 2009. Observam-se muitas áreas de precipitação estratiforme espalhadas por todo o domínio do radar, devido à presença da ZCOU. Na imagem das 2000 UTC nota-se a linha de instabilidade que avança com velocidade de aproximadamente 60 $\mathrm{km} \mathrm{h}^{-1}$. Na imagem das 2030 UTC, já se observa a linha de instabilidade cobrindo todo o Oeste da RMSP e Oeste e Norte da Capital, posicionando sua porção convectiva nestas regiões. No horário das 2050 UTC a linha de atividade convectiva mais intensa não se encontra mais sobre estas regiões, pois avançou rapidamente em direção ao Leste. A partir da imagem das 2300 UTC, uma banda de precipitação se formou na retaguarda da linha de instabilidade e atingiu novamente os domínios da BRP.

Na Fig. 4.28 pode-se acompanhar a evolução do sistema sobre a bacia. Observa-se a rápida passagem da linha de instabilidade de forma quase que perpendicular, em 20 minutos toda a porção convectiva do sistema já havia percorrido os domínios. A banda de precipitação que se formou na retaguarda da linha de instabilidade propagou-se no sentido do escoamento básico, e atingiu a bacia de montante para jusante, como se pode observar nos acumulados para os horários entre 2310 e 2340 UTC (Fig. 4.28).

O desempenho das simulações para este evento precipitação pela telemetria (Fig. 4.9) observa-se um bom ajuste das vazões de pico, da fase de antecipação da vazão crítica assim como da recessão do hidrograma. Este bom ajuste se deve ao fato da boa representação da precipitação pelo instrumento. A linha de instabilidade possui uma estrutura espacial uniforme longitudinalmente e produziu precipitação intensa, porém bem distribuída, em sua porção convectiva e estratiforme.

As simulações efetuadas com entrada de precipitação estimadas pelo RSP mostram uma subestimativa significativa das vazões (Fig. 4.12). Segundo CALVETTI et. al. (2003) eventos com grande velocidade de deslocamento, como linhas de instabilidade, podem não ser representados de forma satisfatória pois entre duas varreduras consecutivas do radar meteorológico, o rápido deslocamento sistema faz com que a precipitação entre estes 2 passos de tempo não seja detectada (Fig. 4.27).

Esta subestimativa da precipitação acumulada explica a subestimativa da vazão simulada neste caso. A banda precipitante que atingiu a bacia após a passagem da linha de instabilidade, se deslocou praticamente com a mesma 
velocidade da linha de instabilidade que a precedeu, causando o mesmo efeito.Nas simulações com entrada de precipitação ANOBES (Fig. 4.15), observa-se que o primeiro pulso de vazão foi subestimado, apesar de a precipitação seguir o comportamento da medida pela telemetria quantitativamente.
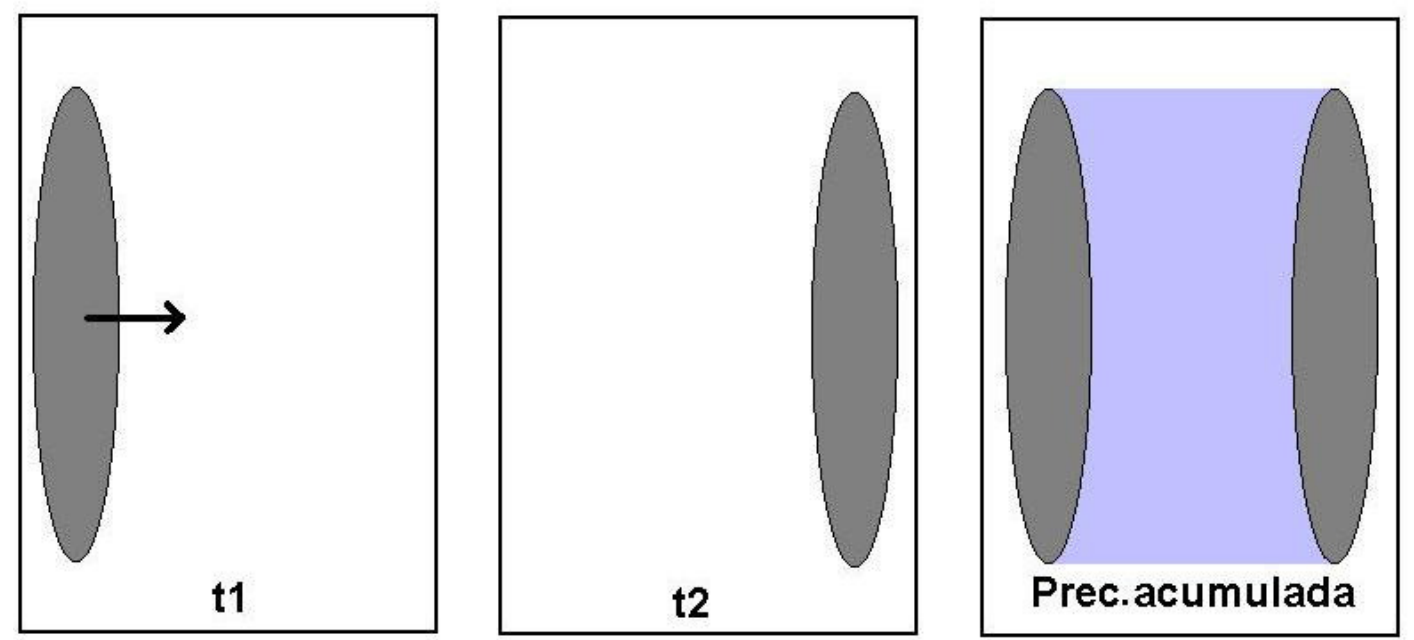

Figura 4.27: Efeito de advecão em uma célula que se desloca zonalmente para leste. O radar mede a célula em $\mathbf{t} 1$ e em $\mathbf{t} 2$ quando ela já deslocou subestimando na acumulação a chuva que ocorreu entre os intervalos das medições (em azul claro). Fonte: CALVETTI (2003) 


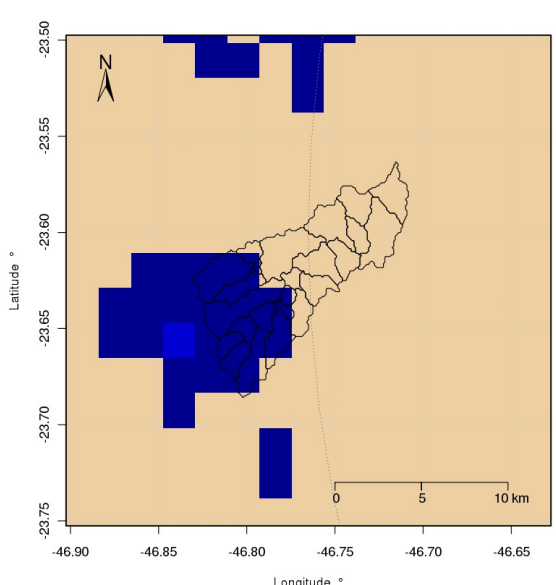

(a)

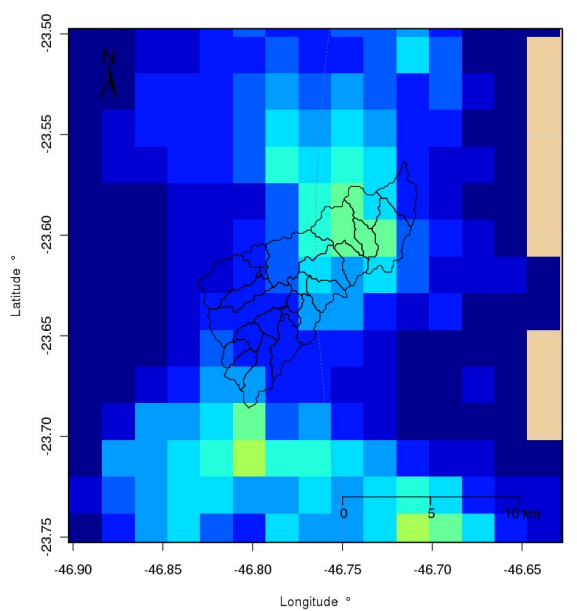

(d)

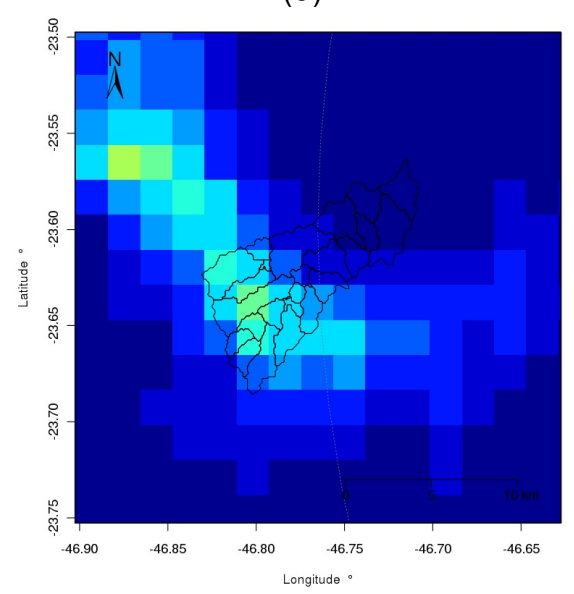

(g)

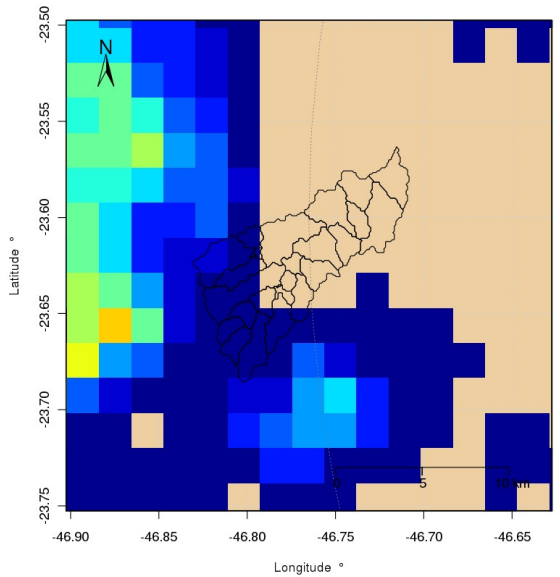

(b)

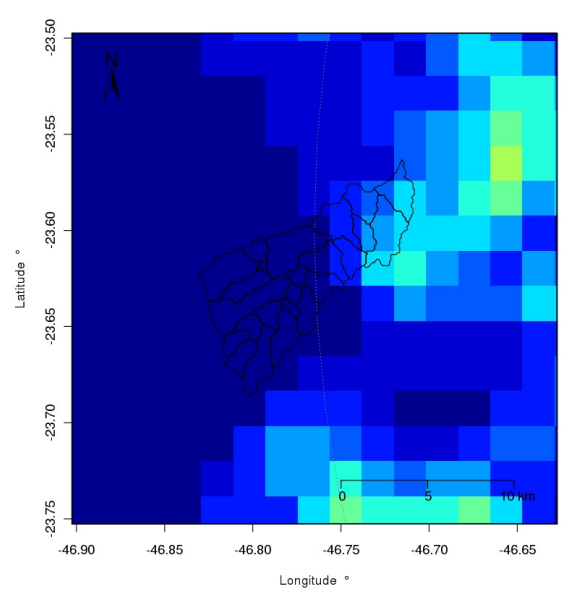

(e)

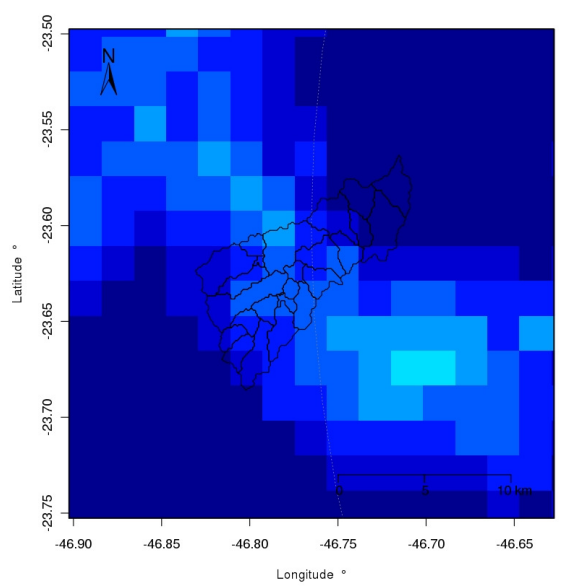

(h)

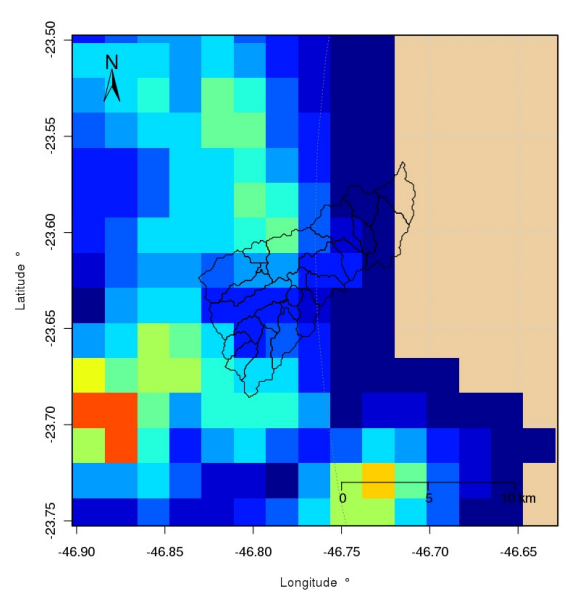

(c)

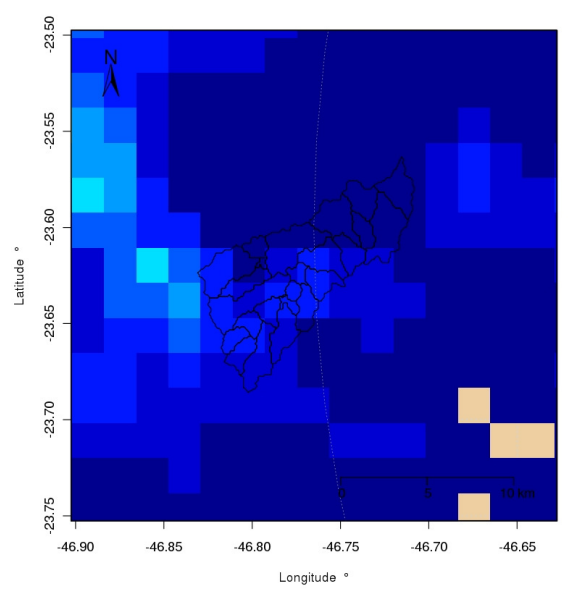

(f)

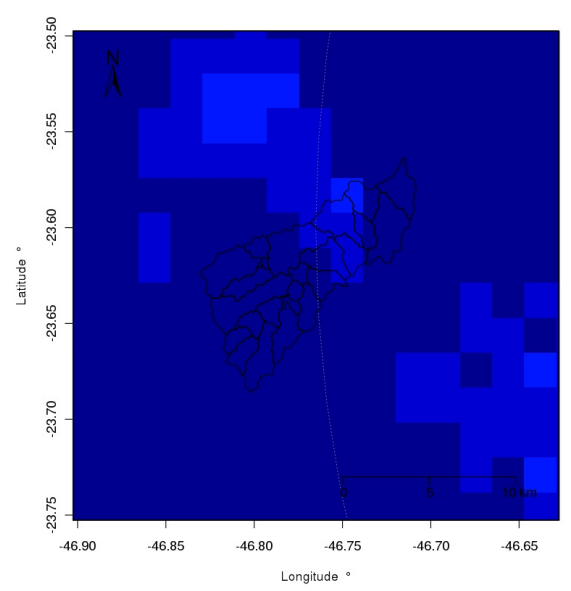

(i)

10

Figura 4.28 - Evolução da precipitação sobre a BRP medida pelo RSP no dia 30/01/2009. A área sombreada representa a precipitação acumulada em 10 minutos em milímetros, utilizando o CAPPI de $3 \mathrm{Km}$ com resolução $2 \times 2 \mathrm{Km}$, as linhas pretas são os divisores de água que compõe a BRP. (a) 2000 UTC ; (b)2020 UTC; (c) 2030 UTC; (d) 2040 UTC; (e) 2050 UTC; (f) 2310 UTC; (g) 2320 UTC; (h) 2330 UTC; (i) 2340 UTC. 


\section{Conclusões e Recomendações}

O objetivo do trabalho foi modelar a hidrológica da uma Bacia do Rio Pirajuçara com o TOPMODEL e medidas e estimativas de chuva de telemetria e radar meteorológico, além da precipitação integrada de ambos. Selecionou-se 18 eventos entre 05 de Outubro de 2008 e 26 de Outubro de 2009. Esses foram classificados em função da sua morfologia, gênese e cinemática.

A análise de sensibilidade do TOPMODEL indicou que a os parâmetros de decaimento da condutividade hidráulica $(m)$, de permeabilidade do solo (InTe) e do retardo da frente de umidade $\left(T_{D}\right)$ são os que apresentaram maior sensibilidade. $A$ invariância dos demais parâmetros limita a aplicação do TOPMODEL e podem resultar em falta aderência entre simulações e observações (SCHULER et al. 2000).

A verificação de desempenho do modelo com a precipitação estimada com o radar na quadrícula sobre o pluviômetro apenas e a obtida da média espacial resultaram em simulações muito discrepantes por causa da falta de representatividade espacial.

A utilização ou não da evapotranspiração nas simulações não alterou as simulações. Sugere-se que a variação temporal desse processo seja muito mais longo do que 0 do escoamento superficial. Ainda, a contribuição da evapotranspiração para o balanço de água seja desprezível. De qualquer forma, a vazão simulada com evapotranspiração média de longo prazo idêntica à nula.

Avaliaram-se as calibrações quanto à antecipação da ascensão do hidrograma de cheia e ao ajuste às vazões de pico com o modelo calibrado e verificado para as três alternativas de precipitação de entrada. $O$ melhor resultado obtido foi com precipitação média estimada com o RSP, com $\mathrm{NASH}=0,5$, contra 0,3 para telemetria e 0,4 para ANOBES. Os EQMs foram de $1,9 \times 10^{-3}, 2,5 \times 10^{-3}$ e 5,9 $\times 10^{-3}$ para radar, ANOBES e telemetria, respectivamente. Verificou-se também que $50 \%, 30 \%$ e $30 \%$ das ascensões do hidrograma de cheia foram adequadamente simulados com os dados de radar, ANOBES e telemetria, respectivamente.

Obteve-se o melhor desempenho das verificações de simulação hidrológica com o TOPMODEL e dados de precipitação estimada com o RSP ( $\mathrm{NASH}=0,7)$ e modelo calibrado com precipitação estimada com o RSP. Observou-se que para 2 das 3 calibrações utilizadas, as simulações do RSP alcançaram os maiores valores 
de eficiência de 0,6 e 0,7 para telemetria e radar, respectivamente. Os menores EQM, 3,6 × $10^{-4}, 4,8 \times 10^{-4}$ e 4,2 × $10^{-4}$ para as verificações das calibrações com telemetria, radar e ANOBES, respectivamente, foram obtidas para as estimativas de precipitação do RSP. As vazões de pico foram simuladas para seis do oito eventos de verificação com precipitação média do RSP. Similarmente, com a telemetria foram cinco eventos apenas.

As vazões simuladas com um único pluviômetro próximo ao exutório da bacia do Pirajuçara foram em geral subestimadas por causa da falta de representatividade espacial e morfologia dos sistemas precipitantes. A estimativa de precipitação de sistemas precipitantes que se deslocaram rapidamente sobre a bacia (e.g., linha de instabilidade) foi subestimada e, concomitantemente, a vazão simulada. Sistemas precipitantes uniformes foram medidos e simulados adequadamente com a telemetria. Entretanto, a maioria dos eventos utilizados neste estudo é de origem convectiva; os que causam enchentes. Sugere-se um adensamento da rede telemétrica além da sua expansão na área de cobertura do RSP.

Portanto, o modelo TOPMODEL é adequado para a simulação de vazões em ambientes urbanos com diferentes conjuntos de parâmetros e fontes de dados de precipitação. Uma de suas principais limitações é o uso da precipitação média sobre a bacia, menos válida para bacias de porte médio e grande. O radar meteorológico é uma ferramenta importante e indispensável para simulações hidrológicas com alta resolução espaço-temporal, mas os erros na estimativa de precipitação normalmente resultam em discrepâncias na simulação de vazão com o TOPMODEL. Estas podem ser minimizadas por meio da integração com os dados da telemetria.

Sugere-se para futuros trabalhos: 1) Implementar a representação da variabilidade espacial da precipitação ao modelo TOPMODEL; 2) Realizar integração com o método ANOBES para tempos de acumulação mais longos; 3) Realizar simulações com saídas de modelos numéricos de previsão do tempo; 4) Realizar estudos com o TOPMODEL para as demais sub-bacias do Alto Tietê com problemas da mesma natureza, citam-se as Bacias do Aricanduva, Tamaduateí, Ribeirão dos Meninos, Cabuçu de Cima. 


\section{Referências Bibliográficas}

AUSTIN, P. M. Relation between measured radar reflectivity and surface rainfall. Monthly Weather Review, v. 115, p. 1053-1070, 1987.

BARNSLEY, M. GEG209 Environmental Modeling. 2004. Disponível em: <http://stress.swan.ac.uk/ mbarnsle/teaching/envmod03/lectures/models_and _modelling.pdf>. Acesso em: 06 jan. 2010.

BATTAN, L. J. Radar Observations of the Atmosphere. Chicago: The University of Chicago Press, 1973. 324p.

BETSON, R. P. What is watershed runoff? Journal of Geophysical Research, v. 69, p. 1541-1551, 1964.

BEVEN, K. J. Runoff production and flood frequency en catchments of order $\mathrm{n}$ : an alternative approach. In: GUPTA, V. K.; RODRIGUES-ITURBE, I.; WOOD, E. F. Scale Problems in Hydrology. Dordrecht: Reidel, 1986. p. 107-131.

BEVEN, K. J. Infiltration, soil moisture, and unsaturated flow. In: BOWLES, D. S.; O'CONNELL, P. E. Recent advances in the modeling of hydrologic systems. Dordrecht: Klumer Academic Publishers, 1991, p. 137-151.

BEVEN, K. J. TOPMODEL: A critique. Hydrological Processes, Chichester, v. 11, n. 9, p.1069-1086, 1997.

BEVEN, K. J. Rainfall-Runoff Modeling: The Primer. Chichester: John Willey \& Sons, 2001. $372 \mathrm{p}$.

BEVEN, K. J. Uncertainty Analysis in Environmental Modeling. 2004. Disponível em:

<http://www.es.lancs.ac.uk/hfdg/uncertainty_workshop/PDF/methods/GLUE_t echnique.pdf>. Acesso em: 08 jan. 2010.

BEVEN, K. J.; BINLEY, A. The future of distributed models: model calibration and uncertainty prediction. Hydrological Processes, v. 6, p. 279-298, 1992.

BEVEN, K. J.; KIRKBY, M. J. A Physically based, variable contributing area model of basin hydrology. Hydrological Sciences Bulletin, v. 24, n. 1, p. 43-69, 1979.

BEVEN, K. J; LAMB, R.; QUINN, P.; ROMANOWICIZ, R.; FREER, J. Topmodel. In: SINGH, V. P. Computer models of watershed hydrology. Water Resource Publication, 1995. p. 627-668.

BORGA, M. S.; DEGLI ESPOSTI, S.; NORBIATO, D. Influence of errors in radar rainfall estimates on hydrological modeling prediction uncertainty. Water Resources Research, 42, W08409, doi: 10.1029/2005WR004559, 2006. 
BOYLE, D. P.; GUPTA, H. V.; SOROOSHIAN, S. Toward improved calibration of hydrologic models: Combining the strengths of manual and automatic methods. Water Resources Research, v. 36, n. 12, p. 3663-3674, 2000.

BURNASH, R. J. C. The NWS river forecast system catchment modeling. In: Singh, V. J. Computer models of watershed hydrology. Highlands Ranch: Water Resources Publications, 1995, cap. 10.

BRAGA JÚNIOR, B. P. F. Rede telemétrica do Alto Tietê. Revista Águas e energia elétrica, São Paulo, v. 5, n. 15, p. 22, jan/abr 1989.

CANIL, K. Indicadores para monitoramento de processos morfodinâmicos: aplicação na bacia do Ribeirão Pirajussara (SP). 2006. 152 f. Tese (Doutorado em Geo) - Faculdade de Filosofia, Letras e Ciências Humanas, Universidade de São Paulo, São Paulo, 2006.

CANHOLI, A. P. Soluções estruturais não convencionais em drenagem urbana. 1995. 215 f. Tese (Doutorado em Engenharia) - Escola Politécnica, Universidade de São Paulo, São Paulo, 1995.

CANHOLI, A. P. Drenagem urbana e controle de enchentes. São Paulo: Oficina de Textos, 2005. 304 p.

CARPENTER, T. M.; GEORGAKAKOS, K. P.; SPERFSLAGEA, J. A. On the parametric and NEXRAD-radar sensitivities of a distributed hydrologic model suitable for operational use. Journal of Hydrology, v. 253, p. 169-193, 2001.

CALVETTI, L.; BENETI, C.; PEREIRA FILHO, A. J. Integração do radar meteorológico doppler do Simepar e uma rede pluviométrica para a estimativa da precipitação. In: SIMPÓSIO BRASILEIRO DE SENSORIAMENTO REMOTO, 2003, Belo Horizonte. Anais do Simpósio de Brasileiro de Sensoriamento Remoto, 2003. CD-ROM.

COLLIER, C. G. On the propagation of uncertainty in weather radar estimates of rainfall through hydrological models. Meteorol. Appl., v. 16, p. 35-40, 2009.

COLLINS, S. H.; MOON, G. C. Algorithms for dense digital terrain models. Photogrammetric Engineering and Remote Sensing, v.47, n.1, p.71-76, 1981.

COLLISCHONN, W. Simulação hidrológica de grandes bacias. 2001. 194 f. Tese (Doutorado em Engenharia) - Universidade Federal do Rio Grande do Sul, Porto Alegre, 2001.

COLLISCHONN, W.; TUCCI, C. E. M. Ajuste multi-objetivo dos parâmetros de um modelo hidrológico. Revista Brasileira de Recursos Hídricos, Porto Alegre, v. 8 , p. 27-39, 2003. 
COLTRINARI, L. Natural and anthropogenic interactions in the Brazilian tropics. In: BERGER, A. R.; IAMS, W. J. Geoindicators: assessing rapid environmental changes in Earth systems. Rotterdam: A. A. Balkema/Brookfield, 1996. p. 295-310.

CORDOVA, J. R.; RODRIGUEZ-ITURBE, I. Geomorphologic estimation of extreme flow probabilities. Journal of Hydrology, v. 65, p. 159-173, 1983.

CRAWFORD, K. C. Considerations for the design of a hydrologic data Network using multivariate sensors. Water Resource Research, v. 15, p. 1752-1762, 1979.

CREUTIN, J. D.; BORGA, M. Radar hydrology modifies the monitoring of flash-flood hazard. Hydrological Processes, v. 17, p. 1453-1456, 2003.

CREUTIN, J. D.; OBLED, C. Objective analyses and mapping techniques for rainfall fields: An objective comparison. Water Resource Research, v. 18, p. 413431, 1982.

CREUTIN, J. D.; OBLED, C. Catchment dynamics and social response during flash floods: the potential of radar rainfall monitoring for warning procedures. Meteorol. Appl., v. 16, p. 115-125, 2009.

DAEE - DEPARTAMENTO DE ÁGUAS E ENERGIA ELÉTRICA. Controle de inundações na bacia do Rio Pirajussara. 1998. Disponível em: $<$ http://www.sigrh.sp.gov.br/sigrh/basecon/macrodrenagem/pirajussara/arquiv os/Indice_Frame.html>.

DAEE - Departamento de ÁGuas e energia elÉtricA. Plano Diretor de Macrodrenagem da Bacia do Alto Tietê. 1999. Disponível em: $<$ http://www.sigrh.sp.gov.br/sigrh/basecon/macrodrenagem/index.html>.

DALEY, R. Atmospheric Data Analysis. Cambridge University Press, 1991. 471 p.

DOUGLAS, I. The urban environment. London: Edward Arnold, 1983, $240 \mathrm{p}$.

DOTY, B. The Grid Analysis and Display System. User's guide. Center of OceanLand-Atmosphere Studies, p. 148, 1995.

DUAN, Q.; SOROOSHIAN, S.; GUPTA, V. Effective and efficient global optimization for conceptual rainfall-runoff models. Water Resources Research, v. 28, n. 4, p. 1015-1031, 1992.

DUNNE, T. Field studies of hillslope flow processes. In: KIRKBY, M. J. Hillslope hydrology. New York: John Wiley \& Sons Ltd, 1978, p. 227-289.

DUNNE, T.; BLACK, R. An experimental investigation of runoff production in permeable soils. Water Resources Research, v. 6, p. 478-499, 1970. 
EMPLASA - EMPRESA METROPOLITANA DE PLANEJAMENTO DA GRANDE SÃO PAULO. $O$ problema das inundações na Grande São Paulo: situação atual e implementação de diretrizes metropolitanas de drenagem. São Paulo: EMPLASA, 1985. 152 p.

FRANCHINI, M.; WENDLING, J.; OBLED, D.; TODINI, E. Physical interpretation and sensitivity analysis of TOPMODEL. Journal of Hydrology, Amsterdam, v. 175, p. 293-338, 1996.

FREER, J. E. et. al. Constraining dynamic TOPMODEL responses for imprecise water table information using fuzzy rule based performance measures. Journal of Hydrology, Amsterdam, v. 291, p. 254-277, 2004.

FUSP - FUNDAÇÃO DE APOIO À UNIVERSIDADE DE SÃO PAULO. Plano da Bacia do Alto Tietê. Sumário executivo. Comitê da Bacia do Alto Tietê, São Paulo, 2002.

GANDIN, L. S. Objective Analysis of Meteorological Fields. English translation by R. Harding, Israel Program for Scientific Translation, 1963, 242 p.

GONÇALVES, F. M. Utilização de Radar Meteorológico em Hidrologia. 2005. 116 f. Tese (Doutorado em Engenharia) - Escola Politécnica, Universidade de São Paulo, São Paulo, 2005.

GONÇALVES, J. E. et. al. Estudo da viabilidade da utilização de estimativas de chuva efetuadas por radar na modelagem hidrológica. In: CONGRESSO BRASILEIRO DE METEOROLOGIA, 13, 2004, Fortaleza. Anais do XIII Congresso Brasileiro de Meteorologia, 2004. CD-ROM.

GOTTSCHALK, L.; MOTOVILOV, Y. Macro-scale hydrological modeling - a Scandinavian experience. In: INTERNATIONAL SYMPOSIUM ON: CAN SCIENCE AND SOCIETY SAVE THE WATER CRISIS IN THE 21ST CENTURY, 2000, Tokyo. Reports from the World's Japan Society of Hydrology and Water Resources, 2000. p. 38-45.

GUERCIO, R.; SOCCODATO, F. M. Procedure for automatic extraction of geomorphological attributes from TIN-DTM. In: KOVAR, K.; NACHTNEBEL, H. $P$. Hydrogis 96: application of geographic information systems in hydrology an water resources management. Paris: IAHS, 1996. p. 175-182.

GUPTA, H.; SOROOSHIAN, S.; YAPO, P. O. Toward improved calibration of hydrologic models: Multiple and noncomensurable measures of information. Water Resources Research, v. 34, n. 4, p. 751-763, 1998.

HANN, C. T. Parametric uncertainty in hydrologic modeling. Transactions of the American Society of Agricultural Engineers, v. 32, n. 1, p 137-145, 1989.

HART, M. G. Geomorphology pure and applied. London: Allen \& Unwim, 1986, $228 \mathrm{p}$. 
HORNBERGER, G.M.; BEVEN, K.J.; COSBY, B.J.; SAPPINGTON, D.E. Shenandoah watershed study: Calibration of a topography-based, variable contributing area hydrological model to a small forested catchment. Water Resources Research, Washington, v. 21, p. 1841-1850, 1985.

HORNBERGER, G. M.; RAFFENSPERGER, J. P.; WIBERG, P. L. Elements of Physical Hydrology. Baltimore: The Johns Hopkins University Press, 1998, $302 \mathrm{p}$.

HEWLETT, J. D.; HIBBERT, A. R. Factors affecting the response of small watersheds to precipitation in humid areas. In: SOPPER, W. E.; LULL, H. W. Forest Hydrology. Oxford: Pergamon Press, 1967, p. 275-290.

HEWLLETT, J. D.; NUTTER, W. L. The varying source area of streamflow from upland basins. In: SYMPOSIUM ON INTERDISCIPLINARY ASPECTS OF WATERSHED MANAGEMENT. August 3-6, 1970, Bozeman, p. 65-83.

IBGE - INSTITUTO BRASILEIRO DE GEOGRAFIA E ESTATÍ́STICA. População urbana de 1940 até 2000 . Disponível em $<$ http://www.ibge.gov.br/series_estatisticas/exibedados.php?idnivel=BR\&idseri e=POP10>.

IORGULESCU, I. ; JORDAN, J. P. Validation of TOPMODEL on a small Swiss catchment. Journal of Hydrology, Amsterdam, v. 159, p. 255 - 273, 1994.

JONES, N. L.; WRIGHT, S. G.; MAIDMENT, D. R. Watershed delineation with triangle-based terrain models. Journal of Hydraulic Engineering, v. 116, n. 10, p. 1232-1250, 1990.

LAMB, R.; BEVEN, K. J.; MYRAB, S. Discharge and water table predictions using a generalized TOPMODEL formulation. Hydrological Processes, Chichester, v. 11, p. $1145-1168,1997$.

LEGATES, D. R.; DELIBERTY, T. L. Measurement biases in the United States rain gauge network. Water Resour. Bull., v. 29, p. 855-861, 1993.

MADSEN, H. Automatic calibration of a conceptual rainfall - runoff model using multiple objectives. Journal of Hydrology, v. 235, p. 276-288, 2000.

MARSHALL, J. S., PALMER, W. MCK. The distribution of raindrops with size. Journal of Meteorology, v. 5, p. 165-166, 1948.

MEYER, R. M. P; GROSTEIN, M. D.; BIDERMAN, C. São Paulo Metrópole. São Paulo: Editora da Universidade de São Paulo/ Imprensa Oficial do Estado de São Paulo, 2004, 296 p.

MINE, M. R. M. Método determinístico para minimizar o conflito entre gerar energia e controlar cheias. 1998. 146 f. Tese (Doutorado em Recursos Hídricos) - Universidade Federal do Rio Grande do Sul, Porto Alegre, 1998. 
MINE, M. R. M.; CLARKE, T. R. O uso do TOPMODEL em condições brasileiras: resultado preliminar. Revista Brasileira de Recursos Hídricos, Porto Alegre, v. 1, n. 2, p. 89-106, 1996.

MOREIRA, I. A. Modelagem hidrológica chuva-vazão com dados de radar e pluviômetros. 2005. 81 f. Tese (Mestrado em Engenharia Hidrológica) Universidade Federal do Paraná, Curitiba, 2005.

MOORE, I.D.; GRAYSON, R.B.; LADSON, A.R. Digital terrain modeling: a review of hydrological, geomorphological, and biological applications. Hydrological Processes, v.5, n.1, p. 3-30, 1991.

MOORE, I. D.; TURNER, A. K.; WILSON, J. P.; JENSON, S. K.; BAND, L. E. GIS and land surface - subsurface process modeling. In: GOODCHILD, M. F.; PARKS, B. O.; STEYAERT L. T. Environmental Modeling with GIS. New York: Oxford University Press, 1993, p. 196-230.

NASH, J. E.; STUCLIFFE, J. V. River flow forecasting through conceptual models part I: a discussion of principles. Journal of Hydrology, Amsterdam, v. 10, p. 282-290, 1970.

OLIVEIRA, A. C. Implementação do modelo atmosférico WRF acoplado com o modelo hidrológico TOPMODEL para a bacia de União das Vitórias. 2006. 70 f. Tese (Mestrado em Engenharia de Recursos Hídricos e Ambiental) Setor de Tecnologia, Universidade Federal do Paraná, Curitiba, 2006

PALACIOS-VÉLEZ, O. L.; CUERVAS-RENAUD, B. Automated river-course, ridge and basin delineation from digital elevation data. Journal of Hydrology, Amsterdam, v. 86, p. 299-314, 1986.

PANIZZA, M. Geomorphological hazards assessment and the analysis of geomorphological risk. In: GARDINER, V. International Geomorphology: part 1. John Wiley \& Sons, 1987.

PEREIRA FILHO, A. J. Uso do radar meteorológico para previsão de chuva a curto prazo à previsão hidrológica em bacias urbanas.1989. $150 \mathrm{f}$. Tese (Mestrado em Meteorologia) - Universidade de São Paulo, São Paulo, 1989.

PEREIRA FILHO, A. J.; CRAWFORD, K. C. Integrating WSR-88D estimates and Oklahoma Mesonet Measurements of rainfall accumulations: a statistical approach. In: INTERNATIONAL CONFERENCE ON RADAR METEOROLOGY, 27, 1995, Vail, Colorado. American Meteorological Society, 1995, p. 240-242.

PEREIRA FILHO, A. J.: CRAWFORD, K. C.; HARTZELL, C. Improving WSR-88D hourly rainfall estimates. Weather and Forecasting, v. 13, n.4, p. 1016-1028, 1998. 
PEREIRA FILHO, A. J. Chuvas de verão e as enchentes na Grande São Paulo: El Niño, Brisa Marítima e llha de Calor. In: CONGRESSO BRASILEIRO DE METEOROLOGIA, 11, 2000, Rio de Janeiro. Anais do XI Congresso Brasileiro de Meteorologia, 2000. CD-ROM.

PEREIRA FILHO, A. J.;HAAS, R.; AMBRIZZI, T. Caracterização de eventos de enchente da bacia do Alto Tietê por meio do radar meteorológico e da modelagem numérica de mesoescala. In: CONGRESSO BRASILEIRO DE METEOROLOGIA, 22, 2002, Foz do Iguaçu, Paraná. Anais do XXII Congresso Brasileiro de Meteorologia, 2002, CD-ROM.

PISANI, A. Avaliação dos Dados do Radar Meteorológico de São Paulo para Aplicação em Hidrologia. 1995. Tese (Doutorado em Engenharia Hidráulica) - Escola Politécnica, Universidade de São Paulo, São Paulo, 1995.

PONCE, V. M. Engineering Hydrology, Principles and Practices. Prentice Hall, 1989. $640 \mathrm{p}$.

QUINN, P. F.; BEVEN, K. J.; LAMB, R. The In $(a / \tan \beta)$ index: how to calculate it and how to use it within the TOPMODEL framework. Hydrological Processes, Chichester, v. 9, p. 161-182, 1995.

RENNÓ, C. D. Construção de em sistema de análise e simulação hidrológica: aplicação a bacias hidrográficas. 2003. 158 p. Tese (Doutorado) - Curso de Pós-graduação e Sensoriamento Remoto do Instituto Nacional de Pesquisas Espaciais, São José dos Campos, 2003.

RINEHART, R. E. Radar for meteorologists. 2 ed. Fargo: Knight Printing Company, 1994, 334p.

ROBBINS, G. L.; COLLIER, C. G. Assessing error in hydrological and hydraulic model output flows. Atmospheric Science Letters, v. 6, p. 47-53, 2005.

ROSENBROCK, H. H. An automatic method for finding the greatest or least value of a function. Computer Journal, v. 3, p. 175-184, 1960.

SANTOS, C. C.; PEREIRA FILHO, A. J. Modelagem hidrológica utilizando redes neurais artificiais em bacias urbanas. In: SEMINÁRIO BRASILEIRO DE HIDROMETEOROLOGIA, 2, 2000, Rio de Janeiro. Anais do XI Congresso Brasileiro de Meteorologia, 2000. CD-ROM.

SANTOS, I.; KOBIYAMA, M. Aplicação do TOPMODEL para determinação de áreas saturadas da bacia do Rio Pequeno, São José dos Pinhais, PR, Brasil. Revista Ambi-Água, v. 3, n. 2, p. 77-89, 2008.

SCHEIDEgGeR, A. E. The Physics of Flow Through Porous Media. 3 ed. University of Toronto Press, 1974, $353 \mathrm{p}$. 
SCHULER, A. E.; MORAES, J. M.; MILDE, L. C.; GROPPO, J. D.; MARTINELLI, L. A.; VICTORIA, R. L. CALIJURI, M. L. Análise da representatividade fisica dos parametros do TOPMODEL emu ma bacia de mesoescala localizada nas cabeceiras do rio Corumbataí, São Paulo. Revista Brasileira de Recursos Hídricos, v. 5, n. 2, p. 5-25, 2000.

SEIBERT, J.; BISHOP, K. H.; NYBERG, L. A test of topmodel's ability to predict spatially distributed groundwater levels. Hydrological Processes, Chichester, v. 11, p. 1131-1144, 1997.

SILVA, F. D. S. Análise objetiva estatística da precipitação estimada com radar e medida por uma rede telemétrica. 2006. $101 \mathrm{f}$. Tese (Mestrado em Meteorologia) - Instituto de Astronomia, Geofísica e Ciências Atmosféricas, Universidade de São Paulo, São Paulo, 2006.

SILVA, R. V. Análise comparativa de três formulações do TOPMOPDEL na bacia do Rio Pequeno - PR. 2005. 128 f. Tese (Mestrado em Engenharia Ambiental) - Programa de Pós-Graduação em Engenharia Ambiental, Universidade Federal de Santa Catarina, Florianópolis, 2005.

SILVA, R. T.; PORTO M. F. A. Gestão urbana e gestão das águas: caminhos da integração. Estudos Avançados, v. 17, n. 47, p. 129-145, 2003.

SINGH, V. P. Watershed modeling. In: Computer Models of Watershed Hydrology. 1 ed. Colorado: Water Resource Publications, 1995. p. 1-22.

STEYARET, L. T. A perspective on the state of environmental simulation modeling. In: GOODCHILD, M. F.; PARKS, B. O.; STEYAERT, L. T. Environmental modeling with GIS. New York, Oxford University Press, 1993. Cap. 3, p. 1630.

SOLOMATINE, D. P. Two strategies of adaptive cluster covering with descent and their comparison to other algorithms. J. Global Optimiz., 14 (1), p. 55-78, 1999.

TARBOTON, D. G. Terrain analysis using digital elevations models in hydrology. In: ESRI INTERNATIONAL USERS CONFERENCE, 23, 2003, San Diego, California. Disponível em:

<http://www.neng.usu.edu/cee/faculty/dtarb/tarpubs.htm>. Acesso em 10 de outubro de 2009.

TUCCI, C. E. M. Hidrologia - Ciência e Aplicação. Porto Alegre: EDUSP/ABRH, 1993, 943 p.

TUCCI, C. E. M. Modelos Hidrológicos. Porto Alegre: Editora Universitária UFRGS, 1998.

TUCCI, C. E. M.; PORTO, R. L.; BARROS, M. T. Drenagem Urbana. Porto Alegre: Editora da Universidade UFRGS, 1995. 428 p. 
VARELLA, R. F.; CAMPANA, N. A. Simulação matemática do processo de transformação de chuva em vazão: Estudo do modelo TOPMODEL. Revista Brasileira de Recursos Hídricos, v. 5, n. 4, p 121-139, 2000.

WERNER, M.; CRANSTON, M. Understanding the value of radar rainfall nowcasts in flood forecasting and warning in flashy catchments. Meteorological Applications, v. 16, p. 41-55, 2009.

XAVIER, L. N. R. Análise da incerteza causada pela representação da precipitação no modelo TOPMOMODEL. 2002. 124 f. Tese (Mestrado em Ciências) - Coordenação dos Programas de Pós-Graduação de Engenharia, Universidade Federal do Rio de Janeiro, Rio de Janeiro, 2002.

YAPO, P. O.; GUPTA, H. V.; SOROOSHIAN, S. Multi-objective global optimization for hydrologic models. Journal of Hydrology, v. 204, p. 83-97, 1998 


\section{APÊNDICE A: Delineamento automático da bacia.}

O processo do cálculo do índice topográfico de BEVEN e KIRKBY (1979) pode ser encontrado com detalhes no trabalho de QUINN et al. (1995). O cálculo do índice topográfico é uma das principais etapas no processo de modelagem hidrológica com o TOPMODEL. Portanto elementos de área externa a bacia podem influenciar a distribuição do histograma de área versus classes de valores de índice topográfico. O delineamento da bacia e exclusão dos elementos de área não pertencentes à mesma se torna fundamental para qualquer estudo com TOPMODEL. Para o calculo do índice topográfico, foram obtidos primeiramente os dados de elevação digital de terreno do SRTM ("Shuttle Radar Topography Mission") disponíveis publicamente no sitio http://www2.jpl.nasa.gov/srtm/, em formato ASCIl. Estes dados possuem resolução espacial de 90 metros, e são disponibilizados para todo o globo. Foi obtido a quadricula de coordenadas $(27,17)$ (Fig. A.1).

Foi escrito um código em FORTRAN 90 para a retirada de falhas, os dados não são consistidos. No local de quadriculas faltante, foi efetuada interpolação linear ponderada, sendo os pesos das quadriculas "ortogonalmente" vizinhas maior do que das quadrículas "diagonais". Os dados foram convertidos para binário de GrADS (The Grid Analysis and Display System) (DOTY,1995) e recortados para o domínio mais próximo à região de interesse (Fig. A.2), exportados novamente para o formato ASCII. 


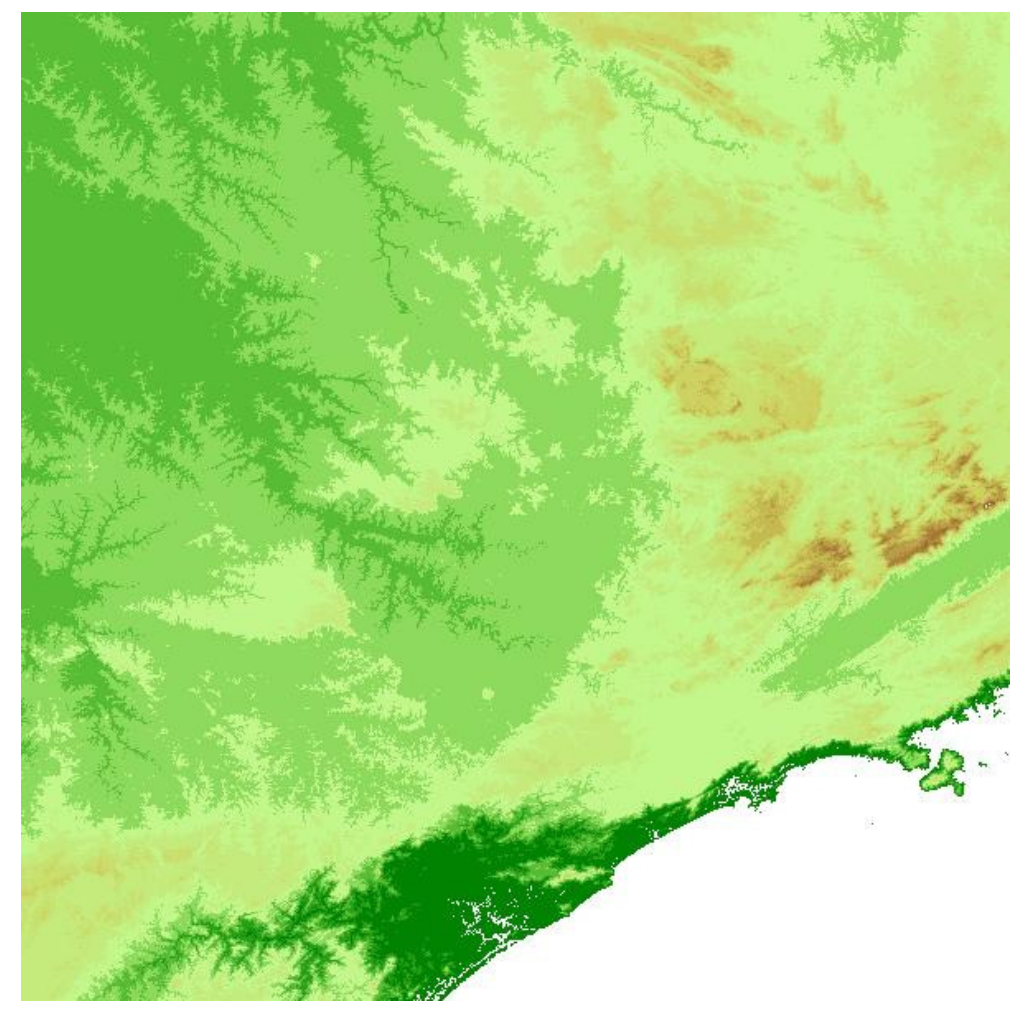

Figura A.6.1: Quadricula $(x, y)=(27,17)$ de $6000 \times 6000$ pontos contendo a elevação digital de terreno, obtidas diretamente do sitio do projeto SRTM.

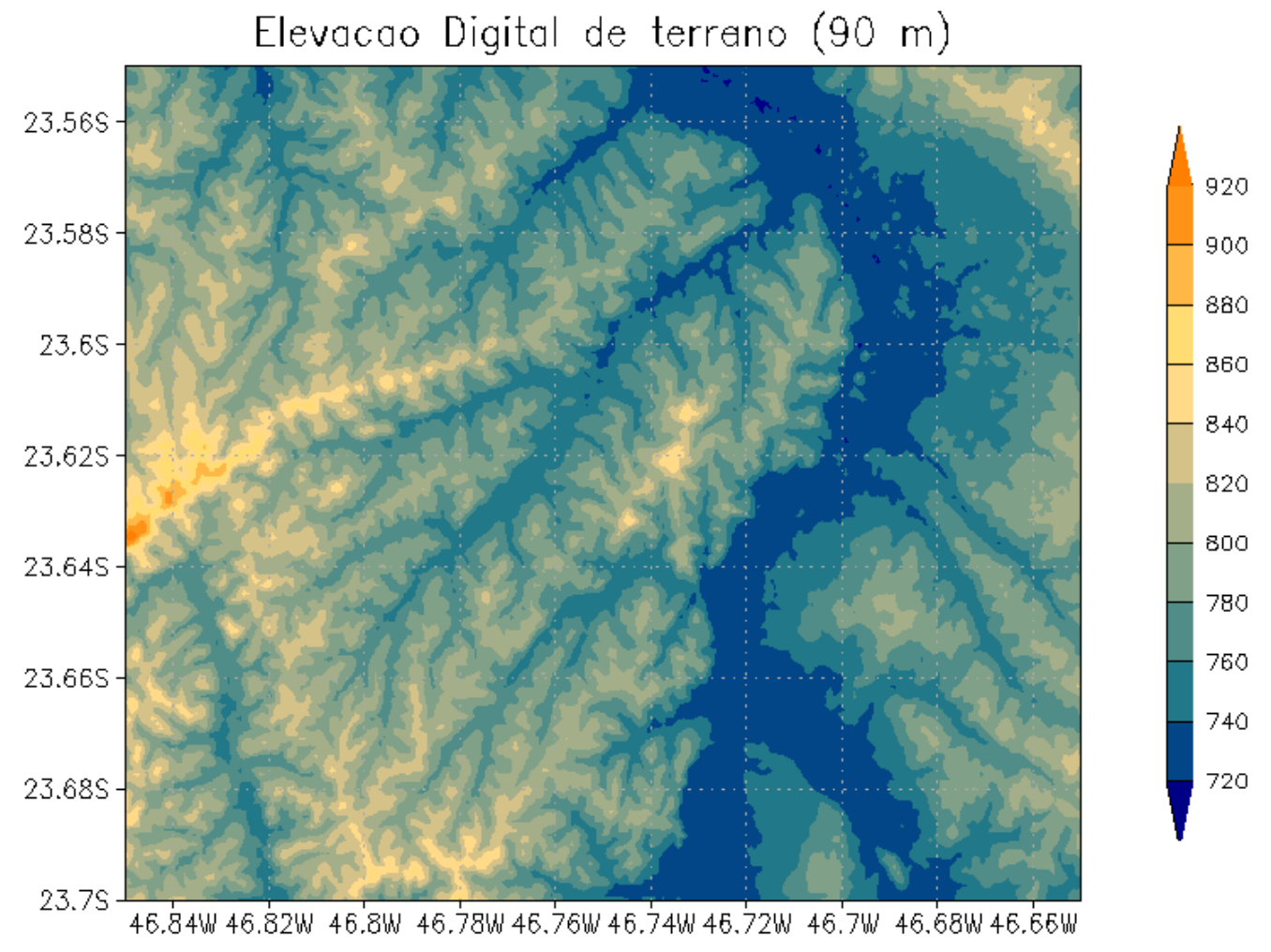

GrADS: COLA/IGES

$2008-01-[8-20: 51$

Figura A.6.2: Domínio retirado após a primeira iteração do processo de delineamento automático da bacia. 
Após os dados consistidos e domínio reduzido, utilizou-se o software MapWindow GIS, disponível para download público no sitio http://www.mapwindow.com/, para a delimitação automática de bacias. Neste procedimento foi utilizado a versão 4.7 .5 do software.

Seguiu-se as seguintes opções do plugin TauDEM (TARBOTON, 2003), na seqüência: watersheed delimitation, Advanced TauDEM functions, select base DEM grid para selecionar o arquivo texto em formato matriz. $O$ arquivo utilizado deve conter um cabeçalho ("header") contendo informações da referencia geográfica da matriz (Tab. A.1), como o ponto mais ao Sul e o ponto mais a Oeste, tamanho da célula na referência utilizada (graus neste caso), numero de células em ambos os eixos.

Tabela A.1 - Exemplo de header utilizado em uma matriz para abertura no software Mapwindow

\begin{tabular}{ll}
\hline NCOLS & 168 \\
NROWS & 167 \\
XLLCORNER & -47.839583 \\
YLLCORNER & -24.699583 \\
DX & 0.000833333 \\
DY & 0.000833333 \\
NODATA_VALUE & -9999 \\
\hline
\end{tabular}

Selecionado o DEM, inicia-se então ao procedimento para a delimitação automática da bacia, com a seqüência: watersheed delimitation, Advanced TauDEM functions, Fill Pits, esta função remove possíveis "buracos" e garante a conectividade hidráulica das bacias. Após este passo pode-se aplicar dentro da opção Advanced TauDEM functions a opção Do all DEM processing, este conjunto de processos irá gerar uma série de campos necessários para o delineamento posterior, como direção dos fluxos por célula, inclinação por unidade de célula, ordenamento de canais pelo método de Strahler. Estes produtos são exportados para arquivos em formato ascii ou shape.

Após a determinação dos produtos necessários, pode-se então efetuar a opção de delineamento automático de bacias, dentro da opção Advanced TauDEM functions a função Do all Network and Watershed Processing que resultará em diversos campos, entre eles, grades de sub-bacias (Watershed grid, em formato ascii), arquivo shape de sub-bacias (Watershed Shapefile, formato shape) e delineamento dos canais. Com base nos arquivos em formato ascii das sub-bacias 
delimitadas (Figura A.3), pode-se então selecionar somente as sub-bacias que formam a Bacia do Rio Pirajuçara.

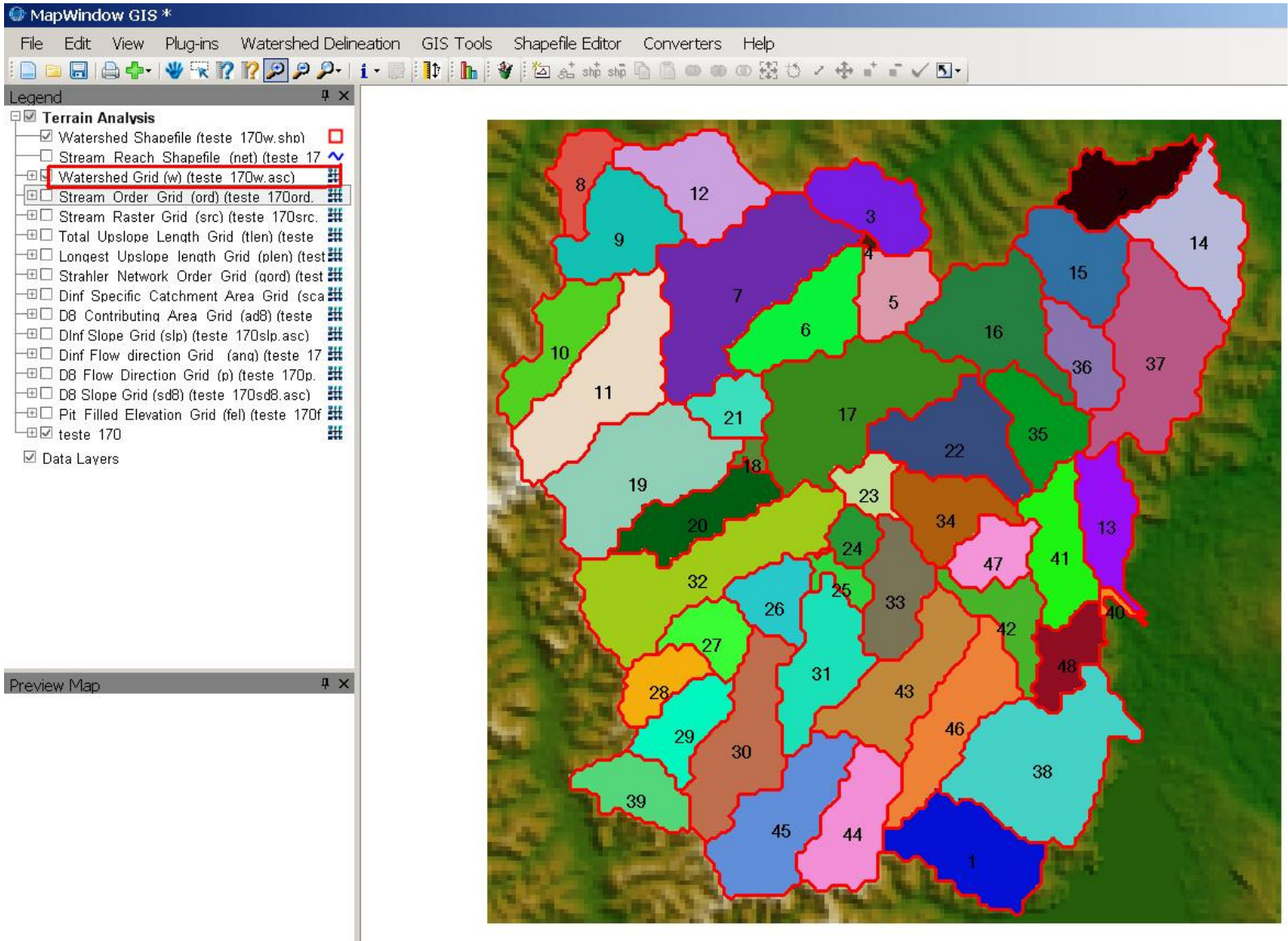

Figura A.6.3: Sub-bacias delimitadas automaticamente pelo software Mapwindow.

Escolhem-se as sub-bacias de interesse de acordo com seus respectivos $i d$ 's. Cada célula pertencente a uma sub-bacia, possui valor igual ao respectivo id, e para células não pertencentes a bacia alguma é atribuído o valor -1 automaticamente. Com esta matriz de id's e a matriz original disponíveis, aplica-se um algoritmo de rejeição ou exclusão simples (Neste trabalho foi escrito em FORTRAN 90) chegando ao resultado final com informações pertencentes somente ao interior da bacia (Fig. A.4). 


\section{Bacia Rio Pirajuçara - Grade Regular 90x90 [m] (Linhas), Elevação [m] (Sombreado)}

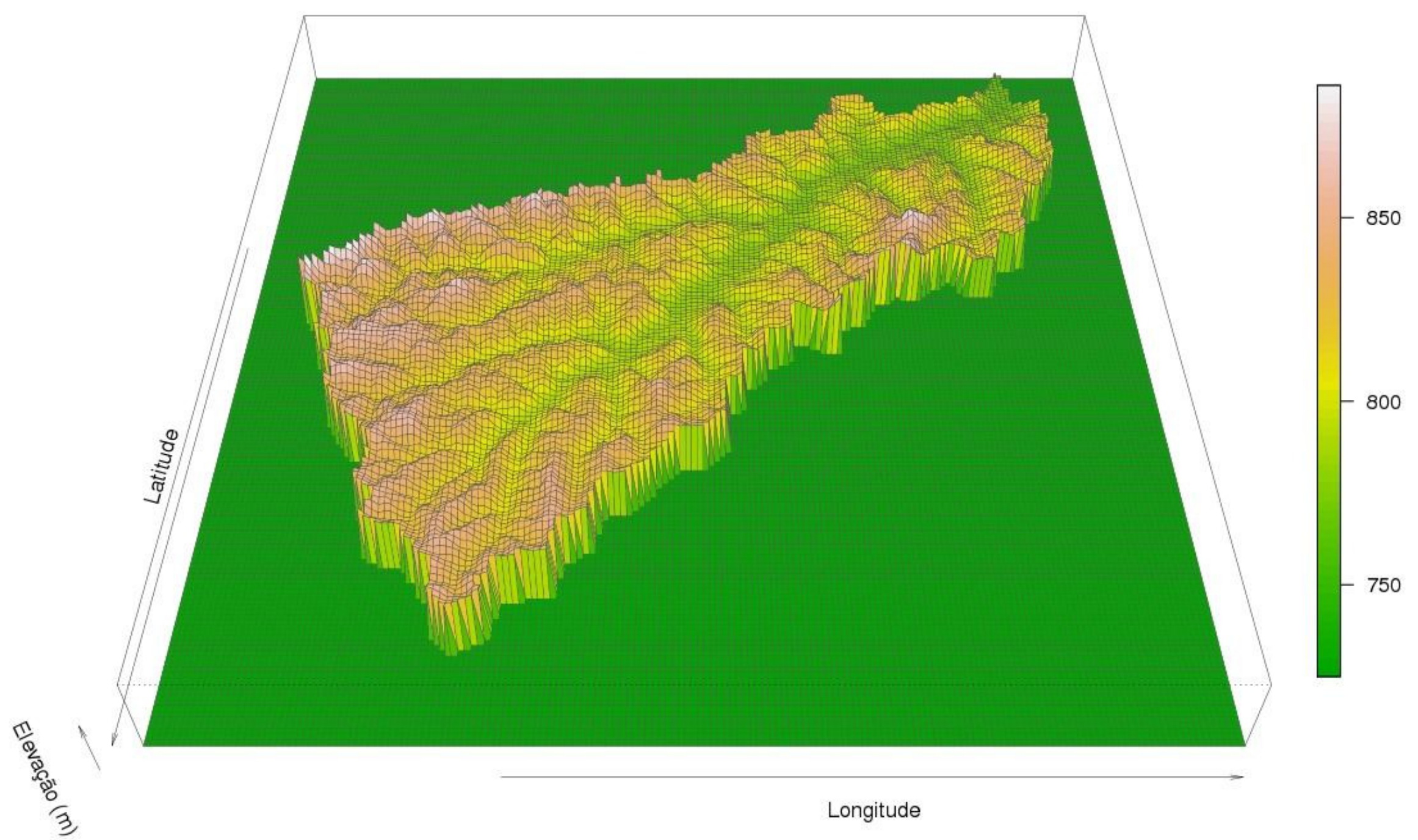

Figura A.4: Resultado da extração da bacia a partir da malha de id's identificados pelo Mapwindow. A área verde escuro representam as regiões externas a bacia. As diferentes cores representam as elevações em metros. As linhas pretas representam a grade de 90 metros de resolução utilizada no trabalho. 


\section{APÊNDICE B: Parâmetros calculados com o TOPMODEL.}

$\mathrm{Na}$ Tab. B.1 encontram-se os conjuntos de parâmetros obtidos na etapa de calibração do TOPMODEL. As unidades dos mesmos se encontram na secção 3.2.6. As calibrações foram efetuadas de forma manual. Os critérios para a aceitação ou não dos conjuntos foram, o ajuste de pico, detecção antecipada da ascensão e o número de NASH (Eq. 2.1).

Tabela B.2 - Valores obtidos na etapa de calibração com o modelo TOPMODEL, para entradas de precipitação telemetria, radar meteorológico e ANOBES, respectivamente.

\begin{tabular}{llll}
\hline \multicolumn{1}{c}{ Parâmetro } & \multicolumn{1}{c}{ Telemetria } & \multicolumn{1}{c}{ Radar } & \multicolumn{1}{c}{ ANOBES } \\
qs0 & $7,0 \times 10^{-3}$ & $12,0 \times 10^{-3}$ & $10,0 \times 10^{-3}$ \\
InTe & 11.8 & 11,5 & 12 \\
m & $7,4 \times 10^{-4}$ & $12,0 \times 10^{-4}$ & $10,2 \times 10^{-4}$ \\
Sr0 & $5,2 \times 10^{-4}$ & $2,1 \times 10^{-4}$ & $7,8 \times 10^{-4}$ \\
Srmax & $5,3 \times 10^{-4}$ & $20,7 \times 10^{-4}$ & $80,0 \times 10^{-4}$ \\
td & $1,6 \times 10^{-1}$ & $0,001 \times 10^{-1}$ & $7,0 \times 10^{-1}$ \\
vch & $5.9 \times 10^{3}$ & $3,5 \times 10^{3}$ & $5.1 \times 10^{3}$ \\
vr & $1,2 \times 10^{3}$ & $1.4 \times 10^{3}$ & $3,1 \times 10^{3}$ \\
k0 & 1,5 & 1 & 0,5 \\
CD & 4,2 & 1,9 & 0,9 \\
\hline
\end{tabular}

